\title{
Role of nano-biomechanics in brain metastasis formation and amyotrophic lateral sclerosis
}

\author{
Ph. D. Thesis
}

Béla VARGA
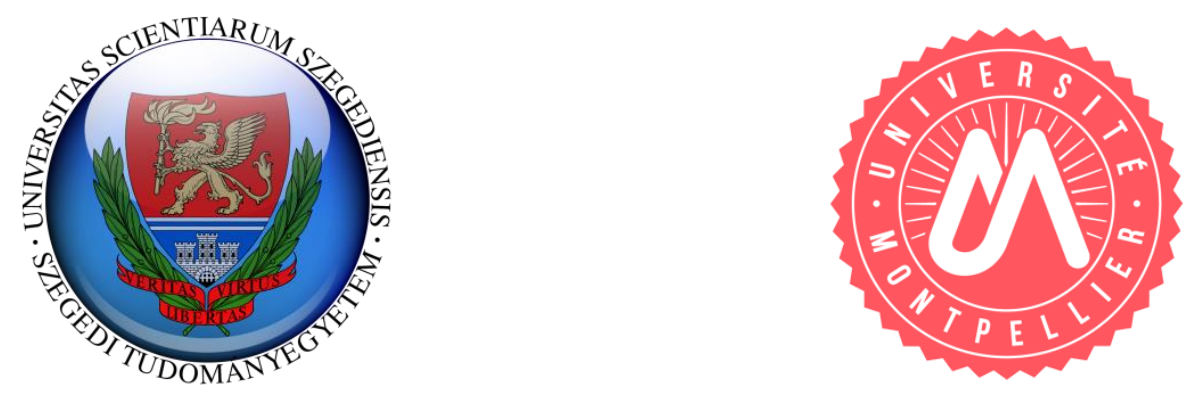

Supervisors:

Dr. György VÁRÓ

Institute of Biophysics

Laboratoire Charles Coulomb

Biological Research Centre

Université de Montpellier

Szeged, Hungary

Montpellier, France

Szeged 


\title{
THÈSE POUR OBTENIR LE GRADE DE DOCTEUR \\ DE L'UNIVERSITÉ DE MONTPELLIER \\ ET
}

\author{
En Biophysique \\ Écoles doctorales : \\ Information Structures \\ Systèmes \\ et \\ Multidisciplinary Medical \\ Sciences \\ Unités de recherche : \\ Laboratoire Charles \\ Coulomb UMR 5221 \\ et \\ Institute of Biophysics, \\ Biological Research Centre
}

Rôle de la nanobiomécanique dans la formation de métastases cérébrales et de la sclérose latérale amyotrophique

\author{
Présentée par Béla VARGA \\ Le 16 Avril 2018 á Szeged \\ Sous la direction des \\ Pr. Csilla GERGELY et Dr. György VÁRÓ
}

Devant le jury composé de

M. Imre DÉKÁNY, Pr, University of Szeged

M. Miklós KELLERMAYER, Pr, Semmelweis University, Budapest

M. Christian LARROQUE, Dr, IRCM, Montpellier

M. Youri ARNTZ, Dr, Université de Strasbourg

M. László NAGY, Dr, University of Szeged
Président

Rapporteur

Rapporteur

Examinateur

Examinateur 


\section{Table of contents}

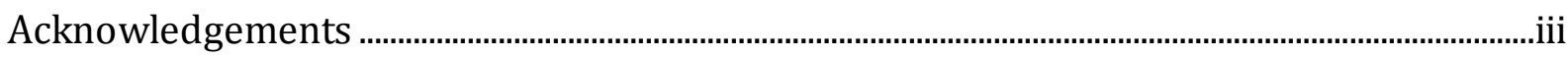

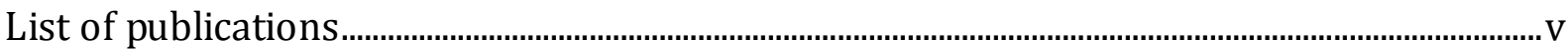

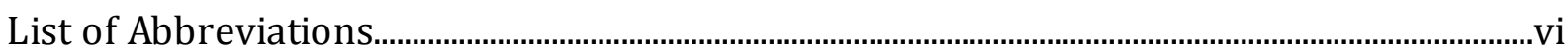

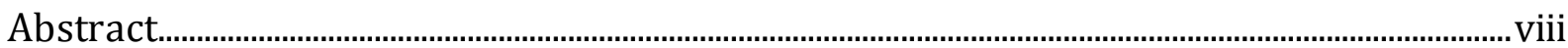

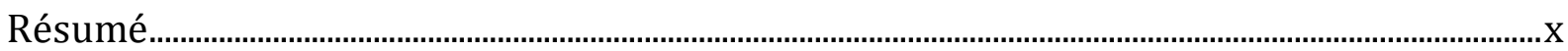

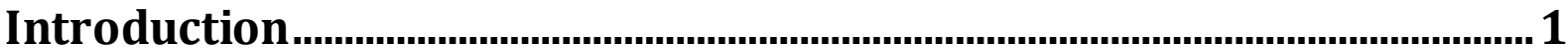

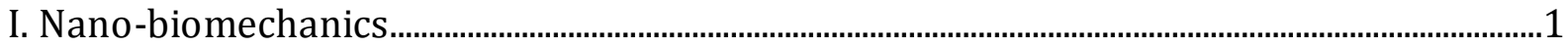

I.1. Atomic force microscopy as a tool for nano-biomechanics .......................................... 2

I.2. Force measurements: force distance curve ................................................................ 3

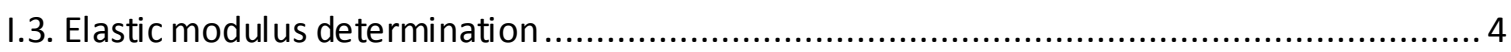

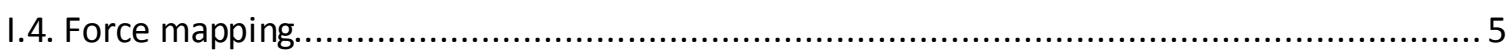

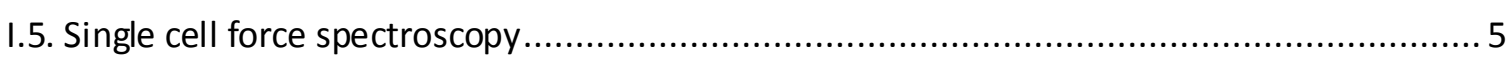

II. Relevance of nano-biomechanics in monitoring diseases........................................................6

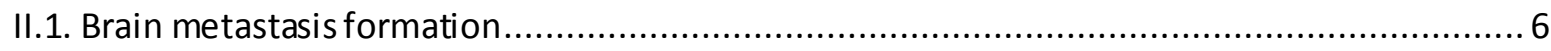

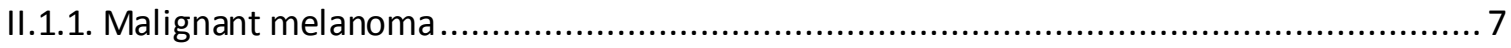

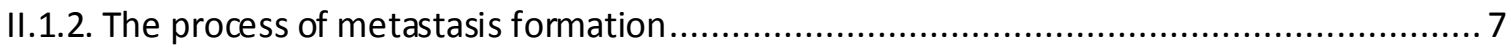

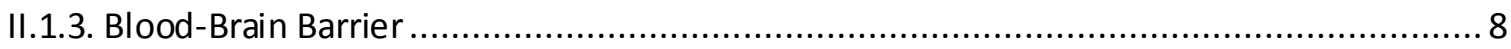

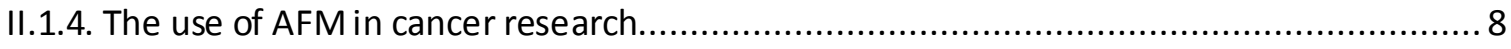

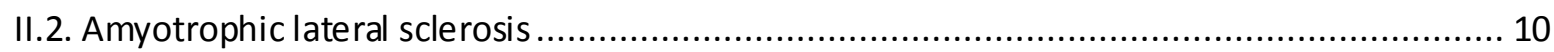

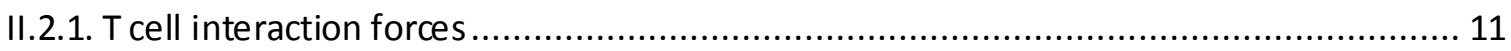

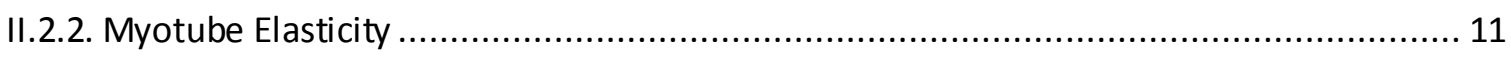

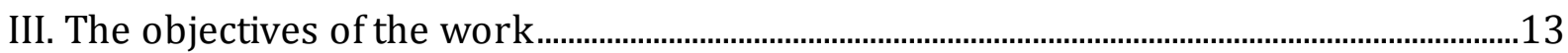

Materials and methods ...................................................................................... 14

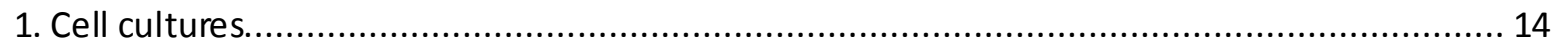

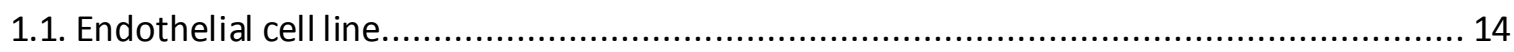

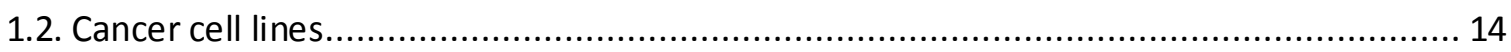

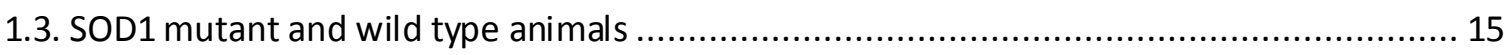

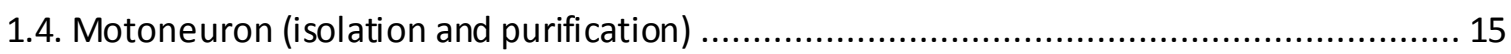




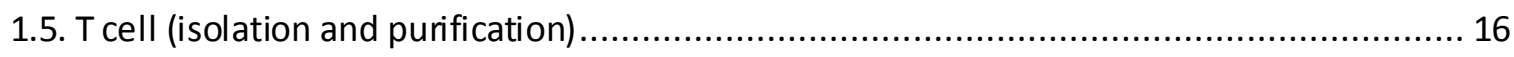

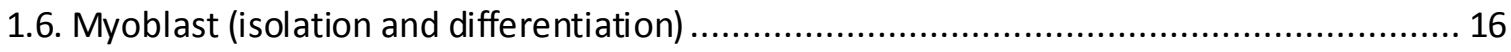

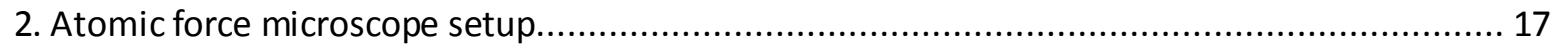

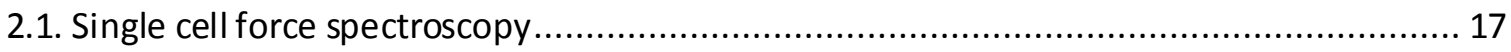

2.2. Force mapping of myotube's elastic modulus ............................................................ 18

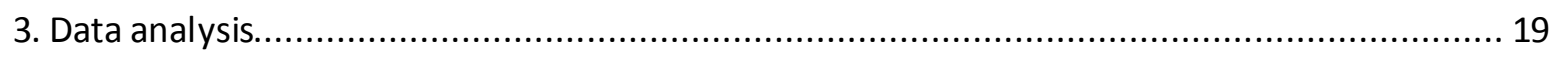

\section{Results and Discussion ...................................................................................... 20}

I. Nanomechanical aspects of brain metastasis formation............................................................20

I.1. Direct mapping of melanoma cell - endothelial cell interactions........................................ 20

I.2. De-adhesion dynamics of melanoma cells from brain endothelial layer ............................... 25

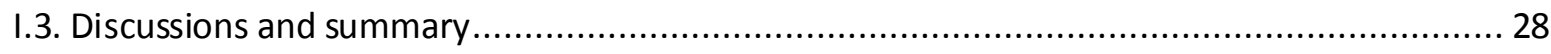

II. Nanomechanical aspects of amyotrophic lateral sclerosis (ALS) ……......................................34

II.1. T cell and motoneuron interaction forces in an ALS diseased mouse model ........................ 34

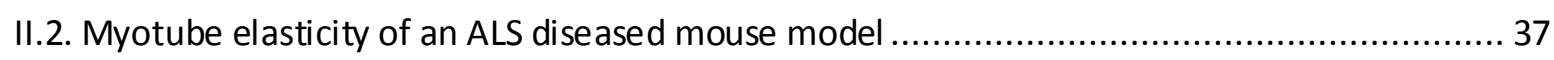

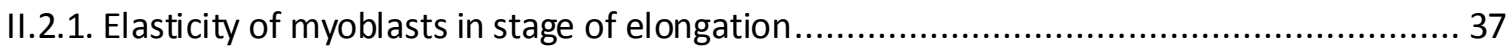

II.2.2. SOD1 mutant myotubes show increased elastic modul us .......................................... 39

II.2.3. SOD1 mutation decreases myosin heavy chain gene isoforms expression...................... 42

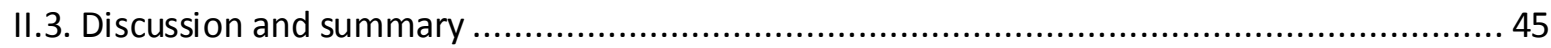

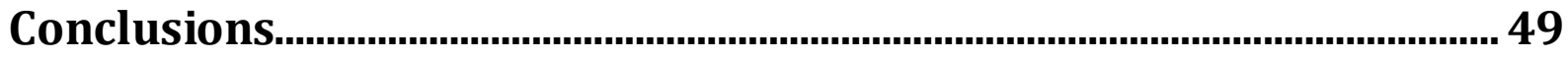

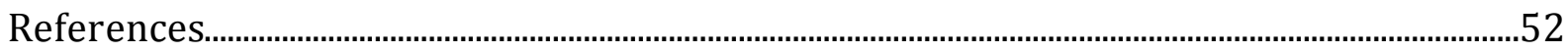

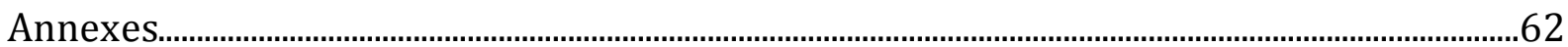




\section{Acknowledgements}

This work would not have been possible without the assistance of several people to whom I would like to express my sincere gratitude.

First, I would like to express my deep gratitude to my admirable supervisors Prof. Csilla Gergely and Dr. György Váró for their supporting guidance, enthusiastic encouragement and valuable critiques throughout my $\mathrm{PhD}$ years. Their exemplary attitude and way of thinking was crucial for my professional and personal development and will always remain a role model for me.

I express my acknowledgements to the reviewers Dr. Miklós Kellermayer and Dr. Christian Larroque, as well as to the jury members Dr. Imre Dékány, Dr. Youri Arntz, and Dr. László Nagy for their valuable assessment of my doctoral dissertation.

I would like to offer my special thanks to Dr. Attila Gergely Végh, an expert colleague and true friend, for his invaluable support, useful critiques, and the fruitful discussions that was indispensable in my scientific and personal progress. My grateful thanks are also extended to my colleagues Dr. Marta Martin, Dr. Thierry Cloitre, and Dr. Zsolt Szegletes for their help and professional advices. I would like to thank Dr. László Zimányi, the director of the Institute of Biophysics, and all the members of the Institute

I am particularly thankful to Prof. Frédéric Cuisinier for the tremendous support and the constant faith in me. My thanks are also extended to all the members of the LBN.

My great appreciation goes to Dr. Frédérique Scamps, Dr. Emmanuelle Coque and Dr. Cédric Raoul for the useful discussions, their constructive suggestions and helpful contribution to this work. I am very grateful for the assistance and valuable advices given by Dr. Csilla Fazakas, Dr. Imola Wilhelm and Dr. István Krizbai.

I was fortunate to be thought by László Erdély during my school years, who handed over not only the solid base of physics but also a part of his immense general knowledge and I am especially indebted to my undergraduate supervisor, Dr. Ferenc Járai-Szabó, who introduced me to physics and inspired me to pursue a scientific carrier.

My deepest thanks go to my family. To my sister, Melinda, who is my second mentor and soulmate. To my parents, Csilla and László, whos' constant support, love, and encouragement 
kept me persistent to reach my goals. And most importantly to my wife, Orsi, whose immense love, selfless devotion and honest critiques helped me to bring the best out of myself.

Finally, I would like to thank my extended family, teachers, friends, and colleagues for their support throughout my studies.

This work was supported by Campus France and the National Excellence Program. 


\section{List of publications}

\section{Papers directly related to the subject of the thesis:}

I. Varga B., Fazakas C., Molnár J., Wilhelm I., Domokos R. A., Krizbai I. A., Szegletes Z., Váró G., Végh A. G. Direct mapping of melanoma cell - endothelial cell interactions, J. Mol. Recognit. 2017, 30(6):e2603, DOI: 10.1002/jmr.2603

IF: 2.175

II. Varga B., Domokos R. A., Fazakas C., Wilhelm I., Krizbai I. A., Szegletes Z., Gergely C., Váró G., Végh A. G. De-adhesion dynamics of melanoma cells from brain endothelial layer, BBA Gen. Subjects, 2018, 1862(3):745-751, DOI: 10.1016/j.bbagen.2017.10.013 IF: 4.702

III. Varga B., Martin M., Hilaire C., Sanchez-Vicente A., Areias J., Salsac C., Cuisinier F.J.G., Cedric Raoul C., Scamps F., and Gergely C. Myotube elasticity of an amyotrophic lateral sclerosis mouse model (Revised manuscript submitted to Sci. Rep.)

\section{Papers directly not related to the subject of the thesis:}

IV. Páll O., Varga B., Collart-Dutilleul P. Y., Gergely C., Cuisinier F. J. G., Comments on: "An Overview of Protocols for the Neural Induction of Dental and Oral Stem Cells In Vitro", Tissue engineering, 2017, DOI: 10.1089/ten.TEB.2016.0512 (Published online)

IF: 3.485

V. Varga B., Fazakas C., Wilhelm I., Domokos R. A., Krizbai I. A., Szegletes Z., Váró G., Végh A. G. Elasto-mechanical properties of living cells, Biochemistry and Biophysics Reports, 2016, 7:303-308, DOI: 10.1016/j.bbrep.2016.06.015

VI. Magyari K., GruianC., Varga B., Ciceo-Lucacel R., Radu T., Steinhoff H. J., Váró G., Simona V., Baia L. Addressing the optimal silver content in bioactive glass systems in terms of BSA adsorption, J. Mater. Chem. B, 2014, 2:5799, DOI: 10.1039/C4TB00733F

IF: 4.543 


\section{List of Abbreviations}

\begin{tabular}{|c|c|c|}
\hline A2058 & - & Amelanotic melanoma cell line 2058 \\
\hline A375 & - & Amelanotic melanoma cell line 375 \\
\hline ALS & - & Amyotrophic lateral sclerosis \\
\hline AFM & - & Atomic Force Microscopy \\
\hline APC & - & Antigen-presenting cells \\
\hline BBB & - & Blood Brain Barrier \\
\hline $\mathrm{BM}$ & - & Brain Metastasis \\
\hline CEC & - & Cerebral Endothelial Cells \\
\hline $\mathrm{CNS}$ & - & Central Nervous System \\
\hline DIV & - & Days in vitro \\
\hline EBM & - & Endothelial Basal Medium \\
\hline $\mathrm{ECM}$ & - & Extracellular Matrix Protein \\
\hline EGM & - & Endothelial Growth Medium \\
\hline fALS & - & familial Amyotrophic Lateral Sclerosis \\
\hline FBS & - & Fetal Bovine Serum \\
\hline FD & - & Force-distance \\
\hline FUS & - & Fused in Sarcoma (an RNA/DNA- binding protein) \\
\hline hCMEC/D3 & - & human Cerebral Microvascular Endothelial Cells / D3 \\
\hline ICAM & - & Intercellular adhesion molecule \\
\hline IR & - & Infrared \\
\hline MAPK & - & Mitogen-activated protein kinase \\
\hline MEK & - & Mitogen-activated protein kinase kinase \\
\hline MFP-3D & - & Molecular Force Probe - 3D \\
\hline MHC & - & Myosin Heavy Chain \\
\hline MHC-I & - & Major histocompatibility complex class I \\
\hline MRE & - & Magnetic resonance elastography \\
\hline PBS & - & Phosphate Buffer Saline \\
\hline
\end{tabular}


pMHC - Peptide + major histocompatibility complex (MHC)

sALS - $\quad$ Sporadic Amyotrophic lateral sclerosis

SEM - - Standard error of the mean

SCFS - $\quad$ Single-Cell Force Spectroscopy

SOD1 - $\quad$ Superoxide dismutase 1

TARDBP - Transactive response DNA-binding protein gene

TCR - T cell antigen receptor

VCAM - Vascular cell adhesion molecule

WM35 - Wistar Institute melanoma cell line 35 


\section{Abstract}

Nano-biomechanics is an emerging field of science that opened a new horizon in scientific research by generating significant contribution in the study of human diseases. In this work, atomic force microscopy-based nanomechanical methods were directly applied in order to elucidate important questions related to brain metastasis formation and amyotrophic lateral sclerosis (ALS). Better understanding of the underlying pathogenic processes of these lifethreatening diseases is fundamental for the advancement of early diagnostics and improved therapeutics.

A malignant tumor cell, in order to spread and form metastasis, has to vary and continuously adapt its adhesive and elastic properties. Here, we combined force mapping with single cell force spectroscopy (SCFS) in order to gain direct insight into the surface "screening" process of tumor cells during their extravasation into the brain parenchyma. Intercellular adhesive forces and works, as well as elastic properties were spatially mapped showing that adhesive properties are only slightly dependent on elastic characteristics, and highlighting the importance of long range tether-like linkages for successful adhesions.

In order to examine how the metastatic potential relates to tumor cell's autonomous and intercellular nanomechanical properties, comparative SCFS measurements were performed between three melanoma cell types (WM35, A2058 and A375), showing altered invasive characteristics, and blood vessel lining endothelials. Our results indicate low relative elasticity, high maximal adhesion and high number of individual linkages, as the key properties of highly metastatic melanoma cells. This enables us to suggest the following ordering of tumor cells from lower to higher metastatic potential: WM35, A2058 and A375.

The pathogenesis of ALS is multifactorial, being characterized by the presence of inflammatory processes as well. In our results significant differences have been observed, by comparing the adhesion of $\mathrm{CD}^{+}$cytotoxic $\mathrm{T}$ cells isolated from wild-type as well as $S O D 1^{G 93 A}$ mutant mice against wild-type motor neurons. Mutant mice derived $\mathrm{T}$ cells show enhanced adhesion strength, compared to the healthy mice derived ones. Moreover, we observe a significant reduction of $\mathrm{T}$ cell - motoneuron interactions after blocking the specific recognition bindings between pMHC-I and TCR. These results corroborate the contribution of cytotoxic T cells in the development of ALS, as an active player in neurodegeneration. 
Investigating primary myoblasts allow deciphering molecular processes involved in muscle development, aging and repair. Therefore in our study high resolution nanomechanical mapping was performed on single elongated myoblasts and multinuclear myotubes, isolated from an ALS mouse model, to reveal elasticity features during early differentiation stage into myotubes. Data show that projections of the elongated myoblasts show significantly increased elastic modulus values compared to their cell body. Regarding myotubes, differences have been observed between the elasticity of a thin and thick population of wild-type myotubes, indicating the different maturity of the two populations. However, in SOD1 mutant, the observed increase in the elastic modulus of the thin population suggests an enhanced autonomous hardening of ALS derived myotubes.

In summary, our cellular-level mechanical studies deciphered various aspects of two different life-threatening pathologies resulting in novel discoveries about their fundamental processes. This work highlights the high impact and the important role of AFM-based nanomechanical methods in providing valuable knowledge about disease pathophysiology, development, diagnostics and progression that could provide new possible target candidates and greatly contribute to the evolvement of future therapies. 


\section{Résumé}

\section{Introduction et objectifs}

La métastase cérébrale (MC) et la sclérose latérale amyotrophique (SLA) sont des pathologies graves accompagnées de temps de survie courts. Pour mieux comprendre les processus pathogènes sous-jacents, il est essentiel de faire progresser le diagnostic précoce et d'améliorer les traitements thérapeutiques. Des méthodes nanomécaniques basées sur la Microscopie à Force Atomique (AFM) ont été directement appliquées afin d'élucider des questions importantes sur les différents aspects de ces maladies potentiellement mortelles.

En ce qui concerne la métastase cérébrale, notre objectif spécifique était d'obtenir une compréhension directe du mécanisme de balayage de surface des cellules tumorales pendant l'extravasation dans le parenchyme cérébral, en quantifiant directement et en résolvant spatialement les paramètres nanomécaniques des interactions entre les cellules cancéreuses métastatiques et la couche endothéliale. De plus, nous avons comparé le phénotype mécanique des mélanomes de différents niveaux de malignité et examiné si le potentiel métastatique est identifiable dans les propriétés nanomécaniques.

Dans le cas de la SLA, notre objectif était d'élucider la contribution des lymphocytes $\mathrm{T}$ cytotoxiques, en tant que nouveau mécanisme pathologique, en quantifiant les forces d'adhésion à court terme entre les lymphocytes $\mathrm{T}$ CD8+ et les motoneurones. De plus, nous avons étudié l'élasticité des cellules musculaires squelettiques différenciées dérivées de la SLA et comparé avec leurs homologues saines dérivées, dans le but d'évaluer les différences au niveau cellulaire.

La nanobiomécanique est un domaine de recherche émergent qui fait le pont entre les sciences physiques et biologiques visant à explorer les aspects mécaniques de la matière biologique à l'échelle nanométrique [1]. Le principal arsenal d'outils de cet science interdisciplinaire est constitué de l'AFM, de la pince magnétique, de la pince optique et de la microscopie à force de traction cellulaire. Parmi eux, l'AFM est l'un des systèmes les plus polyvalents étant capable de mesurer des nanoforces de façon très fiable et précis. 


\section{Techniques appliquées}

L'AFM est une technique de microscopie non-optique qui utilise une pointe nanométrique à l'extrémité d'un levier très souple comme sonde mécanique pour balayer la surface de l'échantillon et construire une image topographique tridimensionnelle hautement résolue [2]. Outre sa capacité d'imagerie à haute résolution, l'AFM peut fournir des données quantitatives sur une grande variété de propriétés physico-chimiques de l'échantillon. C'est ce qu'on appelle la spectroscopie de force [3]. De plus, elle nécessite une préparation minimale de l'échantillon et permet d'effectuer des mesures dans des conditions physiologiquement pertinentes.

Pendant la spectroscopie de force, la position horizontale (x, y) du levier est fixe, tandis que son mouvement vertical (z) et sa déflexion instantanée, en réponse à diverses forces, sont enregistrés, ce qui donne lieu à des courbes de force-distance (courbes FD). De ces différents paramètres de l'information peut être extrait qui est lié aux propriétés mécaniques de l'échantillon ou aux interactions entre le substrat et la pointe, tels que le module élastique (ou Young' s), l'adhérence maximale, mais aussi le nombre, la taille du pas ou la distance des ruptures individuelles. En définissant une grille sur une zone sélectionnée de l'échantillon et en effectuant des mesures de force dans chaque nœud de grille, on peut cartographier la distribution spatiale des propriétés mécaniques des tissus, cellules ou structures souscellulaires entières. Une autre technique, appelée spectroscopie de force monocellulaire (SCFS) [4], concerne un objet biologique qui sert de lui-même sonde. La pointe peut être fonctionnalisée avec différentes molécules pour des mesures spécifiques de liaison intermoléculaire [5] ou avec des bactéries pour tester son adhésion sur différents substrats [6], mais même avec des cellules vivantes entières, immobilisées sur le levier permettant la mesure directe des forces intercellulaires [7]. 


\section{Résultats et discussions}

\section{Nanomécanique du mélanome métastatique}

Étant la principale cause de mortalité des patients atteints de cancer, l'aspect le plus dangereux du cancer est la métastase. Le cancer présentant des métastases cérébrales a un des plus mauvais pronostics [8]. Bien que le mélanome ne représente que 1 à $2 \%$ de tous les cancers, il envahit le cerveau dans la majorité des cas [9] et figure parmi les cancers les plus agressifs et les plus résistants aux thérapies. Comme le système nerveux central (SNC) est dépourvu d'un système lymphatique classique, les cellules cancéreuses ne peuvent atteindre le cerveau que par le sang. Une cellule tumorale maligne, pour former une métastase dans le cerveau, a d'abord besoin de s'échapper du site tumoral primaire, d'envahir les tissus avoisinants, de freiner à travers la paroi des vaisseaux sanguins et d'entrer dans la circulation sanguine par intravasation, ensuite de se propager vers des organes distants, puis de quitter le vaisseau sanguin par extravasation, d'envahir le cerveau parenchyme, et enfin de proliférer et de former une tumeur secondaire. Un aspect important de la formation de métastases cérébrales qui a été abordé dans nos travaux par AFM est l'adhésion des cellules tumorales circulant dans le sang et leur pénétration à travers la couche endothéliale étroitement liée, en tant que première ligne de défense de la barrière hémato-encéphalique.

\section{I.1. Cartographie directe des interactions cellules mélanomateuses - cellules endothéliales}

Pour modéliser le processus de "criblage" des cellules cancéreuses métastatiques lors de leur extravasation dans le parenchyme cérébral, nous avons combiné la cartographie des forces avec des mesures de SCFS et effectué des mesures entre le mélanome métastatique et les cellules endothéliales du cerveau. On a utilisé des leviers sans pointe et décorés de cellules tumorales comme sonde pour cartographier directement les propriétés adhésives et élastiques d'une couche confluente de cellules endothéliales cérébrales (CEC). La distribution spatiale de plusieurs paramètres nanomécaniques a été donc enregistrée. L'objectif était de caractériser spatialement l'élasticité et la force de liaison entre la cellule du mélanome et la CEC. Etant donné qu'aucun modèle spécifique ne peut être trouvé pour extraire les propriétés élastiques des courbes obtenues dans le cas où deux cellules vivantes (de formes arbitraires) sont mises en contact, les différents paramètres d'interaction pourraient être un bon indicateur des processus sous-jacents. Ainsi, nous avons calculé le travail total d'élasticité (ou de 
déformation) nécessaire pour dévier la pointe AFM et déformer les deux cellules, le travail dissipé au cours du cycle de mesure, la force d'adhésion maximale, le travail d'adhérence (ou de détachement) nécessaire pour séparer les deux cellules, ainsi que les travaux de début et de fin de détachement.

Bien que la mesure de l'adhérence entre cellules fasse l'objet d'un nombre croissant d'études, la cartographie spatiale de l'élasticité ou de l'adhérence d'une couche cellulaire vivante avec une autre cellule vivante $n^{\prime}$ a pas encore été rapportée. Comme dans nos mesures d'adhérence intercellulaire à court terme, les deux cellules subissent des déformations lors de l'interaction, les paramètres extraits ne peuvent se référer à aucune d'entre elles séparément, mais caractérisent le système "entier". Pour mieux interpréter la dépendance de chaque paramètre calculé par rapport aux autres, un diagramme de corrélation croisée a été construit. Il est intéressant de noter que les propriétés adhésives ne dépendent que faiblement des caractéristiques élastiques. L'examen des corrélations croisées entre les paramètres mesurés a révélé la contribution accrue des ruptures (détachements tardifs) contre la déformation (détachement précoce) à la force d'adhésion maximale et au travail d'adhérence totale, et a souligné l'importance des liaisons à long terme de type attache pour la réussite des adhésions.

\section{I.2. - Dynamique de désadhésion des cellules mélanomateuses de la couche endothéliale du cerveau}

Depuis des décennies, on sait que les cellules cancéreuses individuelles présentent un module d'élasticité réduit par rapport aux cellules normales, étant donné qu'elles ont été dénouées pour la plupart des types de cancer [10]. Cependant, la question de la relation entre le potentiel métastatique et les propriétés nanomécaniques autonomes et intercellulaires des cellules tumorales a été peu étudiée [11-14]. Dans une deuxième série d'expériences, les rapports entre les différents niveaux de malignité et les paramètres nanomécaniques des interactions tumoroendothéliales hétérocellulaires ont été abordés en utilisant la SCFS. Trois types de cellules mélanomateuses (WM35, A2058 et A375) présentant des caractéristiques invasives altérées ont été examinés. En plus de mesurer les interactions intercellulaires, les mêmes cellules mélanomateuses ont été mesurées également contre une zone exempte de cellules de la boîte de Petri en tant que expérience contrôle. Comme il n'existe pas de modèle permettant d'obtenir des propriétés élastiques ou plastiques lorsque deux cellules sont mises en contact, afin de comparer in situ les propriétés élastiques des trois types de cellules étudiés, un nouveau paramètre a été utilisé, appelé élasticité relative. Ce paramètre relatif sans dimension 
a été défini comme le rapport entre le travail restant et le travail total exercé par le système. Ses valeurs se situent entre 0 et 1 , où 0 correspond à un comportement plastique parfait, tandis que 1 à un comportement parfaitement élastique. Le module de Young apparent, le paramètre le plus fréquemment utilisé pour caractériser l'élasticité cellulaire, a également été déterminé. Les paramètres étudiés plus en détail comprenaient la force d'adhérence maximale, ainsi que le nombre, la taille des ruptures et la distance à laquelle se produisaient les ruptures individuelles.

Les mesures de contrôle effectuées sur la surface de la boîte de Pétri nue indiquent que l'élasticité relative calculée est principalement la propriété des cellules de mélanome, tandis que les cellules endothéliales n'ont qu'une faible contribution. En outre, on a observé une forte dépendance entre l'élasticité relative et le type de cellules mélanomateuses, où les cellules WM35 semblaient avoir une plus grande élasticité, suivies des cellules A2058, tandis que les cellules A375 montrent un comportement plus plastique lors de la déformation. Comme pour l'élasticité relative, les cellules WM35 présentent les valeurs de module d'élasticité les plus élevées, suivies des cellules A2058 et A375. Bien que ce ne soit pas dans le cas d'une boîte de Pétri nue, mais lorsque les cellules de mélanome ont été mises en contact avec l'endothélium, une nette différence de force d'adhésion maximale a été observée, montrant des valeurs croissantes avec un niveau croissant de malignité. De plus, cette relation était inversement corrélée avec l'élasticité relative et en même temps directement corrélée avec le nombre d'événements de rupture, ce qui indiquait la faible élasticité relative, l'adhérence maximale élevée et le nombre élevé de liaisons individuelles, comme propriétés clés des cellules mélanomateuses hautement métastatiques. La taille et la distance à laquelle les événements de désadhésion individuels ont eu lieu ont également été quantifiées, et indiquent que le rôle des propriétés adhésives des cellules envahissantes du mélanome ne peut pas être négligé dans le processus de formation des métastases. Nos données sur la dynamique de la force d'adhésion entre une couche endothéliale confluente du cerveau et trois types de cellules invasives de mélanomes soulignent l'importance des propriétés mécaniques en cas d'interactions intercellulaires. En outre, elle suggère que les caractérisations élastiques et adhésives des cellules pourraient être utilisées comme biomarqueurs de leur malignité. 


\section{Aspects nanomécaniques de la sclérose latérale amyotrophique (SLA)}

La SLA est une maladie neurodégénérative mortelle qui entraîne une dégradation progressive $\mathrm{du}$ système moteur humain. L'origine de la SLA est familiale (fSLA) dans 5 à $10 \%$ des cas, tandis que le reste des patients atteints de SLA ont une maladie sporadique (sSLA) [15]. Les mutations dans le gène de la superoxyde dismutase (SOD1) se liant aux ions cuivre/zinc sont l'un des principaux facteurs responsables du développement de la maladie [16], qui est responsable de $20 \%$ des SLA familiales [17] et de 5\% des sSLA [15]. Il a été prouvé que les souris transgéniques exprimant le gène humain mutant $\mathrm{SOD} 1^{\mathrm{G} 93 \mathrm{~A}}$ ont fourni un bon modèle pour la maladie humaine de la SLA [17]. Dans le cadre de nos expériences in vitro, des cultures primaires isolées à partir de ce modèle de souris ont été étudiées par AFM afin d'élucider différents aspects du développement de la SLA, notamment la nature des interactions entre lymphocytes $\mathrm{T}$ et neurones moteurs ainsi que l'élasticité des myotubes pendant leur maturation.

\section{II:1. Forces d'interaction des lymphocytes $T$ et du motoneurone dans un modèle de souris atteintes de SLA}

Les cellules $\mathrm{T}$, ou lymphocytes $\mathrm{T}$, jouent un rôle important dans l'immunité par médiation cellulaire et leur interaction avec d'autres cellules est cruciale dans la reconnaissance et l'élimination des agents pathogènes potentiels. La nature de ces interactions et ses liens moléculaires ont fait l'objet d'études approfondies [18,19], ce qui a permis d'élucider divers aspects de la réponse immunitaire. La pathogenèse de SLA, un maladie neurodégénérative fatale, est complexe et consiste non seulement en une mort cellulaire autonome, mais aussi en l'apport de plusieurs types cellulaires dans les processus inflammatoires. On sait que la SLA au stade précoce est caractérisée par une accumulation protectrice de lymphocytes $\mathrm{T}$ [20]. Cependant, au fur et à mesure que la maladie progresse, les lymphocytes T CD8+ cytotoxiques s'infiltrent également dans le système nerveux central [21]. Avec l'étude de telles interactions, notre but était d'évaluer quantitativement l'activité neurotoxique dépendante du contact des cellules CD8 $+\mathrm{T}$ dérivées de souris SLA, étayée par des données préliminaires [22]. En comparant les propriétés adhésives de cellules T cytotoxiques CD8+ isolées de souris control (saines) et de souris mutantes SOD $1^{\mathrm{G} 93 \mathrm{~A}}$ aux neurones moteurs, des différences significatives ont été observées. Les cellules $\mathrm{T}$ dérivées de souris mutantes montrent une force d'adhésion améliorée par rapport aux ceux dérivées des souris saines. De plus, après le 
blocage de la liaison spécifique entre les molécules pMHC-I et TCR, impliquées dans le processus de reconnaissance, une réduction très significative de la force d'adhésion a été observée dans le cas des lymphocytes $\mathrm{T}$ mutants, alors que les lymphocytes $\mathrm{T}$ control n'ont qu'un effet révélateur faible ou nul pour les différents temps de contact. Nos résultats sont fortement étayés par les résultats de nos collaborateurs issus d'expériences de co-cultures in vitro indiquant la mort cellulaire de motoneurones en présence de lymphocytes T. Ensemble, ces résultats corroborent fortement la contribution des lymphocytes $\mathrm{T}$ cytotoxiques au développement de la SLA, en tant qu'acteur actif de la neurodégénérescence.

\section{II.2. L'élasticité des myotubes d'un modèle de souris SLA}

La formation des cellules musculaires est un processus en plusieurs étapes et hautement réglementé qui fait l'objet de recherches constantes. Les précurseurs des cellules musculaires sont les myoblastes. Les myotubes, formés par la fusion de myoblastes individuels, sont les fibres musculaires en développement contenant de multiples noyaux situés au centre. Bien que plusieurs études aient examiné les propriétés mécaniques de cellules musculaires squelettiques saines d'origine différente et dans divers états de différenciation [23-25], peu d'entre elles ont étudié l'effet des maladies sur l'élasticité des cellules musculaires squelettiques, dont la majorité porte principalement sur les dystrophies musculaires [26-28]. Nous avons réalisé une étude comparative détaillée sur le module de Young de cellules musculaires primaires squelettiques différenciées de souris saines et atteintes de SLA, isolées des muscles de souris asymptomatiques $\mathrm{SOD} 1^{\mathrm{G} 93 \mathrm{~A}}$. Une cartographie nanomécanique à haute résolution a été obtenue sur des myoblastes et des myotubes multi-nucléaires d'épaisseur variable. Dans le cas des myoblastes simples, les valeurs de module de Young mesurées étaient significativement différentes entre leur portion centrale et leurs saillies allongées. La contribution de la teneur en actine et en myosine à l'élasticité a également été examinée et discutée. Des images d'immunofluorescence ont été obtenues, présentant les régions de contact riches en actine avant la fusion, ainsi que le niveau d'expression de différents gènes codant pour l'actine et la myosine. En ce qui concerne les myotubes, des différences ont été observées entre l'élasticité d'une population mince et épaisse de myotubes de souris contrôle, indiquant la maturité différente des deux populations. Il est intéressant de noter que la même observation n'était pas valable dans le cas des myotubes du muscle squelettique mutant SOD1. Ici, les myotubes minces et donc pré matures ne présentaient pas de valeurs de module élastique significativement différentes par rapport aux myotubes épais et donc plus matures. Cette découverte suggère un durcissement autonome accru des myotubes dérivés de la SLA 
qui pourrait être substantiel dans le développement de cette maladie neurodégénérative incurable.

En résumé, nous pouvons conclure que nos études mécaniques au niveau cellulaire ont porté sur divers aspects de deux pathologies potentiellement mortelles, ce qui a permis de réaliser des découvertes inédites sur leurs processus de développement fondamentaux. Ces travaux mettent en lumière l'impact considérable et le rôle important des méthodes nanomécaniques basées sur l'AFM dans l'acquisition de connaissances précieuses sur la physiopathologie, le développement, le diagnostic et la progression des maladies, qui pourraient contribuer à l'évolution des thérapies futures.

\section{Bibliographie}

[1] K.K. Liu, M.L. Oyen, Nanobiomechanics of living materials, Interface Focus. 4 (2014). doi:10.1098/rsfs.2014.0001.

[2] G. Binnig, C.F. Quate, C. Gerber, Atomic Force Microscope, Phys. Rev. Lett. 56 (1986) 930-933. doi:10.1103/Phys RevLett.56.930.

[3] B. Cappella, G. Dietler, Force-distance curves by atomic force microscopy, Surf. Sci. Rep. 34 (1999) 1-104. doi:10.1016/S0167-5729(99)00003-5.

[4] A. V Taubenberger, D.W. Hutmacher, D.J. Müller, Single-cell force spectroscopy, an emerging tool to quantify cell adhesion to biomaterials., Tissue Eng. Part B. 20 (2014) 40-55. doi:10.1089/ten. TEB.2013.0125.

[5] O.K. Dudko, G. Hummers, A. Szabo, Theory, analysis, and interpretation of singlemolecule force spectroscopy experiments, Proc. Natl. Acad. Sci. 105 (2008) 15755-15760.

[6] A. Beaussart, S. El-Kirat-Chatel, Quantifying the forces guiding microbial cell adhesion using single-cell force spectroscopy, Nat. Protoc. 9 (2014) 1049-55. doi:10.1038/nprot.2014.066.

[7] J. Friedrichs, K.R. Legate, R. Schubert, M. Bharadwaj, C. Werner, D.J. Müller, M. Benoit, A practical guide to quantify cell adhesion using single-cell force spectroscopy, Methods. 60 (2013) 169-178. doi:10.1016/j.ymeth.2013.01.006. 
[8] E. Fokas, J.P. Steinbach, C. Rödel, Biology of brain metastases and novel targeted therapies: Time to translate the research, Biochim. Biophys. Acta - Rev. Cancer. 1835 (2013) 61-75. doi:10.1016/j.bbcan.2012.10.005.

[9] S. Madajewicz, C. Karakousis, C.R. West, J. Caracandas, A.M. Avellanosa, Malignant Melanoma Brain Metastases, Cancer. 53 (1984) 2550-2552.

[10] J. Zemła, J. Danilkiewicz, B. Orzechowska, J. Pabijan, S. Seweryn, M. Lekka, Atomic force microscopy as a tool for assessing the cellular elasticity and adhesiveness to identify cancer cells and tissues, Semin. Cell Dev. Biol. 73 (2017) 115-124. doi:10.1016/j.semcdb.2017.06.029.

[11] Z. Zhou, C. Zheng, S. Li, X. Zhou, Z. Liu, Q. He, N. Zhang, A. Ngan, AFM nanoindentation detection of the elastic modulus of tongue squamous carcinoma cells with different metastatic potentials, Nanomedicine Nanotechnology, Biol. Med. 9 (2013) 864-874. doi:10.1016/j.nano.2013.04.001.

[12] T. Watanabe, H. Kuramochi, A. Takahashi, K. Imai, N. Katsuta, T. Nakayama, H. Fujiki, M. Suganuma, Higher cell stiffness indicating lower metastatic potential in B16 melanoma cell variants and in (2)-epigallocatechin gallate-treated cells, J. Cancer Res. Clin. Oncol. 138 (2012) 859-866. doi:10.1007/s00432-012-1159-5.

[13] W. Xu, R. Mezencev, B. Kim, L. Wang, J. McDonald, T. Sulchek, Cell Stiffness Is a Biomarker of the Metastatic Potential of Ovarian Cancer Cells, PLoS One. 7 (2012) e46609. doi:10.1371/journal.pone.0046609.

[14] R. Omidvar, M. Tafazzoli-shadpour, M.A. Shokrgozar, M. Rostami, Atomic force microscope-based single cell force spectroscopy of breast cancer cell lines: An approach for evaluating cellular invasion, J. Biomech. $47 \quad$ (2014) 3373-3379. doi:10.1016/j.jbiomech.2014.08.002.

[15] M.C. Kiernan, S. Vucic, B.C. Cheah, M.R. Turner, A. Eisen, O. Hardiman, J.R. Burrell, M.C. Zoing, Amyotrophic lateral sclerosis, Lancet. 377 (2011) 942-955. doi:10.1016/S0140-6736(10)61156-7.

[16] D. Rosen, T. Siddique, D. Patterson, A. Hentati, H. Deng, R.H. Brown, Mutations in $\mathrm{Cu} / \mathrm{Zn}$ superoxide dismutase gene are associated with familial amyotrophic lateral sclerosis, Nature. 362 (1993) 59-62. 
[17] M.E. Gurney, H. Pu, A.Y. Chiu, M.C.D. Canto, C.Y. Polchow, D.D. Alexander, J. Caliendo, A. Hentati, Y.W. Kwon, H. Deng, W. Chen, P. Zhai, R.L. Sufit, T. Siddique, Motor Neuron Degeneration in Mice That Express a Human $\mathrm{Cu}, \mathrm{Zn}$ Superoxide Dismutase Mutation, Science (80-. ). 264 (1994) 1772-1775. doi:10.1126/science.8209258.

[18] B.H. Hosseini, I. Louban, D. Djandji, G.H. Wabnitz, J. Deeg, N. Bulbuc, Y. Samstag, M. Gunzer, J.P. Spatz, G.J. Hämmerling, Immune synapse formation determines interaction forces between $\mathrm{T}$ cells and antigen-presenting cells measured by atomic force microscopy, Proc. Natl. Acad. Sci. 107 (2010) 2373-2373. doi:10.1073/pnas.1000184107.

[19] P. Sundd, M.K. Pospieszalska, K. Ley, Neutrophil rolling at high shear: Flattening, catch bond behavior, tethers and slings, Mol. Immunol. 55 (2013) 59-69. doi:10.1016/j.molimm.2012.10.025.

[20] J.S. Henkel, D.R. Beers, S. Wen, A.L. Rivera, K.M. Toennis, J.E. Appel, W. Zhao, D.H. Moore, S.Z. Powell, S.H. Appel, Regulatory T-lymphocytes mediate amyotrophic lateral sclerosis progression and survival, EMBO Mol. Med. 5 (2013) 64-79. doi:10.1002/emmm.201201544.

[21] I.M. Chiu, A. Chen, Y. Zheng, B. Kosaras, S.A. Tsiftsoglou, T.K. Vartanian, R.H. Brown, M.C. Carroll, T lymphocytes potentiate endogenous neuroprotective inflammation in a mouse model of ALS, Proc. Natl. Acad. Sci. 105 (2008) 17913-17918. doi:10.1073/pnas.0804610105.

[22] E. Coque, La neuroimmunité dans la sclérose latérale amyotrophique (defended Thesis), Université de Montpellier, 2017.

[23] A.B. Mathur, A.M. Collinsworth, W.M. Reichert, W.E. Kraus, G.A. Truskey, Endothelial, cardiac muscle and skeletal muscle exhibit different viscous and elastic properties as determined by atomic force microscopy, J. Biomech. 34 (2001) 1545-1553. doi:10.1016/S0021-9290(01)00149-X.

[24] A.M. Collinsworth, S. Zhang, W.E. Kraus, G.A. Truskey, Apparent elastic modulus and hysteresis of skeletal muscle cells throughout differentiation, Am. J. Physiol. Cell Physiol. 283 (2002) C1219-C1227. doi:10.1152/ajpcell.00502.2001. 
[25] E. Defranchi, E. Bonaccurso, M. Tedesco, M. Canato, E. Pavan, R. Raiteri, C. Reggiani, Imaging and elasticity measurements of the sarcolemma of fully differentiated skeletal muscle fibres, Microsc. Res. Tech. 67 (2005) 27-35. doi:10.1002/jemt.20177.

[26] C. Pasternak, S. Wong, E.L. Elson, Mechanical function of dystrophin in muscle cells, J. Cell Biol. 128 (1995) 355-361. doi:10.1083/jcb.128.3.355.

[27] S. Puttini, M. Lekka, O.M. Dorchies, D. Saugy, T. Incitti, U.T. Ruegg, I. Bozzoni, A.J. Kulik, N. Mermod, Gene-mediated Restoration of Normal Myofiber Elasticity in Dystrophic Muscles, Mol. Ther. 17 (2009) 19-25. doi:10.1038/mt.2008.239.

[28] R.W. van Zwieten, S. Puttini, M. Lekka, G. Witz, E. Gicquel-Zouida, I. Richard, J.A. Lobrinus, F. Chevalley, H. Brune, G. Dietler, A.J. Kulik, T. Kuntzer, N. Mermod, Assessing dystrophies and other muscle diseases at the nanometer scale by atomic force microscopy, Nanomedicine. 9 (2014) 393-406. doi:10.2217/nnm.12.215. 


\section{Introduction}

\section{Nano-biomechanics}

Biomechanics forms a bridge between physical and biological sciences dealing with the function and movement of the body and the dynamics of blood flow. It greatly developed in the last decades demonstrating the high potential of interdisciplinary sciences and bringing fundamental knowledge in the topics of macroscopic mechanics. As the technology has been developed an increasing number of devices became available to study mechanical properties at cellular and molecular level, allowing sub-nanometer scale spatial and piconewton scale force measurements. Consequently, an increasing amount of novel knowledge has accumulated about the forces interacting between cells, cell adhesiveness against different surfaces or to the ECM, but also the extent of unfolding forces of molecules and unbinding forces between specific pair of molecules were revealed [1,2]. Besides that, forces that a cell or a molecular structure can exert on its environment were measured [3-5], as well as elastic properties of different types of cells were determined and compared in physiologic and pathologic conditions [6].

The growing number of methods and investigations aiming to elucidate the principles of lifesupporting molecular and cellular interactions initiated the field of nano-biomechanics, as a new research area merging the topics of mechanics, engineering, biology, and medicine [7].

The "toolbox" of this cross-field is wide, containing several novel and redesigned experimental approaches, such as micropipette aspiration, cell poker, magnetic twisting cytometry, wrinkling membrane and substrate strain techniques, microelectromechanical systems (MEMS) or acoustic methods [8]. However, the main toolset consists of atomic force microscopy (AFM), magnetic tweezer, optical tweezer/stretcher and cell traction force microscopy. Apart from probing whole-cell mechanics, optical and magnetic tweezers are particularly useful to analyze mechanical properties of sub-cellular structures. These have been applied to determine binding/unbinding forces of ligand-receptor bonds and focal adhesion proteins, reveal DNA mechanical properties, but also to quantify the forces generated by molecular motors or the polymerization of actin filaments and microtubules 
$[2,4,5,8]$. Despite their high force sensitivity, maximal adhesion forces that optical tweezers can exert are limited, usually below $100 \mathrm{pN}$. Among the above methods, AFM is the most versatile system serving as a reliable and accurate nanoforce tool. It offers the largest range of detectable forces (from $10 \mathrm{pN}$ up to $1000 \mathrm{nN}$ ), precise spatial $(\sim 1 \mathrm{~nm}$ to $\sim 100 \mu \mathrm{m}$ ) and temporal $(\sim 0.1 \mathrm{~s}$ to $>10 \mathrm{~min})$ control, a relatively simple use, and provides physiological conditions by allowing measurements in liquid and at physiological temperature.

\section{I.1. Atomic force microscopy as a tool for nano-biomechanics}

Atomic force microscopy (AFM) is a non-optic microscopy technique developed in the 80's by Binnig, Quate, and Gerber, and it is the key member of the scanning probe microscope superfamily [9]. Although strong improvements have taken place since then, the main concept is still the same: driven by different feedback methods a sharp probe is taken in close proximity to the sample to scan its surface building up a highly resolved three-dimensional topographic image. This relatively simple working principle opened the way for fast developments resulting in unique capabilities such as imaging structures from tissue to single molecules [10,11], video rate scanning [12], or measuring forces on the $\mathrm{pN}$ scale [13].

The vital part of the AFM is an extremely sharp (nanometer-sized) tip micro fabricated at the end of a very flexible cantilever that deflects when the tip interacts with the sample surface. The optical lever method is the most used approach to detect the slight deflection changes of the cantilever and to provide a constant feedback keeping the tip in the near-field of the sample. Principally, it uses a focused laser beam reflected from the backside of the cantilever that falls on a quadrant photodiode. Hence, the slight bending of the cantilever causes enhanced spatial variations of the laser spot on the detector that can be precisely determined.

Apart from its high resolution imaging capacity the AFM holds several other advantages. It provides a real three-dimensional surface profile, requires minimal sample preparation, and can be easily combined with optical microscopy or spectroscopy techniques, like Raman or IR $[14,15]$. The presence of a physical probe in close proximity to the sample allows exploring a wide variety of physico-chemical properties. Hence, together with surface topography, AFM can provide quantitative data, about the sample's elasticity [16], friction [17], or adhesion forces [18]. In addition, maybe its most important capability in respect to life sciences is to perform measurements under physiologically relevant conditions. 


\section{I.2. Force measurements: force distance curve}

Although atomic force microscopy (AFM) was first utilized in biology as a surface imaging technique, soon after its invention researchers have applied it to study the mechanical properties of living cells and other biological samples by force spectroscopy [19]. During force spectroscopy measurements the horizontal ( $\mathrm{x}, \mathrm{y}$ ) position of the cantilever is fixed, while its vertical movement $(\mathrm{z})$ and instantaneous deflection, in response to various forces, are recorded resulting the so called force-distance curves (FD-curves) in a cyclic manner.

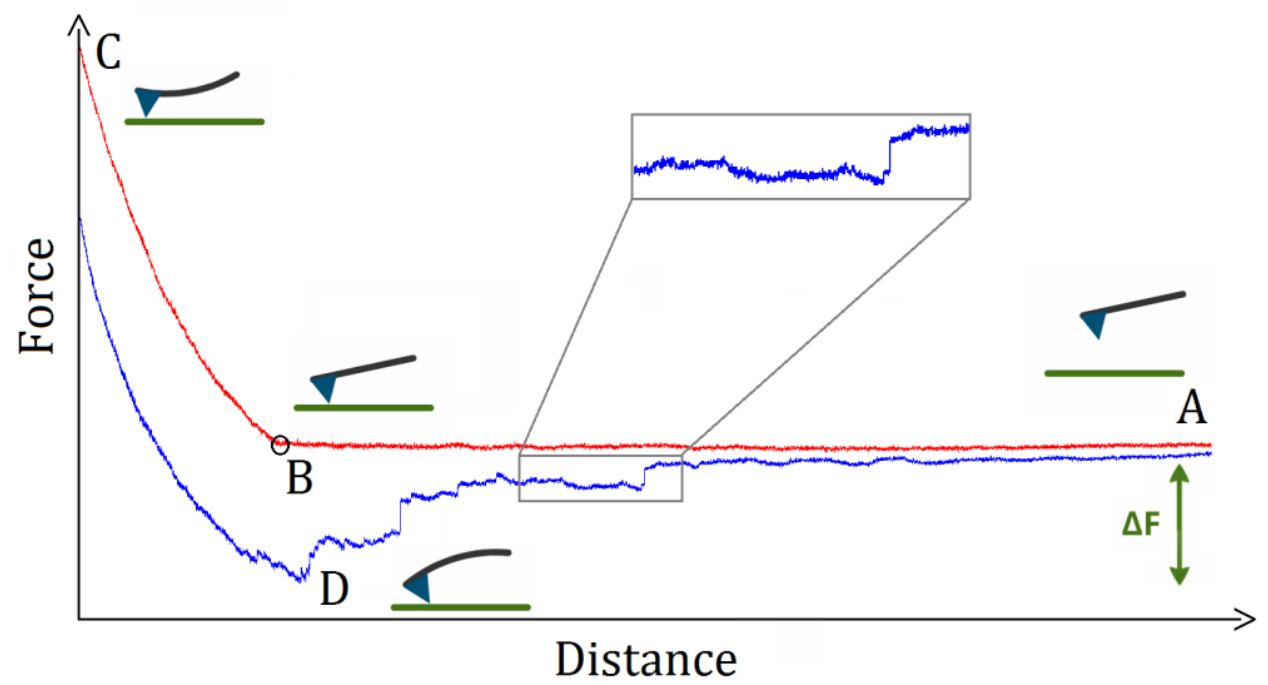

FIGURE 1. A representative force-distance curve.

Figure 1 depicts a representative FD-curve. The force cycle starts at several micrometers far from the surface (A). The probe approaches the sample with a constant velocity, the tip reaches the surface (B), and the cantilever starts to deflect until its deflection will correspond to the preset trigger force $(\mathrm{C})$. Following a certain contact time the cantilever is withdrawn. If adhesion is present, the forces required to detach the probe from the investigated surface will deflect the cantilever in the opposite direction. The strength, length, and number of individual un-bindings will alter the shape of the retraction part of the curve that serves as a fingerprint of the probe-sample interaction. After the probe has been withdrawn enough, where all interaction forces cease, the cycle finishes. The resulted FD-curves are the raw data of force spectroscopy measurements enabling the extraction of various parameters related to the mechanical properties of the sample or to the interactions between the substrate and the tip. By fitting the approaching (red) part of the FD curve with appropriate theoretical models the Young's modulus of the sample can be obtained. The force difference between the starting and minimum points in the FD curve provides the maximal adhesion. This is composed by 
individual ruptures (close-up) whose number, step-size, but even their occurring distances are important parameters of the interaction. Besides these, several type of works can be extracted, such as work of de-adhesion, total work used to bend the cantilever, but also the dissipated (or plastic) work during the cycle and the elastic work exerted by the sample to recover the initial shape. By extracting these parameters a mechanical phenotype of the sample can be quantified that is well defined for different type of cells, and tissues [20,21].

\section{I.3. Elastic modulus determination}

Living cells are continuously perceiving, processing, and responding to mechanical signals received from their surroundings. Elastic properties are crucial for cells to perform their role properly. AFM based nanoindentation measurements has provided valuable data about the elastic modulus of various living cell cultures. The obtained values vary over a wide range from 0.1 up to $100 \mathrm{kPa}$, depending on cell type and sample preparation [6,8]. The role of cytoskeleton is dominant in cell stiffness, as several studies have demonstrated. However, the different cytoskeletal components have varying degrees of contribution. While cytoskeleton F-actin depolymerization by cytochalasin $\mathrm{D}$ resulted in a reduced cell elasticity, showing the crucial role of the F-actin network [22], studies on microtubule depolymerization obtained little effect on cell membrane mechanical resistance [23].

To quantify the elastic (or Young's) modulus of the sample the data points at the contact region of FD-curves must be fitted with theoretical models, of which the Hertz-Sneddon model is the most widely used. The problem of contact between a rigid spherical probe and an elastic half-space was first solved by Hertz [24] that was further developed by Sneddon for different tip shapes $[25,26]$. The relation between loading force $(F)$ and indentation depth $(\delta)$ for a conical hard indenter is the following:

$$
F=\frac{E}{1-v^{2}} \frac{2 \tan (\alpha)}{\pi} \delta^{2}
$$

Here, E is the Young's modulus of the sample, $\alpha$ is the half-opening angle of the cone, while $v$ denotes the sample's Poisson ratio. Despite its simplistic assumptions, provided that adhesion forces are much smaller than the maximum force-load and indentation depths are less than $10 \%$ of cell thickness, the Hertz-Sneddon model is applicable widely accepted and used [6,27]. 


\section{I.4. Force mapping}

Thanks to the precise positioning capabilities of the AFM, an elegant way of data acquisition is to define a grid over a selected area of the sample and to perform force measurements in every grid node. This enables one to study the spatial distribution of mechanical properties over entire tissues, cells, or sub-cellular structures. The result is a set of data that contains not only morphological information, but it can be spatially correlated with the various parameters extracted from the individual FD-curves. Using this technique several maps can be reconstructed about the selected area, each showing the different spatially resolved physicochemical properties of the sample (see Figures 3-9 and 21, 24, 25 in Result's subsection I.1 and II.2 respectively).

\section{I.5. Single cell force spectroscopy}

Cells are in continuous communication with their environment by means of a constant exchange of physical and biochemical signals. Apart from their fundamental role in the shaping, development, and maintenance of tissues, cellular-level forces are essential in stimulating signaling pathways that regulate important cellular processes, such as migration, proliferation, survival, and differentiation [28]. AFM was proven to be a versatile tool to quantify a wide range of adhesion forces at physiological conditions. While in usual force measurements the probe is a stiff material, in most cases made out of silicon or silicon nitride, several biological objects could also serve as a probe. The AFM tip can be functionalized with various molecules for specific intermolecular binding measurements [29] or with bacteria for testing its adhesion to different substrates [30], but even whole living cells can be immobilized on the cantilever, thereby applying the cell as a probe [21]. The latter case belong to the method called as single-cell force spectroscopy (SCFS) [21,31]. This method has the exceptional ability to directly quantify interaction forces between two living cells down to the contribution of single molecules. Since the first pioneering studies $[32,33]$, SCFS have been applied in a wide range of studies involving cell biology, biophysics, biomaterial science, clinical and pharmaceutical research, but also tissue engineering and regenerative medicine $[1,31,34]$. 


\section{Relevance of nano-biomechanics in monitoring diseases}

Nano-biomechanics, as an emerging powerful technology to explore mechanical aspects of biological matter at the nanoscale, has recently opened a new horizon in scientific research by generating significant contribution in the study of human diseases. Biomechanical research of physiological and pathological processes of different diseases beside being instrumental in increasing our understanding of cellular behavior and cellular manifestations behind disease condition and progression, it provides valuable knowledge for the development of therapies [35]. During the last two decades great progress has been made in elasticity imaging at whole organ level with the development of ultrasonic elasticity imaging and magnetic resonance elastography (MRE) [36,37]. MRE has a wide application area starting with cancer detection in almost all major organs [38], through the investigation of chronic liver diseases, but it has also been applied to probe the mechanical properties of intracranial tumors [39] and muscle stiffness of patients with neuromuscular disorders [40] as well. In contrast with the clinical use of whole organ elasticity imaging methods, the tools of nano-biomechanics hold the advantage of providing valuable information about mechanical changes at the cellular-level. Changes in cells' mechanical phenotype, such as adhesion or elasticity, affects a wide range of human diseases. Therefore, nanomechanical investigations of pathologically altered cells or tissues may contribute to the understanding of the pathophysiology and the progress of arthritis [41], asthma [42], vascular disorders [43], malaria [44,45], sickle cell anemia [46], muscular dystrophies [47-49], cancer [45,50], among others. This work will particularly focus on AFM-based nanomechanical measurements addressing brain metastasis formation and amyothrophic lateral sclerosis.

\section{II.1. Brain metastasis formation}

Cancer remains the second leading cause of morbidity and mortality worldwide in countries of all income levels, with approximately 14 million new cancer cases every year and it was responsible for 8.2 million deaths in 2012 worldwide [51]. Globally, nearly every $6^{\text {th }}$ death is due to cancer. Being the main cause of cancer patient mortality, the most life-threatening aspect of cancer is metastasis. Among all types, the presence of brain metastasis (BM) is one with the poorest prognosis, often causing life-impairing neurological symptoms, where the median survival time can be counted in months, occasionally a few years [52]. While the 
different cancers show different propensities to form BM, the majority of BMs originate from the primary tumor of lung cancer $(40 \%-50 \%)$, breast cancer $(15 \%-25 \%)$ and malignant melanoma (5\%-20\%) [53]. Although melanoma is only 1 to $2 \%$ of all cancers, it invades the brain with one of the highest frequencies [54]. Autopsy studies showed that up to $90 \%$ of patients with end-stage melanoma had BM [55]. Brain metastasis is difficult to treat; local surgery, whole brain radio therapy, stereotactic radiosurgery have been the only treatment approaches for a long time [56]. Recently, incorporation of systemic treatments such as molecularly targeted therapies and immunotherapies have emerged as alternatives [57]. Although results of these therapies seem to be promising, along with this, prevention might be important as well. Despite our growing knowledge about biology of BM formation, the precise details that trigger and guide tumor cell toward the brain are still under debate. In order to find effective prevention strategies, missing details of brain metastasis formation need to be elucidated.

\section{II.1.1. Malignant melanoma}

Melanoma is among the most aggressive and therapy-resistant human cancers. Occurrence of melanoma has increased worldwide, being responsible for over $80 \%$ of skin cancer deaths [58]. Despite the fact that metastatic melanoma has relatively low abundance, it shows high resistance to conventional therapies [59,60]. The main reason for this is the high level of its genetic heterogeneity. Among all human cancers melanomas carry the highest number of mutations, generally more than 10 per mega base pairs [61], resulting in tumors with differently mutated domains that necessitate different treatments [62]. In some cases even the metastases could show different genotypes compared to their primary tumor [63]. The most affected signaling cascade by melanoma is the mitogen-activated protein kinase (MAPK) pathway, which includes the signaling molecules Ras, Raf, MEK and MAPK, and plays an important role in the regulation of cellular growth, migration, and survival. BRAF ( 50\%) and NRAS (20-25\%) are the two major mutations in melanoma, causing constitutive activation of the MAPK pathway which then leads to the expression of genes encoding proteins that induce uncontrollable cell proliferation and survival.

\section{II.1.2. The process of metastasis formation}

Cancer cells can use blood or lymphatic transport to form metastases in distant organs. Since the central nervous system (CNS) lacks a classical lymphatic system, the only way for cancer cells to reach the brain is via the blood stream, termed as hematogenic pathway. However, a 
tumor cell in order to form a metastasis, especially in the brain, needs to go through several challenging processes, which requires a high degree of motility and adaptability to the different environments. After the acquisition of a motile phenotype the cell must escape from the primary tumor site, invade nearby tissues, brake through the blood vessel wall and enter into the blood circulation, referred to as intravasation. Here the cancer cells are exposed to a turbulent blood flow and exposed to the offensive of immune cells that recognize them as pathogens. If a cancer cell is able to survive in this extreme environment and avoid to be recognized by immune cells, it can disseminate and reach distant organs, like the brain. Through extravasation, after firmly attached to the blood vessel wall the cell transmigrate through the cerebral endothelial layer into the brain. Here it interacts with the microenvironment, which could result in a survival, proliferation, and lastly the formation of a secondary tumor [64].

\section{II.1.3. Blood-Brain Barrier}

The first challenge for hematogenously disseminated melanoma cells in order to reach the brain parenchyma is to break through the tight layer of brain endothelial cells that forms the morphological basis of the blood-brain barrier (BBB) [65]. This precisely regulated barrier between the systemic circulation and the CNS protects the neuronal tissue by restricting the free movement of solutes and cells between the two compartments, while at the same time serves as a carrier for the specific nutrients and metabolites. Since several environmental and molecular factors play a crucial role in preventing its penetration into the CNS and arresting melanoma cells at the luminal surface of the blood vessels, melanoma cells must have special attributes to overcome obstacles and facilitate BBB breaching [66]. However, after a successful transmigration, the BBB may have some supportive role as well by protecting the metastatic cells from the immune surveillance of the organism or releasing favorable substances for metastasis growth [65]. This fact and the melanocytes' neural crest origin might be among the main causes for the high brain metastasis formation tendency of melanoma.

\section{II.1.4. The use of AFM in cancer research}

Nanomechanical cellular information provided by atomic force microscopy can identify morphological variations, cellular binding forces, cell stiffness changes, and surface adhesion behaviors that could enhance our understanding of cancer and thus could lead to the development of advanced clinical solutions [67]. The first pioneering comparative study on 
the elastic properties of cancerous cells reported a one order of magnitude decrease in the Young's modulus of cancerous cells (Hu456, T24, BC3726) in contrast to normal cells (Hu609 and HCV29) [68], focusing the attention on the importance of cancer cell mechanics investigations. This led to the initiation of numerous studies providing quantitative biomechanical data of cancer-related changes and contributing greatly to cancer research that may even facilitate the development of future cancer therapies [69,70]. Data accumulated so far clearly demonstrated that individual cancer cells are more deformable than their healthy counterparts in the majority of cancers, including bladder, breast, prostate, ovarian, colon, thyroid, kidney, and others [71,72]. A few studies went further by raising the question whether invasiveness can be reflected in the nanomechanical parameters of cancer cells and obtained decreased elastic modulus along with higher metastatic potential [73-75].

Changes in cell adhesion are crucial in the development of cancer. There is growing evidence showing that cancer cells, by changing their structure and behavior, can alter their mechanical phenotype thereby facilitating their dissemination [66]. It has been reported that malignant breast cancer cells show reduced inter-homocellular adhesion that decreases with metastatic potential, hence promoting their escape from the primary site [76]. In addition, other studies obtained that cancer cells display an increased adherence to the ECM, apparently for the same purpose [66]. Moreover, in case of melanoma a modulation of cell-cell interaction strength was observed, which depended on the extracellular protonation [77].

A crucial step in the multistage process of cancer metastasis, especially in case of BM formation, is the firm adhesion of blood-travelling tumor cells to the blood vessel lining endothelial layer. This can be addressed directly by AFM based single-cell force spectroscopy (SCFS) to investigate cellular mechanics and the dynamics of intercellular interactions throughout tumor cell transmigration [67,78]. Excluding the immobilization of the cancer cell, during these measurements there is no need for any staining or other cell-life impairing preparation. In vitro cell co-culture models dealing with the whole transmigration process have already been successfully established [79]. A detailed understanding of tumor cell endothelial cell interaction could lead to the identification of mechanisms which could reduce transmigration and thus BM formation. A recent study showed how the expression of cell adhesion molecules in endothelial cells influence their adhesive properties to bladder cancer cells [80]. Thickening of the outer glycocalyx layer of the endothelial cells, induced by short term hyperglycemia, resulted in higher adhesion between lung carcinoma and human aorta endothelial cells [81]. The accumulated knowledge about the contribution of biomechanical 
properties such as elasticity, adhesion dynamics, or strength to the cell's mechanical phenotype are essential for improvement of early cancer identification, thus could be substantial in future cancer therapeutics.

\section{II.2. Amyotrophic lateral sclerosis}

Amyotrophic lateral sclerosis (ALS) is a fatal neurodegenerative disease, which causes a gradual degradation of the human motor system, with an incidence of 2.16 per 100000 person-years in Europe [82]. The wasting of motoneurons in the brain and spinal cord results in muscle weakness, followed by gradual motor disability, and finally leads to death due to respiratory failure, typically within 2-5 years of symptom onset [83]. The origin of ALS in 5$10 \%$ of the cases is familial (fALS), while the rest of the patients diagnosed with ALS have a sporadic disease (sALS) [84]. However, the two are clinically undistinguishable from each other [85]. The survival time after first symptoms for $50 \%$ of the patients is below 30 months, while only $20 \%$ of patients survive after 5 years and a small percentage live for more than 10 years [86].

For more than a century following the first description of ALS by Jean-Martin Charcot (1874), our general knowledge about its origin, pathogenesis and useful therapies was limited. The scientific interest to investigate the disease started to raise in the 90's, after some new insights in the glutamate neurotransmitter system and the discovery of genes linked to the development of familial ALS [84]. Since then several genetic studies have dealt with the ALS, revealing the involvement of mutations in the genes of SOD1, TARDBP and FUS, but also a genetic defect in a noncoding nucleotide sequence was associated with ALS [85]. Although for a long time ALS was considered merely as a motor neuron disease, due to recent findings it is now related to a range of neurological disorders [83]. Despite the numerous findings, that revealed several potential pathogenic mechanisms and the involvement of different cell types in the development of ALS, its etiology remains elusive [85].

Mutations in the gene of copper/zinc ion-binding superoxide dismutase (SOD1) is one of the main causing factor for the development of the disease [87], which is responsible for $20 \%$ of the familial [88] and 5\% of the seemingly sporadic ALS [84]. Transgenic mice expressing mutant human SOD1 ${ }^{G 93 A}$ gene were proven to provide a good model for the human ALS disease [88], and have been invaluable in understanding of the underlying pathogenic 
processes [89]. In our in vitro experiments primary cultures isolated from this mouse model was addressed by AFM-based nanomechanics to unravel different aspects of ALS development, namely lymphocyte - motor neuron interactions and myotube elasticity.

\section{II.2.1. T cell interaction forces}

$\mathrm{T}$ cells, or $\mathrm{T}$ lymphocytes, play an important role in cell-mediated immunity and their interaction with other cells is pivotal in the recognition and elimination of potential pathogens. During adaptive immune responses, $\mathrm{T}$ lymphocytes recognize antigenic peptides presented by major histocompatibility complex (MHC) molecules on antigen-presenting cells (APCs). The forces of these interactions and the relating molecular linkages have been extensively studied [90,91], unraveling various aspects of the immune response. A series of studies have dealt with the binding force and dynamics of LFA-1 / ICAM-1, as the key molecular structures involved in lymphocyte adhesion [92,93]. The recognition process, involving bindings between $\mathrm{T}$ cell antigen receptor (TCR) and agonist peptide presenting major histocompatibility complex (pMHC), was also addressed by AFM-based force measurements [94]. Long-term contact followed force measurements between $\mathrm{T}$ cells and APCs revealed substantial data about the strength and time-dependence of immune synapse formation [90,95], but several other work have studied T cell - APC adhesion by SCFS [96].

Indications about the involvement of T cells in ALS pathogenesis are recent. It was found that the early stage ALS is characterized with protective T cell accumulation [97]. However, as the disease progress, cytotoxic $\mathrm{CD}^{+} \mathrm{T}$ cells also infiltrate into the CNS [98]. To the extent of our knowledge there was no study subjecting direct force measurements between motoneurons and cytotoxic $\mathrm{T}$ cells. By examining such interactions our aim was to quantitatively evaluate, contact-dependent neurotoxic activity of ALS mouse derived $\mathrm{CD}^{+} \mathrm{T}$ cells, supported by our preliminary data [99].

\section{II.2.2. Myotube Elasticity}

Muscle cell formation is a multistep and highly regulated process under constant research [100]. The precursors of the subsequent muscle cells are the myoblasts, which are a type of embryogenic stem cells. By the fusion of single myoblasts myotubes are forming, which are developing muscle fibers that contain multiple centrally located nuclei and start to present the ordered structure of the actin-based thin and myosin-based thick filaments. 
Muscle cell elastic properties have been the subject of AFM-based nanomechanical measurements for long. Some early AFM studies on skeletal muscles have investigated the surface morphology and transverse elasticity of rabbit and drosophila myofibrils [101,102]. The myofibrils sectioned from mature skeletal muscle have shown elasticity values from 11 to $94 \mathrm{kPa}$, depending on the loci. The first measurements on intact cells were done by Mathur et al. [103]. They compared the general elasticity of skeletal and cardiac muscle cells in liquid, obtaining $24.7 \pm 3.5 \mathrm{kPa}$ and $100.3 \pm 10.7 \mathrm{kPa}$ elastic modulus values, respectively. A work from the same group investigated the elastic modulus of skeletal muscle cells throughout differentiation [104], and have reported a sharp increase in the average elasticity from $10 \mathrm{kPa}$ (day 1) to $35-45 \mathrm{kPa}$ after 8 days in vitro (DIV) differentiation. In both studies a C2C12 murine myoblast cell line was used. The first complete three-dimensional topography and mechanical characterization of intact, living skeletal muscle fibers were performed by Defranchi and his coworkers [105], measuring an average elasticity value of $61 \pm 5 \mathrm{kPa}$ on the sarcolemma of the fibers, while Ogneva et al. have characterized the mechanical properties of muscle fibers at sites corresponding to Z-disks, M-bands, and intermediate regions [106].

Although several studies have examined the mechanical properties of healthy skeletal muscle cells from different origin and in various states of differentiation, few investigated the effect of diseases on skeletal muscle cell elasticity, out of which the majority addresses mainly muscular dystrophies [47-49]. To the best of our knowledge there is no study addressing the mechanical properties of ALS muscle cells at the single cell level. Our objective was to study the elasticity of ALS diseased myoblasts and myotubes, isolated from the muscles of asymptomatic SOD1 $1^{G 93 A}$ mice, and compare them to their healthy counterparts. The final aim was to understand whether early structural disturbances could contribute to ALS pathogenesis, which may lead to improved early diagnostic methods and therapeutics of ALS. 


\section{The objectives of the work}

- Direct application of AFM-based methods in order to elucidate important questions related to life-threatening diseases, namely brain metastasis and amyotrophic lateral sclerosis.

- Gain direct insight into the surface scanning mechanism of tumor cells during extravasation into the brain parenchyma, by directly quantifying and spatially resolving the nanomechanical parameters of metastatic cancer cell - endothelial layer interactions.

- Compare the mechanical phenotype of melanoma cells of different malignancy levels and examine whether the metastatic potential is identifiable in nanomechanical properties.

- Elucidate the contribution of cytotoxic T cells, as a new pathological mechanism, to the development of ALS, by quantifying short term adhesion forces between $\mathrm{CD}^{+} \mathrm{T}$ cells and motoneurons.

- Monitor the elasticity of ALS derived differentiated skeletal muscle cells and compare them with their healthy derived counterparts, with the aim to assess cellular-level differences. 


\section{Materials and methods}

\section{Cell cultures}

\subsection{Endothelial cell line}

The human cerebral microvascular endothelial cell line hCMEC/D3, as a proven blood brain barrier model, was used in our SCFS experiments to mimic the inner side of brain capillaries. It expresses normal endothelial markers (CD31, VE cadherin, von Willebrand factor), exhibits contact inhibition at confluence in tissue cultures, shows enhanced proliferation response to endothelial growth factors, and forms capillary-like structures in Matrigel, but no colonies in soft agar [107]. In addition, it expresses chemokine receptors (CCR3-6, CXCR1-5), upregulated adhesion molecules (VE-cadherin, $\gamma$ - and $\beta$-catenin) in response to inflammatory cytokines, tight junctional proteins (ZO-1, claudin-5, JAM-1) and ABC transporters (MDR-1, BCRP, MRP-1) to actively exclude drugs [107].

The cells were cultured on rat tail collagen-coated dishes in EBM-2 medium (Lonza) supplemented with EGM-2 Bullet Kit (Lonza) and 2.5\% FBS (Sigma). The culture dishes were only half-coated with collagen in order to leave an empty (endothelial-free) space on the dish that can later help to easily find and immobilize the suspended cancer cells on the tipless AFM cantilever. Cells were cultured until confluence was reached on the coated portion.

\subsection{Cancer cell lines}

Three different melanoma cell lines, WM35, A2058 and A375, were used as candidates for the brain metastasis model during the SCFS experiments. WM35 originates from a skin tumor being in a radial growth phase (RGP) and is considered as a malignant, but yet non-metastatic melanoma cell line. However, A375 and A2058 cell lines are highly metastatic. The former derives from a primary melanoma of a middle-aged woman, while the latter one was extracted form a lymph node melanoma metastases of a Caucasian man. All three cell types bear a BRAF Val600Glu mutation, but are NRAS wild type.

WM35 human primary melanoma cells and the highly invasive A375 human melanoma cells were cultured in DMEM (GIBCO), supplemented with 5\% FBS (Lonza). A2058 human metastatic melanoma cells (obtained from the European Collection of Cell Cultures) were 
maintained in EMEM (Sigma) supplemented with 5\% FBS (Sigma). During culturing, cells were kept at $5 \% \mathrm{CO}_{2}$ atmosphere at $37^{\circ} \mathrm{C}$.

\subsection{SOD1 mutant and wild type animals}

Transgenic mice with an enhancement in copper/zinc ion-binding superoxide dismutase (SOD1) gene expression were used as a model to mimic the ALS disease. SOD1 ${ }^{G 93 A}$ and wildtype mice were maintained on a C57BL/6 background and purchased from Jackson Labs. Mice were housed in cages with a $12 \mathrm{~h}$ light/12 h dark cycle, with food and water supplied ad libitum.

Genotyping was carried out on tail clips originating DNA by a multiplex PCR with the following primers: SOD13 Forward: 5'-TTCTGTTCCCTTCTCACTGT-3'; SOD13 Reverse: 5'TCCCCTTTGGCACTTGTATT-3'; SOD15 Forward: 5'-TGTTGGGAGGAGGTAGTGATTA-3'. SOD15 reverse: 5'-AGCAGAGTTGTGTTAGTTTTAG-3'.

\subsection{Motoneuron (isolation and purification)}

During SCFS experiments purified primary motoneuron cultures, isolated from wild type GFP expressing mice, served as a target for the lymphocytes, derived from wild-type and transgenic SOD1 $1^{G 93 A}$ mutant mice. The motoneurons were isolated from E12.5 spinal cord of Hb9::HGFP embryos using iodixanol density gradient centrifugation, as described elsewhere [108]. The trypsin treatment of the dissected spinal cords was followed by a mechanical dissociation of the cells. After a first BSA cushion, the largest cells were isolated using iodixanol density gradient purification (OptiPrep, Sigma). Following a final BSA cushion, motoneurons were plated onto collagen- and laminin-coated wells at a density of 1500 cells $/ \mathrm{cm}^{2}$ in supplemented Neurobasal medium (Life Technologies) with neurotrophic factors $(1 \mathrm{ng} / \mathrm{ml} \mathrm{BDNF}, 100 \mathrm{pg} / \mathrm{ml} \mathrm{GDNF}$, and $10 \mathrm{ng} / \mathrm{ml} \mathrm{CNTF})$, completed with $2 \%$ horse serum, B27 supplement (Life Technologies), $50 \mu \mathrm{M}$ L-glutamine, $25 \mu \mathrm{M}$ L-glutamate, $25 \mu \mathrm{M}$ mercaptoethanol and $0.5 \%$ penicillin/streptomycin. While culturing, the motoneurons were kept at $37^{\circ} \mathrm{C}$ and $7.5 \% \mathrm{CO} 2$. For blocking the recognition of antigen presented MHC-I by TCR the motoneuron culture was incubated for 90 minutes with monoclonal anti-MHC-I blocking antibody (clone 28.14.8) in $1 \mu \mathrm{g} / \mathrm{mL}$ final concentration. 


\section{5. $T$ cell (isolation and purification)}

$\mathrm{T}$ cells were isolated from cervical, axillaries, brachial, inguinal and mesenteric lymph nodes of wild-type and $S O D 1^{G 93 A}$ mutant mice. After dissection, lymph nodes were crushed onto a nylon membrane and the disaggregated cells were suspended in PBS. CD8 ${ }^{+} \mathrm{T}$ cells were isolated by negative selection on magnetic field using $\mathrm{CD}^{+} \mathrm{a}^{+} \mathrm{T}$ cells isolation kit (Miltenyi Biotec), according to manufacturer's instruction. That consist in incubating the cells (approx. number $10^{7}$ ) in PBS containing $0.5 \%$ BSA with a mixture of biotin-antibodies against CD4, CD11b, CD11c, CD19, CD45R, CD49b, CD105, MHC class II, and TCR $\alpha / \delta$. Afterwards by the addition of anti-biotin microbeads $\mathrm{CD}^{+} \mathrm{T}$ cells can be isolated on magnetic column.

\subsection{Myoblast (isolation and differentiation)}

Primary cultures of wild-type myoblasts were obtained from C57BL/6 mice, while the ALS modeling myoblast cultures were isolated from the offspring of crosses between female C57BL/6 and male SOD1 $1^{G 93 A}$ mice. Satellite cells were obtained from the hind limb muscle of 3-4 weeks old mice (pre-symptomatic for $S O D 1^{G 93 A}$ ). Muscle mincing was followed by an enzymatic digestion in Ham's F10 media (Gibco) supplemented with $2.5 \mathrm{mM} \mathrm{CaCl}$, 0.5 $\mathrm{mg} / \mathrm{ml}$ dispase II (Sigma) and $10 \mathrm{mg} / \mathrm{ml}$ collagenase B (Sigma). After incubation for 15 minutes at $37^{\circ} \mathrm{C}$, a mechanical dissociation was performed. The obtained muscle digest was passed through a $70 \mu \mathrm{m}$ mesh filter, transferred to a $15 \mathrm{ml}$ tube and spined for $5 \mathrm{~min}$ at $1000 \mathrm{rpm}$. The pellet was suspended in culture media (Ham's F10, 20\% fetal bovine serum, $2 \%$ penicillin/streptomycin, $2.5 \mathrm{ng} / \mathrm{ml}$ recombinant human fibroblast growth factor-basic, bFGF, Gibco) and placed in a $60 \mathrm{~mm}$ uncoated plastic plate for $1 \mathrm{hr}$ to favor fibroblasts adherence. Afterwards, the content was transferred into culture dishes coated with net-like patterned structure of collagen (as described elsewhere [109]) at $37^{\circ} \mathrm{C}, 7 \% \mathrm{CO}_{2}$, to promote strong surface adherence. Satellite cells were allowed to multiply until they reach $70-80 \%$ confluence and then split with $0.25 \%$ trypsin to enhance the colony. Experiments were

performed from fourth to sixth passage. For myoblasts differentiation and fusion, the serum was decreased to $2 \%$ and the cells were cultured until 6 to 8 days in vitro (DIV). 


\section{Atomic force microscope setup}

The experimental setup for all measurements consisted of an Asylum Research MFP-3D atomic force microscope head, linked to a Molecular Force Probe 3D controller (Asylum Research, Santa Barbara, CA; driving software written in IgorPro 6.34A, Wavemetrics) and supported by an inverted optical microscope (Zeiss Axiovert 200/ Olympus ix-71) for positioning and optical image acquisition.

All SCFS measurements were performed with tipless gold-coated rectangular cantilevers (MikroMasch, Sofia, Bulgaria), having a nominal spring constant of $50 \mathrm{pN} / \mathrm{nm}$ and a resonant frequency of $10 \mathrm{kHz}$ in air and $3 \mathrm{kHz}$ in water, respectively.

For nanoindentation measurements on myotubes short rectangular silicon-nitride BioLevers (BL-RC150VB, Olympus, Japan) were used, with gold coating on both sides. The nominal and calibrated spring constants were $30 \mathrm{pN} / \mathrm{nm}$ and in the range of $16.6-30.4 \mathrm{pN} / \mathrm{nm}$, respectively, while the resonance frequency in air was about $37 \mathrm{kHz}$, which drops to $6 \mathrm{kHz}$ in water. The cantilevers were equipped with a V-shaped tip, having a half-opening angle of $45^{\circ}$ and a radius around $30 \mathrm{~nm}$.

Ahead of each measurement the spring constant of cantilevers was determined through a contactless calibration process using a combination of thermal noise and Sader methods, available within the driving software [110-112]. All experiments were carried out at $35^{\circ} \mathrm{C}$ in serum-free Leibovitz medium (Sigma), which enables maintaining the physiological conditions for several hours in $\mathrm{CO}_{2}$ free atmosphere.

\subsection{Single cell force spectroscopy}

Right before the measurements the probe cells were suspended, labelled with CellTracker ${ }^{\mathrm{TM}}$ Red CMTPX Dye (LifeTechnologies) to ensure their clear identification, and a small quantity of the suspension was added into the culture dish of the target cells. After the probe cells descended to the bottom of the dish they were immobilized at the very end of the tipless cantilever by using a concanavalin-A-mediated linkage [18,113].

During SCFS between melanoma cells and the surface-adherent endothelial cell layer the force curves were recorded at a constant loading speed of $2 \mu \mathrm{m} / \mathrm{s}$ and a sampling frequency of $2 \mathrm{kHz}$. The maximal distance was kept at $8 \mu \mathrm{m}$, with a trigger force of $2.0 \mathrm{nN}$. After reaching the trigger force, a dwell time of $3 \mathrm{~s}$ was applied before the retraction of the cantilever. 
Experiments were repeated more than five times for each type of melanoma cell, in each case 40 curves at four different places (10 curves at each place) was recorded with the very same pre-set parameters.

In the case of SCFS mapping of the endothelial layer by A2058 melanoma, the total force distance was lowered to $3 \mu \mathrm{m}$ for time optimization reasons. Here 32 lines by 32 point maps were recorded at each selected area of $90 \times 90 \mu \mathrm{m}$, total data collection being less than 15 minutes.

During SCFS between $\mathrm{CD}^{+} \mathrm{T}$ cells and motoneurons, lymphocytes were immobilized on the cantilever and brought in contact with surface adhered motoneurons. The measurements were repeated at least seven times using different $\mathrm{T}$ cell - motoneuron pairs, both in case of wildtype and SOD1 $\mathrm{T}$ cells, and repeated on the same motoneurons after incubation with MHC-I blocking antibody. A maximal trigger force of $500 \mathrm{pN}$ was used and force acquisition was performed after a 1 second and 5 second contact time as well.

\subsection{Force mapping of myotube's elastic modulus}

Following 6 to 8 days of differentiation in vitro, the measurements were performed at $35^{\circ} \mathrm{C}$ within $4 \mathrm{~h}$ after the cells were taken out from the incubator. According to our observations, the cells preserve their viability during this period.

Mechanical mapping on differentiated myoblasts were performed with a resolution of $25 \times 100$ lines/points at each selected area of usually $10 \times 80 \mu \mathrm{m}$, total data collection time being less than 35 minutes. At every pixel of the map single force curves were recorded with a constant loading speed of $7 \mu \mathrm{m} / \mathrm{s}$ and sampling frequency of $5 \mathrm{kHz}$. Maximal distance was kept at $3 \mu \mathrm{m}$ with a maximum load of $500 \mathrm{pN}$. All force curves had higher indentations than $100 \mathrm{~nm}$, with maximal indentation depths up to $1200 \mathrm{~nm}$. The Young's modulus was calculated for each force from the approaching part of the force curves, using a modified Hertz model [24] based on the work of Sneddon [25] and further developed for different AFM tip shapes [27,114,115]. The Poisson's ratio of the cells was assumed to be 0.5 , as suggested for soft incompressible materials [116]. All the force curves were fitted manually in order to avoid any poorly fitted data points, as a possible consequence of automatic software calculations that may lead to an inaccurate elasticity maps. 


\section{Data analysis}

The relevant parameters from the SCFS data were extracted by an in-house MATLAB routine. Apparent Young's modulus was extracted from individual force curves using the formula for spherical indenters in case of SCFS measurements, while the one for conical indenters in case of myotube measurements. Maximal adhesion force values were considered as the force difference between the initial value at non-contact state and the maximal negative deflection of the cantilever. Disruption events were identified as sudden deflection changes during retraction. Only those rupture events were considered where the level difference was higher than threefold the standard deviation at the end of the respective curve. Rupture size was calculated as a force level difference between the mean of 5 points before and after the place of occurrence. Rupture length represents the distance from the place of maximal adhesion force (maximal deflection) and the position of the last point before an identified disruption event. Distribution of rupture size and length are represented by histograms showing the probability to find a given value within the whole data population calculated for each cell type. In case of rupture length, a logarithmic scale was chosen to balance the unequal representation for abundant and rare events. In order to cover the level, spread, and symmetry of the data values, box plots show the median, the approximate quartiles and the lowest and highest data points. This allows showing the eventual skewness in the distribution of the values. Extreme values of more than 1.5 fold away from the interquartile range were considered as outliers and marked with "plus" signs. After normality testing, an F-test for equal variance and two samples t-test for means comparison were performed. Where normality was not fulfilled Kruskal-Wallis rank test was used. Significant differences were accepted and marked at $\mathrm{p}<0.05(*)$ level.

The analysis and interpretation of myotube nanoindentation data were performed within the Asylum Research software, while optical and fluorescent image processing was performed with ImageJ software. 


\section{Results and Discussion}

\section{Nanomechanical aspects of brain metastasis formation}

Firm adhesion establishment to cerebral endothelial cells (CEC) is critical for metastasizing tumor cells to reach the brain parenchyma. In this work we addressed this crucial step of metastasis formation by AFM-based SCFS. The aim is twofold. Firstly, to gain novel knowledge about how cancer cell maps out the surface of blood vessel lining endothelial. Secondly, to assess the correlations between tumor cells' metastatic potential and their in situ nanomechanical properties.

\section{I.1. Direct mapping of melanoma cell - endothelial cell interactions}

To model how a metastatic cancer cell "screens" the surface of blood vessels in the brain before its extravasation and invasion into the brain parenchyma, SCFS measurements between metastatic melanoma and brain endothelial cells were performed. Single tumor cell-decorated tip-less cantilevers were used as a probe to directly map adhesive and elastic properties of a confluent CEC layer.

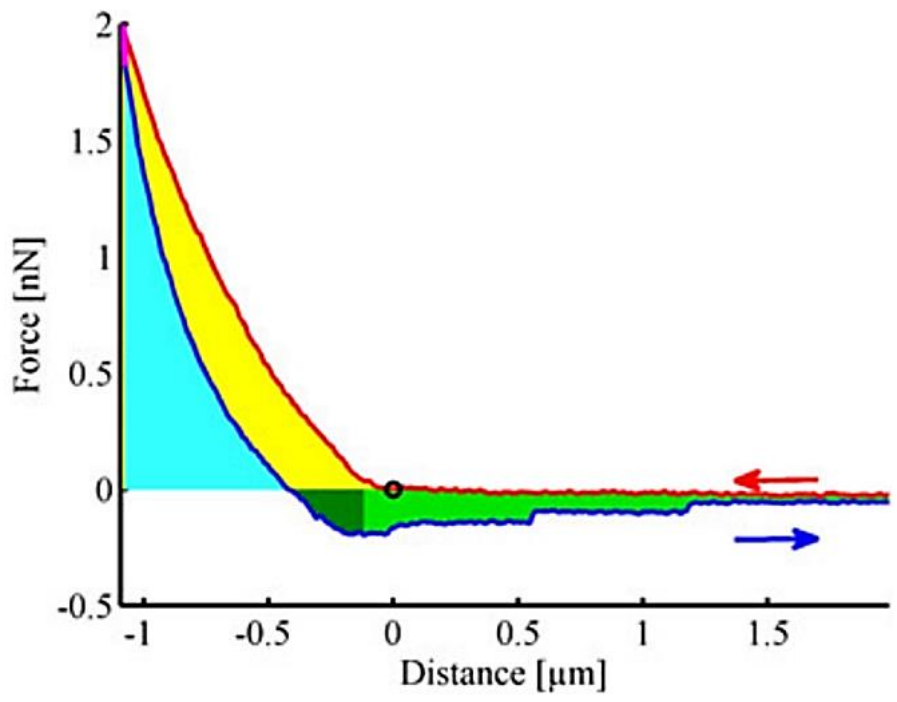

FIGURE 2. Representative force-distance curve collected along SCFS measurements. Contact point is marked with "o," cyan area marks the remnant work, yellow area marks the dissipated work, while the sum of dark and light green areas represent the total detachment work. 
Spatial distribution of several nanomechanical parameters, as shown on pseudo-colored maps, was recorded with the decorated probe. The aim was to spatially characterize the elasticity and linkage strength between the melanoma cell and the CEC. Figure 3 shows the 3dimensional topography of the confluent endothelial layer reconstructed from the contact points of single FD curves, where the individual cells, mostly the nuclei, can be clearly distinguished.

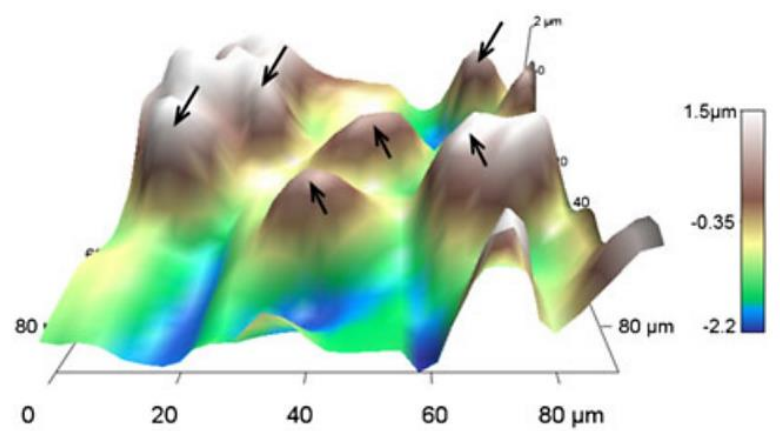

FIGURE 3. Topography map, reconstructed from contact point of individual force curves measured on a confluent layer of cerebral endothelial cells with a melanoma celldecorated cantilever. Endothelial nucleus regions are marked with arrows.

As most models deal with indentation of elastic material with a hard indenter, unfortunately, no specific model can be found to extract elastic properties from the obtained curves in case when two living (arbitrary shaped) cells are pushed against each other. However, the different work-like parameters of the interaction could be a good indicator of the underlying processes. The color code on the topography map in Figure 4 represents the total elastic (or deformation) work that is needed to deflect the cantilever and deform the two cells (cyan+yellow area in Figure 2). Peripheral regions appear to be more rigid, which might result partly due to a denser cytoskeletal network at these areas. Even more interestingly, neighbor cells might exhibit different characteristics, ranging from harder (light blue color) to 2-fold softer cells (red areas).

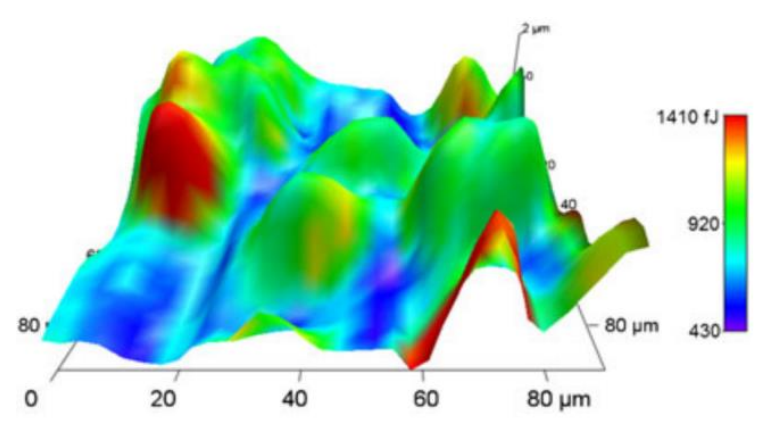

FIgURE 4. Total elastic (or deformation) work colored topography

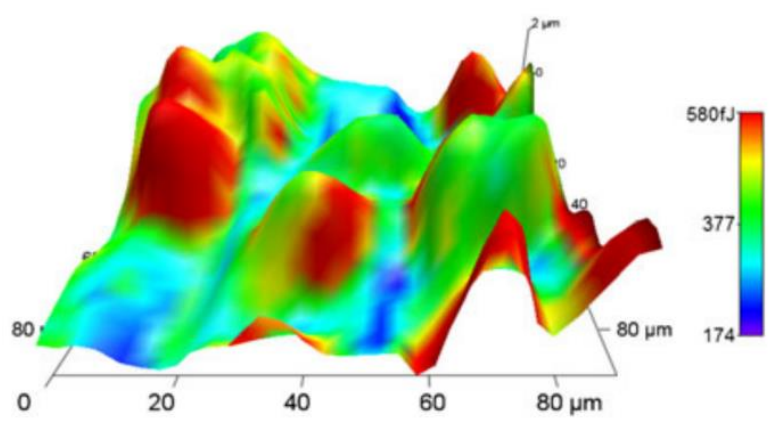

FIGURE 5. Plasticity (dissipated work) colored map 
During cantilever retraction the cells in contact regain their quasi-original shape, which imply the reorganization of cellular organelles and cytoskeletal elements for both cells. This ability of reorganization can be quantified by calculating the amount of work the two cells can still exhibit during cantilever retraction, represented by the remnant work parameter (cyan area in Figure 2), while the dissipated energy during the measurements cycle (yellow area in Figure 2) is given by the subtraction of the remnant work from the total work and is a characteristic parameter of plasticity (represented in Figure 5). Here, the lower values can be associated with more elastic portions, while the higher values indicate the more plastic ones.

Although, the resulted maps on total elastic work and dissipated work are similar, remarkable differences can be noticed. Not only individual cells show distinct plasticity, but alterations can be observed even within a single cell. This indicates that regions of the same cell might behave differently.

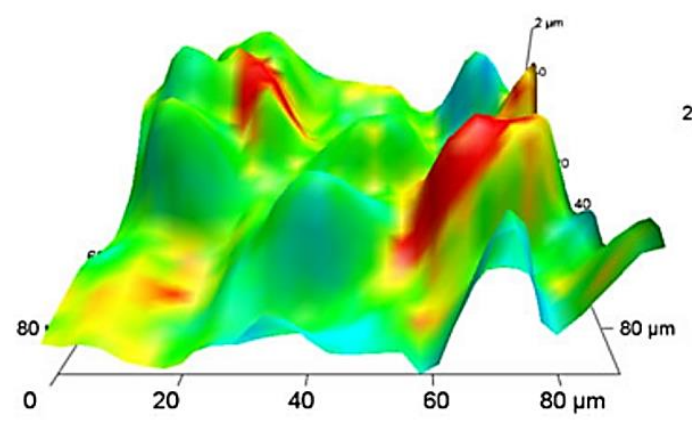

FiguRE 6. Maximal adhesion force colored topography

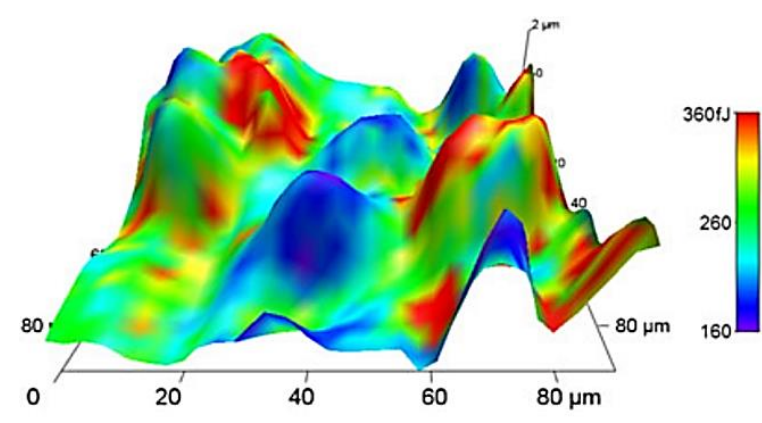

FiguRE 7. Adhesion (or detachment) work colored map

During the detachment of the melanoma from the endothelial layer the cantilever deflects in negative direction. This part of the FD-curves allows determining a further set of parameters to quantify the interaction strength between the cells. The most important parameter is the maximal adhesion force (Figure 6). As elastic and plastic behaviors might influence adhesive properties, it would be anticipated that total and dissipated work would strongly correlate with the adhesive properties, resulting a similar color distribution for the maximal adhesion force map as well. In contrast, the color-coded maximal adhesion force map of the recorded topography (Figure 6) shows completely different distribution. The most adhesive areas (red zones in Figure 6) are not the most deformable (red zones in Figure 4) or even the most plastic zones (red zones in Figure 5). An even more remarkable difference can be seen on the distribution of the adhesion work values (Figure 7), as the total energy needed to separate the contacting cells, represented as the sum of light and dark green areas in Figure 2. This total 
separation energy (or adhesion work) can be further separated into: early-detachment work (dark green in Figure 2), the area prior to maximal adhesion occurrence related to deformation dependent work, and late-detachment work (light green in Figure 2), the area where the deadhesion events take place and which includes the contribution of each active bond that builds up the linkage strength.

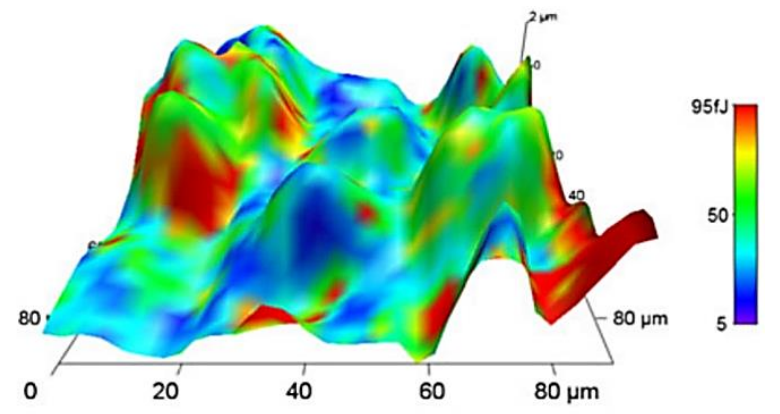

FiguRE 8. Early-detachment work colored topography

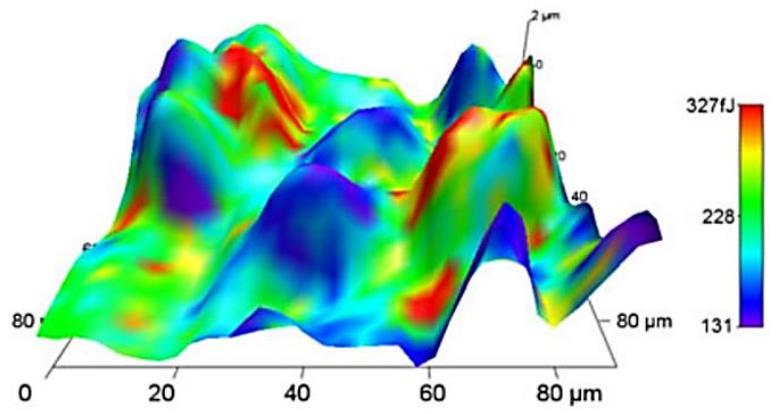

FIGURE 9. Late-detachment work colored topography

By comparing the early-detachment work color-coded topography map (Figure 8) with the total elastic map (Figure 4), remarkable similarities can be found. This signifies that the earlydetachment work depends mostly on elastic deformation. In contrast, the adhesive "hot spots" observed in adhesive maps (Figure 6 and Figure 7) show stronger co-localization with latedetachment work (Figure 9). This suggests that the active cell adhesion molecule-based linkage (rupture) is responsible for higher adhesive properties. In addition, quantitatively the late-detachment work (Figure 9) dominates the early-detachment indicating again the importance of long distance rupture events in de-adhesion. These events are the hallmark of linkage formation, representing the number of newly formed active focal contacts between the interacting cells. Qualitatively late-detachment work is not directly linked to early-detachment work. Moreover, sometimes it shows exactly opposite behavior. However, the strong correlation between late-detachment work (Figure 9) and maximal adhesion force (Figure 6) indicates that differences in linkage establishment between the neighbor cells can be attributed predominantly to higher number of active cell adhesion molecule bounds. 


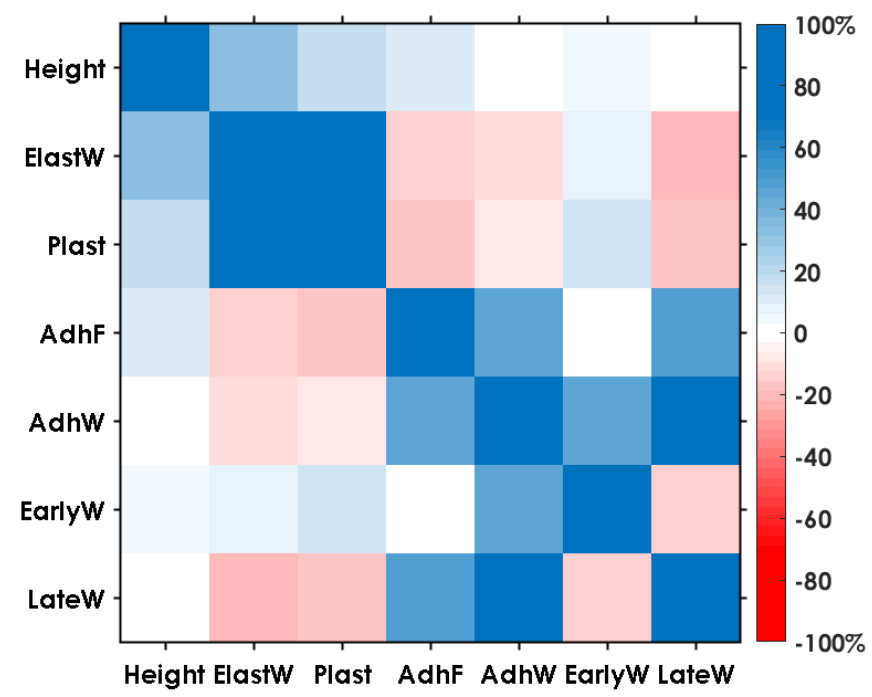

FIGURE 10. Cross-correlation table of the calculated parameters based on Pearson correlation coefficient

To visualize the dependence of each calculated parameter to the others, a cross-correlation plot was constructed (Figure 10). Here, the color of each square reflects the calculated Pearson correlation coefficient corresponding to the intersecting parameter pairs. The scale goes from perfect anti-correlation $-100 \%$ (red on Figure 10) to perfect correlation as $100 \%$ (blue on Figure 10), while if the corresponding parameters are perfectly independent the color of their intersection point is close to white that represents 0 values. As it can be observed, no perfectly independent parameter can be found. However, the most independent one is apparently the height. 


\section{I.2. De-adhesion dynamics of melanoma cells from brain endothelial layer}

In order to reveal how metastatic potential manifests in cancer cells' nanomechanical properties SCFS measurements were performed between three different types of human melanoma cells and a confluent layer of human cerebral endothelial cells, as a model of the inner side of brain capillaries. The three melanoma cell types, with different metastatic characteristics, were represented by WM35, A2058, and A375 cell lines, while the CEC layer was formed by the hCMEC/D3 (shortly D3) cell line. In addition to measuring the intercellular interactions, in each case the very same melanoma cells were tested against a cell free area of the Petri dish as an internal comparison, by using the same parameters (load, force speed, dwell time in contact) for all cell types.

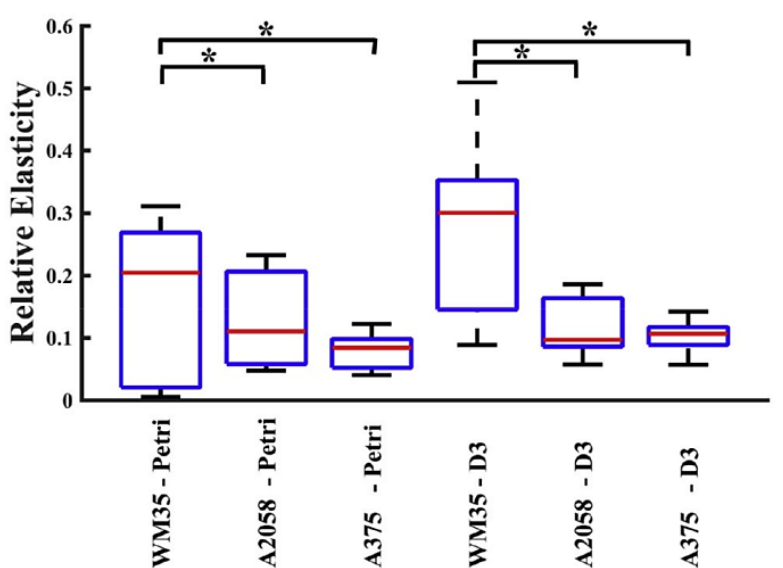

Figure 11. Relative elasticity of the three studied cell types against bare Petri dish surface and confluent endothelial (D3) layer, respectively. Significantly different $(p<0.05)$ groups are marked with black link bars.

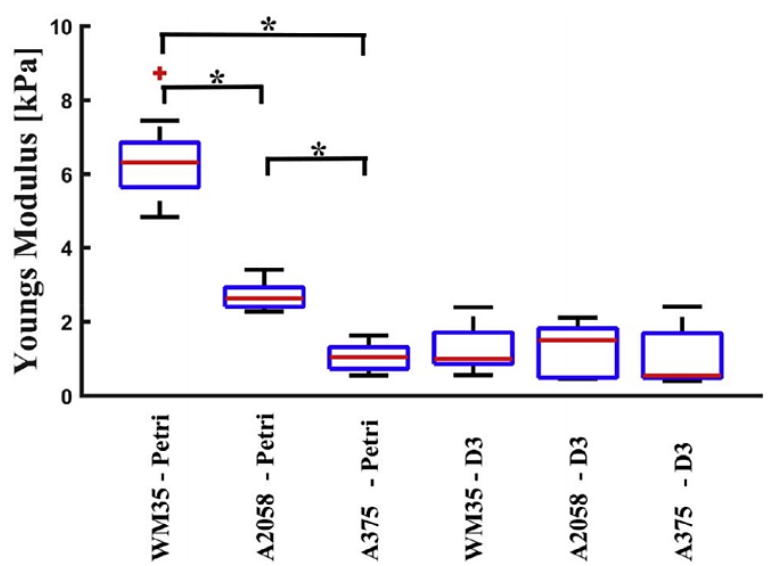

Figure 12. Apparent Young's modulus of the studied cell types against bare Petri dish surface and confluent endothelial layer (D3), respectively. Significantly different groups $(p<0.05)$ are marked with black link bars.

In order to get a more illustrative comparison of elastic behavior we used a dimensionless parameter, termed relative elasticity, which similarly to the plasticity index in case of polymers [117], was defined as the ratio between the remnant work (cyan area, Figure 2) and the total work (cyan + yellow area, Figure 2). Its values range between 0 and 1 , where 0 corresponds to a perfectly plastic, while 1 to a perfectly elastic behavior. Figure 11 represents the calculated relative elasticity of the studied cell types, showing similar dependence pattern both when melanoma cells are pushed to bare Petri dish and against endothelial cells. This underlines that the measured parameters reflect mainly the characteristics of melanoma cells, 
hence the endothelial layers can be considered practically invariable. In Figure 11 a strong dependence between the relative elasticity and the melanoma cell type can be observed, where WM35 cells appear to have a more elastic, while A2058 and A375 cells a more plastic behavior upon deformation. The slightly higher values when two cells are pushed together might be attributed to the presence of the endothelium. The most frequent parameter to characterize cellular elasticity is the Young's modulus. Figure 12 represents the apparent Young's modulus values obtained for the studied cell types when pressed against the bare Petri dish and to a confluent endothelial layer. Similarly to relative elasticity, WM35 cells show the highest elastic modulus values, followed by A2058 and A375 cells being the softest. Interestingly, when these cells were pushed against a confluent layer of endothelial cells, the observed differences practically vanished.

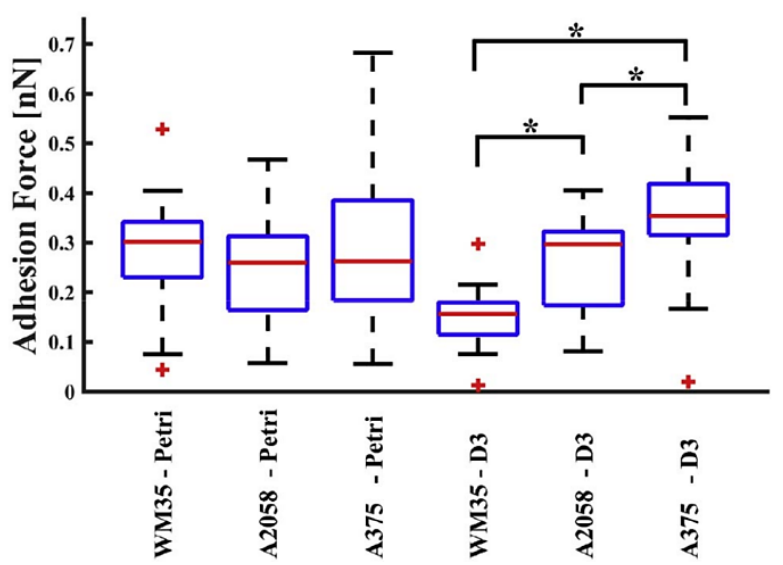

Figure 13. Maximal adhesion force between the studied cell types against bare Petri dish surface and confluent endothelial layer (D3), respectively. Significantly different groups $(p<0.05)$ are marked with black link bars.

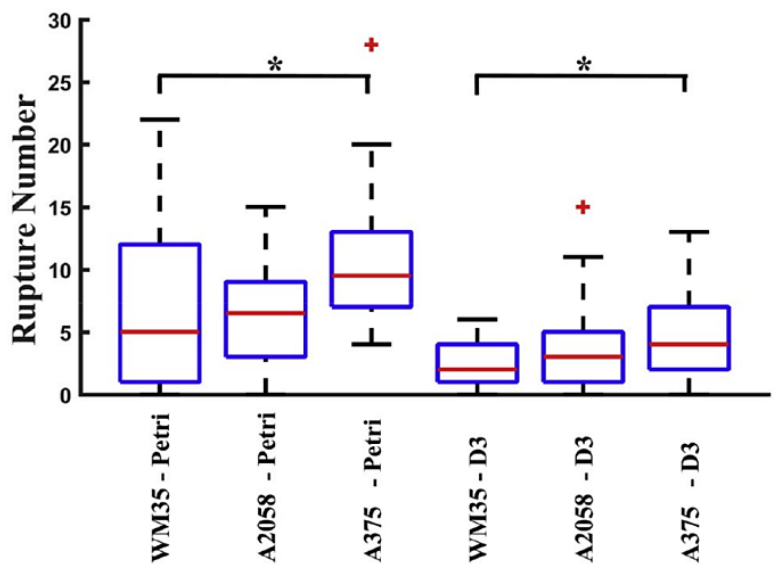

Figure 14. Number of rupture events per force curve for the three studied cell types against bare Petri surface and confluent endothelial layer (D3). Significantly different groups $(p<0.05)$ are marked with black link bars.

As a first parameter to characterize the linkage strength between melanoma cells and endothelium we have used the maximal adhesion force. Figure 13 shows the comparison of the calculated maximal adhesion forces between the three studied cell types contacting a bare Petri dish and the endothelial layer. In spite of observing similar adhesion strength between the melanoma cells and the bare Petri dish, clear cell type dependence can be observed when melanoma cells were pushed against the endothelium. In addition, by comparing the results in Figure 11 with those in Figure 13, an inverse correlation can be observed between relative elasticity and maximal adhesion force. As the overall adhesion of the cells is built up by numerous discrete linkages, the individual ruptures like events of these can be distinguished on the recorded force plots (see Figure 2). Figure 14 summarizes the number of these events 
for the studied melanoma cells, showing a similar dependence for both recorded sets, where more aggressive cells establish more active connections. Despite the weak negative correlation revealed between the number of ruptures and relative elasticity, the exact reason why higher number of ruptures appears in the case of melanoma cells-bare Petri than melanoma cells - endothelium is still under debate. However, a clear dependence can be observed in both studied cases (Petri surface and endothelial layer), showing that the highest number of connections are formed in the case of A375 cells, while the least for the WM35 cells. In addition, the number of apparent bonds, step size and occurring place (length) carries important information as well. Size distribution of the active de-adhesive events is depicted in Figure 15. The apparent rupture size can be associated mostly with the molecular background of the studied cells. As Figure 15A shows, when the melanoma cells are pushed against the Petri dish, slightly shifted and more skewed distribution patterns were observed. However, in case of confluent endothelium the distribution patterns were similar (Figure 15B), with the most frequent values around $30 \mathrm{pN}$.

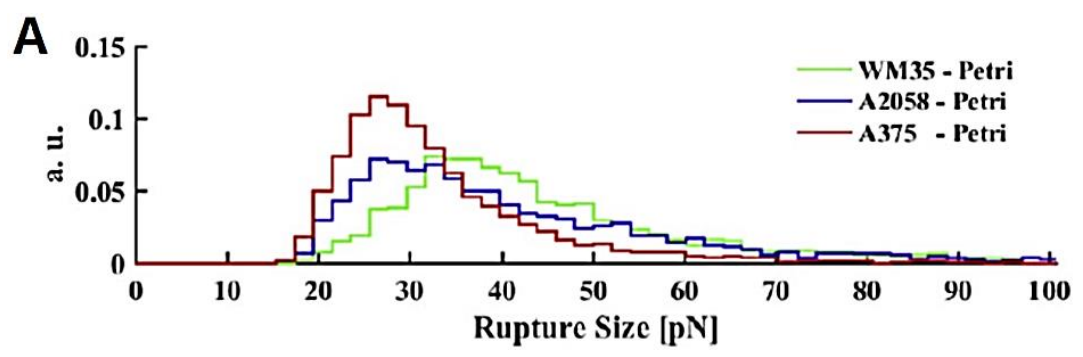

Figure 15. Rupture size probability distribution of the studied melanoma cells when

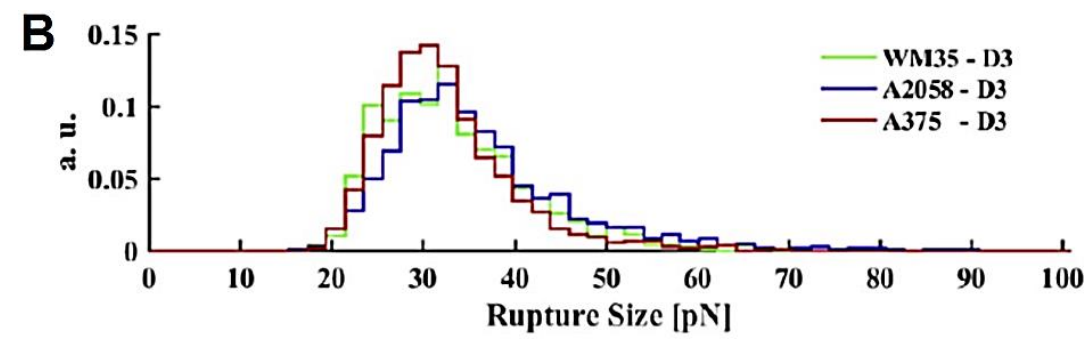
pushed to Petri dish and endothelial layer (D3), respectively.

An even more interesting feature is the distance of the occurrence of rupture events from the contact point. The length distribution of these distances are plotted in Figure $16 \mathrm{~A}$ and B. Since cells suffer a slight shape deformation during their contact (mostly the melanoma, as the endothelial cell is adhered and flattened) the highest peaks can be observed below $1 \mu \mathrm{m}$. This zone is characterized by simultaneous events whose number is dependent on the contact area. Rupture length distribution of longer distances can be mainly associated with membrane dynamics, and spontaneous unlocking of cell adhesion molecules and other molecular cross talks. 
The higher frequencies of rupture lengths below one micrometer can be associated with the apparent relative elasticity of the melanoma cells. As they are more elastic, they regain their original size quicker, resulting in presence of most de-adhesion events at close distances to the contact point.

FiguRE 16. Rupture length probability distribution of deadhesion events occurring during melanoma cell - Petri dish and melanoma cell endothelial layer detachment, respectively.
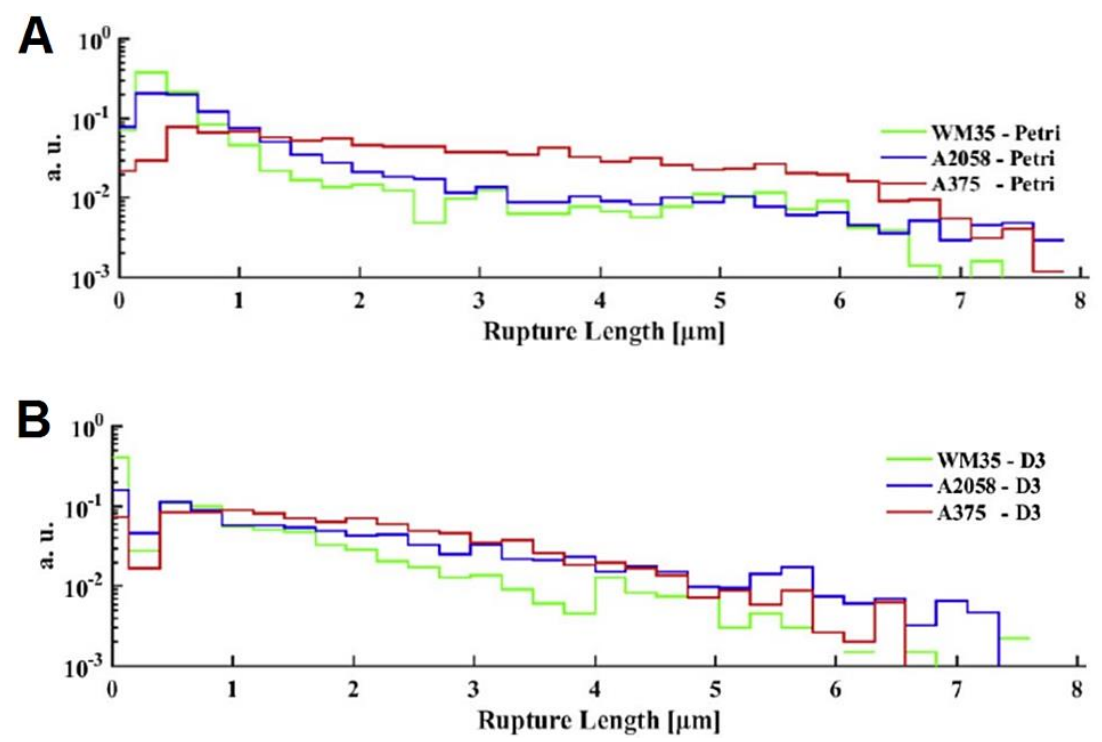

De-adhesion events occurring at high distances ( $>2 \mu \mathrm{m}$ from contact point) can be predominantly associated with membrane tether formations, regarded as membrane nanotubes extruded from a large membrane reservoir. These long rupture lengths are observed in both melanoma cell - Petri and melanoma cell - endothelial interactions.

\section{I.3. Discussions and summary}

Cell to cell adhesion measurement is the subject of an increasing number of studies affecting many different areas ranging from bacterial to eukaryotic cell adhesion [118], quantification of adhesion forces between metastatic tumor cells [76], or their adhesiveness against the endothelium [119]. However, spatial mapping for elasticity or adhesiveness of a living cell layer with another living cell has not yet been reported. In our first study, the initial step of brain metastasis formation was modeled by mapping the short-term adhesion of a human melanoma cell (A2058) to a confluent layer of human CECs (hCMEC/D3). Spatial distribution of several adhesive and elastic properties was recorded and presented on pseudocolored maps. Since both cells suffer deformation during the interaction, the extracted parameters cannot refer to neither of them separately, but characterize the "whole" system. 
Previously published elasticity maps on CECs revealed their heterogeneity within a single cell, showing that the area of the nucleus being softer, thus more deformable, than the peripheral regions [120]. As the immobilized melanoma cell has much larger dimensions compared to the few nanometer sharp tip apex, the intracellular inhomogeneities are averaged out. Consequently, the differences seen in the presented maps can be associated mostly with individual cells, or with their largest organelle, the nuclei [121].

The comparison of the spatial distribution between maximal adhesion force and total elastic work revealed that the highly adhesive sites do not consequently show lower elasticity. This is also true for the comparison of maximal adhesion force with plasticity. As elastic and plastic properties are strongly linked to cytoskeletal network organization and reorganizing ability [122], they may reflect endothelial functionality, including permeability. Locally increased permeability might be linked to putative transmigration sites for invading cancer cells. The stronger co-localization of adhesive "hot spots", observed in adhesive maps, with latedetachment work suggests that active cell adhesion molecule-based linkage (rupture) is responsible for higher adhesive properties. Taking into account that these are represented by long range ruptures, tether formation might be crucial in melanoma-endothelial interaction. Here, we have to note that all these results are deducted by simple mechanical measurements and calculations and no invasive labeling or staining was involved in the experiments.

Quantification of the correlation between the measured parameters has been visualized in a cross-correlation plot, as color-coded Pearson correlation coefficients for each parameter pair. Although no perfectly independent parameter was observed, apparently the most independent one was found to be the height, which underlines that the spatial distribution of elastic properties of the endothelial cell layer has only a moderate contribution to the obtained results. The further observation that total detachment work, together with maximal adhesion force, is more rupture (late-detachment) than deformation dependent (early-detachment) again highlights the importance of membrane tether formation and breakage during cell-cell interaction.

Arrest of melanoma cells on the inner surface of the brain blood vessels is a crucial but not a sufficient step in the process of brain metastasis formation. Nevertheless, those bloodtravelling melanoma cells which show higher adhesiveness to the brain endothelium might have higher chance to successfully colonize the brain. The mechanism of melanoma cell arrest and establishment of firm contact to brain endothelial cells is still only partially 
described and understood. Therefore in our further study a comparison of the dynamics of the first short term contact of three different types of melanoma cells (WM35, A2058 and A375), having altered invasive characteristics, were performed against brain endothelial cells.

The WM35 is a cutaneous, non-metastatic cell line, while A2058 and A375 are highly metastatic cell lines [123]. The difference in the metastatic potential between the A2058 cells and A375 cells has not been clearly established so far. Both cell lines are VCAM-1 negative [27], however, it was found that transmigration of A2058 cells across bovine brain capillary endothelial cells, was twice as effective compared to A375 [124]. Both A2058 and A375 cells show similar adhesive properties to brain endothelial cells with similar junction damaging potential in static models [125,126]. A study denotes A375 cells as highly invasive [127] and compares its elasticity to WM35 emphasizing that the former has lower elastic modulus (which correlates well with our results). The above mentioned studies deal with the total transmigration process of the melanoma cells across the endothelium, which includes but is not restricted to initial affinity dynamics of firm adhesion establishment. Furthermore, these studies were conducted in static conditions. Referring to the first short term contact to brain endothelial cells our data suggests the following order from lower to higher metastatic potential - WM35, A2058 and A375 - based on apparent affinity to brain endothelial cells.

Intercellular adhesion dynamics depends on multiple factors, amongst which we can find apparent whole cell elasticity, visco-elastic properties, surface charge density, surface linked adhesion molecule distribution and glycocalyx thickness as well. Unfortunately, no proper model exists to obtain elastic or plastic properties when two cells are pushed against each other. Therefore, in order to compare the elastic properties of the studied cell types in situ, we have used relative elasticity, or elasticity index, as a dimensionless comparing factor, which was defined as the ratio between the remnant and total work needed to obtain the pre-set load. The obtained relative elasticity values were similar both in the case when melanoma cells were pushed against the Petri dish surface and against the endothelial layer. This indicated that the calculated relative elasticity is predominantly the property of the melanoma cells, while endothelial cells have only low contribution. The highest relative elasticity values were shown by WM35 cells, followed by A2058 and A375 cells respectively. These results are in line with other findings, which demonstrate a higher Young's modulus for WM35 cells compared to A375 cells [128]. Furthermore, another paper reported the same relation between Young's Modulus and metastatic potential in case of ovarian cancer cells probed with a spherical indenter [75]. In our case similar relation was observed when the studied melanoma 
cells were pushed against a Petri dish surface: WM35 has the highest apparent Young's modulus succeeded by A2058 and A375 cells respectively. However, this relation vanishes when the same cells were put in contact with endothelial cells. The supporting connection between apparent Young's modulus and invasiveness is an important control, which in case of melanoma-endothelial interaction might be hindered by several factors. In our opinion the calculated apparent Young's modulus is less sensitive to the characteristics of the probing melanoma cell, while the value of relative elasticity is more suitable for proper comparison.

Cell elasticity is mainly determined by cytoskeletal structures and low elasticity may reflect disorganization of the cytoskeletal characteristic of aggressive cancer cells [129]. Besides mechanical properties of a cell, physical aspects of cell-cell interaction may influence cellular behavior, too. The force necessary to separate two cells (adhesion force) reflects well the strength of the connection. Therefore, maximal adhesion force is a well-established parameter to characterize adhesion properties of biological samples, ranging from individual molecules to living cells [1]. In case of adhesion forces against the Petri dish, no differences were found between the investigated melanoma cells, suggesting the dominance of nonspecific interactions. In contrast, when melanoma cells were pushed against the endothelium a clear dependence was observed, where WM35 cells show the lowest, A2058 cells present higher, whereas A375 cells show the highest adhesion force values. This indicates that the more aggressive melanoma cell types adhere stronger to the cerebral endothelium possibly leading to an enhanced transmigratory and metastasis forming capacity. Interestingly, although independent of cell type, adhesion forces are higher in case of Petri dish-melanoma cell contacts compared to melanoma cell-endothelial cell contact. An explanation of this observation could be the specially treated, cell culture grade plastic surface to which cultured cells can easily adhere.

Cell adhesion depends on multiple and even multivariate individual molecular connections between specific cell-cell adhesion molecules and non-specific interactions of the glycocalyx [81], where the individual players are difficult to identify. The process of de-adhesion is not continuous; it can be decomposed into a series of de-adhesion events. Due to the high forceresolution provided by the AFM besides maximal adhesion forces, individual de-adhesion events can be identified and compared accurately, which are the hallmark of the established connection [1,130]. When pulling apart two adhering cells these interactions have to be released. These bond ruptures can occur close to the contact point if the adhesion molecules are well anchored to the underlying cytoskeleton. In case of non-anchored adhesion molecules 
during the release these are either ripped out from the membrane or form a tether (membrane nanotube), depending on the membrane properties [131]. The dynamics of these tethers highly depend on the physical parameters (pulling speed, temperature) as reported in case of rolling neutrophils [91] and in the adhesion of the monocytic cell line THP-1 to a surface coated with ICAM-1 [132]. In our case membrane nanotube formation can be also observed during the release of the contact.

In our results the number of rupture events, which are directly related to active contact points, show same relation as observed for the maximal adhesion force, indicating that more aggressive cells establish more active connections. This implies the presence of a surface size related active binding process, which has higher weighting in case of more inelastic cells. From the size distributions of the active de-adhesive events the most abundant values were obtained around $30 \mathrm{pN}$. According to literature, this value is associated with de-coupling of membrane bound adhesion molecules in case of membrane tether ruptures [133], and it is very close to the adhesion forces reported in case of E-cadherin fragments [134]. Additionally, the occurring place of these de-adhesion events is an important characteristic of membrane dynamics, since in many cases they appear at several micrometer distances from the contact point. Since physical parameters (pulling speed, contact time, temperature) were not altered through the experiments, all melanoma cell types were subjected to the same set of external parameters. Hence, differences in release dynamics are associated to alterations in membrane or cytoskeletal network properties. Based on our data, we can conclude that the shift towards higher distances of occurring places of detected de-adhesion events (Figure 16) might indicate that the role of tether based adhesive properties of invading melanoma cells cannot be neglected in the metastasis formation process. Tether formation and dynamics might contribute considerably to site selection of melanoma cells ending in successful arrest on the surface of brain endothelial layer. Although it is not an easy task to quantify the weight of tether based adhesive contribution within the full detachment force, it might grant metastatic melanoma cells one step forward to successful colonization.

As a summary, we can conclude that successful direct mapping of a confluent layer of CECs were reported with a melanoma cell as a probe. Topography-based elastic, plastic, and adhesive maps were reconstructed from the recorded force-distance curves. The reconstructed maps reveal elastic, plastic, and adhesive heterogeneity of the endothelial layer but they are not directly linking these parameters. Our data points toward the observation that the invading 
melanoma cell might somehow "screen" for the best places prior to starting the transmigration process over the endothelial layer.

In addition, AFM based single cell spectroscopy were used for comparison and analysis of adhesion force dynamics between a confluent brain endothelial layer and three different type of melanoma cells presenting different invasive characteristics. Apparent mechanical properties such as elasticity, maximal adhesion force, as well as number, size, and distance of individual rupture events showed altered values pointing towards cell type dependent aspects. Our results show that nanomechanical properties can be associated with higher metastatic potential, and invasive characteristics may rely on stronger adhesive properties mediated by altered tether formation dynamics.

These results highlight the importance of cellular mechanics in brain metastasis formation and emphasize the enormous potential toward exploration of intercellular dynamic-related processes. Moreover, it suggests that elastic and adhesive properties might be used as biomarkers of tumor cell malignancy. 


\section{Nanomechanical aspects of amyotrophic lateral sclerosis (ALS)}

Amyotrophic lateral sclerosis, ALS is a multifactorial neurodegenerative disease, where a number of different cell types contribute to the pathological mechanism [83]. Deciphering the exact intra- and inter-cellular mechanical properties of the contributing cells is essential not only to better understand the development and progress of the diseases, but to promote the improvement of future therapeutic approaches. By AFM-based nanomechanical investigations we have addressed two aspects of ALS, namely the interaction forces between ALS derived T cells and motoneurons, and the elastic properties of ALS derived differentiated myotubes.

\section{1. T cell and motoneuron interaction forces in an ALS diseased mouse model}

According to recent findings motor neuron degeneration in ALS, instead of being the result of only neuronal autonomous cell death, is rather a more complex mechanism accompanying neurotoxic inflammatory processes [85], where $\mathrm{T}$ cells play an important role. This led us to investigate motor neuron - $\mathrm{T}$ cell interactions by monitoring short term adhesion forces on primary motoneurons probed both by wild-type and $S O D 1^{G 93 A}$ derived $\mathrm{T}$ cells immobilized on a tip-less AFM cantilever. Acquisition of force-distance-curves, with 1 and 5 second contact times, were performed on a series of motoneurons.
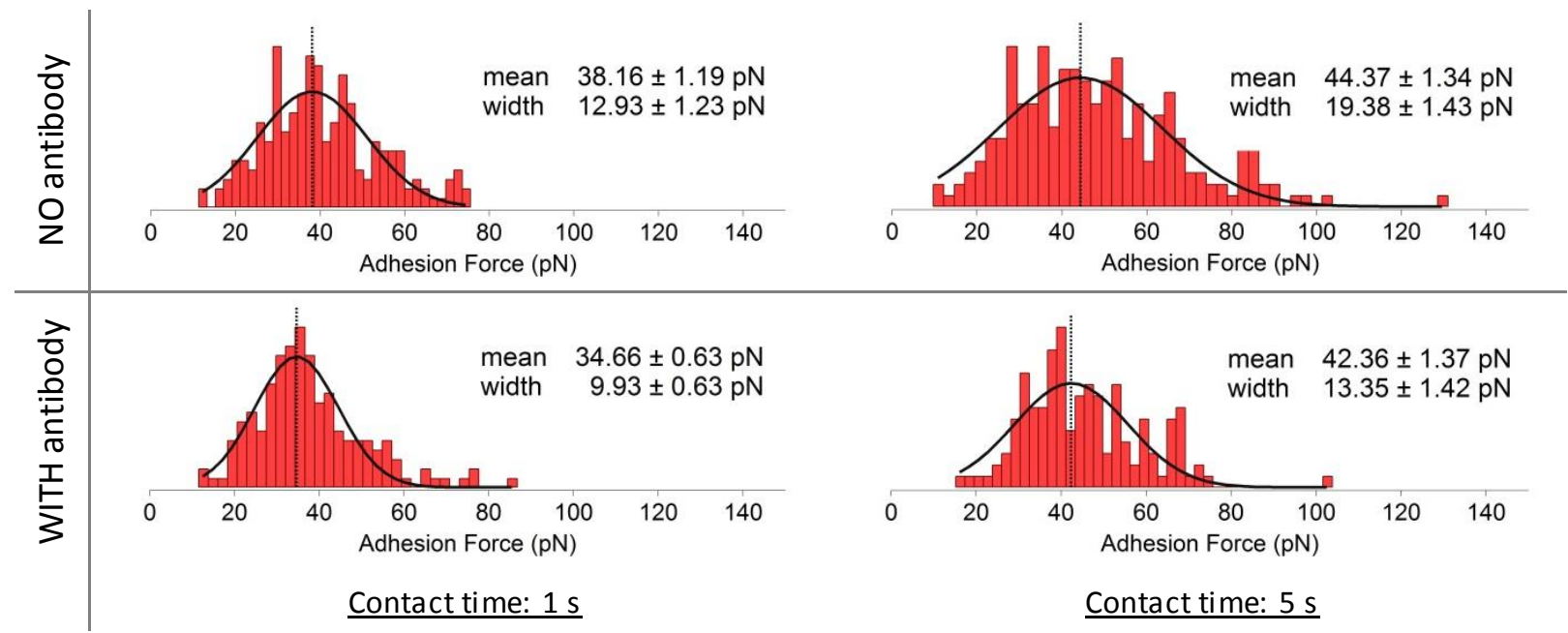

FIGURE 17. Adhesion force distributions measured between wild-type T cell and motoneuron before (top row) and after (bottom row) application of blocker antibody, observed after 1 (left column) and 5 second (right column) contact time, respectively. 
The measurements were repeated on the same selected motoneurons also after adding a specific antibody to the sample medium, which binds to the antigen presenting major histocompatibility complex class $\mathrm{I}$, in order to impede the possibility of further interactions with its (TCR) receptor pair. Figure 17 presents the obtained adhesion forces between the wild-type T cells and wild-type motor neurons for the two contact time, respectively also in presence of blocking agent. As indicated by the maxima of the Gaussian fitting on the histograms, the mean motoneuron - $\mathrm{T}$ cell adhesion strength for wild-type $\mathrm{T}$ cells is $38.16 \pm$ $1.19 \mathrm{pN}$ and $44.37 \pm 1.34 \mathrm{pN}$ for 1 and 5 second contact time, respectively. These shift toward lower values only slightly after applying the pMHC-binding antibodies, amounting $34.66 \pm$ $0.63 \mathrm{pN}$ and $42.36 \pm 1.37 \mathrm{pN}$ for the two contact times respectively.

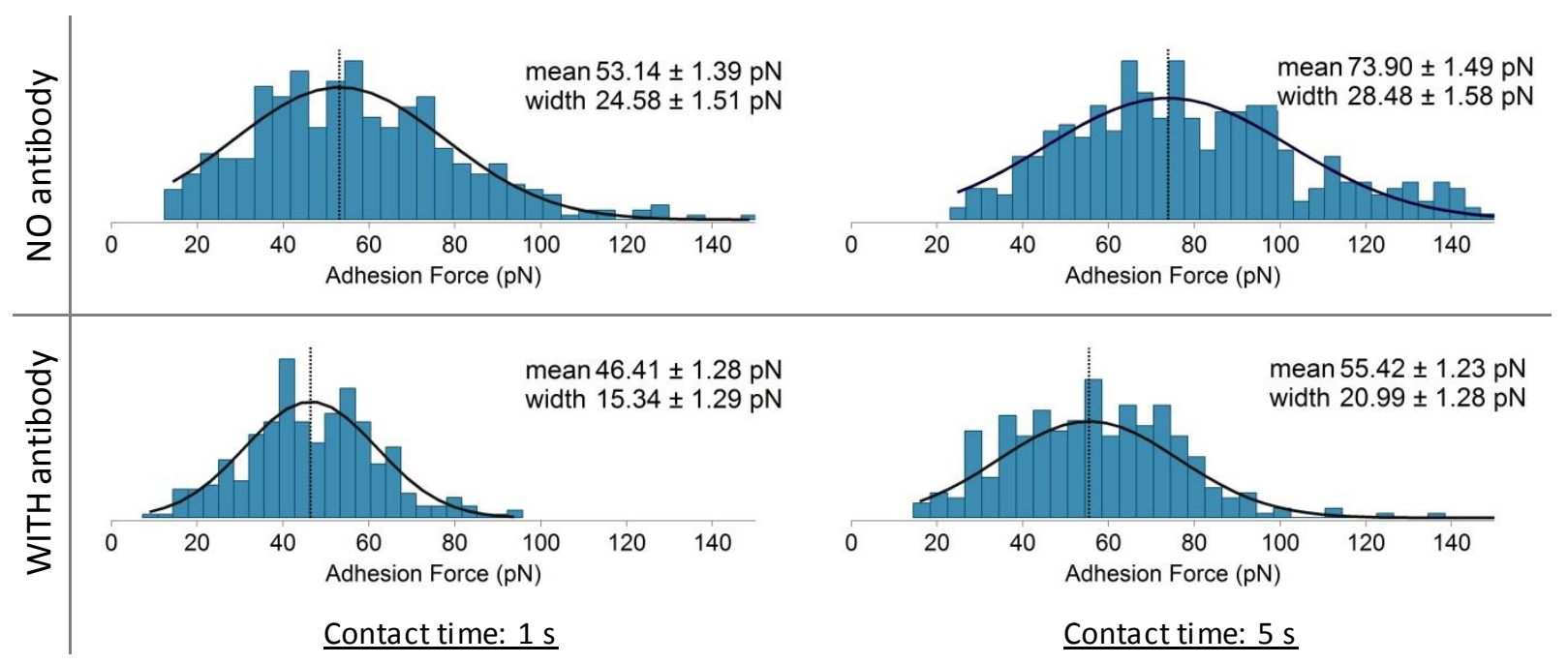

FIGURE 18. Adhesion force distributions between $S O D 1^{G 93 A} \mathrm{~T}$ cell and motoneuron before (top row) and after (bottom row) blocker antibody application, observed after 1 (left column) and 5 second (right column) contact time, respectively.

Experimental data of forces measured between $S O D 1^{G 93 A}$ mutant $\mathrm{T}$ cells and wild-type motor neurons, using the same parameters, are presented in Figure 18. In contrast with the wild-type cells, SOD1 ${ }^{G 93 A}$ mutant $\mathrm{T}$ cells not only present higher adhesiveness before blocking, amounting to $53.14 \pm 1.39 \mathrm{pN} / 73.90 \pm 1.49 \mathrm{pN}$, but also show a highly significant decrease after antibody application down to $46.41 \pm 1.28 \mathrm{pN} / 55.42 \pm 1.23 \mathrm{pN}$ (Figure 19). This observation strongly supports the results, provided by a range of in vitro studies obtained by our collaborators [99]. They found decreased viability of motoneurons when co-culturing with mutant $\mathrm{T}$ cells, but not with wild-type $\mathrm{T}$ cells. Moreover, the contact dependence of $\mathrm{CD} 8^{+} \mathrm{T}$ cells' neurotoxic activity was proven with the lack of neurotoxicity in membrane separated co-cultures. 


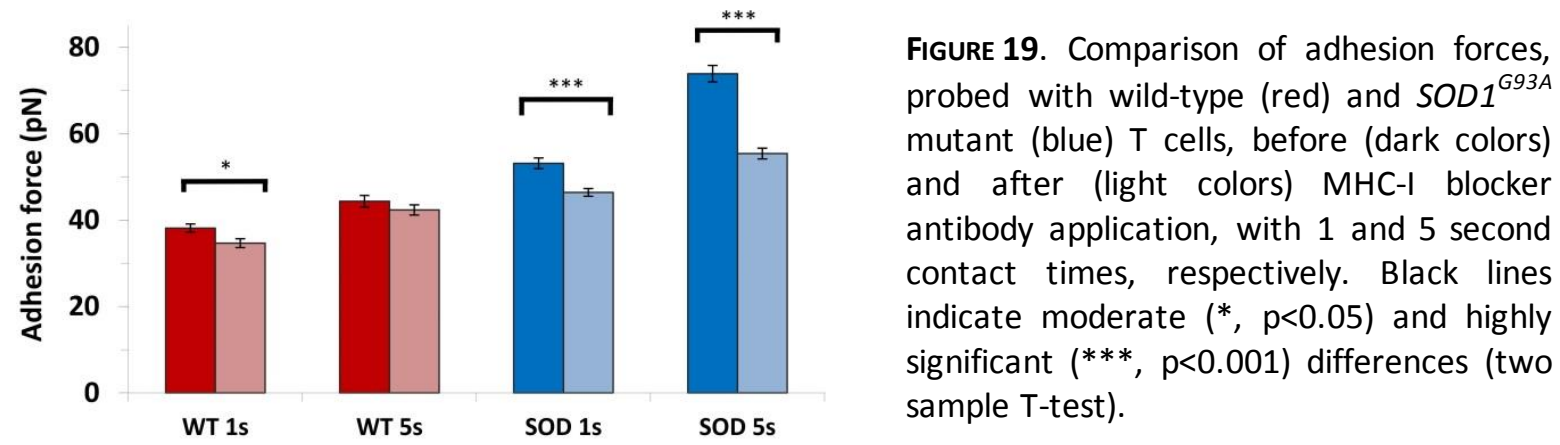

In addition to the overall adhesion, the individual de-adhesion steps during the detachment of the two interacting cells were quantified. The obtained size-distributions of the measured deadhesion steps are presented in Figure 20. For each condition (wild-type, SOD1 mutant T cell with and without the blocking agent) the most probable rupture size was found to be around $20 \mathrm{pN}$.

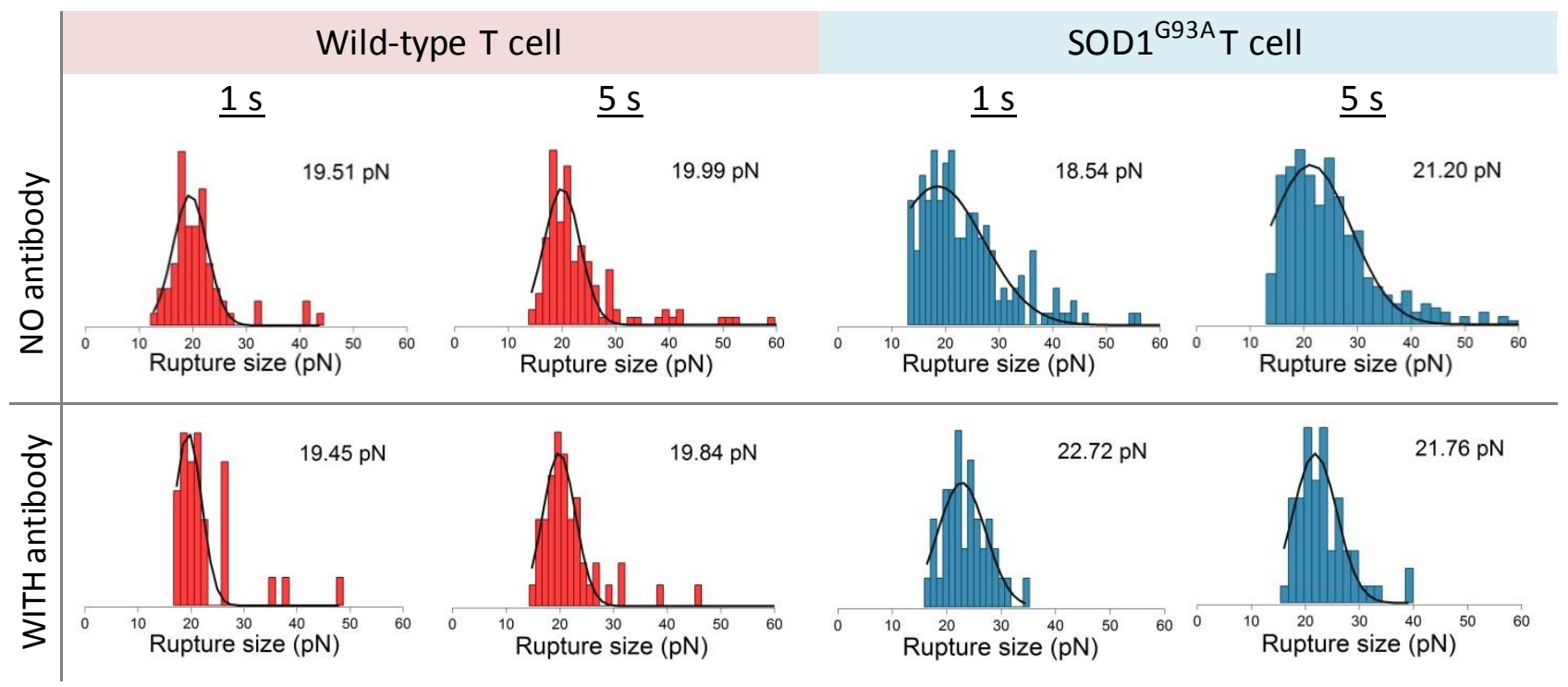

FIGURE 20. Individual ruptures size distributions between wild-type T cell - motoneuron (red histograms) and SOD1 ${ }^{\text {G93A }} \mathrm{T}$ cell - motoneuron (blue histograms) before (top row) and after (bottom row) blocker antibody application, observed after 1 and 5 second contact time correspondingly. Most probable rupture size, as means of Gaussian fittings, are indicated. 


\section{2. Myotube elasticity of an ALS diseased mouse model}

In order to reveal its elastic properties, force spectroscopy has been applied by means of AFM on primary myoblasts, isolated from wild-type and $S O D 1^{G 93 A}$ mutant mice following a differentiation period from 6 to 8 days in vitro (DIV). Numerous studies were performed on differentiating myotubes and fully differentiated myofibers, most of which used single force measurements addressing only specific parts of the cells [104,106]. As cells are largely heterogeneous, mapping the nanomechanical properties of the entire cell is indeed provides more comprehensive data to better understand the investigated processes. Accordingly, we have generated force maps along large portions, usually $80 \times 20 \mu \mathrm{m}^{2}$; of wild-type and SOD1 ${ }^{\text {G93A }}$ mutant myotubes, with a resolution of $100 \times 25$ pixels, where each pixel corresponds to a single force curve. This method allows interpreting the results as a three dimensional topographic image with a true elasticity coloration, where the height values are derived from the contact point, while the elasticity values are obtained from the fitted indentation of the force curves, as shown in A and B of Figure 21, Figure 24, and Figure 25.

\section{II.2.1. Elasticity of myoblasts in stage of elongation}

To obtain comprehensive information about the elastic properties, whole cell force maps were recorded on primary myoblasts after 6 to 8 DIV differentiation. The heterogeneity of cell culture allows examining not only different populations of myotubes, but single myoblasts as well.
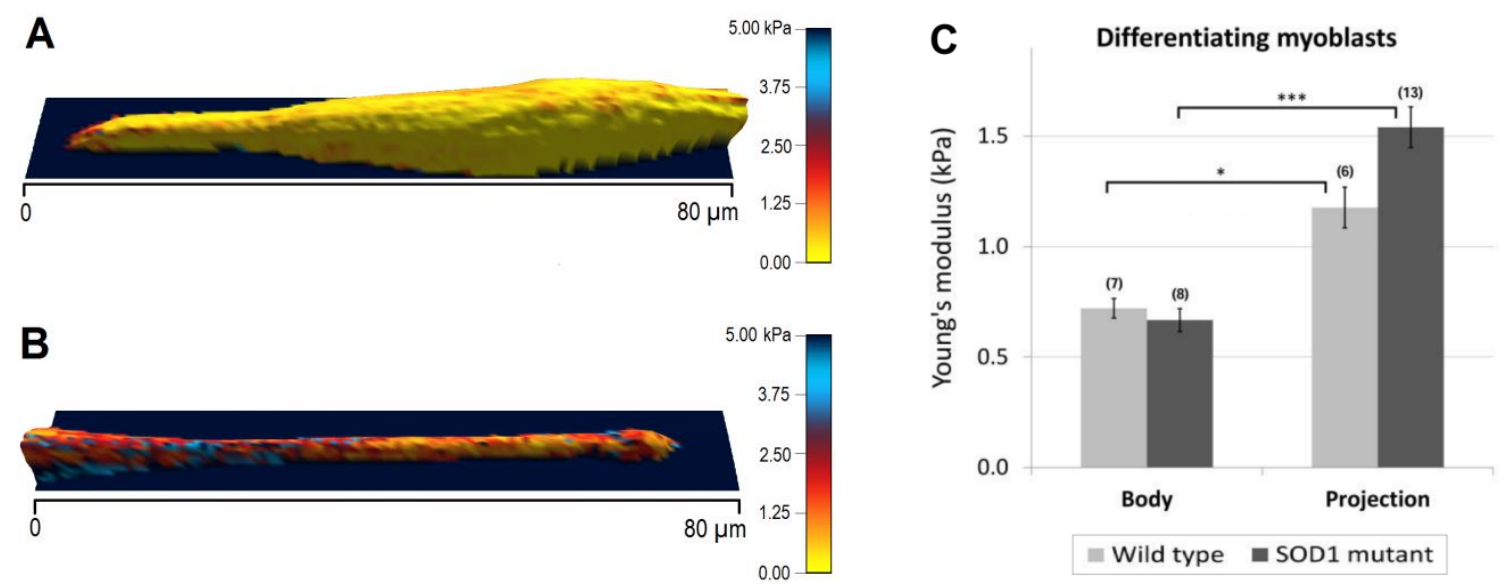

FIGURE 21. Elasticity color-coded 3D-reconstructions of differentiating myoblasts in different stages: a spindle-like morphology (A) and an elongated projection (B). Yellow color depicts softer portions, while red to blue colors show stiffer regions. C: Comparison of cell body's and projection's average elasticity of wild-type and SOD1 mutant single myoblasts, prior cell fusion $(* p<0.05, * * * p<0.001)$. The number of the analyzed force maps is indicated in brackets. Error bars are the standard error of the mean. 
Figure 21 displays the elastic modulus distribution along the surface of myoblasts in two different stages of myotube formation. Figure 21A depicts a myoblast in spindle like morphology stage with reduced and homogenously distributed elasticity, while in Figure 21B the projection of a more elongated, but still single, myoblast is represented. The average elastic modulus values measured over the central area of the cells were similar for wild-type and SOD1 mutant myoblasts, amounting $720.47 \pm 88.55 \mathrm{~Pa}$, and $667.25 \pm 103.72 \mathrm{~Pa}$, respectively (Figure 21C-Body). However, the elastic modulus of projections of the more elongated myoblasts were significantly higher compared with body values, amounting $1176.64 \pm 183.94 \mathrm{~Pa}(* p<0.05)$ in wild-type myoblast and $1540 \pm 184.50 \mathrm{~Pa}(* * * p<0.001)$ in $S O D 1^{G 93 A}$ myoblasts. As for the central area, no differences in projections were observed between the two genotypes (Figure 21C-Projection).
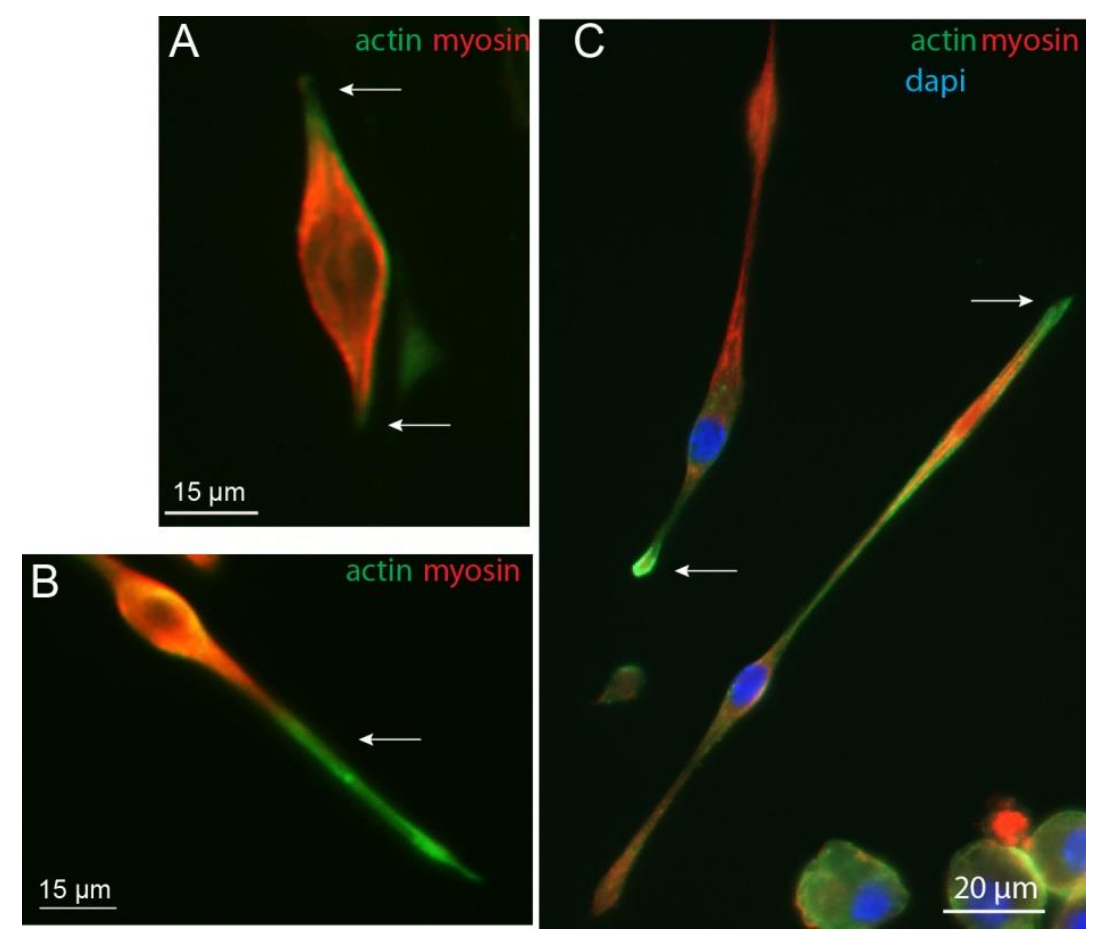

FigURE 22. Immunofluorescence images of myoblasts in the process of elongation with actin (green), myosin (red) and nucleus (blue) staining, observed at 7 DIV.

Previous works reported that changes in elastic modulus during myotube maturation is mainly dependent on actin and myosin, but not on beta-tubulin levels [104,135]. To correlate the observed elasticity changes between soma and projection with cytoskeletal protein content, the ratio of actin-myosin expression was determined using immunocytochemistry. As observed in earlier studies, myoblasts in vitro have bipolar-shaped forms prior fusion (Figure 22) with actin cytoskeleton playing a major role in this differentiation process [136]. Double staining experiments clearly show that myosin expression was higher than actin in the soma, while the opposite was observed in projections (Figure 22 A,B arrows). Unlike myosin, actin staining was expressed up to the extremities of the bundles during process of myoblast 
elongation, which is consistent with its structural role for initiating and maintaining the growing process (Figure 22C) [109,137].

Altogether, these results suggest that low Young's modulus values (around $500 \mathrm{~Pa}$ ) reflect myosin abundance while high values (from $1000 \mathrm{~Pa}$ ) would be a marker of higher actin expression over myosin. In addition, as no differences in elasticity were evidenced between wild-type and SOD1 ${ }^{G 93 A}$ myoblasts, this suggests similar expression and compartmentation in these cytoskeletal proteins at this early stage preceding fusion and maturation.

\section{II.2.2. SOD1 mutant myotubes show increased elastic modulus}

As cell cultures present large heterogeneity regarding the myotube diameter during fusion process, we performed a Gaussian fitted distribution analysis of myotube thickness, using the optical microscope images, as depicted in Figure 23. Tube diameter varies from $1.7 \mu \mathrm{m}$ to $15 \mu \mathrm{m}$, with a mean value of $5.19 \pm 0.14 \mu \mathrm{m}(n=415)$ for wild-type and $5.17 \pm 0.11 \mu \mathrm{m}$ $(n=599)$ for SOD1 mutant myotubes $(\mathrm{p}=0.89)$. The absence of significant differences between wildtype and SOD1 mutant myotube diameter suggests that at this stage the mutation does not induce atrophy. Therefore, we used the median value of $4.62 \mu \mathrm{m}$ as a cut-off value for a narrow/wide classification of myotubes, due to an equal grouping of data into thin and thick populations. In the following experiments, AFM was used to compare the elastic modulus of thin and thick myotubes in wild-type $(n=28)$ and $S O D 1^{G 93 A}(n=42)$ cultures.
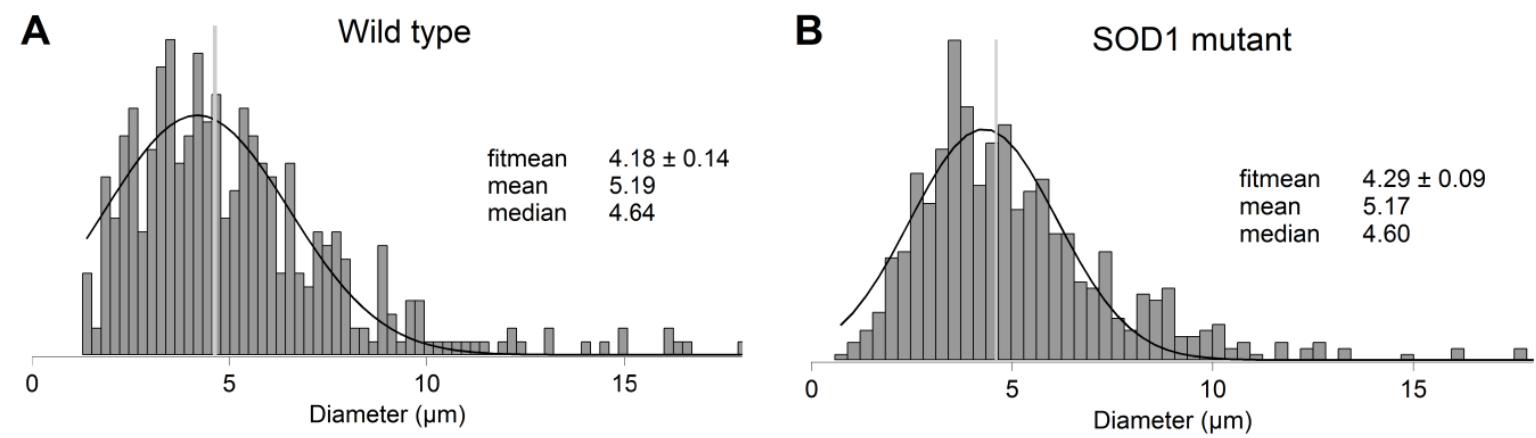

FIGURE 23. Transverse dimension distributions of wild-type (A) and SOD1 mutant (B) myotubes, measured on optical images. Black curves represent the Gaussian fitting, while vertical gray lines indicate the median of the data.

Figure $24 \mathrm{~A}$ and B shows two representative topographical images of thin and thick wild-type myotubes, reconstructed from force maps by using the contact point of the collected force curves as height, and the elasticity parameter for coloration. The values of measured elastic modulus had large variations, ranging from few hundreds of $\mathrm{Pa}$ up to $10 \mathrm{kPa}$ observed not only between individuals, but also within single force maps. These variations were addressed 
by fitting elasticity distributions of each force map with a sum of two Gaussian functions, illustrated as light gray curves in Figure 24C, D. Consequently, all force maps were associated with a double average, corresponding to the peaks of the double Gaussian fit, which provides an index on the variability of elasticity. Collecting optical images (Figure 24E, F), before, during and after the measurements, ensured the exclusion of those data where potential morphological changes throughout force volume acquisition were observed. The obtained average elasticity values of double fitting were $557.05 \pm 83.81 \mathrm{~Pa}$ and $1200.70 \pm 165.89 \mathrm{~Pa}$ for thin myotubes and 1027.88 $\pm 110.38 \mathrm{~Pa}$ and $1865.47 \pm 204.14 \mathrm{~Pa}$ for thick myotubes, respectively, indicating a significant difference $(* * \mathrm{p}<0.01, * \mathrm{p}<0.05)$ between the two population on both peaks (Figure 24G). Therefore, there was an overall significant difference in myotube elasticity, the thicker ones being stiffer.
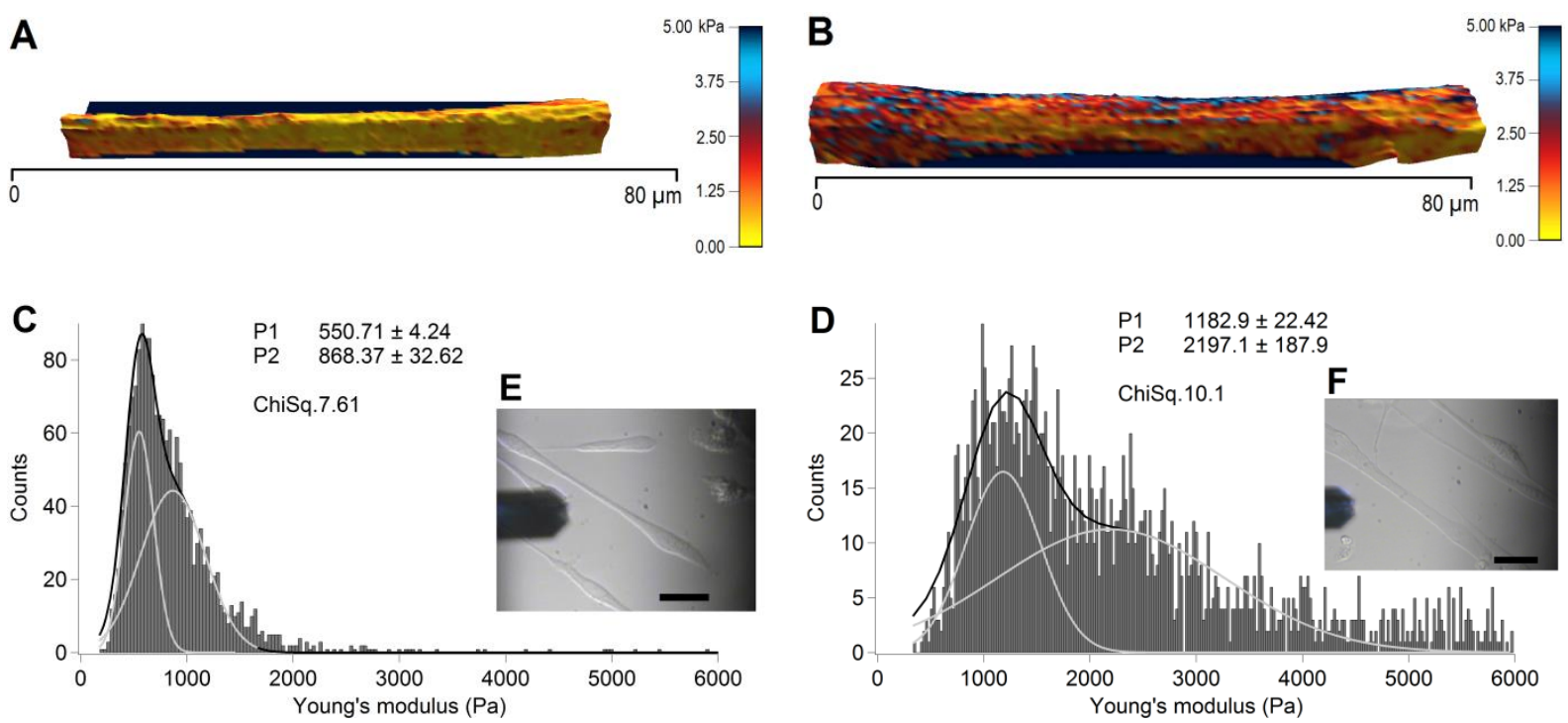

FiguRE 24. Elasticity color-coded 3Dreconstruction of representative thin $(\mathbf{A})$ and thick (B) wild-type myotubes. Yellow color shows softer portions, while red to blue colors show stiffer regions. $\mathbf{C}$ and $\mathbf{D}$ are the elastic modulus distributions of the corresponding force maps, where light gray curves are single Gaussians, while black curves represent the sum of the two. Insets $E$ and $F$ are optical images about the measured myotubes. Scale bars are $30 \mu \mathrm{m}$.

$\mathbf{G}$ represents the obtained average of the fitted double Gaussians (Peak 1 and Peak 2) on the elasticity value distributions of

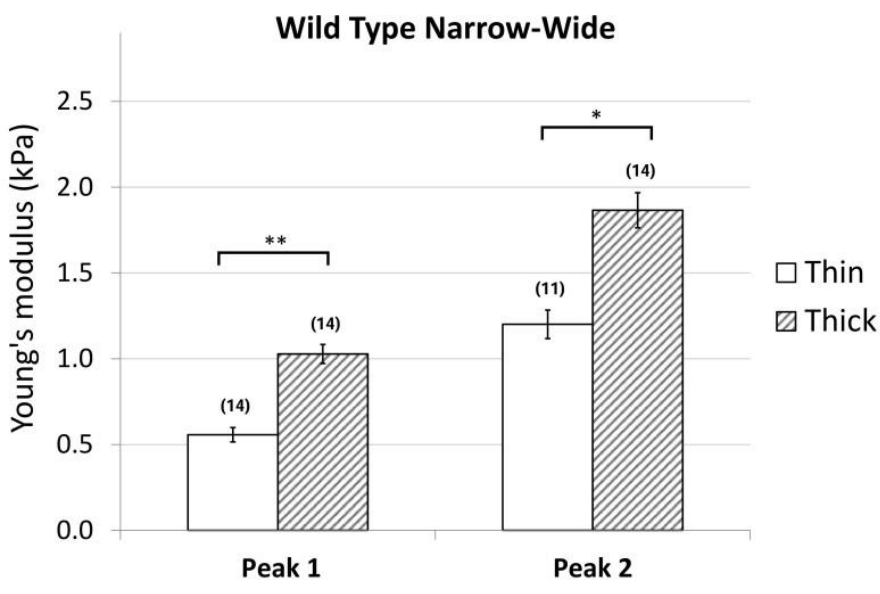
individual force maps, measured on thin and thick myotubes. In brackets the number of the analyzed force maps is denoted. Error bars are the standard error of the mean. As indicated, significant difference was found on both peaks of the Gaussian fit $(* p<0.05, * * p<0.01)$. 
Representative elasticity colored topographical maps (A and B) and the corresponding optical images $(\mathrm{E}$ and $\mathrm{F})$ of thin and thick $S O D 1^{G 93 A}$ mutant myotubes are shown in Figure 25. Force map analysis of $S O D 1^{G 93 A}$ myotubes show Young's moduli of $974.14 \pm 107.34 \mathrm{~Pa} / 1839.34 \pm$ 206.48 Pa for thin myotubes (Figure 25C) and 1280.81 $\pm 115.97 \mathrm{~Pa} / 2337.47 \pm 239.14 \mathrm{~Pa}$ for the thick population (Figure 25D). Interestingly, these values presented no statistical difference suggesting no differences in elasticity between thin and thick SOD1 ${ }^{G 93 A}$ myotubes (Figure 25).
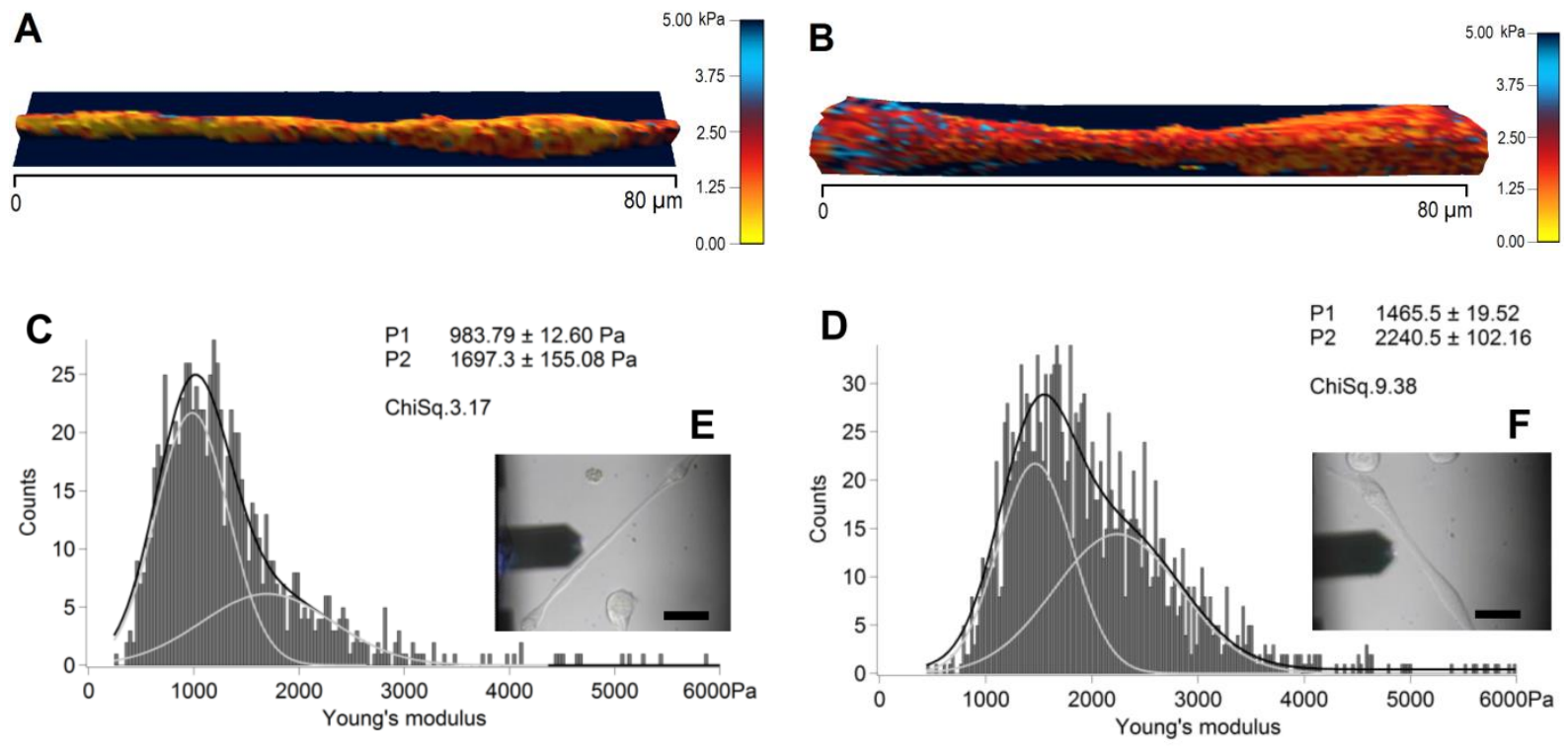

Figure 25. Elasticity color-coded 3Dreconstructions of representative thin (A) and thick (B) SOD1 mutant myotubes. Yellow color indicates softer portions, while red to blue colors show harder regions. $\mathbf{C}$ and $\mathbf{D}$ are elastic modulus distributions of the corresponding force maps, where light gray curves are single Gaussians, while black curves represent the sum of the two. Insets $\mathbf{E}$ and $\mathbf{F}$ are optical images about the measured myotubes. Scale bars are $30 \mu \mathrm{m}$.

G represents the obtained average of the double Gaussians (Peak 1 and Peak 2), fitted on the elasticity value distributions of

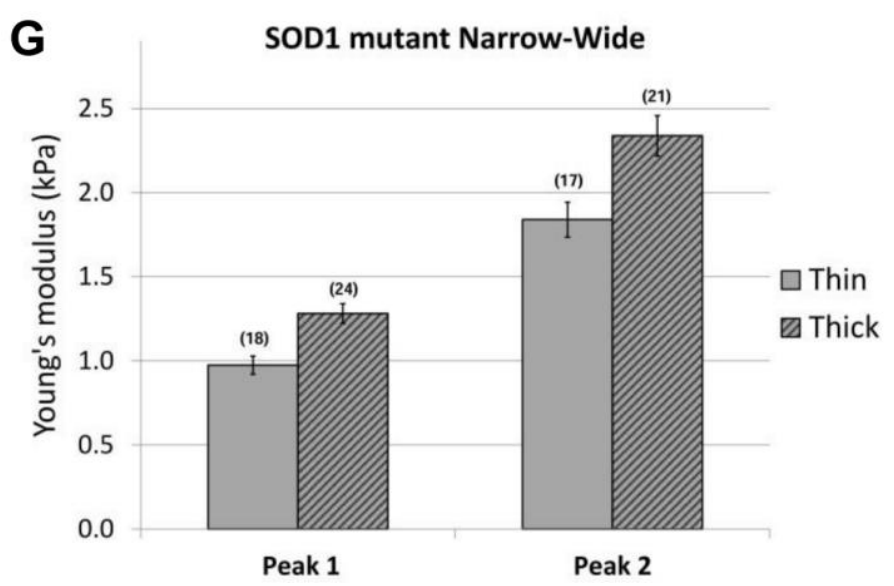
individual force maps. In brackets the number of the analyzed force maps is indicated. Error bars are the standard error of the mean. No significant difference was found between the two populations.

Analysis of elasticity between wild-type and SOD1 myotubes evidenced a shift for the thin myotubes expressing $S O D 1^{G 93 A}$ mutant towards higher elasticity values compared to wildtype, while there was no significant difference in elasticity values between the two thick populations of wild-type and $S O D 1^{G 93 A}$ myotubes (Figure 26). 
Altogether, these results suggest that the population of wild-type myotube at 6-8 DIV is highly heterogeneous in term of elasticity, while expression of $S O D 1^{G 93 A}$ leads to homogenization of the entire population towards hardest structures.

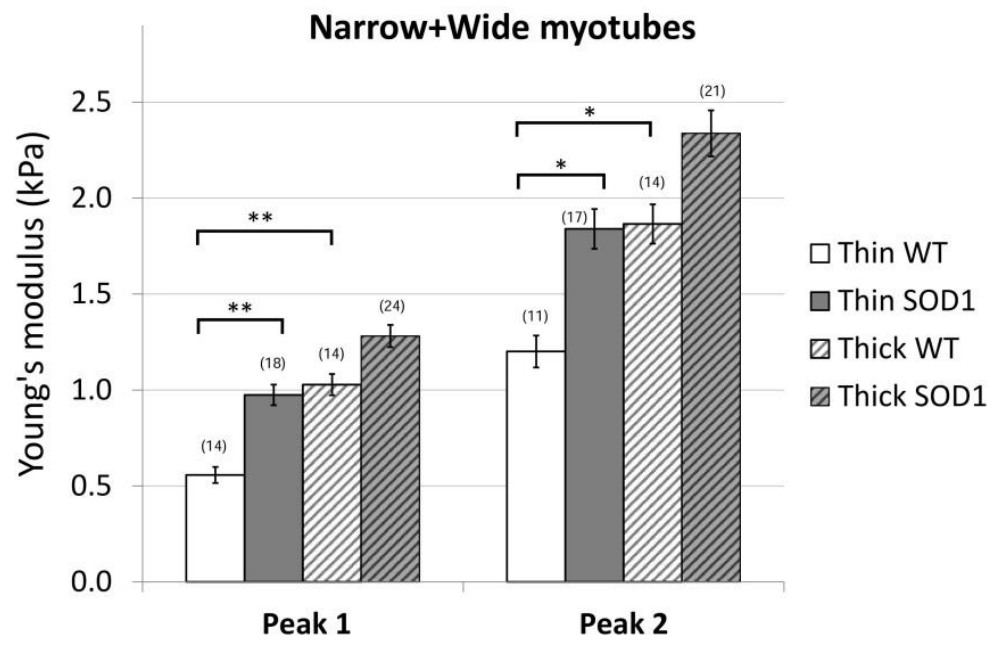

FIGURE 26. Average elasticity of wildtype and SOD1 mutant myotubes. The bars (Peak 1 and Peak 2) represent the mean of the double Gaussians, fitted on the elasticity value distributions of individual force maps. In brackets the number of the analyzed force maps is marked. Error bars are the standard error of the mean. As indicated, the elasticity of thin wild-type (WT) myotubes is significantly lower than thin SOD1 and thick wild-type as well $(* p<0.05, * * p<0.01)$.

\section{II.2.3. SOD1 mutation decreases myosin heavy chain gene isoforms expression}

From our force-map data on myoblasts, it appeared that a higher relative content of myosin to actin soften the cells and that wild-type myotubes are softer than $S O D 1^{G 93 A}$ myotubes. Therefore, we tentatively correlated biophysical properties of myotubes with myosin and actin expression during myotube formation.
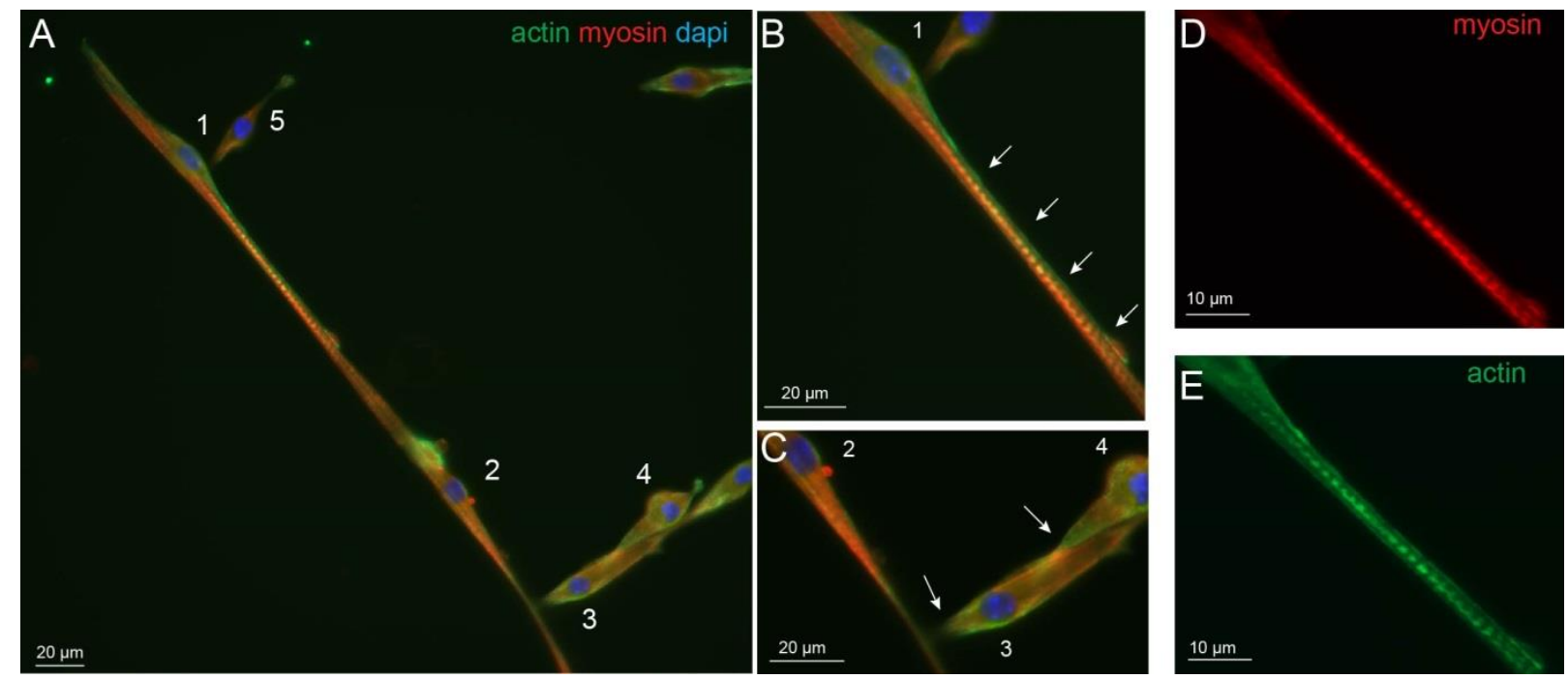

FIGURE 27. Immunofluorescence images on the primary fusion of wild-type myotubes with actin (green), myosin (red) and nucleus (blue) staining, observed at 7 DIV. A: Primary fusion process can be observed while the actin rich projection of myoblast 1 (B, white arrows) is elongated along myotube 2 and seems to initiate fusion with it. Myoblasts 3-5 present fusion initiation with perpendicular orientation on the 
myotube by an actin rich contact region (C, white arrows). The enlargements $\mathbf{D}$ and $\mathbf{E}$ show the well separated striations of myotube 2 with myosin and actin staining, respectively.

Immunostaining of actin and myosin were performed on wild-type myotubes at 7 DIV in differentiation medium. Using these cytoskeletal markers, two processes of myotube formation could be evidenced. The first correspond to the so-called primary fusion that consists in the construction of a poly-nucleated single fiber as shown in Figure 27A. In this representative example, myoblast 1 is in the process of fusion that allows seeing an elongated actin structure that seems to initiate the fusion process with myotube 2. Perpendicular to the fiber, several myoblasts (3-5) make contact between themselves towards forming a myotube using an actin-rich edge before the fusion. This thin myotube illustrates the mixed contribution of actin and myosin with stronger staining for myosin for the fiber that could account for elasticity corresponding to peak 1. In addition, punctiform actin and myosin staining, reminiscent to striation, were observed in some regions of the myotubes (Figure 27D-E). These spots of actin could account for the harder structures evidenced by peak 2 in the previous analysis.
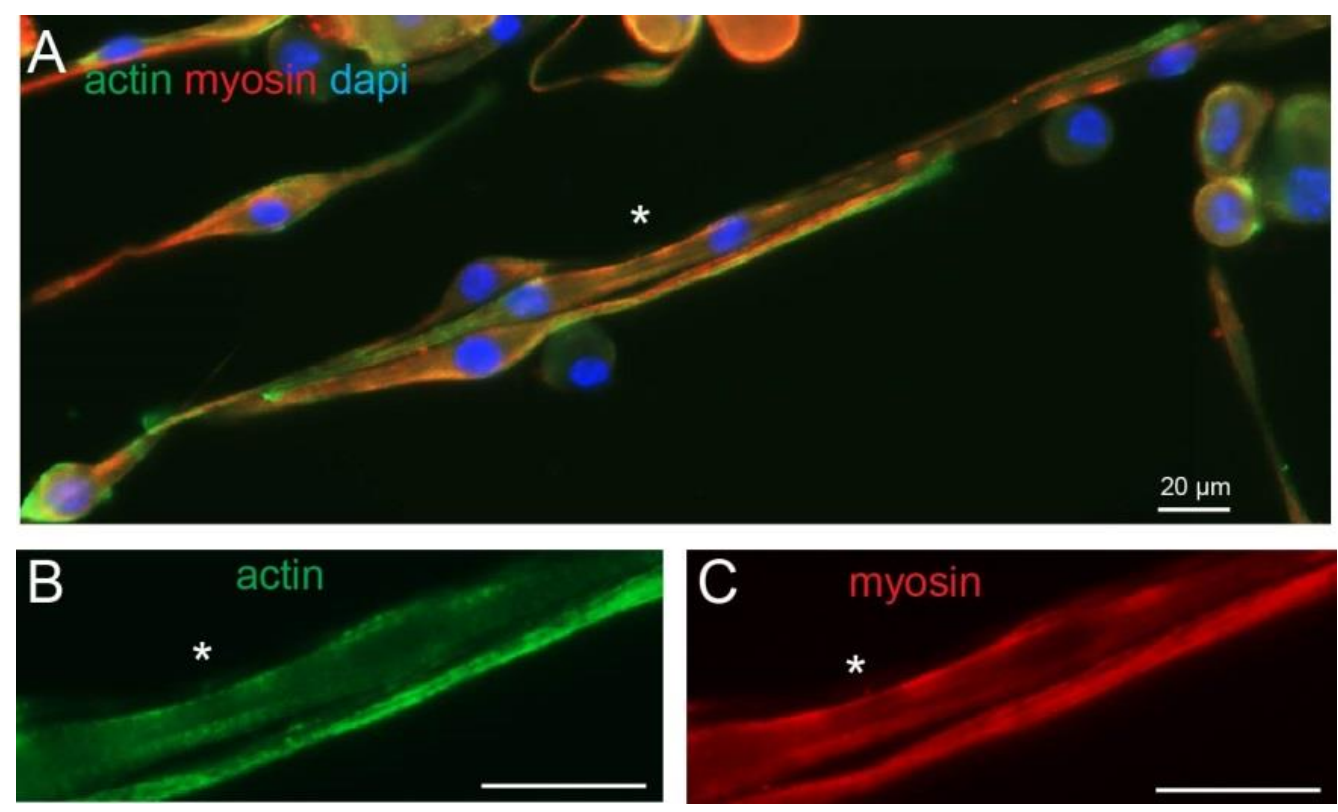

FIGURE 28. Maturation of wild-type myotubes (A) at 7 DIV with actin (green), myosin (red) and nucleus (blue) staining. B and $\mathbf{C}$ represent an enlargement of the marked area showing a more ordered actin, but a less ordered myosin distribution along the myotube. All scale bars are $20 \mu \mathrm{m}$.

An illustration of a thick myotube is shown in Figure 28 under a fusion process. While we could discern spots of actin, it was much harder to obtain such a resolution with myosin. This seems to corroborate the trends towards harder elasticity in thick myotubes. However, same 
analysis of actin-myosin staining in $S O D 1^{G 93 A}$ myotubes did not show differences compared with wild-type (data not shown).

Due to the limit of detection and quantification, we used quantitative RT-PCR to address whether SOD1 mutation induces changes in actin and myosin gene expression at 7 DIV. As displayed in Figure 29A, the two actin skeletal isoforms, Actal v1 and Actal v2, tended to be increased in SOD1G93A expressing myotubes. At this early developmental stage, embryonic and neonatal myosin heavy chain (MHC) genes Mhy3 and Myh8 were abundantly expressed and SOD1 mutation induced an apparent decreased expression of Myh3, although not significant. Although less expressed than immature isoforms, the adult MHC gene isoforms, Myhl coding for MHCIIx, fast fibers, Myh2 coding for MHCIIa, the fast fatigue resistant fibers, Myh4 coding for MHCIIb, the fast fatigable fibers and Myh7 coding for MHC- $\beta$, the slow fibers [138], were also detected in 7 DIV myotube cultures (Figure 29B). Interestingly, among these 4 isoforms, there was a three-fold decrease in Myh2 expression level and a 2-fold decrease in Mhy4 expression level in $S O D 1^{G 93 A}$ myotubes. The overexpression of human $S O D 1^{G 93 A}$ in myotube was confirmed using primer against the human SOD1 (cycle threshold was around 18, $n=3 S O D 1^{G 93 A}$ mice, a value reflecting a high expression of the transgene) that was absent in wild-type myotubes (cycle threshold was $0, n=3 \mathrm{WT}$ mice).

A

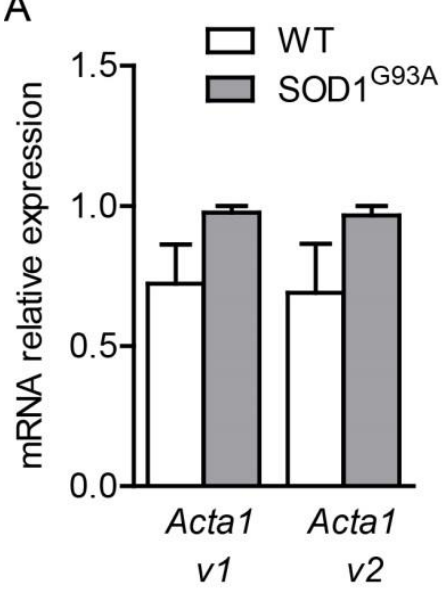

B

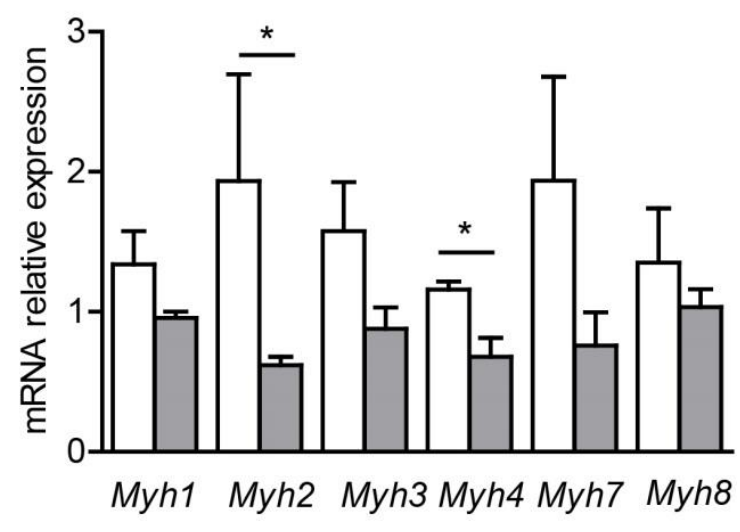

FIGURE 29. Gene expression of two actin isoforms (Acta1 v1, Acta1 v2) as well as embryonic (Myh3), neonatal (Myh8), and adult myosin isoforms (Myh1, 2, 4, and 7) in wild-type (WT) and SOD ${ }^{693 A}$ mutant myotubes (Mann-Whitney test, $* p<0.05 ; n=3 S O D 1^{G 93 A}$ and WT cultures). 


\section{II.3. Discussion and summary}

The proper understanding of the underlying mechanisms regarding interactions between lymphocytes and antigen-presenting cells is crucial in various physiological processes and has been the subject of a wide range of scientific studies [90,91]. We performed SCFS measurements on the mechanical interaction between primary $\mathrm{T}$ cells isolated from wild-type and SOD1 $1^{G 93 A}$ mutant mice (a well-established model of the human ALS disease) and primary cultures of motor neurons isolated from wild-type mice. The aim was to reveal if lymphocytes from diseased mice present enhanced adhesion forces to healthy motor neurons that could serve as a sign of a bio-recognition process between the two. Preliminary data of in vitro coculturing experiments performed by our collaborators have already indicated the death triggering effect of diseased mice derived $\mathrm{CD}^{+}$cytotoxic $\mathrm{T}$ cells on wild-type motor neuron cultures, while healthy mice derived $\mathrm{CD}^{+} \mathrm{T}$ cells presented no neurotoxic activity. Moreover, the effect was observable only in case of motor neurons, while cortical, hippocampal and striatal neurons were not sensitive to this neurotoxicity [99].

We found that the intercellular adhesion forces between healthy mice derived $\mathrm{T}$ cells and motor neurons show lower values compared to the adhesions measured on diseased mice derived $\mathrm{CD}^{+} \mathrm{T}$ cell and wild-type motorneuron interactions. In addition, after blocking the specific pMHC - TCR binding, force values decreased only slightly in case of wild-type T cell, while $S O D 1^{G 93 A}$ mutant $\mathrm{T}$ cells show highly significant force reduction following the blocking antibody application. This large force decrease implies the presence of MHC-ITCR bindings, of which a considerable proportion has been impeded from interaction, as a result of blocking, therefore suggesting a bio-recognition process.

In contrast with single molecule force approaches, where the tip (or surface) is functionalized by a layer of specific molecules and the adhesion forces can be attributed directly to their specific unbinding, in the case of SCFS a range of ligand-receptor pairs will interact simultaneously between the cell and the probe. Nevertheless, by analyzing the sudden changes in the measured FD-curves during cell-cell detachment, the probability distribution of the hindered individual rupture sizes can be determined. The step size distribution analysis of the gathered FD-curves indicated that the most probable individual rupture value in all cases differs only slightly, each being close to $20 \mathrm{pN}$. Moreover, the most frequent step size value is not varying significantly after blocking, suggesting that the type of participating receptorligand pairs remains unchanged, while only the likelihood of their interaction decreases. 
Although this value cannot be surely related to any specific receptor-ligand detachment, the binding strength between pMHC and TCR complex has been suggested, by others, as being close to this value [94].

Elasticity depends both on protein expression and cytoskeletal organization, rendering nano-biomechanics an effective tool to monitor subtle modifications in diseased cells. As primary myoblasts allow deciphering molecular processes involved in muscle development, aging and repair, in a further study we applied atomic force spectroscopy on primary myoblasts isolated from an ALS mouse model to reveal elasticity features during early differentiation stage into myotubes.

The process of myotube formation is composed by a series of complex morphological events. It starts with the surface anchorage and proliferation of myoblasts, which then aligned in a spindle like morphology with growing elongated projections are constantly searching for other cells and is finally followed by cell fusion in case of a successful encounter. Following 6 to 8 days of differentiation the cell culture presents a high heterogeneity, which is not limited to myotubes with different thicknesses, but contains a considerable amount of differentiating single myoblasts, still in search of other cells to fuse with. For myoblasts two different stages of myotube formation can be observed. According to our observations, one has usually a spindle like morphology exhibiting generally a homogeneous distribution and rather low values of elasticity. The second state is characterized by well elongated projections on one or both sides of the spindle like cell body, with an increased elasticity. While the less elongated myoblasts and the central portions of more elongated myoblasts show similar elastic modulus for both cell types, the projections of the more elongated myoblasts show significantly increased elastic modulus values, SOD1 mutant myoblast projections presenting the stronger increase.

Unlike myoblasts, in case of myotubes elastic inhomogeneity were observed that can be recognized in the elasticity distributions as a widening effect. To better interpret this inhomogeneity, the histograms of the calculated Young's modulus values of each force map were fitted by a sum of two Gaussians. The most commonly occurring elastic modulus values ranged from some hundreds of $\mathrm{Pa}$ up to $4 \mathrm{kPa}$, which is slightly smaller than it would be expected according to previously reported experiments [103,104]. One reason for this could be the use of a $\mathrm{C} 2 \mathrm{C} 12$ murine cell line, in the case of these earlier studies, while we used 
primary murine cells. Another explanation might be the hardness of the collagen coating we used to promote strong anchorage of the cells onto the plate [139].

Width analysis of myotubes shows a continuum from very thin ones, presumably right after their fusion, to rather thick myotubes apparently in a more mature state. Elastic modulus was monitored relative to myotube thickness. This interpretation was corroborated with morphological analysis of the actin and myosin content. Not only the diameter, but also the number of fused cells, as the building blocks of myotubes was highly variable. Previous studies reported a large increase in elastic moduli value of myotubes throughout differentiation [104]. Consistent with these studies, we show that elasticity variations between the different morphologies of wild-type myotubes correlate a higher elastic modulus with advanced maturation state. While in SOD1 mutant, a shift in elastic modulus was observed towards higher values in the thin population, which could suggest that there is an increased maturation process. However, the dimension frequency measurements (Figure 23), using optical microscopy images, show no differences with the wild-type population that argues against an increased number of fusioning ALS myotubes. This demonstrates that, at this developmental stage, the mutation does not induce atrophy.

Apparently, no obvious differences were observed between wild-type and $S O D 1^{G 93 A_{-}}$ expressing myotubes using actin and myosin staining. However, the more sensitive quantitative analysis of gene expression evidenced a decrease in MHC genes coding for the fast fatigue resistant fibers (Mhy2) and the fast fatigable fibers (Mhy4) together with the tendency towards less embryonic myosin expression which could account for the shift of mutant myotubes towards harder elasticity. These results suggest that in addition to motoneuron death, loss of regenerative potential of the ALS-sensitive fiber types contributes to muscle wasting in ALS disease progression. In agreement with our data several studies on satellite cells, obtained at later stage of the same ALS mouse model or from symptomatic ALS patients skeletal muscles, evidenced a decrease in myosin heavy chain protein [140], and the altered capacity of satellite cells to activate the myogenic program necessary for muscle mass maintenance [141,142]. Altogether, these data support that the decrease in Mhy2 and Mhy4 expression level is a potential contributor to pathology. Moreover, the existence of some threshold level of expression of multiple proteins that contributes to change in membrane elasticity has been also suggested [104]. Therefore, our data obtained at early presymptomatic stage points that early defects in myosin heavy chain composition or distribution 
reflected by changes in elasticity could be a major factor leading to progressive muscular weakness, independently of denervation [143].

In summary, our results on $\mathrm{T}$ cell - motoneuron adhesion suggest the presence of recognition and consequently a potential death triggering behavior of ALS model derived CD8+ cytotoxic $\mathrm{T}$ cells against wild-type motor neurons. This dataset is part of a more comprehensive work based on other, mostly biological studies indicating similar findings [99]. The direct involvement of $\mathrm{CD}^{+} \mathrm{T}$ lymphocytes in the pathophysiology of ALS is a novel finding that, besides widening our general knowledge about this fatal neurodegenerative disease, it could serve as a new biological marker or therapeutic target of improved future therapies.

In addition, our force spectroscopy data revealed differences between the nanomechanical behavior of SOD1 mutant myotube populations and wild-type myotubes, consistent with the trend towards higher actin content and a lower myosin content observed with qPCR experiments in SOD1 mutant myotubes. These results suggest a faster hardening without accompanying faster maturation process of ALS diseased skeletal myoblasts during myotube differentiation. 


\section{Conclusions}

The importance of nano-biomechanics in elucidating the diverse aspects of pathophysiology mechanisms of various life-threatening diseases, including cellular-level disease diagnostic, is well recognized. A wide range of studies demonstrated the impact of cellular-level mechanical changes in diseases like arthritis [41], asthma [42], vascular disorders [43], malaria [44,45], sickle cell anemia [46], muscular dystrophies [47-49], cancer [45,50], among others. In this work we applied AFM-based nanomechanical methods with the particular aim to address important questions related to brain metastasis formation and amyotrophic lateral sclerosis.

A malignant tumor cell, in order to spread and form metastasis, has to vary and continuously adapt its adhesive and elastic properties, its mechanical phenotype [66]. One bottleneck of brain metastasis formation is the firm adhesion of blood-travelling tumor cells and their successful penetration through the tightly connected endothelial layer, as a first defense line of the blood-brain barrier. Here, as a novel method, we combined force mapping with single cell force spectroscopy (SCFS) in order to gain direct insight into the surface "screening" process of tumor cells during their extravasation into the brain parenchyma. Intercellular adhesive force and work, as well as elastic properties were mapped. Interestingly, the data showed that adhesive properties are only slightly dependent on elastic characteristics. Examining the cross-correlations between the measured parameters revealed the enhanced contribution of ruptures (late-detachments) against deformation (early-detachment) to maximal adhesion force and total adhesion work and highlighted the importance of long range tether-like linkages for successful adhesions.

Since decades we know that individual cancerous cells show reduced elastic modulus compared to normal ones for most cancer types [71]. However, the question how the metastatic potential relates to tumor cell's autonomous and inter-cellular nanomechanical properties has been examined by only a few studies [73-76]. Therefore, in a second series of experiments the relations between the different levels of malignancy and the nanomechanical parameters of tumor - endothelial heterocellular interactions were addressed by SCFS. Three melanoma cell types (WM35, A2058 and A375) with altered invasive characteristics were examined. As no proper model exists to obtain elastic or plastic properties when two cells are 
pushed against each other, in order to compare the elastic properties of the studied cell types in situ, a new parameter was used, called relative elasticity. This relative dimensionless parameter was defined as the ratio of remnant and total work exerted by the system. The further investigated parameters included maximal adhesion force as well as number, size and location of de-adhesive rupture events. The performed control measurements against bare Petri dish surface indicated that the calculated relative elasticity is predominantly the property of melanoma cells, while endothelial cells have only low contribution. The highest relative elasticity values were exhibited by WM35 cells, followed by A2058 and A375 cells. This was in good correlation with the measured apparent Young's modulus against endothelial-free surface, being consistent with results obtained by others on different cancer cells. Although not in case of bare Petri dish, but when melanoma cells were pushed against the endothelium a clear difference in maximal adhesion force was observed, showing increasing values along with the increasing level of malignancy. Moreover, this correlated inversely with relative elasticity and at the same time directly with the number of rupture events, indicating a low relative elasticity, high maximal adhesion and high number of individual linkages, as the key properties of highly metastatic melanoma cells. The size and occurring distance of the individual de-adhesion events were also quantified, indicating that the role of tether based adhesive properties of invading melanoma cells cannot be neglected in the metastasis formation process. Our adhesion force dynamics data recorded between a confluent brain endothelial layer and three melanoma cell types of different invasiveness underline the importance of mechanical details in intercellular interactions. Moreover, it suggests that elastic and adhesive properties might be used as biomarkers for tumor cell malignancy.

Important questions about amyotrophic lateral sclerosis (ALS) can be addressed as well by AFM-based nanomechanical methods. The pathogenesis of this fatal neurodegenerative disease is complex, consisting not only in autonomous cell death, but involving the contribution of several cell types and characterized by the presence of inflammatory processes as well. In our work a SCFS study on $\mathrm{CD}^{+} \mathrm{T}$ cell and motor neuron interaction was performed. By comparing adhesive properties of $\mathrm{CD}^{+}$cytotoxic $\mathrm{T}$ cells isolated from wild-type as well as $\mathrm{SOD} 1^{\mathrm{G} 93 \mathrm{~A}}$ mutant mice against wild-type motor neurons, significant differences have been observed. Mutant mice derived $\mathrm{T}$ cells show enhanced adhesion strength compared to the healthy mice derived ones. Moreover, after blocking specific binding between pMHC-I and TCR highly significant reduction in adhesion force have been observed in case of mutant $\mathrm{T}$ cells, while wild-type $\mathrm{T}$ cells show only slight or no 
telling effect for the different contact times, respectively. Our results are strongly supported by the findings of our collaborators from in vitro co-culturing experiments, showing that the presence of $\mathrm{CD}^{+} \mathrm{T}$ cells trigger motoneuron death [99]. Together these results strongly corroborate the contribution of cytotoxic $\mathrm{T}$ cells in the development of ALS as an active player in neurodegeneration.

Although several studies have examined the mechanical properties of healthy skeletal muscle cells from different origin and in various states of differentiation, few investigated the effect of diseases on skeletal muscle cell elasticity, the majority of which addresses mainly muscular dystrophies [47-49]. We reported for the first time a detailed comparative study on the elastic modulus of healthy and ALS diseased mice derived differentiated primary skeletal muscle cells. High resolution nanomechanical mapping was performed on single elongated myoblast and multinuclear already-fused myotubes with varying thickness. In case of single myoblasts the measured elastic modulus values were significantly different between their central portion and elongated projections. The contribution of actin and myosin content to the elasticity was also examined and discussed. Immunofluorescence images were reported, presenting the actin rich contact regions prior fusion, as well as the expression level of different actin and myosin coding genes were quantified. Regarding myotubes, differences have been observed between the elasticity of a thin and thick population of wild-type myotubes, indicating the different maturity of the two populations. Interestingly, the same observation was not valid for the case of SOD1 mutant skeletal muscle myotubes. Here the thin, and thus pre-mature, myotubes showed no significantly different elastic modulus values compared to thick and therefore more mature myotubes. This finding suggests an enhanced autonomous hardening of ALS derived myotubes that could be substantial in the development of this yet incurable neurodegenerative disease.

In summary, we can conclude that our cellular-level mechanical studies have been performed involving various aspects of two different life-threatening pathologies resulting in novel findings about their fundamental processes. This work highlights the high impact and the important role of AFM-based nanomechanical methods in providing valuable knowledge about disease pathophysiology, development, diagnostics and progression and might contribute to the evolvement of future therapies. 


\section{References}

[1] J. Helenius, C.P. Heisenberg, H.E. Gaub, D.J. Müller, Single-cell force spectroscopy, J. Cell Sci. 121 (2008) 1785-1791. doi:10.1242/jcs.030999.

[2] K.K.C. Neuman, A. Nagy, Single-molecule force spectroscopy: optical tweezers, magnetic tweezers and atomic force microscopy, Nat. Methods. 5 (2008) 491-505.

doi:10.1038/nmeth.1218.Single-molecule.

[3] M. Prass, K. Jacobson, A. Mogilner, M. Radmacher, Direct measurement of the lamellipodial protrusive force in a migrating cell, J. Cell Biol. 174 (2006) 767-772. doi:10.1083/jcb.200601159.

[4] M. Footer, J. Kerssemakers, J. Theriot, M. Dogterom, Direct measurement of force generation by actin filament polymerization using an optical trap, Proc. Natl. Acad. Sci. 104 (2007) 21812186. doi:10.1073/pnas.0607052104.

[5] E.A. Abbondanzieri, W.J. Greenleaf, J.W. Shaevitz, R. Landick, S.M. Block, Direct observation of base-pair stepping by RNA polymerase, Nature. 438(2005) 460-465.

doi:10.1038/nature04268.

[6] T.G. Kuznetsova, M.N. Starodubtseva, N.I. Yegorenkov, S.A. Chizhik, R.I. Zhdanov, Atomic force microscopy probing of cell elasticity, Micron. 38 (2007) 824-833.

doi:10.1016/j.micron.2007.06.011.

[7] K.K. Liu, M.L. Oyen, Nanobiomechanics of living materials, Interface Focus. 4 (2014) 20140001. doi:10.1098/rstb.2008.2269.

[8] M.L. Rodriguez, P.J. McGarry, N.J. Sniadecki, Review on cell mechanics: Experimental and modeling approaches, Appl. Mech. Rev. 65 (2013) 60801. doi:10.1115/1.4025355.

[9] G. Binnig, C.F. Quate, C. Gerber, Atomic Force Microscope, Phys. Rev. Lett. 56 (1986) 930-933. doi:10.1103/PhysRevLett.56.930.

[10] M. Lekka, D. Gil, K. Pogoda, J. Dulińska-Litewka, R. Jach, J. Gostek, O. Klymenko, S. PrauznerBechcicki, Z. Stachura, J. Wiltowska-Zuber, K. Okoń, P. Laidler, Cancer cell detection in tissue sections using AFM, Arch. Biochem. Biophys. 518 (2012) 151-156.

doi:10.1016/j.abb.2011.12.013.

[11] L. Gross, F. Mohn, N. Moll, P. Liljeroth, G. Meyer, The Chemical Structure of a Molecule Resolved by Atomic Force Microscopy, Science (80-. ). 325 (2009) 1110-1114.

doi:10.1126/science. 1176210 .

[12] N. Kodera, D. Yamamoto, R. Ishikawa, T. Ando, Video imaging of walking myosin v by high speed atomic force microscopy, Nature. 468 (2010) 72-76. doi:10.1038/nature09450.

[13] A.B. Churnside, R.M.A. Sullan, D.M. Nguyen, S.O. Case, M.S. Bull, G.M. King, T.T. Perkins, Routine and timely Sub-picoNewton force stability and precision for biological applications of atomic force microscopy, Nano Lett. 12 (2012) 3557-3561. doi:10.1021/nl301166w.

[14] P. Verma, Tip-Enhanced Raman Spectroscopy: Technique and Recent Advances, Chem. Rev. 117 (2017) 6447-6466. doi:10.1021/acs.chemrev.6b00821. 
[15] A. Dazzi, C.B. Prater, AFM-IR:Technology and applications in nanoscale infrared spectroscopy and chemical imaging, Chem. Rev. 117 (2017) 5146-5173. doi:10.1021/acs.chemrev.6b00448.

[16] Q. Guo, Y. Xia, M. Sandig, J. Yang, Characterization of cell elasticity correlated with cell morphology by atomic force microscope, J. Biomech. 45 (2012) 304-309.

doi:10.1016/j.jbiomech.2011.10.031.

[17] J.M. Coles, J.J. Blum, G.D. Jay, E.M. Darling, F. Guilak, S. Zauscher, In Situ Friction Measurement on Murine Cartilage by Atomic Force Microscopy, J. Biomech. 41 (2008) 541548. doi:10.1016/j.jacc.2007.01.076.White.

[18] A.G. Végh, C. Fazakas, K. Nagy, I. Wilhelm, J. Molnár, I.A. Krizbai, Z. Szegletes, G. Váró, Adhesion and stress relaxation forces between melanoma and cerebral endothelial cells, Eur. Biophys. J. 41 (2012) 139-145. doi:10.1007/s00249-011-0765-5.

[19] B. Cappella, G. Dietler, Force-distance curves by atomic force microscopy, Surf. Sci. Rep. 34 (1999) 1-104. doi:10.1016/S0167-5729(99)00003-5.

[20] Y.F. Dufrêne, D. Martínez-Martín, I. Medalsy, D. Alsteens, D.J. Müller, Multiparametric imaging of biological systems by force-distance curve-based AFM, Nat. Methods. 10 (2013) 847-54. doi:10.1038/nmeth.2602.

[21] J. Friedrichs, K.R. Legate, R. Schubert, M. Bharadwaj, C. Werner, D.J. Müller, M. Benoit, A practical guide to quantify cell adhesion using single-cell force spectroscopy, Methods. 60 (2013) 169-178. doi:10.1016/j.ymeth.2013.01.006.

[22] C. Rotsch, M. Radmacher, Drug-induced changes of cytoskel etal structure and mechancics in fibroblasts: an Atomic Force Microscopy study, 78 (2000) 520-535.

[23] W.R. Trickey, T.P. Vail, F. Guilak, The role of the cytoskeleton in the viscoelastic properties of human articular chondrocytes, J. Orthop. Res. 22 (2004) 131-139. doi:10.1016/S07360266(03)00150-5.

[24] H. Hertz, Üeber die Berührung fester elastischer Körper, J. Fur Die Reine Und Angew. Math. (1881) 156-171. doi:10.1515/crll.1882.92.156.

[25] I.N. Sneddon, The relation between load and penetration in the axisymmetric boussinesq problem for a punch of arbitrary profile, Int. J. Eng. Sci. 3 (1965) 47-57. doi:10.1016/00207225(65)90019-4.

[26] E.U. Azeloglu, K.D. Costa, Atomic Force Microscopy in Mechanobiology: Measuring Microelastic Heterogeneity of Living Cells, in: P.C. Braga, D. Ricci (Eds.), At. Force Microsc. Biomed. Res., Springer, 2011: pp. 303-330. doi:10.1007/978-1-61779-105-5.

[27] H.J. Butt, B. Cappella, M. Kappl, Force measurements with the atomicforce microscope: Technique, interpretation and applications, Surf. Sci. Rep. 59 (2005) 1-152. doi:10.1016/j.surfrep.2005.08.003.

[28] S. Huang, D.E. Ingber, The structural and mechanical complexity of cell-growth control, Nat. Cell Biol. 1(1999) E131-E138. doi:10.1038/13043.

[29] O.K. Dudko, G. Hummers, A. Szabo, Theory, analysis, and interpretation of single-molecule force spectroscopy experiments, Proc. Natl. Acad. Sci. 105 (2008) 15755-15760.

[30] A. Beaussart, S. El-Kirat-Chatel, Quantifying the forces guiding microbial cell adhesion using single-cell force spectroscopy, Nat. Protoc. 9 (2014) 1049-55. doi:10.1038/nprot.2014.066. 
[31] A. V Taubenberger, D.W. Hutmacher, D.J. Müller, Singl e-cell force spectroscopy, an emerging tool to quantify cell adhesion to biomaterials., Tissue Eng. Part B. 20 (2014) 40-55. doi:10.1089/ten.TEB.2013.0125.

[32] M. Benoit, D. Gabriel, G. Gerisch, H.E. Gaub, Discrete interactions in cell adhesion measured by single-molecule force spectroscopy, Nat. Cell Biol. 2 (2000) 313-317. doi:10.1038/35014000.

[33] M. Thie, R. Röspel, W. Dettmann, M. Benoit, M. Ludwig, H.E. Gaub, H.W. Denker, Interactions between trophoblast and uterine epithelium: monitoring of adhesiv e forces, Hum. Reprod. 13 (1998) 3211-3209.

[34] J. Friedrichs, K.R. Legate, R. Schubert, M. Bharadwaj, C. Werner, D.J. Müller, M. Benoit, A practical guide to quantify cell adhesion using single-cell force spectroscopy, Methods. 60 (2013) 169-178. doi:10.1016/j.ymeth.2013.01.006.

[35] G.Y.H. Lee, C.T. Lim, Biomechanics approaches to studying human diseases, Trends Biotechnol. 25(2007) 111-118. doi:10.1016/j.tibtech.2007.01.005.

[36] G. Low, S.A. Kruse, D.J. Lomas, General review of magnetic resonance elastography, World J. Radiol. 8 (2016) 59-72. doi:10.4329/wjr.v8.i1.59.

[37] A. Sarvazyan, T.J. Hall, M.W. Urban, M. Fatemi, S.R. Aglyamov, B.S. Garra, An Overview of Elastography-An Emerging Branch of Medical Imaging, Curr. Med. Imaging Rev. 7 (2011) 255-282. doi:10.2174/157340511798038684.

[38] K.M. Pepin, R.L. Ehman, K.P. McGee, Magnetic resonance elastography (MRE) in cancer: Technique, analysis, and applications, Prog. Nucl. Magn. Reson. Spectrosc. 90-91 (2015) 3248. doi:10.1016/j.pnmrs.2015.06.001.

[39] M. Reiss-Zimmermann, K.J. Streitberger, I. Sack, J. Braun, F. Arlt, D. Fritzsch, K.T. Hoffmann, High Resolution Imaging of Viscoel astic Properties of Intracranial Tumours by Multi -Frequency Magnetic Resonance Elastography, Clin. Neuroradiol. 25 (2015) 371-378. doi:10.1007/s00062-014-0311-9.

[40] J.R. Basford, T.R. Jenkyn, K.N. An, R.L. Ehman, G. Heers, K.R. Kaufman, Evaluation of healthy and diseased muscle with magnetic resonance elastography, Arch. Phys. Med. Rehabil. 83 (2002) 1530-1536. doi:10.1053/apmr.2002.35472.

[41] W.R. Trickey, G.M. Lee, F. Guilak, Viscoelastic properties of chondrocytes from normal and osteoarthritic human cartilage, J. Orthop. Res. 18 (2000) 891-898. doi:10.1002/jor.1100180607.

[42] S.S. An, B. Fabry, X. Trepat, N. Wang, J.J. Fredberg, Do biophysical properties of the airway smooth muscle in culture predict airway hyperresponsiveness?, Am. J. Respir. Cell Mol. Biol. 35 (2006) 55-64. doi:10.1165/rcmb.2005-04530C.

[43] H. Qiu, Y. Zhu, Z. Sun, J.P. Trzeciakowski, M. Gansner, C. De pre, R.R.G. Resuello, F. Filipinas, W.C. Hunter, G.M. Genin, E.L. Elson, D.E. Vatner, G.A. Meininger, S.F. Vatner, Vascular Smooth Muscle Cell Stiffness as a Mechanism for Increased Aortic Stiffness with Aging, Circ. Res. 107 (2011) 615-619. doi:10.1161/CIRCRESAHA.110.221846.Vascular.

[44] F.K. Glenister, R.L. Coppel, A.F. Cowman, N. Mohandas, B.M. Cooke, Contribution of parasite proteins to altered mechanical properties of malaria-infected red blood cells, Blood. 99 (2002) 1060-1063. doi:10.1182/blood.V99.3.1060. 
[45] S. Suresh, J.P. Spatz, J.P. Mills, A. Micoulet, M. Dao, C.T. Lim, M. Beil, T. Seufferlein, Connections between single-cell biomechanics and human disease states: gastrointestinal cancer and malaria, Acta Biomater. 1 (2005) 15-30. doi:10.1016/j.actbio.2015.07.015.

[46] G.B. Nash, C.S. Johnson, H.J. Meiselman, Mechanical Properties in Sickle, Blood. 63 (1984) 7382.

[47] C. Pasternak, S. Wong, E.L. Elson, Mechanical function of dystrophin in muscle cells, J. Cell Biol. 128 (1995) 355-361. doi:10.1083/jcb.128.3.355.

[48] S. Puttini, M. Lekka, O.M. Dorchies, D. Saugy, T. Incitti, U.T. Ruegg, I. Bozzoni, A.J. Kulik, N. Mermod, Gene-mediated Restoration of Normal Myofiber Elasticity in Dystrophic Muscles, Mol. Ther. 17 (2009) 19-25. doi:10.1038/mt.2008.239.

[49] R.W. van Zwieten, S. Puttini, M. Lekka, G. Witz, E. Gicquel-Zouida, I. Richard, J.A. Lobrinus, F. Chevalley, H. Brune, G. Dietler, A.J. Kulik, T. Kuntzer, N. Mermod, Assessing dystrophies and other muscle diseases at the nanometer scale by atom ic force microscopy, Nanomedicine. 9 (2014) 393-406. doi:10.2217/nnm.12.215.

[50] S. Suresh, Biomechanics and biophysics of cancer cells, Acta Mater. 55 (2007) 3989-4014. doi:10.1016/j.actamat.2007.04.022.

[51] L.A. Torre, F. Bray, R.L. Siegel, J. Ferlay, J. Lortet-Tieulent, A. Jemal, Global Cancer Statistics, 2012, CA A Cancer J. Clin. 65 (2015) 87-108. doi:10.3322/caac.21262.

[52] E. Fokas, J.P. Steinbach, C. Rödel, Biology of brain metastases and novel targeted therapies: Time to translate the research, Biochim. Biophys. Acta - Rev. Cancer. 1835 (2013) 61-75. doi:10.1016/j.bbcan.2012.10.005.

[53] P.Y. Wen, P.M. Black, J.S. Loeffler, Metastatic Brain Cancer, in: V.T. DeVita, S. Hellman, S.A. Rosenberg (Eds.), Cancer Princ. Pract. Oncol., 6th ed., 2001.

[54] S. Madajewicz, C. Karakousis, C.R. West, J. Caracandas, A.M. Avellanosa, Malignant Melanoma Brain Metastases, Cancer. 53 (1984) 2550-2552.

[55] J.L. Chason, F.B. Walker, J.W. Landers, Metastatic carcinoma in the central nervous system and dorsal root ganglia. A prospective autopsy study, Cancer. 16 (1963) 781-787.

[56] I.J. Fidler, G. Schackert, R. Zhang, R. Radinsky, T. Fujimaki, The biology of melanoma brain metastasis, Cancer Metastasis Rev. 18 (1999) 387-400.

[57] S. Jang, M.B. Atkins, Treatment of Melanoma CNS Metastases, in: H.L. Kaufman, J.M. Mehnert (Eds.), CancerTreat. Res. Melanoma, Springer, 2016: pp. 236-279. doi:10.1007/978-3-31922539-5.

[58] J. Paluncic, Z. Kovacevic, P.J. Jansson, D. Kalinowski, A.M. Merlot, M.L.H. Huang, H.C. Lok, S. Sahni, D.J.R. Lane, D.R. Richardson, Roads to melanoma: Key pathways and emerging players in melanoma progression and oncogenic signaling, Biochim. Biophys. Acta - Mol. Cell Res. 1863 (2016) 770-784. doi:10.1016/j.bbamcr.2016.01.025.

[59] C. Abildgaard, P. Guldberg, Molecular drivers of cellular metabolic reprogramming in melanoma, Trends Mol. Med. 21 (2015) 164-171. doi:10.1016/j.molmed.2014.12.007.

[60] M. Batus, S. Waheed, C. Ruby, L. Petersen, S.D. Bines, L. Kaufman, Optimal management of metastatic melanoma: current strategies and future directions, Am J Clin Dermatol. 14 (2014) 179-194. doi:10.1007/s40257-013-0025-9.Optimal. 
[61] V.J. Mar, S.Q. Wong, J. Li, R.A. Scolyer, C. McLean, A.T. Papenfuss, R.W. Tothill, H. Kakavand, G.J. Mann, J.F. Thompson, A. Behren, J.S. Cebon, R. Wolfe, J.W. Kelly, A. Dobrovic, G.A. McArthur, BRAF/NRAS wild-type melanomas have a high mutation load correlating with histologic and molecular signatures of UV damage, Clin. Cancer Res. 19 (2013) 4589-4598. doi:10.1158/1078-0432.CCR-13-0398.

[62] M. Sensi, G. Nicolini, C. Petti, I. Bersani, F. Lozupone, A. Molla, C. Vegetti, D. Nonaka, R. Mortarini, G. Parmiani, S. Fais, A. Anichini, Mutually exclusive NRASQ61R and BRAFV600E mutations at the single-cell level in the same human melanoma, Oncogene. 25(2006) 33573364. doi:10.1038/sj.onc.1209379.

[63] J. Lin, Y. Goto, H. Murata, K. Sakaizawa, A. Uchiyama, T. Saida, M. Takata, Polyclonality of BRAF mutations in primary melanoma and the selection of mutant alleles during progression, Br. J. Cancer. 104 (2011) 464-468. doi:10.1038/sj.bjc.6606072.

[64] I.T. Gavrilovic, J.B. Posner, Brain metastases: Epidemiology and pathophysiology, J. Neurooncol. 75(2005) 5-14. doi:10.1007/s11060-004-8093-6.

[65] I. Wilhelm, J. Molnár, C. Fazakas, J. Haskó, I.A. Krizbai, Role of the Blood-Brain Barrier in the Formation of Brain Metastases, Int. J. Mol. Sci. 14 (2013) 1383-1411. doi:10.3390/ijms14011383.

[66] S. Kumar, V.M. Weaver, Mechanics, malignancy, and metastasis: The force journey of a tumor cell, Cancer Metastasis Rev. 28 (2009) 113-127. doi:10.1007/s10555-008-9173-4.

[67] M.M. Yallapu, K.S. Katti, D.R. Katti, S.R. Mishra, S. Khan, M. Jaggi, S.C. Chauhan, The Roles of Cellular Nanomechanics in Cancer, Med. Res. Rev. 35 (2015) 198-223. doi:10.1002/med.

[68] M. Lekka, P. Laidler, D. Gil, J. Lekki, Z. Stachura, A.Z. Hrynkiewicz, Elasticity of normal and cancerous human bladder cells studied by scanning force microscopy., Eur. Biophys. J. 28 (1999) 312-316. doi:10.1007/s002490050213.

[69] R. Lal, M.F. Arnsdorf, Multidimensional atomic force microscopy for drug discovery: A versatile tool for defining targets, designing therapeutics and monitoring their efficacy, Life Sci. 86 (2010) 545-562. doi:10.1016/j.Ifs.2009.02.030.

[70] J. Wang, Z. Wan, W. Liu, L. Li, L. Ren, X. Wang, P. Sun, L. Ren, H. Zhao, Q. Tu, Z. Zhang, N. Song, L. Zhang, Atomic force microscope study of tumor cell membranes following treatment with anti-cancer drugs, Biosens. Bioelectron. 25 (2009) 721-727. doi:10.1016/j.bios.2009.08.011.

[71] J. Zemła, J. Danilkiewicz, B. Orzechowska, J. Pabijan, S. Seweryn, M. Lekka, Atomic force microscopy as a tool for assessing the cellular elasticity and adhesiveness to identify cancer cells and tissues, Semin. Cell Dev. Biol. 73 (2017) 115-124. doi:10.1016/j.semcdb.2017.06.029.

[72] S.E. Cross, J. Yu-Sheng, R. Jianyu, J.K. Gimzewski, Nanomechanical analysis of cells from cancer patients, Nat. Nanotechnol. 2 (2007) 780-783. doi:10.1038/nnano.2007.388.

[73] Z. Zhou, C. Zheng, S. Li, X. Zhou, Z. Liu, Q. He, N. Zhang, A. Ngan, AFM nanoindentation detection of the elastic modulus of tongue squamous carcinoma cells with different metastatic potentials, Nanomedicine Nanotechnology, Biol. Med. 9(2013) 864-874. doi:10.1016/j.nano.2013.04.001.

[74] T. Watanabe, H. Kuramochi, A. Takahashi, K. Imai, N. Katsuta, T. Nakayama, H. Fujiki, M. Suganuma, Higher cell stiffness indicating lower metastatic potential in B16 melanoma cell variants and in (2)-epigal locatechin gallate-treated cells, J. Cancer Res. Clin. Oncol. 138 (2012) 
859-866. doi:10.1007/s00432-012-1159-5.

[75] W. Xu, R. Mezencev, B. Kim, L. Wang, J. McDonald, T. Sulchek, Cell Stiffness Is a Biomarker of the Metastatic Potential of Ovarian Cancer Cells, PLoS One. 7 (2012) e46609. doi:10.1371/journal.pone.0046609.

[76] R. Omidvar, M. Tafazzoli-shadpour, M.A. Shokrgozar, M. Rostami, Atomic force microscopebased single cell force spectroscopy of breast cancer cell lines: An approach for evaluating cellular invasion, J. Biomech. 47 (2014) 3373-3379. doi:10.1016/j.jbiomech.2014.08.002.

[77] V. Hofschroër, K.A. Koch, F.T. Ludwig, P. Friedl, H. Oberleithner, C. Stock, A. Schwab, Extracellular protonation modulates cell-cell interaction mechanics and tissue invasion in human melanoma cells, Sci. Rep. 7 (2017) 1-13. doi:10.1038/srep42369.

[78] A.A. Khalili, M.R. Ahmad, A Review of cell adhesion studies for biomedical and biological applications, Int. J. Mol. Sci. 16 (2015) 18149-18184. doi:10.3390/ijms160818149.

[79] I. Wilhelm, C. Fazakas, I.A. Krizbai, In vitro models of the blood-brain barrier, Acta Neurobiol. Exp. (Wars). 71 (2011) 113-128.

[80] V.Sundar Rajan, V.M. Laurent, C. Verdier, A. Duperray, Unraveling the Receptor-Ligand Interactions between Bladder Cancer Cells and the Endothelium Using AFM, Biophys. J. 112 (2017) 1246-1257. doi:10.1016/j.bpj.2017.01.033.

[81] K.E. Malek-Zietek, M. Targosz-Korecka, M. Szymonski, The impact of hyperglycemia on adhesion between endothelial and cancer cells revealed by single-cell force spectroscopy, J. Mol. Recognit. 30 (2017). doi:10.1002/jmr.2628.

[82] G. Logroscino, B.J. Traynor, O. Hardiman, A. Chio, D. Mitchell, R.J. Swingler, A. Millul, E. Benn, E. Beghi, Incidence of amyotrophic lateral sclerosis in Europe, J. Neurol. Neurosurg. Psychiatry. 81 (2010) 385-391. doi:10.1136/jnnp.2009.183525.

[83] L. Ferraiuolo, K. Meyer, B. Kaspar, The Use of Human Samples to Study Familial and Sporadic Amyotrophic Lateral Sclerosis : New Frontiers and Challenges, in: Curr. Adv. Amyotroph. Lateral Scler., 2013: pp. 159-182.

[84] M.C. Kiernan, S. Vucic, B.C. Cheah, M.R. Turner, A. Eisen, O. Hardiman, J.R. Burrell, M.C. Zoing, Amyotrophic lateral sclerosis, Lancet. 377 (2011) 942-955. doi:10.1016/S01406736(10)61156-7.

[85] F. Rossi, M.C. Franco, A.G. Estevez, Pathophysiology of Amyotrophic Lateral Sclerosis, in: Curr. Adv. Amyotroph. Lateral Scler., 2013: pp. 1-33. doi:10.5772/67458.

[86] K. Talbot, Motor neuron disease, Pract. Neurol. 9(2009) 303-309. doi:10.1136/jnnp.2009.188151.

[87] D. Rosen, T. Siddique, D. Patterson, A. Hentati, H. Deng, R.H. Brown, Mutations in Cu/Zn superoxide dismutase gene are associated with familial amyotrophiclateral sclerosis, Nature. 362 (1993) 59-62.

[88] M.E. Gurney, H. Pu, A.Y. Chiu, M.C.D. Canto, C.Y. Polchow, D.D. Alexander, J. Caliendo, A. Hentati, Y.W. Kwon, H. Deng, W. Chen, P. Zhai, R.L. Sufit, T. Siddique, Motor Neuron Degeneration in Mice That Express a Human Cu,Zn Superoxide Dismutase Mutation, Science (80-. ). 264 (1994) 1772-1775. doi:10.1126/science.8209258. 
[89] K.C. Kanning, A. Kaplan, C.E. Henderson, Motor Neuron Diversityin Development and Disease, Annu. Rev. Neurosci. 33(2010) 409-440. doi:10.1146/annurev.neuro.051508.135722.

[90] B.H. Hosseini, I. Louban, D. Djandji, G.H. Wabnitz, J. Deeg, N. Bulbuc, Y. Samstag, M. Gunzer, J.P. Spatz, G.J. Hämmerling, Immune synapse formation determines interaction forces between Tcells and antigen-presenting cells measured by atomic force microscopy, Proc. Natl. Acad. Sci. 107 (2010) 2373-2373. doi:10.1073/pnas.1000184107.

[91] P. Sundd, M.K. Pospieszalska, K. Ley, Neutrophil rolling at high shear: Flattening, catch bond behavior, tethers and slings, Mol. Immunol. 55(2013) 59-69. doi:10.1016/j.molimm.2012.10.025.

[92] X. Zhang, E.P. Wojcikiewicz, V.T. Moy, Force spectroscopy of the leukocyte functionassociated antigen-1/intercellular adhesion molecule-1 interaction., Biophys. J. 83 (2002) 2270-9. doi:10.1016/S0006-3495(02)73987-8.

[93] E.P. Wojcikiewicz, M.H. Abdulreda, X. Zhang, V.T. Moy, Force Spectroscopy of LFA-1 and Its Ligands, ICAM-1 and ICAM-2, Biomacromolecules. 7(2006) 3188-3195. doi:10.1021/bm060559c. Force.

[94] P.H. Puech, D. Nevoltris, P. Robert, L. Limozin, C. Boyer, P. Bongrand, Force measurements of TCR/pMHC recognition at T cell surface, PLoS One. 6 (2011). doi:10.1371/journal.pone.0022344.

[95] S.C. Hoffmann, B.H. Hosseini, M. Hecker, I. Louban, N. Bulbuc, N. Garbi, G.H. Wabnitz, Y. Samstag, J.P. Spatz, G.J. Hämmerling, Single cell force spectroscopy of T cells recognizing a myelin-derived peptide on antigen presenting cells, Immunol. Lett. 136 (2011) 13-20. doi:10.1016/j.imlet.2010.11.005.

[96] T.S. Lim, P. Ricciardi-Castagnoli, Single-cell force spectroscopy: Mechanical insights into the functional impacts of interactions between antigen-presenting cells and T cells, Immunol. Res. 53 (2012) 108-114. doi:10.1007/s12026-012-8290-x.

[97] J.S. Henkel, D.R. Beers, S. Wen, A.L. Rivera, K.M. Toennis, J.E. Appel, W. Zhao, D. H. Moore, S.Z. Powell, S.H. Appel, Regulatory T-lymphocytes mediate amyotrophic lateral sclerosis progression and survival, EMBO Mol. Med. 5 (2013) 64-79. doi:10.1002/emmm.201201544.

[98] I.M. Chiu, A. Chen, Y. Zheng, B. Kosaras, S.A. Tsiftsoglou, T.K. Vartanian, R.H. Brown, M.C. Carroll, T lymphocytes potentiate endogenous neuroprotective inflammation in a mouse model of ALS, Proc. Natl. Acad. Sci. 105 (2008) 17913-17918. doi:10.1073/pnas.0804610105.

[99] E. Coque, La neuroimmunité dans la sclérose latérale amyotrophique (defended Thesis), Université de Montpellier, 2017.

[100] D.P. Millay, J.R. O’Rourke, L.B. Sutherland, S. Bezprozvan naya, J.M. Shelton, R. Bassel-Duby, E.N. Olson, Myomaker is a membrane activator of myoblast fusion and muscle formation. (Supp), Nature. 499 (2013) 301-5. doi:10.1038/nature12343.

[101] Y. Yoshikawa, T. Yasuike, A. Yagi, T. Yamada, Transverse elasticity of myofibrils of rabbit skeletal muscle studied by atomicforce microscopy, Biochem. Biophys. Res. Commun. 256 (1999) 13-19. doi:10.1006/bbrc.1999.0279.

[102] L.R. Nyland, D.W. Maughan, Morphology and transverse stiffness of Drosophila myofibrils measured by atomic force microscopy, Biophys. J. 78 (2000) 1490-7. doi:10.1016/S00063495(00)76702-6. 
[103] A.B. Mathur, A.M. Collinsworth, W.M. Reichert, W.E. Kraus, G.A. Truskey, Endothelial, cardiac muscle and skeletal muscle exhibit different viscous and elastic properties as determined by atomic force microscopy, J. Biomech. 34 (2001) 1545-1553. doi:10.1016/S00219290(01)00149-X.

[104] A.M. Collinsworth, S. Zhang, W.E. Kraus, G.A. Truskey, Apparent elastic modulus and hysteresis of skeletal muscle cells throughout differentiation, Am. J. Physiol. Cell Physiol. 283 (2002) C1219-C1227. doi:10.1152/ajpcell.00502.2001.

[105] E. Defranchi, E. Bonaccurso, M. Tedesco, M. Canato, E. Pavan, R. Raiteri, C. Reggiani, Imaging and elasticity measurements of the sarcolemma of fully differentiated skeletal muscle fibres, Microsc. Res. Tech. 67 (2005) 27-35. doi:10.1002/jemt.20177.

[106] I. V Ogneva, D. V Lebedev, B.S. Shenkman, Transversal stiffness and young's modulus of single fibers from rat soleus muscle probed by atomic force microscopy, Biophys. J. 98 (2010) 418424. doi:10.1016/j.bpj.2009.10.028.

[107] B.B. Weksler, Blood-brain barrier-specific properties of a human adult brain endothelial cell line, FASEB J. (2005) 1872-1874. doi:10.1096/fj.04-3458fje.

[108] C. Raoul, A.G. Estévez, H. Nishimune, D.W. Cleveland, O. DeLapeyriere, C.E. Henderson, G. Haase, B. Pettmann, Motoneuron Death Triggered by a Specific Pathway Downstream of Fas: Potentiation by ALS-Linked SOD1 Mutations, Neuron. 35 (2002) 1067-1083. doi:10.1159/000072860.

[109] M. Martin, O. Benzina, V. Szabo, A.G. Végh, O. Lucas, T. Cloitre, F. Scamps, C. Gergely, Morphology and nanomechanics of sensory neurons growth cones following peripheral nerve injury, PLoS One. 8 (2013) e56286. doi:10.1371/journal.pone.0056286.

[110] M.J. Higgins, R. Proksch, J.E. Sader, M. Polcik, S. McEndoo, J.P. Cleveland, S.P. Jarvis, Noninvasive determination of optical lever sensitivity in atomicforce microscopy, Rev. Sci. Instrum. 77 (2006) 1-5. doi:10.1063/1.2162455.

[111] J.E. Sader, B.D. Hughes, J.A. Sanelli, E.J. Bieske, Effect of multiplicative noise on least-squares parameter estimation with applications to the atomic force microscope, Rev. Sci. Instrum. 83 (2012). doi:10.1063/1.4709496.

[112] J.L. Hutter, J. Bechhoefer, Calibration of atomic-force microscope tips, Rev. Sci. Instrum. 64 (1993) 1868-1873. doi:10.1063/1.1143970.

[113] X. Zhang, E.P. Wojcikiewicz, V.T. Moy, Dynamic Adhesion of T Lymphocytes to Endothelial Cells Revealed by Atomic Force Microscopy, Exp. Biol. Med. 231 (2006) 1306-1312. doi:10.1016/j.immuni.2010.12.017.Two-stage.

[114] A.L. Weisenhorn, M. Khorsandi, S. Kasas, V. Gotzos, H.J. Butt, Deformation and height anomaly of soft surfaces studied with an AFM, Nanotechnology. 4(1993) 106-113. doi:10.1088/0957-4484/4/2/006.

[115] A. Vinckier, G. Semenza, Measuring elasticity of biological materials by atomicforce microscopy, FEBS Lett. 430 (1998) 12-16. doi:10.1016/S0014-5793(98)00592-4.

[116] T. Boudou, J. Ohayon, C. Picart, P. Tracqui, An extended relationship for the characterization of Young's modulus and Poisson's ratio of tunable polyacrylamide gels, Biorheology. 43 (2006) 721-728. doi:10.1063/1.3603933. 
[117] B.J. Briscoe, K.S. Sebastian, The elastoplastic response of poly(methylmethacrylate) to indentation, Proc. R. Soc. London A. 452 (1996) 439-457.

[118] Y. Liu, P.A. Pinzón-Arango, A.M. Gallardo-Moreno, T.A. Camesano, Direct adhesion force measurements between E. coli and human uroepithelial cells in cranberry juice cocktail, Mol. Nutr. Food Res. 54 (2010) 1744-1752. doi:10.1002/mnfr.200900535.

[119] K.J. Reeves, J. Hou, S.E. Higham, Z. Sun, J.P. Trzeciakowski, G.A. Meininger, N.J. Brown, Selective measurement and manipulation of adhesion forces between cancer cells and bone marrow endothelial cells using atomic force microscopy, Nanomedicine. 8 (2013) 921-934. doi:10.2217/nnm.12.139.

[120] P. Galajda, L. Kelemen, A.G. Végh, Micro- and nanotechnology for cell biophysics, Acta Biol. Szeged. 59 (2015) 303-321.

[121] N. Caille, O. Thoumine, Y. Tardy, J.J. Meister, Contribution of the nucleus to the mechanical properties of endothelial cells, J. Biomech. 35 (2002) 177-187. doi:10.1016/S00219290(01)00201-9.

[122] A.A. Birukova, F.T. Arce, N. Moldobaeva, S.M. Dudek, J.G.N. Garcia, R. Lal, K.G. Birukov, Endothelial permeability is controlled by spatially defined cytoskeletal mechanics: Atomic force microscopy force mapping of pulmonary endothelial monolayer, Nanomedicine Nanotechnology, Biol. Med. 5(2009) 30-41. doi:10.1016/j.nano.2008.07.002.

[123] V. Cardile, G. Malaponte, C. Loreto, M. Libra, S. Caggia, F.M. Trovato, G. Musumeci, Raf kinase inhibitor protein (RKIP) and phospho-RKIP expression in melanomas, Acta Histochem. 115 (2013) 795-802. doi:10.1016/j.acthis.2013.03.003.

[124] Y. Rolland, M. Demeule, L. Fenart, R. Béliveau, Inhibition of melanoma brain metastasis by targeting melanotransferrin at the cell surface, Pigment Cell Melanoma Res. 22 (2008) 86-98. doi:10.1111/j.1755-148X.2008.00525.x.

[125] C. Fazakas, I. Wilhelm, P. Nagyoszi, A.E. Farkas, J. Haskó, J. Molnár, H. Bauer, H.C. Bauer, F. Ayaydin, N.T.K. Dung, L. Siklós, I.A. Krizbai, Transmigration of melanoma cells through the blood-brain barrier: Role of endothelial tight junctions and melanoma-released serine proteases, PLoS One. 6 (2011). doi:10.1371/journal.pone.0020758.

[126] J. Molnár, C. Fazakas, J. Haskó, O. Sipos, K. Nagy, Á. Nyúl-Tóth, A.E. Farkas, A.G. Végh, G. Váró, P. Galajda, I.A. Krizbai, I. Wilhelm, Transmigration characteristics of breast cancer and melanoma cells through the brain endothelium: Role of Rac and PI3K, Cell Adhes. Migr. 10 (2016) 269-281. doi:10.1080/19336918.2015.1122156.

[127] K. Pogoda, J. Jaczewska, J. Wiltowska-Zuber, O. Klymenko, K. Zuber, M. Fornal, M. Lekka, Depth-sensing analysis of cytoskeleton organization based on AFM data, Eur. Biophys. J. 41 (2012) 79-87. doi:10.1007/s00249-011-0761-9.

[128] M. Lekka, K. Pogoda, J. Gostek, O. Klymenko, S. Prauzner-Bechcicki, J. Wiltowska-Zuber, J. Jaczewska, J. Lekki, Z. Stachura, Cancer cell recognition - Mechanical phenotype, Micron. 43 (2012) 1259-1266. doi:10.1016/j.micron.2012.01.019.

[129] G. Smolyakov, B. Thiebot, C. Campillo, S. Labdi, C. Severac, J. Pelta, É. Dague, Elasticity, Adhesion, and Tether Extrusion on Breast Cancer Cells Provide a Signature of Their Invasive Potential, ACS Appl. Mater. Interfaces. 8(2016) 27426-27431. doi:10.1021/acsami.6b07698.

[130] P. Panorchan, M.S. Thompson, K.J. Davis, Y. Tseng, K. Konstantopoulos, D. Wirtz, Single - 
molecule analysis of cadherin-mediated cell-cell adhesion, J. Cell Sci. 119 (2006) 66-74. doi:10.1242/jcs.02719.

[131] J. Schmitz, M. Benoit, K.E. Gottschalk, The viscoelasticity of membrane tethers and its importance for cell adhesion., Biophys. J. 95 (2008) 1448-1459.

doi:10.1529/biophysj.107.124289.

[132] F. Rico, C. Chu, M.H. Abdulreda, Y. Qin, V.T. Moy, Temperature modulation of integrinmediated cell adhesion, Biophys. J. 99 (2010) 1387-1396. doi:10.1016/j.bpj.2010.06.037.

[133] M. Benoit, C. Selhuber-Unkel, Measuring cell adhesion forces: theory and principles, in: P.C. Braga, D. Ricci (Eds.), At. Force Microsc. Biomed. Res., 2011: pp. 355-378.

[134] O. Roure, A. Buguin, H. Feracci, P. Silberzan, Homophilic Interactions between Cadherin Fragments at the Single Molecule Level : An AFM Study, Langmuir. 22 (2006) 4680-4684.

[135] M.E. Grady, R.J. Composto, D.M. Eckmann, Cell elasticity with altered cytoskeletal architectures across multiple cell types, J. Mech. Behav. Biomed. Mater. 61 (2016) 197-207. doi:10.1016/j.jmbbm.2016.01.022.

[136] M. Peckham, Engineering a multi-nucleated myotube, the role of the actin cytoskeleton, J. Microsc. 231 (2008) 486-493. doi:10.1111/j.1365-2818.2008.02061.x.

[137] E.W. Dent, F.B. Gertler, Cytoskeletal Dynamics and Review Transport in Growth Cone Motility and Axon Guidance, Neuron. 40(2003) 209-227. doi:10.1016/S0896-6273(03)00633-0.

[138] S. Schiaffino, C. Reggiani, Fiber Types in Mammalian Skeletal Muscles, Physiol. Rev. 91(2011) 1447-1531. doi:10.1152/physrev.00031.2010.

[139] A.J. Engler, M.A. Griffin, S. Sen, C.G. Bönnemann, H.L. Sweeney, D.E. Discher, Myotubes differentiate optimally on substrates with tissue-like stiffness: Pathological implications for soft or stiff microenvironments, J. Cell Biol. 166 (2004) 877-887. doi:10.1083/jcb.200405004.

[140] P.-F. Pradat, A. Barani, J. Wanschitz, O. Dubourg, A. Lombès, A. Bigot, V. Mouly, G. Bruneteau, F. Salachas, T. Lenglet, V. Meininger, G. Butler-Browne, Abnormalities of satellite cells function in amyotrophic lateral sclerosis, Amyotroph. Lateral Scler. 12 (2011) 264-271. doi:10.3109/17482968.2011.566618.

[141] A. Scaramozza, V. Marchese, V. Papa, R. Salaroli, G. Sorarù, C. Angelini, G. Cenacchi, Skeletal Muscle Satellite Cells in Amyotrophic Lateral Sclerosis, Ultrastruct. Pathol. 38(2014) 295-302. doi:10.3109/01913123.2014.937842.

[142] R. Manzano, J.M. Toivonen, A.C. Calvo, S. Oliván, P. Zaragoza, C. Rodellar, D. Montarras, R. Osta, Altered in vitro proliferation of mouse SOD1-G93A skeletal muscle satellite cells, Neurodegener. Dis. 11 (2013) 153-164. doi:10.1159/000338061.

[143] J.-P. Loeffler, G. Picchiarelli, L. Dupuis, J.-L. Gonzalez De Aguilar, The Role of Skeletal Muscle in Amyotrophic Lateral Sclerosis, Brain Pathol. 26 (2016) 227-236. doi:10.1111/bpa.12350.

[144] S. Pieraut, O. Lucas, S. Sangari, C. Sar, M. Boudes, C. Bouffi, D. Noel, F. Scamps, An Autocrine Neuronal Interleukin-6 Loop Mediates Chloride Accumulation and NKCC1 Phosphorylation in Axotomized Sensory Neurons, J. Neurosci. 31 (2011) 13516-13526.

doi:10.1523/JNEUROSCI.3382-11.2011. 


\section{Annexes}

\section{Annex 1 - Supplementary Methods}

\section{A1.1. Immunocytochemistry}

Differentiated myotubes at 7 DIV were first fixed for 15 min in $4 \%$ paraformaldehyde in PBS and then incubated for $20 \mathrm{~min}$ in $15 \%$ donkey serum in PBS. This was followed by an incubation for $2 \mathrm{~h}$ at room temperature with the primary antibodies (anti-rabbit Actin; 1:100; Sigma and anti-mouse Myosin Heavy Chain 1:100; A4.1025 DSHB). Following a washing step in PBS, cultures were incubated for $1 \mathrm{~h}$ at room temperature with secondary antibodies and mounted in Mowiol. Images were collected using a Zeiss 40X EC Plan Neofluar 1.3NA oil objective.

\section{A1.2. Quantification of gene expression}

Myoblasts were seeded at the density of 10,000 cells per $\mathrm{cm}^{2}$ in $60 \mathrm{~cm}$ collagen coated plates. After 2 days in multiplication, total mRNA was extracted at 7 DIV in the differentiation medium with the RNeasy Mini Kit (Qiagen) as described by Pieraut et al. [144]. The eluted mRNA was quantified by spectrophotometry (Nanodrop). Following gDNA wipe out, RT was performed with Quantitect RT kit (Qiagen). The primer sequences, designed with PrimerBLAST at NCBI, are listed in Table 1. Quantitative RT-PCR (qRT-PCR) was performed with 100 ng of total cDNA using SYBR Green (Qiagen) and the LightCycler system (Roche Diagnostics), after initial activation for $15 \mathrm{~min}$ at $95^{\circ} \mathrm{C}, 45$ cycles of $94^{\circ} \mathrm{C}$ for $15 \mathrm{~s}, 60^{\circ} \mathrm{C}$ for $20 \mathrm{~s}$ and $72^{\circ} \mathrm{C}$ for $35 \mathrm{~s}$ were carried out. After PCR amplification, a melting curve analysis was carried out to ensure PCR specificity. Polymerase (RNA) II polypeptide J (Polr2J) levels were used to normalize the amounts of cDNA. $\Delta \mathrm{Ct}$ was calculated as the difference between the $\mathrm{Ct}$ values, determined with the equation $2-\Delta \mathrm{Ct}$.

Table 1. Primers. Name, sequence, amplicon length (Al) and melting point (Tm) of primers used for qRTPCR are listed below.

\begin{tabular}{l|l|l|l} 
Target genes & Sequences & Al & Tm \\
\hline Acta1 & F: AAGTCCTGCAAGTGAACAAGC & 80 & 59 \\
(Actin skeletal muscle variant 1) & R: TTCGTCGCACATGGTGTCTA & & \\
Acta2 & F: ACGTGAAGCCTCACTCCTA & 64 & 58 \\
(Actin skeletal muscle variant 2) & R: TGTCTAGTTCTGCTGCTCTG & &
\end{tabular}




\begin{tabular}{|c|c|c|}
\hline $\begin{array}{l}\text { Myh1 } \\
\text { (adult Myosin Heavy Chain IIx) }\end{array}$ & $\begin{array}{l}\text { F: TTCAAGTTTGGACCCACGGT } \\
\text { R: AGTGAGAGAGCCTGCCTTA }\end{array}$ & 54 \\
\hline $\begin{array}{l}\text { Myh2 } \\
\text { (adult Myosin Heavy Chain Ila) }\end{array}$ & $\begin{array}{l}\text { F: TCCAAGTTCCGCAAGATCCA } \\
\text { R: GCGCATGACCAAAGGTTTCA }\end{array}$ & 193 \\
\hline $\begin{array}{l}\text { Myh3 } \\
\text { (embryonic Myosin Heavy Chain) }\end{array}$ & $\begin{array}{l}\text { F: TGTTGAGATTGCAGGATCTGG } \\
\text { R: TGCTGGGCTTTCCTGAACTT }\end{array}$ & 121 \\
\hline $\begin{array}{l}\text { Myh4 } \\
\text { (adult Myosin Heavy Chain Ilb) }\end{array}$ & $\begin{array}{l}\text { F: TTCCGTAAGATCCAGCACGA } \\
\text { R: TCCTGTCACCTCTCAACAGA }\end{array}$ & 151 \\
\hline $\begin{array}{l}\text { Myh7 } \\
\text { (adult Myosin Heavy Chain-beta) }\end{array}$ & $\begin{array}{l}\text { F: TGAGCATTCTCCTGCTGTTTC } \\
\text { R: TGAGCCTTGGATTCTCAAACG }\end{array}$ & 138 \\
\hline $\begin{array}{l}\text { Myh8 } \\
\text { (neonatal Myosin Heavy Chain) }\end{array}$ & $\begin{array}{l}\text { F: ACAATCCAATGCCAACCTGG } \\
\text { R: TCCTTCCTCTGCAAGATGTGT }\end{array}$ & 156 \\
\hline $\begin{array}{l}\text { hSOD1 } \\
\text { (human superoxide dismutase 1) }\end{array}$ & $\begin{array}{l}\text { F: ACAAAGATGGTGTGGCCGAT } \\
\text { R: AACGACTTCCAGCGTTTCCT }\end{array}$ & 162 \\
\hline $\begin{array}{l}\text { Polr } 2 j \\
\text { (polymerase (RNA) Il polypeptide J) }\end{array}$ & $\begin{array}{l}\text { F: ACCACACTCTGGGGAACATC } \\
\text { R: CTCGCTGATGAGGTCTGTGA }\end{array}$ & 160 \\
\hline
\end{tabular}


Annex 2 - Publications

I. Direct mapping of melanoma cell - endothelial cell interactions

Varga B., Fazakas C., Molnár J., Wilhelm I., Domokos R. A., Krizbai I. A.,

Szegletes Z., Váró G., Végh A. G 


\title{
Direct mapping of melanoma cell - endothelial cell interactions
}

\author{
Béla Varga $^{1,2}$ | Csilla Fazakas ${ }^{1}$ | Judit Molnár ${ }^{1}$ | Imola Wilhelm ${ }^{1}$ | Réka A. Domokos ${ }^{3 \dagger}$ | \\ István A. Krizbai ${ }^{1,4}$ | Zsolt Szegletes ${ }^{1}$ | György Váró ${ }^{1}$ | Attila G. Végh ${ }^{1}$
}

${ }^{1}$ Institute of Biophysics, Biological Research Centre, Hungarian Academy of Sciences, Szeged, Hungary

${ }^{2}$ Laboratoire Charles Coulomb L2C, UMR 5221, CNRS, Université de Montpellier, Montpellier, France

${ }^{3}$ Babes-Bolyai University, Faculty of Physics, Cluj-Napoca, Romania

${ }^{4}$ Institute of Life Sciences, Vasile Goldiş Western University, Arad, Romania

\section{Correspondence}

Attila G. Végh, Institute of Biophysics, Biological Research Centre, Hungarian Academy of Sciences, Szeged, Hungary, Temesvári krt 62, Szeged H-6726, Hungary. Email: vegh.attilagergely@brc.mta.hu

†Current Address: Institute of Biophysics, Biological Research Centre, Hungarian Academy of Sciences, Szeged, Hungary

\section{Funding information}

National Science Fund of Hungary, Grant/ Award Number: OTKA K116158, PD115697, and the GINOP-2.3.2-15-2016-00020.

\begin{abstract}
The most life-threatening aspect of cancer is metastasis; cancer patient mortality is mainly due to metastasis. Among all metastases, presence of brain metastasis is one with the poorest prognosis; the median survival time can be counted in months. Therefore, prevention or decreasing their incidence would be highly desired both by patients and physicians. Metastatic cells invading the brain must breach the cerebral vasculature, primarily the blood-brain barrier. The key step in this process is the establishment of firm adhesion between the cancer cell and the cerebral endothelial layer.

Using the atomic force microscope, a high-resolution force spectrograph, our aim was to explore the connections among the cell morphology, cellular mechanics, and biological function in the process of transendothelial migration of metastatic cancer cells. By immobilization of a melanoma cell to an atomic force microscope's cantilever, intercellular adhesion was directly measured at quasi-physiological conditions. Hereby, we present our latest results by using this melanoma-decorated probe. Binding characteristics to a confluent layer of brain endothelial cells was directly measured by means of single-cell force spectroscopy. Adhesion dynamics and strength were characterized, and we present data about spatial distribution of elasticity and detachment strength.

These results highlight the importance of cellular mechanics in brain metastasis formation and emphasize the enormous potential toward exploration of intercellular dynamic-related processes.
\end{abstract}

\section{KEYWORDS}

atomic force microscope, cancer, cell adhesion, cerebral endothelial cell, direct mapping, living cell, nanomechanics, single-cell force spectroscopy

\section{1 | INTRODUCTION}

One of the most feared complications of cancer incompatible with life are brain metastases (BMs), often causing life-impairing neurological symptoms. Presence of BM has a very poor prognosis; the median survival time can be counted in months, rarely few years. ${ }^{1}$ Different cancers show different propensities to form BM. Although melanoma is only 1 to $2 \%$ of all cancers, it has the highest tendency to invade the central nervous system. ${ }^{2}$ Autopsy studies showed that up to $90 \%$ of patients with end-stage melanoma had BM. ${ }^{3}$ Despite our growing knowledge about biology of BM formation, the precise details that trigger and guide tumor cell toward the brain are still under debate.

Formation of BM requires escape of tumor cells from primary sites, their hematogenous dissemination, attachment to the blood vessel wall, transmigration through cerebral endothelial layer into the brain parenchyma which must be followed by invasion, and interaction with the microenvironment, resulting in survival and proliferation. ${ }^{4}$ This multistage process has a crucial step, namely, the firm adhesion of blood-travelling tumor cells to the cerebral endothelial cells (CECs) which form the cellular basis of the first defense line of the brain, the blood-brain barrier (BBB). By forming a precisely regulated barrier between the circulation and the central nervous system, the BBB restricts the free movement of solutes and cells between the two compartments.

Cancer cells and especially melanoma cells must have special attributes which somehow facilitate breaching the BBB. Tumor cellendothelial cell interactions are key steps of BM formation; therefore, a detailed understanding of this interaction could lead to the identification of mechanisms which could reduce transmigration and thus BM formation. Biochemical characteristics are strongly linked to 
biophysical manifestations; hence, nanomechanical characterization of a tumor cell-endothelial attachment has important information on their dynamics of attachment. In vitro cell co-culture models dealing with the whole transmigration process have already been successfully established. ${ }^{5}$ Characterization of the elasticity, adhesion dynamics, or strength might provide additional and complementary information.

To investigate mechanics from single molecule ${ }^{6}$ to single cell ${ }^{7}$ level, the atomic force microscope (AFM) is an outstanding system. Being a member of the scanning probe microscope superfamily, the AFM, soon after its invention, ${ }^{8}$ became the most reliable and accurate nanoforce tool in the research of cellular biomechanics. ${ }^{9}$ Using AFMbased single-cell force spectroscopy, interaction of living cells can be monitored in liquid environment and at human body temperature. ${ }^{10,11}$ Moreover, high-resolution topographical maps can be reconstructed based on the measured mechanical parameters. ${ }^{12,13}$

It has been shown previously that short-term adhesion of a human melanoma cell to CEC layer is highly dependent on contact time and applied load. ${ }^{14}$ In this study, we report direct mechanical mapping of a human CEC layer by using a human melanoma cell as a probe. Spatial distribution of several nanomechanical parameters is shown to characterize the elasticity and linkage strength between the melanoma cell and the CEC layer.

\section{2 | MATERIALS AND METHODS}

\section{1 | Cell culture}

Human cerebral microvascular endothelial cell line (shortly D $3^{15}$ ) were grown on rat tail collagen-coated dishes in endothelial basal medium-2 medium (Lonza) supplemented with endothelial growth medium-2 Bullet Kit (Lonza) and 2.5\% fetal bovine serum (Sigma).

Highly-invasive A2058 human melanoma cells (obtained from the European Collection of Cell Cultures) were maintained in Eagle Minimum Essential Medium (Sigma) supplemented with 5\% fetal bovine serum (Sigma). These cells were derived from metastatic site (lymph node) of a 43-year-old white man. Tumor cells were labeled with CellTracker $^{\text {TM }}$ Red CMTPX Dye (Life Technologies), ensuring that they can be clearly identified prior to immobilization at the end of the cantilever.

\subsection{Atomic force microscope}

All experiments were carried out with an Asylum Research MFP-3D AFM (Asylum Research, Santa Barbara, CA; driving software IgorPro 6.32A, Wavemetrics), mounted on a Zeiss Axiovert 200 optical microscope.

The experiments were performed with rectangular tipless cantilevers having a nominal spring constant of $50 \mathrm{pN} / \mathrm{nm}$, a resonant frequency of $10 \mathrm{kHz}$ in air (MikroMasch, Tallinn, Estonia), which drops to $3 \mathrm{kHz}$ in water. The spring constant of the cantilever was determined each time by thermal calibration. ${ }^{16,17}$

Cancer cells were immobilized at the very end of the tipless cantilever by using a concanavalin-A-mediated linkage which is described elsewhere. ${ }^{7,14}$ During culturing, the cells were kept at $5 \% \mathrm{CO}_{2}$ atmosphere at $37^{\circ} \mathrm{C}$. All experiments were conducted in serum-free
Leibovitz medium at $37^{\circ} \mathrm{C}$ within 1 hour after the cells were taken out from the incubator. According to our experience, they preserve their viability far beyond this period.

\section{3 | Single-cell force spectroscopy}

During a force measurement cycle, a cancer cell immobilized at the end of a tipless cantilever was brought into contact with surface-adherent endothelial cells. The schematic representation can be found in Figure 1. Each cycle consisted of approaching the cell-decorated cantilever to the endothelial layer until the preset deflection was reached and pulling it back to initial position. Force curves were recorded at constant loading speed $(8 \mu \mathrm{m} / \mathrm{s})$ and sampling frequency $(2 \mathrm{kHz})$. Total force distance was kept at $3 \mu \mathrm{m}$ with a maximum load of $2.0 \mathrm{nN}$. Thirty-two lines by 32 point maps were recorded at each selected area of $90 \times 90 \mu \mathrm{m}$, total data collection being less than 15 minutes.

Figure 2 shows a typical force-distance curve: Contact point is marked with "o," approaching phase is drawn in red, while blue represents retraction, as pointed by accordingly colored arrows.

\section{4 | Data analysis}

A custom-written MATLAB routine was used to extract all the parameters. Elastic work (yellow + cyan area, Figure 2) represents the deformation of the cells by the applied force and plastic work (cyan area, Figure 2) when the cell regain its original state; their difference (yellow area, Figure 2) is the plastic deformation of the two cells.

Values of maximal adhesion force were considered as the difference between the maximal downward deflection of the cantilever compared with the initial noncontact level.

Total adhesion work (sum of light and dark green) at the detachment phase represents the energy needed to totally separate the two contacting cells. Darker green area can be associated mostly with cell deformation while lighter green with individual rupture events breaking up during retraction. Late ruptures at large distances from contact point are mainly due to membrane tethers pulled out from cells.

For correlation analysis, Pearson cross-correlation coefficient was calculated for each parameter pair reported. Perfect correlation was denoted with $100 \%$ while perfect anticorrelation with $-100 \%$.

All rainbow-colored topographical maps represent low (purple) to high (red) values. Experiments were repeated more than 5 times each

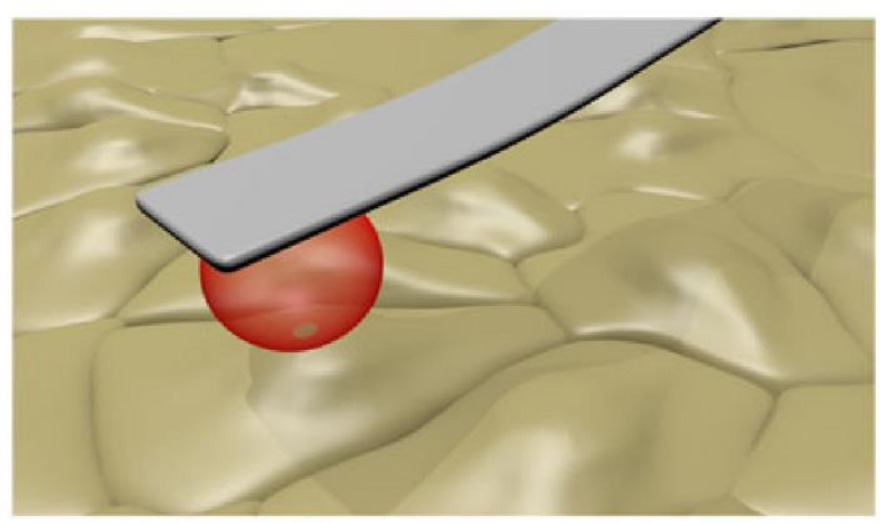

FIGURE 1 Schematic representation of experimental mapping setup 


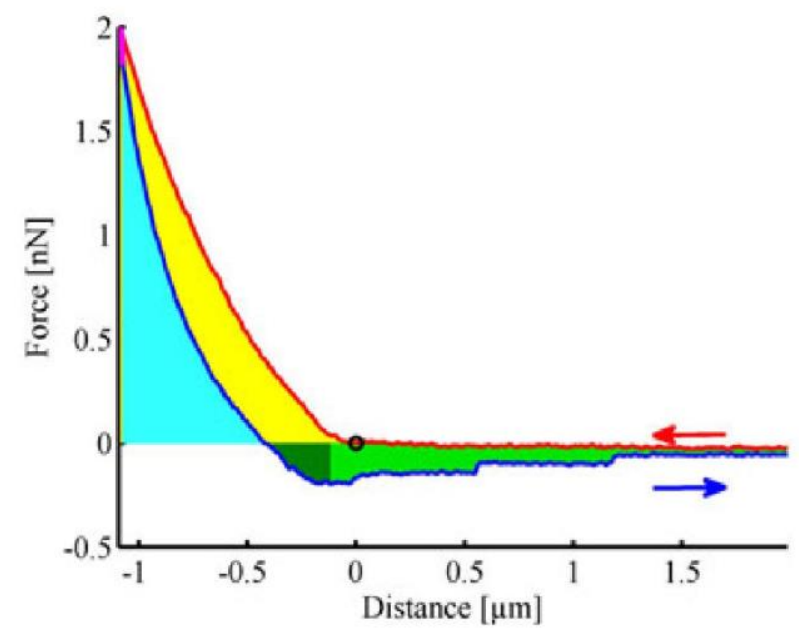

FIGURE 2 A representative force-distance curve. Contact point is marked with "o," cyan area marks the plastic work, cyan + yellow area marks the total elastic work and sum of dark and light green area represents the total adhesion work

time similar features were observed. In this study, only a representative set is presented.

\section{3 | RESULTS}

Firm adhesion establishment to CECs is critical for metastasizing tumor cells to reach the brain parenchyma. In this study, single tumor celldecorated tipless cantilevers (Figure 3 ) were used as a probe to directly map adhesive and elastic properties of a confluent endothelial layer. Pseudo-colored maps were reconstructed from the 32 points by 32 lines of $90 \times 90 \mu \mathrm{m}$ area recorded with the decorated probe. Figure 4 shows the reconstructed 3-dimensional topography of the confluent endothelial layer. The individual cells, mostly the nuclei, can be clearly distinguished.

Probably the most ubiquitous intracellular parameters linked strongly to cell behavior are the elasticity and plasticity. In our case, it is challenging to interpret and to extract elasticity in a classical way because most models deal with indentation of an elastic material with a hard indenter. Unfortunately, no specific model can be found to extract elastic properties from the obtained curves in case when two living (arbitrary shaped) cells are pushed against each other.

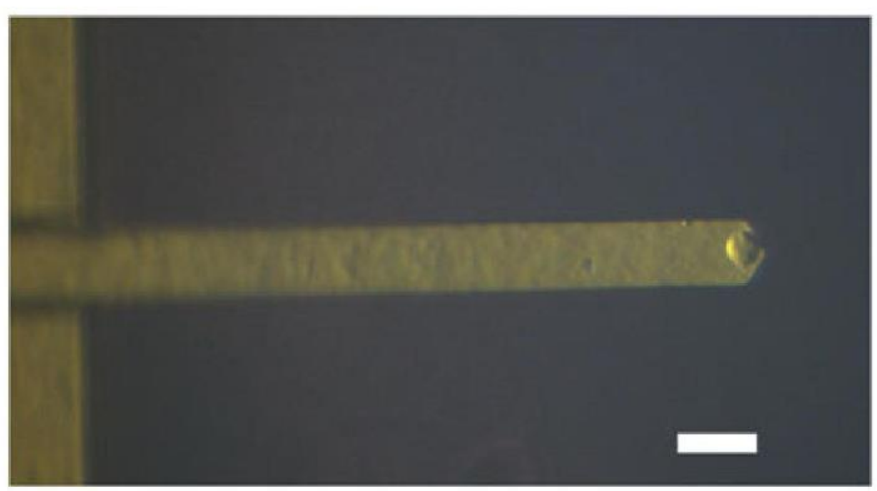

FIGURE 3 Bottom view of a tumor cell immobilized at the end of an atomic force microscope cantilever (scale bar is $50 \mu \mathrm{m}$ )

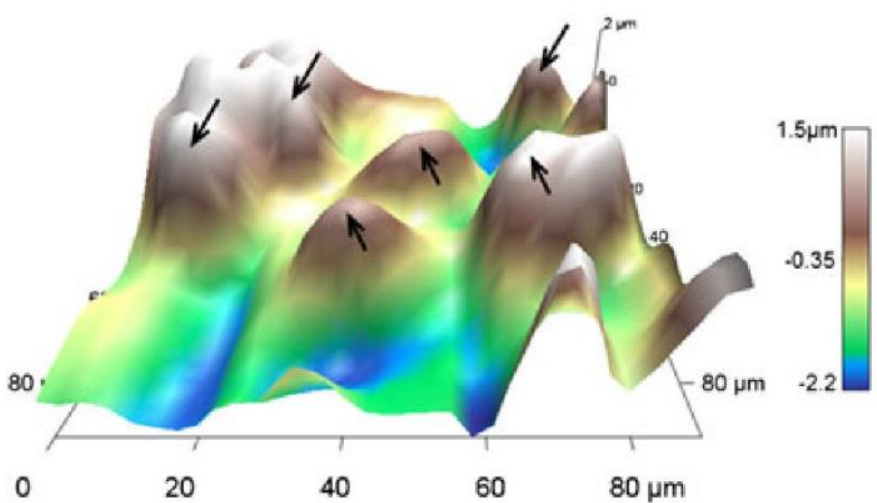

FIGURE 4 Topography map, reconstructed from contact point of individual force curves measured on a confluent layer of cerebral endothelial cells with a melanoma cell-decorated cantilever. Endothelial nucleus regions are marked with arrows

Therefore, to characterize the two contacting, we have decided to calculate the energy needed to push the cells against each other by a preset force of $2 \mathrm{nN}$. The elastic work parameter represents the deformation of the cell by the applied force. This is shown in Figure 2 with the sum of yellow + cyan colored area between the contact point and the maximal deflection point. The resulted elasticity (elastic work) colored topography map is shown in Figure 5. Peripheral regions appear to be more rigid, which might result partly due to a denser cytoskeletal network at these areas. Even more interestingly, neighbor cells might exhibit different characteristics, ranging from harder (light blue color) to 2-fold softer cells (red areas).

After reaching the maximal deflection, the cantilever is pulled back and the applied force becomes reduced (blue line on Figure 2); the cells in contact regain their quasi-original shape. This might imply presence of reorganization of cellular organelles and cytoskeletal elements for both cells as well. The ability of reorganization can be quantified by calculating the amount of work the two cells can still exhibit during cantilever retraction. This is represented by the plastic work parameter (colored by cyan area, Figure 2).

The calculated plasticity would be the elastic minus the plastic work, represented as yellow area on Figure 2. The resulted plasticity map is shown in Figure 6. The value of plasticity close to 0 is associated with a perfectly elastic material, while higher values indicate more plastic material.

Although, the resulted difference map (Figure 6) is similar to the elastic map on Figure 5, remarkable alterations can be observed. Not

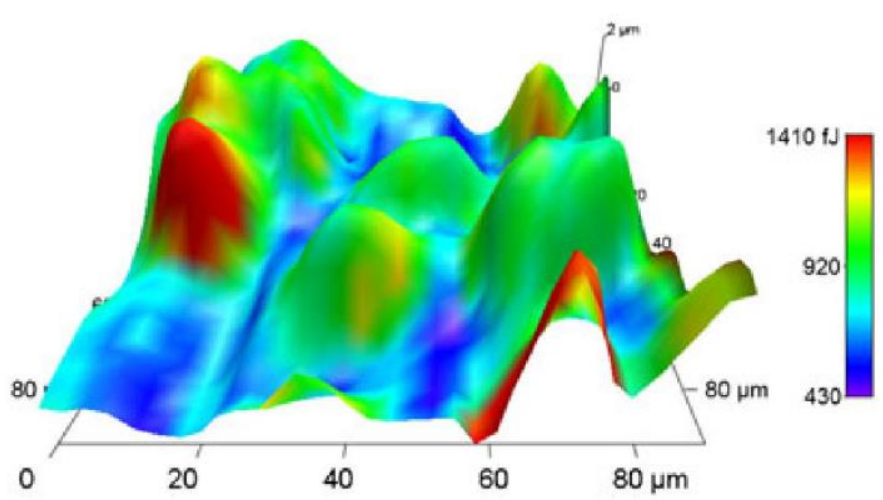

FIGURE 5 Total elastic work colored topography 


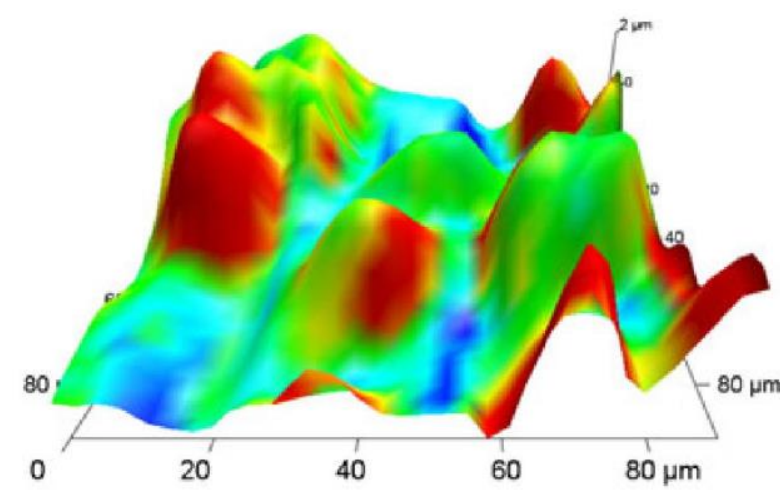

FIGURE 6 Plasticity (ElastW - PlastW) colored topography

only individual cells show different plasticity values, but even alterations within a single cell can be observed. This indicates that regions of the same cell might behave differently.

To characterize the connection strength between the cerebral endothelial layer and the tumor cell, the most widespread parameter is the calculation of the maximal adhesion force (considered as the difference between the maximal downward deflection of the cantilever compared with the initial noncontact level, Figure 2).

The pseudo-colored maximal adhesion force map of the recorded topography is shown in Figure 7. It is noteworthy that elastic and plastic behaviors might influence adhesive properties as well. This would imply that apparent elasticity and plasticity would be strongly related to adhesive properties which would result a very similar color distribution in case of maximal adhesion force as well. In contrary, the maximal adhesion force colored topography (Figure 7) shows completely different distribution. The most adhesive areas (red zones on Figure 7) are not the most elastic (red zones on Figure 5) or even the most plastic zones (red zones on Figure 6). Compared with maximal adhesion force, there is an even more remarkable difference in the adhesion work parameter (Figure 8), which is the total energy needed to separate the contacting cells. Adhesion work is represented in Figure 2 as the sum of light and dark green areas.

The total separation energy denoted with adhesion work can be separated into two different areas: adhesion work1 (dark green are on Figure 2) which is prior to maximal adhesion occurrence and adhesion work2 (light green on Figure 2) as the area where the de-adhesion events take place. First is related to deformation dependent work, while the second sums up the contribution of each active bond which builds up the linkage strength.

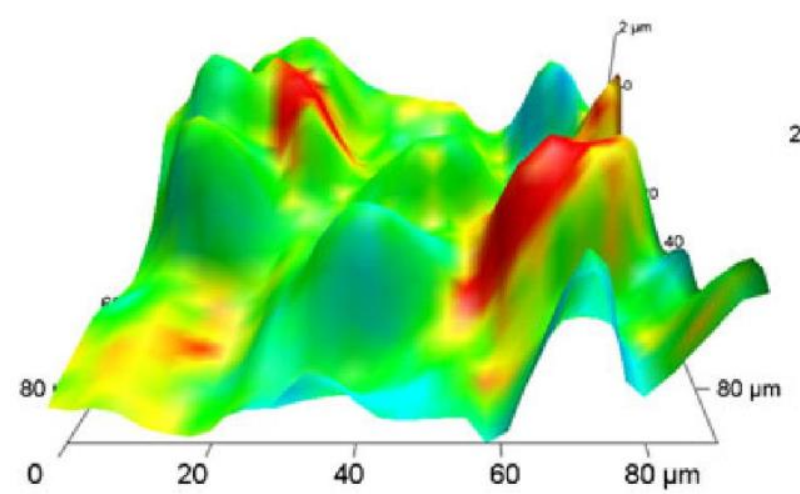

FIGURE 7 Maximal adhesion force colored topography

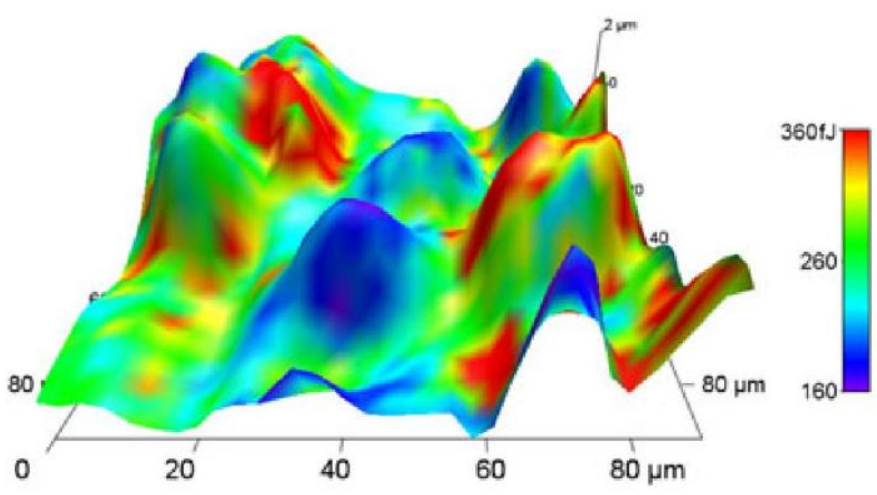

FIGURE 8 Total adhesion work colored topography

The reconstructed topography colored by adhesion work1 is shown in Figure 9. If we compare with the elastic map, then remarkable similarities can be found, which indicates that adhesion work1 is truly elastic deformation dependent.

Quantitatively the adhesion work2 (Figure 10) overcomes work1, which indicates that in most cases, long distance rupture events dominate. These events represent the hallmark of the linkage establishment formation, indicating the number of newly formed active focal contacts between the two cells.

Qualitatively, work2 is not directly linked to work1; moreover, it sometimes shows exactly opposite behavior. Similarities of work2 distribution (Figure 10) to those of maximal adhesion force (Figure 7) indicates that differences in linkage establishment between the neighbor cells can be attributed predominantly to higher number of active cell adhesion molecule bounds. Quantified pondering of work1 and work2 in the total adhesion establishment requires further carefully designed experiments and properly performed analysis.
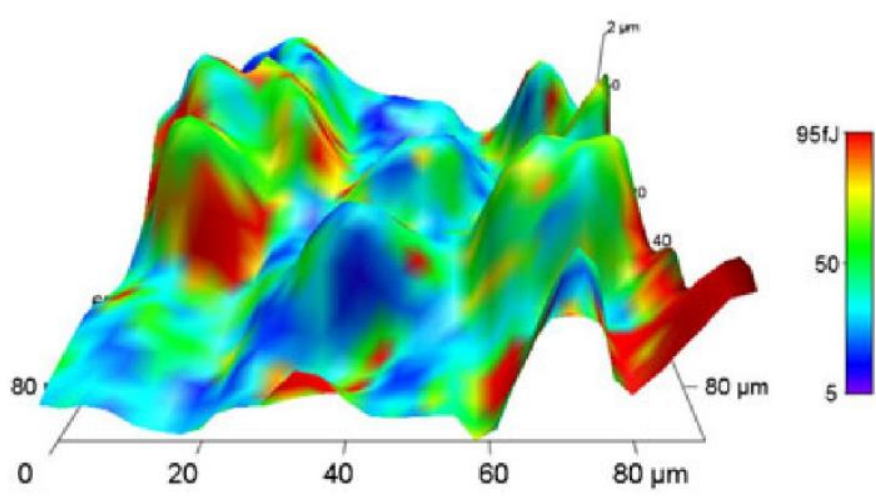

FIGURE 9 Adhesion work1 colored topography

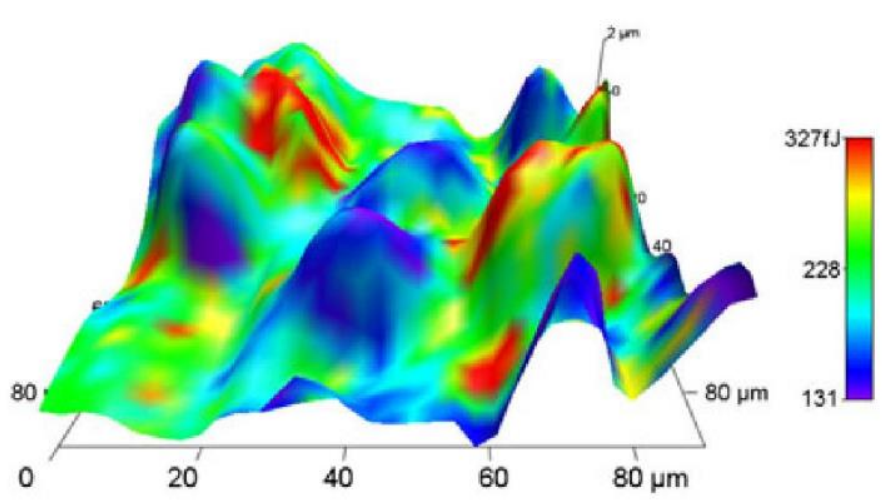

FIGURE 10 Adhesion work2 colored topography 


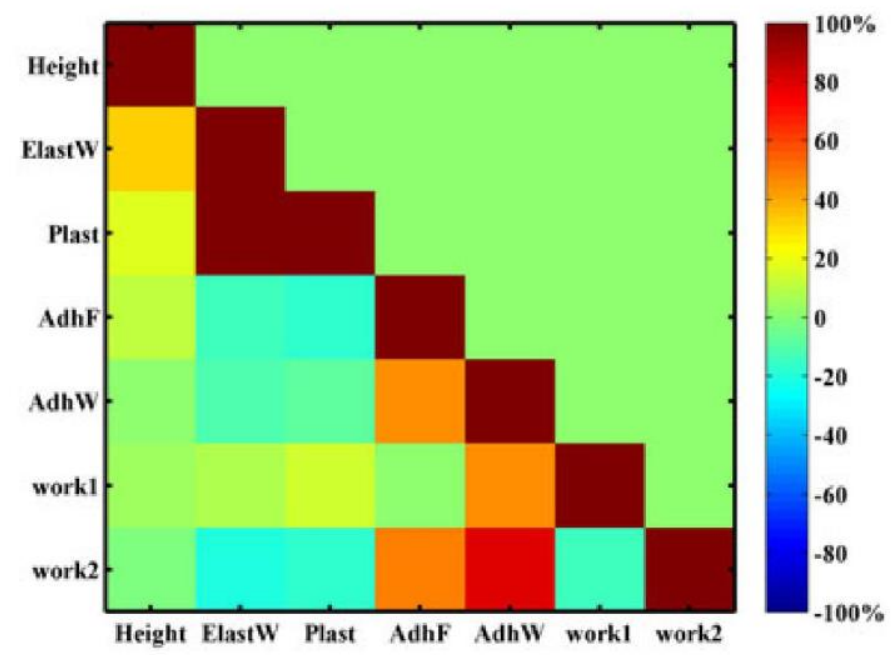

FIGURE 11 Cross-correlation table of the calculated parameters based on Pearson correlation coefficient

To visualize the dependence of each calculated parameter to the others, a cross-correlation plot was constructed. For each parameter pair, a Pearson correlation coefficient was calculated and scaled from perfect anticorrelation -100\% (purple on Figure 11) to perfect correlation as $100 \%$ (brown on Figure 11).

\section{4 | DISCUSSION AND SUMMARY}

Many papers were published with cell-to-cell adhesion measurements as a subject: starting from bacterial adhesion to eukaryotic cells, ${ }^{18}$ quantification of metastatic cell adhesion to each other, ${ }^{19}$ or to endothelium. ${ }^{20}$ Spatial mapping for elasticity or adhesiveness of a living cell layer with another living cell has not yet been reported.

In this study, we modeled the initial step toward brain metastasis formation, namely, the short-term adhesion of a human melanoma cell to a confluent layer of human CECs. It is important to note that during interaction of the two cells, not only the melanoma cell suffers deformation but the endothelial cell as well. As a result, in most of the cases, the recorded and analyzed parameters can be regarded as characteristics of the two cells pushed together as a "whole" system.

We have shown previously that inhibition of the Rho-kinase has increased the number of both the adhered and transmigrated cells. This observation was supported by single-cell force spectroscopy as well. Distribution of the number and average size of maximal adhesion force rupture events were followed. Noteworthy, upon administration of Rho-kinase inhibitor, the enlargement of average rupture size has occurred prior to increase of rupture number. ${ }^{21}$ These alterations might point toward surface-based adhesion increase which might be due to a morphological change. This underlines the importance of a constant probe cell shape during data collection. In our case, the shape of the probe cell was checked prior and after recording the force maps. No considerable difference was found.

Elasticity maps on CECs were published previously, revealing their heterogeneity within a single cell: the area of the nucleus being more elastic than the peripheral regions. ${ }^{22}$ As the immobilized melanoma cell (Figure 3) has much larger dimensions compared with a few nanometer of a tip apex on a cantilever, the intracellular inhomogeneities are practically averaged out. Hence, the differences seen in the presented maps can be associated mostly with individual cells, or with their largest organelle, the nuclei. ${ }^{23}$ Comparing the elastic map (Figure 5) with the adhesive map (Figure 7), it can be clearly seen that not the cells with apparently lower elasticity exhibit the highest adhesiveness. This is true for comparing plasticity map (Figure 6) to maximal adhesion force map (Figure 7) as well. As elastic and plastic properties are strongly linked to cytoskeletal network organization and reorganizing ability, ${ }^{24}$ they may reflect endothelial functionality, including permeability. Locally increased permeability might be linked to putative transmigration sites for invading cancer cells. Adhesive "hot spots" observed in adhesive maps (Figure 7 and similarly on Figure 8) show stronger co-localization with adhesion work2 presented in Figure 10. This suggests that active cell adhesion molecule-based linkage (ruptures) is responsible for higher adhesive properties. Taking into account that these are represented by long range ruptures, tether formation might be crucial in melanoma-endothelial interaction. Here, we have to note that all these results are deducted by simple mechanical measurements and calculations and no invasive labeling or staining was involved in the experiments.

Quantification of the correlation between the measured parameters is presented in Figure 11, showing the color-coded Pearson correlation coefficient for each parameter pair. As we can see in Figure 11, no perfectly independent parameter can be found. The most independent one is apparently the height, which underlines that the spatial distribution of elasticity of the endothelial cell layer contributes only moderately to the obtained results. The total adhesion work similarly to maximal adhesion force is more rupture (work2) than deformation dependent (work1), which suggests the importance of membrane tether formation and breakage during cell-cell interaction.

As a summary, we can say that successful direct mapping of a confluent layer of CECs is reported with a melanoma cell as a probe. Topography-based elastic, plastic, and adhesive maps were reconstructed from the recorded force-distance curves. The reconstructed maps reveal elastic, plastic, and adhesive heterogeneity of the endothelial layer but not directly linking these parameters. All these data point toward that the invading melanoma cell might somehow "screen" for the best places prior to start the transmigration process over the endothelial layer.

These results highlight the importance of cellular mechanics in brain metastasis formation and emphasize the enormous potential toward exploration of intercellular dynamic-related processes.

\section{ACKNOWLEDGEMENTS}

This work was supported by the National Science Fund of Hungary OTKA K116158, PD115697, and the GINOP-2.3.2-15-2016-00020 program. Imola Wilhelm and Attila G Végh were supported by the János Bolyai Fellowship of the Hungarian Academy of Sciences BO/00334/ $16 / 8$ and $\mathrm{BO} / 00598 / 14 / 8$, respectively.

\section{REFERENCES}

1. Fokas E, Steinbach JP, Rödel C. Biology of brain metastases and novel targeted therapies: time to translate the research. Biochim Biophys Acta. 2013;1835:61-75. 
2. Madajewicz S, Karakousis C, West CR, et al. Malignant melanoma brain metastases. Review of Roswell Park Memorial Institute experience. Cancer. 1984;53:2550-2552.

3. Chason JL, Walker FB, Landers JW. Metastatic carcinoma in the central nervous system and dorsal root ganglia. A prospective autopsy study. Cancer. 1963;16:781-787.

4. Sul J, Posner JB. Brain metastases: epidemiology and pathophysiology. Cancer Treat Res. 2007;136:1-21.

5. Wilhelm I, Fazakas C, Krizbai IA. In vitro models of the blood-brain barrier. Acta Neurobiol Exp (Wars). 2011;71:113-128.

6. Gad M, Itoh A, Ikai A. Mapping cell wall polysaccharides of living microbial cells using atomic force microscopy. Cell Biol Int. 1997;21:697-706.

7. Zhang X, Chen A, De Leon D, et al. Atomic force microscopy measurement of leukocyte-endothelial interaction. Am J Physiol Heart Circ Physiol. 2003;286:H359-H367.

8. Binnig G, Quate CF, Gerber C. Atomic force microscope. Phys Rev Lett. 1986;56:930-933

9. Torre B, Ricci D, Braga PC. How the atomic force microscope works? Methods Mol Biol Clifton NJ. 2011;736:3-18.

10. Benoit M. Cell adhesion measured by force spectroscopy on living cells. Methods Cell Biol. 2002;68:91-114.

11. Benoit M, Selhuber-Unkel C. Measuring cell adhesion forces: theory and principles. In: Braga PC, Ricci D, eds. At. Force Microsc. Biomed. Res. New York: Springer Protocols; 2011:355-377.

12. Azeloglu EU, Costa KD. Atomic force microscopy in mechanobiology: measuring microelastic heterogeneity of living cells. In: Braga PC, Ricci D, eds. At. Force Microsc. Biomed. Res. Methods Protoc. New York: Springer, Springer Protocols; 2011:303-329.

13. Ludwig T, Kirmse R, Poole K. Challenges and approaches-probing tumor cell invasion by atomic force microscopy. Educ Top Microsc. 2007;49:11-22.

14. Végh AG, Fazakas C, Nagy K, et al. Adhesion and stress relaxation forces between melanoma and cerebral endothelial cells. Eur Biophys J EBJ. 2012;41:139-145.

15. Weksler BB, Subileau EA, Perrière N, et al. Blood-brain barrier-specific properties of a human adult brain endothelial cell line. FASEB J Off Publ Fed Am Soc Exp Biol. 2005;19:1872-1874.
16. Hutter JL, Bechhoefer J. Calibration of atomic-force microscope tips. Rev Sci Instrum. 1993;64:3342-3342.

17. Sader JE, Sanelli JA, Adamson BD, et al. Spring constant calibration of atomic force microscope cantilevers of arbitrary shape. Rev Sci Instrum. 2012;83:103705

18. Liu Y, Pinzon-Arango PA, Gallardo-Moreno AM, et al. Direct adhesion force measurements between $E$. coli and human uroepithelial cells in cranberry juice cocktail. Mol Nutr Food Res. 2010;54:1744-1752.

19. Omidvar R, Tafazzoli-Shadpour M, Shokrgozar MA, et al. Atomic force microscope-based single cell force spectroscopy of breast cancer cell lines: an approach for evaluating cellular invasion. J Biomech. 2014;47:3373-3379.

20. Reeves KJ, Hou J, Higham SE, et al. Selective measurement and manipulation of adhesion forces between cancer cells and bone marrow endothelial cells using atomic force microscopy. Nanomedicine. 2013;8:921-934.

21. Wilhelm I, Fazakas C, Molnar J, et al. Role of Rho/ROCK signaling in the interaction of melanoma cells with the blood-brain barrier. Pigment Cell Melanoma Res. 2014;27:113-123.

22. Galajda P, Kelemen L, Vegh AG. Micro- and nanotechnology for cell biophysics. Acta Biol Segediensis. 2015;59:303-321.

23. Caille N, Thoumine O, Tardy $\mathrm{Y}$, et al. Contribution of the nucleus to the mechanical properties of endothelial cells. J Biomech. 2002; 35:177-187.

24. Birukova AA, Arce FT, Moldobaeva N, et al. Endothelial permeability is controlled by spatially defined cytoskeletal mechanics: atomic force microscopy force mapping of pulmonary endothelial monolayer. Nanomedicine Nanotechnol Biol Med. 2009;5:30-41.

How to cite this article: Varga B, Fazakas C, Molnár J, Wilhelm I, Domokos RA, Krizbai IA, Szegletes Z, Váró G, Végh AG. Direct mapping of melanoma cell - endothelial cell interactions. J Mol Recognit. 2016;e2603. doi: 10.1002/ jmr.2603 
Annex 2 - Publications

\section{De-adhesion dynamics of melanoma cells from brain endothelial layer}

Varga B., Domokos R. A., Fazakas C., Wilhelm I., Krizbai I. A., Szegletes Z., Gergely C., Váró G., Végh A. G. 


\title{
De-adhesion dynamics of melanoma cells from brain endothelial layer
}

\author{
Béla Varga ${ }^{\mathrm{a}, \mathrm{c}}$, Réka Anita Domokos ${ }^{\mathrm{a}, \mathrm{b}}$, Csilla Fazakas ${ }^{\mathrm{a}}$, Imola Wilhelm ${ }^{\mathrm{a}, \mathrm{d}}$, István A. Krizbai ${ }^{\mathrm{a}, \mathrm{d}}$, \\ Zsolt Szegletes ${ }^{\mathrm{a}}$, Csilla Gergely ${ }^{\mathrm{c}}$, György Váró ${ }^{\mathrm{a}}$, Attila G. Végh ${ }^{\mathrm{a}, *}$ \\ a Institute of Biophysics, Biological Research Centre, Hungarian Academy of Sciences, Szeged, Hungary \\ ${ }^{\mathrm{b}}$ Babes-Bolyai University, Faculty of Physics, Cluj-Napoca, Romania \\ ${ }^{\mathrm{c}}$ Laboratoire Charles Coulomb, UMR 5221 CNRS, - Université de Montpellier, Montpellier, France \\ d Institute of Life Sciences, Vasile Goldiş Western University, Arad, Romania
}

\section{A R T I C L E I N F O}

\section{Keywords:}

Atomic force microscope

Single-cell force spectroscopy

Cell mechanics

Melanoma cell adhesion

Cerebral endothelial cell

Metastatic potential

\begin{abstract}
A B S T R A C T
Metastasis formation is a complex and not entirely understood process. The poorest prognosis and the most feared complications are associated to brain metastases. Melanoma derived brain metastases show the highest prevalence. Due to the lack of classical lymphatic drainage, in the process of brain metastases formation the haematogenous route is of primordial importance. The first and crucial step in this multistep process is the establishment of firm adhesion between the blood travelling melanoma cells and the tightly connected layer of the endothelium, which is the fundamental structure of the blood-brain barrier. This study compares the deadhesion properties and dynamics of three melanoma cells types (WM35, A2058 and A375) to a confluent layer of brain micro-capillary endothelial cells. Cell type dependent adhesion characteristics are presented, pointing towards the existence of metastatic potential related nanomechanical aspects. Apparent mechanical properties such as elasticity, maximal adhesion force, number, size and distance of individual rupture events showed altered values pointing towards cell type dependent aspects. Our results underline the importance of mechanical details in case of intercellular interactions. Nevertheless, it suggests that in adequate circumstances elastic and adhesive characterizations might be used as biomarkers.
\end{abstract}

\section{Introduction}

Occurrence of melanoma has increased worldwide, being responsible for over $80 \%$ of skin cancer deaths [1]. Although metastatic melanoma has relatively low abundance, it shows high resistance to conventional therapies [2,3]. Metastasis to brain is difficult to treat; local surgery, whole brain radio therapy, stereotactic radiosurgery have been the only treatment approaches for a long time [4]. Recently, incorporation of systemic treatments such as molecularly targeted therapies and immunotherapies have emerged as alternatives [5]. Although results of these therapies seem to be promising, at the opposite side, prevention might be important as well. In order to find effective prevention strategies, lacking details of brain metastasis formation needs to be elucidated.

The first obstacle for hematogenously disseminated melanoma cells to enter the brain parenchyma is the tight layer of brain endothelial cells, forming the blood-brain barrier (BBB) [6]. The first step in the highly orchestrated process of melanoma cell transmigration over the brain endothelium is the establishment of firm connection. Several environmental and molecular factors play crucial role in this process which manifests in the arrest of melanoma cells at the luminal surface of the blood vessels [7]. Dynamics of this first but crucial adhesive step might reveal important information about its nature and characteristics.

Atomic force microscopy (AFM) based single-cell force spectroscopy is an emerging method to directly investigate cellular mechanics and the dynamics of intercellular interactions [8,9]. Excluding the immobilization of the melanoma cell, during these measurements there is no need for any staining or other cell-life impairing preparation. Short term (up to a few tens of seconds) adhesive properties can be studied upon analysis of the detaching process of individual cells. Due to the high force-resolution provided by the AFM besides maximal adhesion forces, individual de-adhesion events can be identified and compared accurately, which are the hallmark of the established connection $[10,11]$. Furthermore, even topographical mapping can be reconstructed based on adhesive data, which might reveal alterations at sub cellular level [12].

Basically every active and passive connection might contribute to the established adhesive strength between a blood travelling tumor cell and the endothelial cells. It has been reported, that in case of breast cancer cells the elasticity is inversely proportional to the inter-

\footnotetext{
- Corresponding author at: BRC, Temesvári krt 62, Szeged H-6726, Hungary.

E-mail address: vegh.attilagergely@brc.mta.hu (A.G. Végh).
} 
homocellular adhesion which decreases with metastatic potential [13]. Expression of cell adhesion molecules in endothelial cells influences their adhesive properties to bladder cancer cells [14]. Cell-cell interaction strength might be modulated by extracellular protonation too, hence it plays an important role in tissue invasion of melanoma cells [15]. The thickness of the outer glycocalyx layer on the surface of the endothelial cells is influencing their adhesive properties. Short term hyperglycaemia induces thickening of glycocalyx layer and higher adhesion between lung carcinoma and human aorta endothelial cells [16].

Cell adhesion depends on multiple and even multivariate individual molecular connections, where the individual players are difficult to identify. On single-cell force spectroscopy based mechanical assumptions, hereby we present our latest data on the interaction of three different types of melanoma cells, having altered invasive characteristics, with brain endothelial cells. Our results show that nanomechanical properties can be associated to higher metastatic potential and invasive characteristics may rely on stronger adhesive properties mediated by altered tether formation dynamics.

\section{Materials and methods}

\subsection{Cell culture}

hCMEC/D3 human microvascular cerebral endothelial cells (shortly D3 [17]) were grown on rat tail collagen-coated dishes in EBM-2 medium (Lonza) supplemented with EGM-2 Bullet Kit (Lonza).

Highly invasive A2058 human melanoma cells (obtained from the European Collection of Cell Cultures) were maintained in EMEM (Sigma) supplemented with 5\% FBS (Sigma). The A2058 cells were derived from metastatic site (lymph node) of a 43 years old Caucasian man. A375 human metastatic melanoma cells were derived from skin and the less invasive WM35 human primary melanoma cells were cultured in DMEM (GIBCO), supplemented with 5\% FBS. During culturing, cells were kept at $5 \% \mathrm{CO}_{2}$ atmosphere at $37^{\circ} \mathrm{C}$.

All three cell types are BRAF: V600E mutant, NRAS wild type. Melanoma cells were labelled with CellTracker ${ }^{\mathrm{TM}}$ Red CMTPX Dye (Life Technologies), ensuring that they can be clearly identified prior to immobilization at the end of the cantilever.

\subsection{Atomic force microscope}

All experiments were performed with an Asylum Research MFP-3D atomic force microscope (Asylum Research, Santa Barbara, CA; driving software written in IgorPro 6.34A, Wavemetrics), mounted on the top of a Zeiss Axiovert 200 optical microscope for optical positioning.

The experiments were carried out with rectangular tipless gold coated cantilevers, having a nominal spring constant of $50 \mathrm{pN} / \mathrm{nm}$, resonant frequency of $10 \mathrm{kHz}$ in air (MikroMasch, Tallinn, Estonia), which drops to $3 \mathrm{kHz}$ in water. The spring constant of the cantilever was determined each time by thermal calibration [18-20].

Cancer cells were immobilized at the very end of the tipless cantilever using a Concanavalin-A mediated linkage which is described in details elsewhere $[21,22]$. All experiments were conducted in serum free Leibovitz medium at $37{ }^{\circ} \mathrm{C}$ within $2 \mathrm{~h}$ after the cells were taken out from the incubator. According to our experience, they preserve their viability far beyond this period.

\subsection{Single cell force spectroscopy}

During a force measurement cycle, a cancer cell immobilized at the end of a tipless cantilever was brought into contact with surface-adherent endothelial cells. The schematic representation can be found in Fig. 1.

Each cycle consisted of approaching the cell-loaded cantilever to the endothelial layer until the pre-set deflection was reached and pulling it back to initial position. Force curves were recorded at constant loading

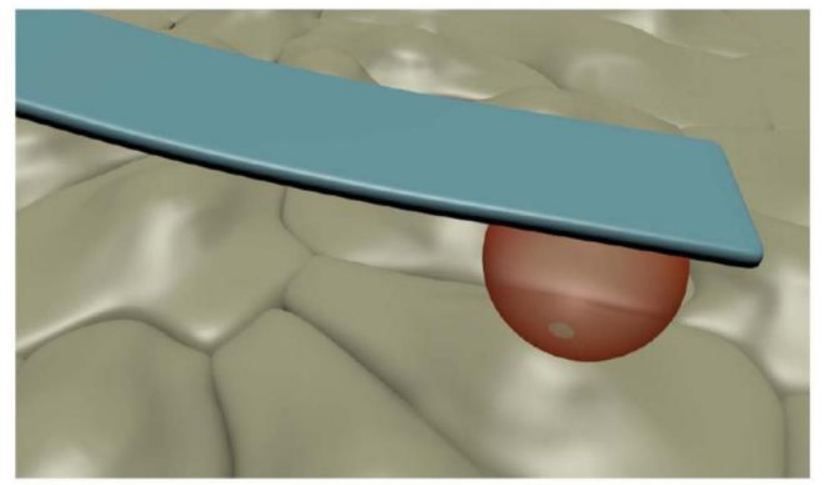

Fig. 1. Schematic representation of experimental arrangement.

Melanoma cell labelled with CellTracker ${ }^{\mathrm{TA}}$ Red dye immobilized at the end of a tipless cantilever, pushed to a confluent layer of endothelial cells.

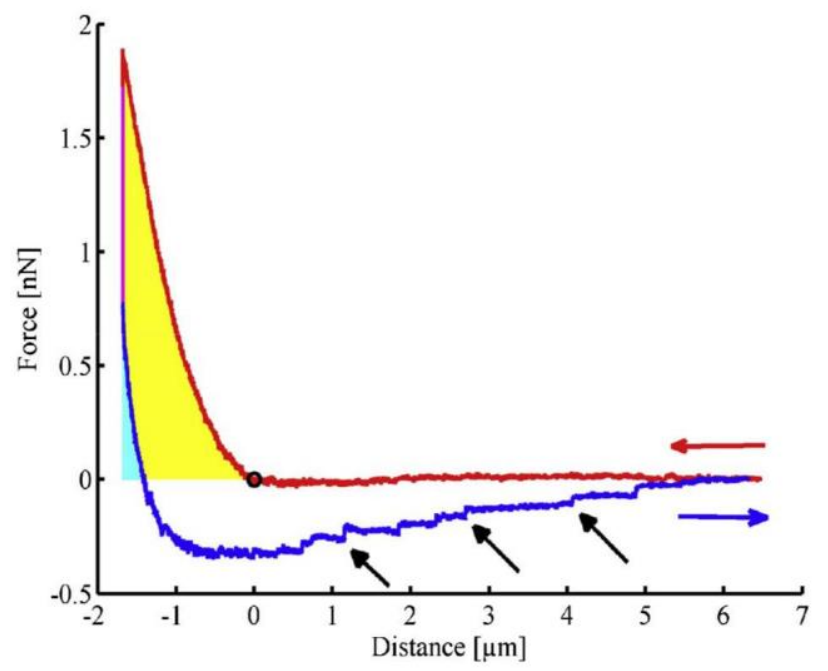

Fig. 2. A representative force-distance curve. Trace is drawn in red, retrace in blue. Contact point is marked with "o", cyan area marks the remanent work, cyan + yellow area marks the total work, black arrows indicate the place of located rupture events.

speed $(2 \mu \mathrm{m} / \mathrm{s})$ and sampling frequency $(2 \mathrm{kHz})$. Total force distance was kept at $8 \mu \mathrm{m}$ with maximum load of $2.0 \mathrm{nN}$. After the maximal load was reached, a dwell time of $3 \mathrm{~s}$ was applied before the retraction of the cantilever.

Fig. 2 shows a typical force-distance curve: point of contact is marked with "o", approaching phase is drawn in red while blue represents retraction, as pointed by accordingly coloured arrows.

\subsection{Data analysis}

A homemade MATLAB routine was used to extract all parameters. A relative elasticity, similar to the elasticity index in case of polymers [23], was calculated as the ratio between the remanent work (cyan area, Fig. 2) and the total work (cyan + yellow area, Fig. 2). This parameter can take values between 0 and 1 , where 0 represents perfectly plastic while 1 perfectly elastic behaviour. Apparent Young's modulus was extracted from individual force curves using the formula for spherical indenters [24]. Here we have to mention, that the values obtained can only be the subject of a qualitative comparison, since all forces for different cell types were recorded with the same parameters.

Values of maximal adhesion force were considered as the difference between the force at the maximal downward deflections of the cantilever compared to the initial value during non-contact state. Disruption events were identified as sudden deflection changes during retraction. Only those were considered where the level difference was higher than threefold the standard deviation at the end of the respective curve. Rupture size was calculated as a level difference of mean of 5 point 
before and after the place of occurrence. Rupture length represents the distance from the place of maximal adhesion force (maximal deflection) and the position of the last point before an identified disruption event.

Distribution of rupture size and length are represented by histograms showing the probability to find a given value within the whole data population calculated for each cell type. Using this representation, the eventual distortions due to different abundances can be avoided. In case of rupture length, a logarithmic scale was chosen to balance the unequal representation for abundant and rare events.

The calculated values for relative elasticity, maximal adhesion force and number of rupture events are presented with the help of "box and whisker plots". In order to cover the level, spread and symmetry of the data values, box plots show the median, the approximate quartiles and the lowest and highest data points [25]. This representation has the advantage to show eventual skewness in the distribution of the values, while treats extreme values as outliers: in our case 1.5 fold the interquartile range away from the top or bottom of the box was considered as outlier and marked with "plus" signs.

Kruskal-Wallis rank test was performed in order to compare the calculated groups, since this test does not presume normal distribution of values and gives accurate results for relatively small sample sizes as well. Significant differences were accepted and marked at $\mathrm{p}<0.05$ (*) $^{*}$ level. These are marked with black linking bars between the groups in Fig. 3, Fig. 4, Fig. 5 and Fig. 6. In order to quantify the dependence of rupture numbers on relative elasticity the Pearson's correlation coefficient was calculated.

Experiments were repeated more than five times for each type of melanoma cell, in each case 40 curves at four different places (10 curves at each place) were recorded with the very same pre-set parameters.

\section{Results}

Adhesion of three different types of human melanoma cells to a confluent layer of human brain endothelial cells was measured. In our dynamic experiments the three types of melanoma cells of different metastatic characteristics were represented by WM35, A2058 and A375 cell lines, while the endothelial layer was formed by the hCMEC/D3 (shortly D3) cell line. As an internal comparison in each case prior to measuring intercellular interactions the very same melanoma cells were contacted to a cell free area of the Petri dish as well. Same parameters (load, force speed, dwell time in contact) were used in case of all cell types.

In order to achieve a more illustrative comparison of elastic behaviour, a relative dimensionless parameter was used: the relative

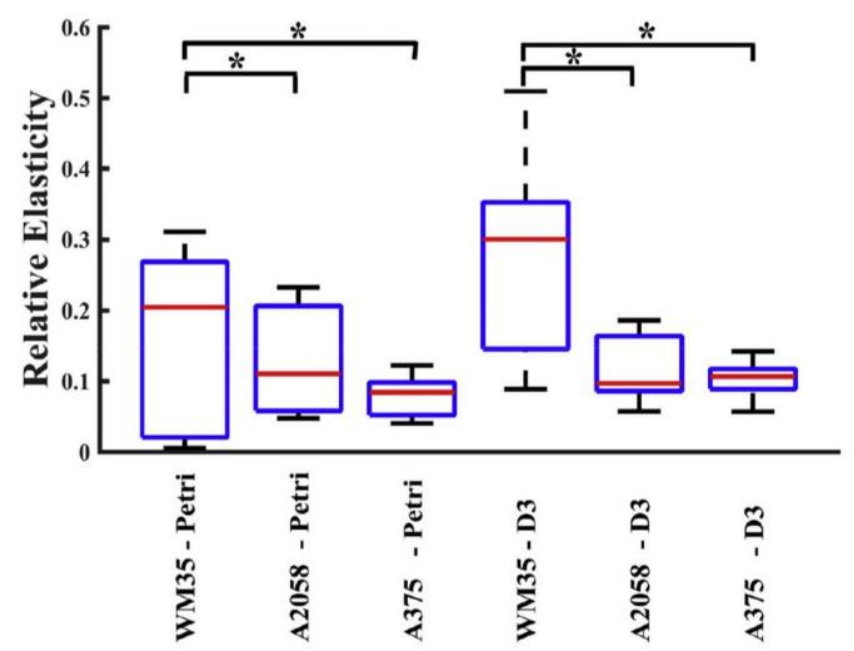

Fig. 3. Comparison of relative elasticity of the three studied cell types, when pushed towards a bare Petri dish surface and a confluent endothelial layer successively. Significantly different groups are marked with black link bars, * signs $(\mathrm{p}<0.05)$.

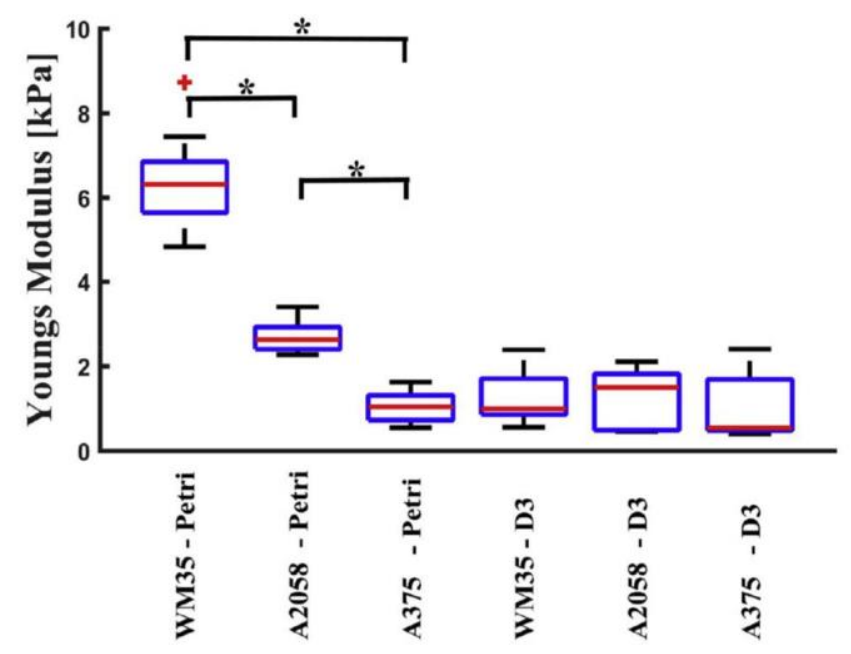

Fig. 4. Calculated values of apparent Young's modulus of the studied cell types when pushed to a bare Petri dish surface and a confluent endothelial layer, respectively. Plus signs represent outlier values. Significantly different groups are marked with black link bars, * signs $(\mathrm{p}<0.05)$.

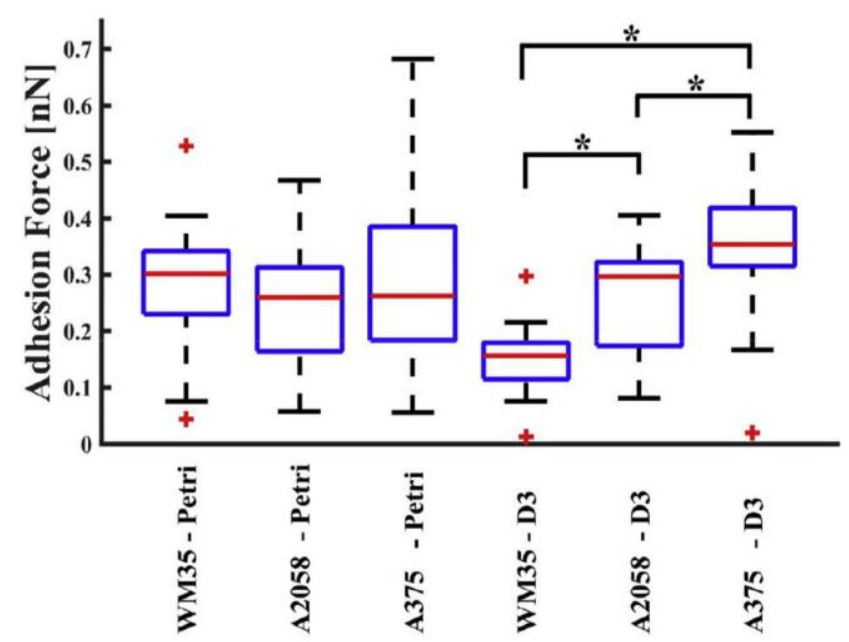

Fig. 5. Maximal adhesion force between the studied cell types when pushed to a bare Petri dish surface and a confluent endothelial layer, respectively. Plus signs represent outlier values. Significantly different groups are marked with black link bars, * signs (p $<0.05)$.

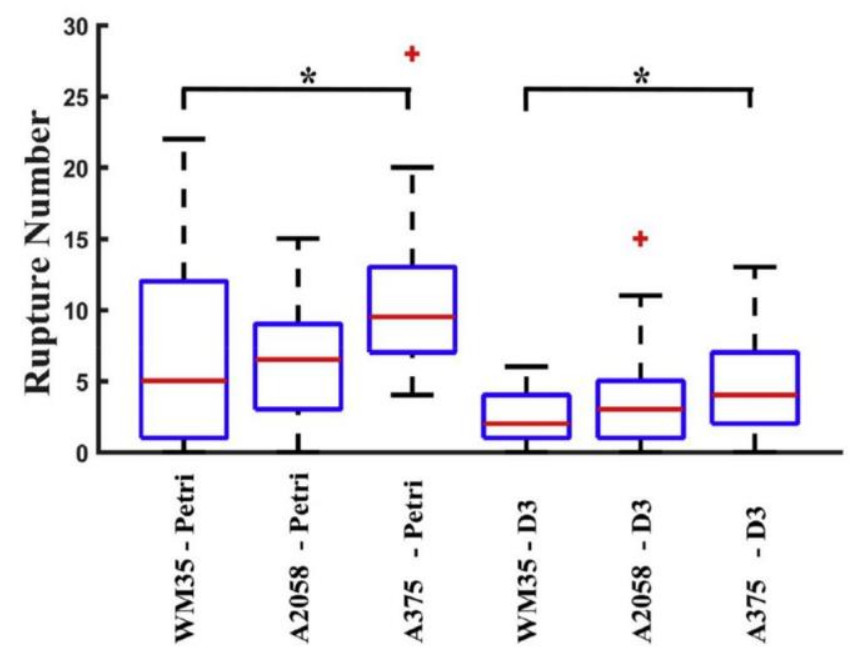

Fig. 6. Comparison of occurred number of rupture events per force curve for the three studied cell types, when pushed to a bare Petri surface and a confluent endothelial layer. Plus signs represent outlier values. Significantly different groups are marked with black link bars, * signs $(\mathrm{p}<0.05)$. 
elasticity (see section of Materials and methods for details). Fig. 3 shows the calculated relative elasticity of the studied cell types. Similar dependence pattern can be observed when the melanoma cells are pushed to bare Petri dish and to endothelial cells. This underlines that the measured parameters reflect mainly the characteristics of the melanoma cells, hence the endothelial layers can be considered practically invariable. As Fig. 3 depicts, a strong dependence can be observed between the relative elasticity and the melanoma cell type. WM35 cells apparently show a more elastic, while A2058 and A375 cells a more plastic behaviour upon deformation. The slightly higher values when two cells are pushed together might be attributed to the presence of the endothelium. The most frequent parameter to characterize cellular elasticity is the value of the Young's modulus. Fig, 4 depicts the values obtained for the studied cell types when pressed alone to Petri dish and to a confluent endothelial layer. WM35 cells appeared to have the highest Young's modulus, succeeded by A2058 and A375 cells. Interestingly, when these cells were pushed against a confluent layer of endothelial cells, the observed differences practically vanished.

In order to characterize the linkage strength between the melanoma cells and the endothelium, first the maximal adhesion force was calculated. When the melanoma cells are pushed to a bare Petri dish, all show similar adhesion strength, while a clear dependence on cell type can be observed in case of endothelium (see Fig. 5). If we compare the results in Fig. 3 with those in Fig. 5, one can observe that the relative elasticity is inversely correlated with maximal adhesion force.

As the de-adhesion process is not continuous, individual rupture like events can be distinguished on the recorded force plots (see Fig. 2 for explanation and example). Fig. 6 shows the number of these events for the studied melanoma cells. In both recorded sets the dependence is rather similar, more aggressive cells establish more active connections while brought into contact with same load and dwell time. The exact reason why higher number of ruptures can be identified when the melanoma cells are pushed to a bare Petri dish compared when brought in contact with the endothelium is still under debate. Relative elasticity can be an important factor in this process, but the exact reasons are unclear since it shows a negative but weak correlation with the observed number of ruptures (see Fig. 7). However, a remarkable correlation can be observed which is similar for both studied cases (Petri surface and endothelial layer) assuming that the most formed connections occur in case of A375 cells, while the least are for the WM35 cells.

Besides the number of apparent bonds their size and occurring place (length) carries important information as well. The apparent rupture size can be associated mostly with the molecular background of the studied cells. Slightly shifted and more skewed distribution patterns can be observed when the melanoma cells are pushed to Petri dish (Fig. 8). However, in case of confluent endothelium the distribution patterns are similar (Fig. 9). The most frequent values are around $30 \mathrm{pN}$, which is independent of the substrate. The relative abundance varies with the measured cell type, from WM35 with lower values to A375 with higher frequency values showing a slight shift towards lower rupture size values.

Even more interesting feature is at what distance occur these rupture events from the contact point. The distribution of these distances in case of melanoma-Petri and melanoma-endothelium are plotted in Figs. 10 and 11. As the cells undergo a slight shape change during their contact (mostly the melanoma, as the endothelial cell is adhered and flattened), the highest peaks can be observed below one micrometre. This is the zone where simultaneous events occur and their number is dependent on the contact area. After the initial quick shrinkage of this area, rupture length distribution can be mainly associated with membrane dynamics, and spontaneous unlocking of cell adhesion molecules and other molecular cross talks.

The higher frequencies of values below one micrometre can be associated with the apparent relative elasticity of the melanoma cells. As they appear more elastic, they regain their original size quicker, resulting most of de-adhesion events at close distances to contact point.
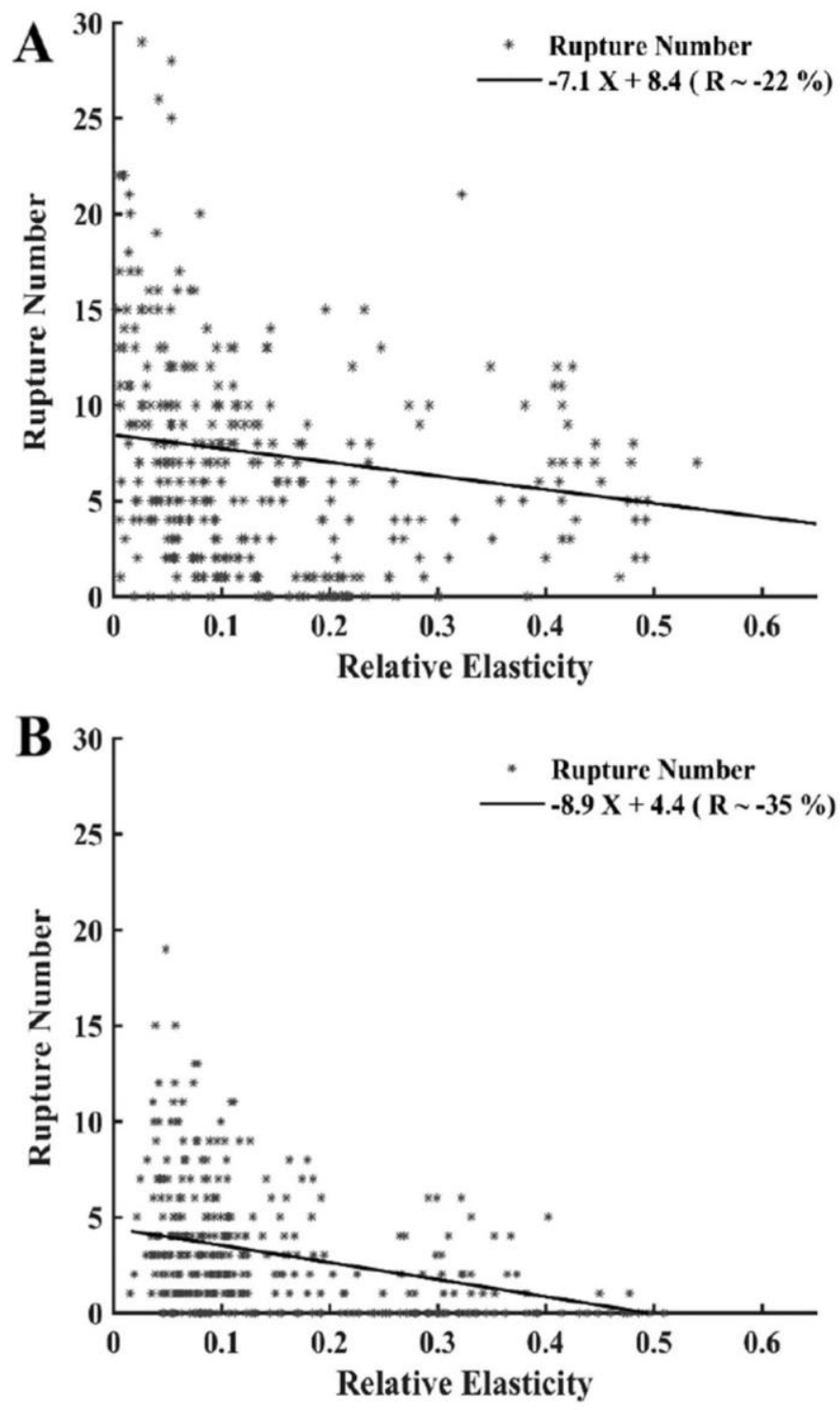

Fig. 7. Relative elasticity $v s$ number of occurred ruptures in case of all melanoma cell Petri surface(A) and melanoma cell - endothelial cell interaction (B). Solid black line marks the simple linear regression, with the negative Pearson's coefficient of -0.22 (A) and $-0.35(\mathrm{~B})$ respectively.

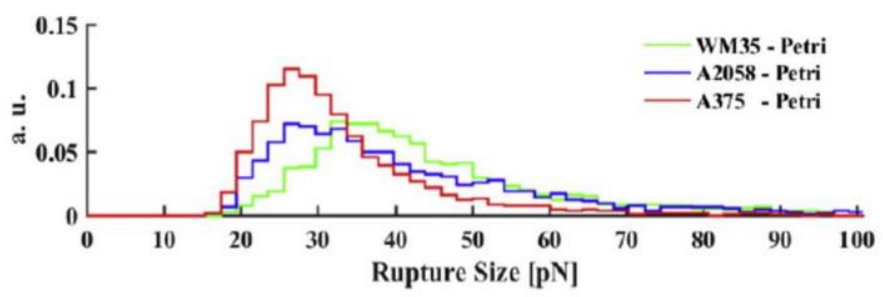

Fig. 8. Rupture size probability distribution of the rupture size between the studied melanoma cells when pushed to Petri dish surface.

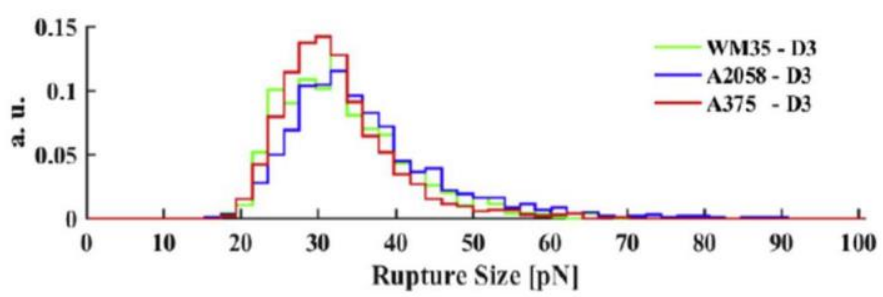

Fig. 9. Rupture size probability distribution of the rupture size between the studied melanoma cells when pushed to a confluent layer of endothelial cells. 


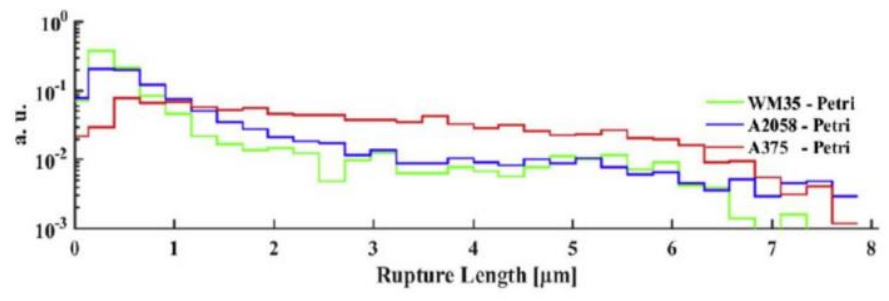

Fig. 10. Probability distribution of the rupture length for the de-adhesion events occurred during melanoma cell - Petri dish contact.

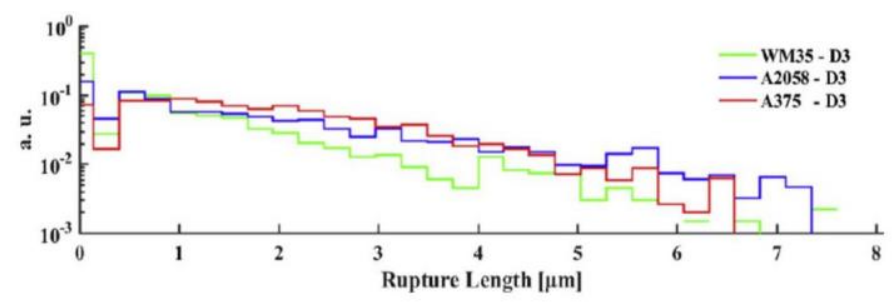

Fig. 11. Probability distribution of the rupture length for the de-adhesion events occurred in case of melanoma cell - endothelial interaction.

De-adhesion events occurring at high distances ( $>2 \mu \mathrm{m}$ from contact point) can be predominantly associated with membrane tether formations, regarded as membrane nanotubes extruded from a large membrane reservoir observed in both cases, melanoma cell - Petri and melanoma cell - endothelial interactions.

\section{Discussion \& summary}

Arrest of melanoma cells on the inner surface of the brain blood vessels is a crucial but not a sufficient step in the process of brain metastasis formation. Nevertheless, those blood-travelling melanoma cells which show higher adhesiveness to the brain endothelium might have higher chance to successfully colonize the brain. The mechanism of melanoma cell arrest and establishment of firm contact to brain endothelial cells is still only partially described and understood. Here we show a comparison of the dynamics of the first short term contact of three types of melanoma cells (WM35, A2058 and A375) with brain endothelial cells. The WM35 is a cutaneous, non-metastatic cell line, while A2058 and A375 are highly metastatic cell lines [26]. The difference in the metastatic potential between the A2058 cells and A375 cells has not been clearly established so far. Both cell lines are VCAM-1 negative [27], however, Rolland et al. found that transmigration of A2058 cells across bovine brain capillary endothelial cells, was twice as effective compared to A375 [28]. Both A2058 and A375 cells show similar adhesive properties to brain endothelial cells with similar junction damaging potential in static models $[29,30]$. Pogoda et al. denotes A375 cells as highly invasive [31] and compares its elasticity to WM35 emphasizing that the former has lower elastic modulus (which correlates well with our results). The above mentioned studies deal with the total transmigration process of the melanoma cells across the endothelium, which includes but is not restricted to initial affinity dynamics of firm adhesion establishment. Furthermore, these studies were conducted on static conditions.

Intercellular adhesion dynamics depends on multiple factors, amongst which we can find apparent whole cell elasticity, visco-elastic properties, surface charge density, surface linked adhesion molecule distribution and glycocalyx thickness as well. The parameters investigated by us include relative elasticity, maximal adhesion force, size and location of de-adhesive rupture events. Referring to the first short term contact to brain endothelial cells our data suggests the following order from lower to higher metastatic potential - WM35, A2058 and A375 - based on apparent affinity to brain endothelial cells.

Unfortunately, no proper model exists to obtain elastic or plastic properties when two cells are pushed against each other. Therefore, in order to compare the elastic properties of the studied cell types in situ. Similarly to the plasticity index [23] we have used the relative elasticity, or elastic index, as a dimensionless comparing factor, which consists of the ratio between the remanent and total work needed to obtain the pre-set load (for details see section of Materials and methods). In our case the perfect elasticity would be 1 while total plasticity 0 . As presented in Fig. 3 the obtained relative elasticity values are similar both in the case when melanoma cells were pushed against the Petri dish surface and against the endothelial layer. This indicates that the calculated relative elasticity is predominantly the property of the melanoma cells and the endothelial cells have low contribution. The highest relative elasticity values were shown by WM35 cells, followed by A2058 and A375 cells respectively. These results are in line with the findings of Lekka et al., which demonstrate a higher Young's modulus for WM35 cells compared to A375 cells [32]. Furthermore, Xu et al. has reported the same relation between Young's Modulus and metastatic potential in case of ovarian cancer cells probed with a spherical indenter [33]. In our case Fig. 4 depicts similar relation in case when the studied melanoma cells were pushed to a Petri dish surface: WM35 has the highest apparent Young's modulus succeeded by A2058 and A375 cells respectively. This relation vanishes when the same cells were pushed to endothelial cells. The supporting connection between apparent Young's modulus and invasiveness is an important control, which in case of melanoma-endothelial interaction might be hindered by several factors. In our opinion the calculated apparent Young's modulus (Fig. 4) is less sensitive to the characteristics of the probing melanoma cell, while value of relative elasticity (Fig. 3) is more suitable for proper comparison in our case.

Cell elasticity is mainly determined by cytoskeletal structures and low elasticity may reflect disorganization of the cytoskeletal characteristic to aggressive cancer cells [34]. Besides mechanical properties of a cell, physical aspects of cell-cell interaction may influence cellular behaviour, too. The force necessary to move apart two cells (adhesion force) reflects well the strength of the connection. Maximal adhesion force is a well-established parameter to characterize adhesion properties of biological samples, ranging from individual molecules to living cells [10]. Fig. 5 shows the comparison of the calculated maximal adhesion forces between the three studied cell types contacting a bare Petri dish and the endothelial layer. In case of the Petri dish, no differences can be found between the investigated cells suggesting a nonspecific interaction between the plastic surface of the Petri dish and the cells. In contrast, when melanoma cells were pushed against the endothelium a clear difference can be observed. WM35 cells show the lowest adhesion force, higher values can be observed in the case of A2058 cells, whereas the A375 cells show the highest adhesion forces from brain endothelial cells. This indicated that the more aggressive melanoma cell types adhere stronger to the cerebral endothelium possibly leading to an enhanced transmigratory and metastasis forming capacity. Interestingly, - although independent of cell type - adhesion forces are higher in case of Petri dish - melanoma cell contacts compared to melanoma cell - endothelial cell contact. An explanation of this observation could be the specially treated, cell culture grade plastic surface to which cultured cells can easily adhere.

The process of de-adhesion is not continuous; it can be decomposed into a series of de-adhesion events. Intercellular adhesion is largely determined by specific cell-cell adhesion molecules and non-specific interactions of the glycocalyx. When pulling apart two adhering cells these interactions have to be released. These bond ruptures can occur close to the contact point if the adhesion molecules are well anchored to the underlying cytoskeleton. In case of non-anchored adhesion molecules during the release these are either ripped out from the membrane or form a tether (membrane nanotube), depending on the membrane properties [35]. Dynamics of these tethers highly depends on the physical parameters (pulling speed, temperature) as reported in case of rolling neutrophils [36] and adhesion of the monocytic cell line THP-1 to a surface coated with ICAM-1 [37]. In our case membrane nanotube 
formation can also be observed during the release of the contact.

Comparing the number of the observed rupture events (Fig. 6), which is directly related to active contact points, the same relation can be observed as for the maximal adhesion force. This implies the presence of a surface size related active binding process, which has higher weighting in case of more inelastic cells (see Fig. 3). Size distribution of the active de-adhesive events is depicted in Fig. 8 and Fig. 9 for melanoma - Petri surface and melanoma - endothelial contact respectively. The most abundant values are around $30 \mathrm{pN}$, presenting a slight downshift with the cell type for both cases. According to literature, this value is associated with de-coupling of membrane bound adhesion molecules in case of membrane tether ruptures [38], although it is very close to the adhesion forces reported in case of E-cadherin fragments [39].

Additionally, the occurrence place of these de-adhesion events is an important characteristic of membrane dynamics, since in many cases they appear at several micrometre distances from the contact point. Since physical parameters (pulling speed, contact time, temperature) were not altered through the experiments, all melanoma cell types were subjected to the same set of external parameters. Hence, differences in release dynamics are associated to alterations in membrane or cytoskeletal network properties. Based on our data, we can conclude that the shift towards higher distances of occurrence places of detected de-adhesion events (Figs. 10 and 11) might indicate that the role of tether based adhesive properties of invading melanoma cells cannot be neglected in the metastasis formation process. Tether formation and dynamics might contribute considerably to site selection of melanoma cells ending in successful arrest on the surface of brain endothelial layer. Although it is not an easy task to quantify the weighting of tether based adhesive contribution within the full detachment force, it might grant metastatic melanoma cells one step forward to successful colonization.

\section{Conclusion}

Finally, as a conclusion we can say that we have used successfully the AFM based single cell spectroscopy for comparison and analysis of adhesion force dynamics between a confluent brain endothelial layer and three different type of melanoma cells presenting different invasive characteristics. Apparent mechanical properties such as elasticity, maximal adhesion force, number, size and distance of individual rupture events showed altered values pointing towards cell type dependent aspects. Our results underline the importance of mechanical details in case of intercellular interactions. Nevertheless, it suggests that in adequate circumstances elastic and adhesive characterizations might be used as biomarkers.

\section{Transparency document}

The http://dx.doi.org/10.1016/j.bbagen.2017.10.013 associated with this article can be found, in online version.

\section{Acknowledgement}

This work was supported by the National Science Fund of Hungary OTKA K116158, PD115697, PD121130, FK124114, the GINOP-2.3.215-2016-00001 / 00020 / 00034 and GINOP-2.3.3-15-2016-00030 programs. Imola Wilhelm and Attila G. Végh were supported by the János Bolyai Fellowship of the Hungarian Academy of Sciences BO/ 00334/16/8 and BO/00598/14/8 respectively.

The authors declare no conflict of interest.

\section{References}

11] J. Paluncic, Z Kovacevic, P.J. Jansson, D. Kalinowski, A.M. Merlot, M.L.-H. Huang, H.C. Lok, S. Sahni, D.J.R. Lane, D.R. Richardson, Roads to melanoma: key pathways and emerging players in melanoma progression and oncogenic signaling, BBA-Mol.
Cell. Res, 1863 (2016) 770-784.

[2] C. Abildgaard, P. Guldberg, Molecular drivers of cellular metabolic reprogramming in melanoma, Trends Mol. Med. 21 (2015) 164-171.

[3] M. Batus, S. Waheed, C. Ruby, L. Petersen, S.D. Bines, H.L. Kaufman, Optimal management of metastatic melanoma: current strategies and future directions, Am. J. Clin. Dermatol. 14 (2013) 179-194.

[4] I.J. Fidler, G. Schackert, R.D. Zhang, R. Radinsky, T. Fujimaki, The biology of melanoma brain metastasis, Cancer Metastasis Rev. 18 (1999) 387-400.

[5] S. Jang, M.B. Atkins, Treatment of melanoma CNS metastases, Cancer Treat. Res. 167 (2016) 263-279.

[6] I. Wilhelm, J. Molnar, C. Fazakas, J. Hasko, I.A. Krizbai, Role of the blood-brain barrier in the formation of brain metastases, Int. J. Mol. Sci. 14 (2013) 1383-1411.

[7] S. Kumar, V.M. Weaver, Mechanics, malignancy, and metastasis: the force journey of a tumor cell, Cancer Metastasis Rev. 20 (2009) 113-127.

[8] A. Ahmad Khalili, M.R. Ahmad, A review of cell adhesion studies for biomedical and biological applications, Int. J. Mol. Sci. 16 (2015) 18149-18184.

[9] M.M. Yallapu, K.S. Katti, D.R. Katti, S.R. Mishra, S. Khan, M. Jaggi, S.C. Chauhan, The roles of cellular nanomechanics in cancer, Med. Res. Rev. 35 (2015) 198-223.

10] J. Helenius, C.-P. Heisenberg, H.E. Gaub, D.J. Muller, Single-cell force spectroscopy, J. Cell Sci. 121 (2008) 1785-1791.

[11] P. Panorchan, M.S. Thompson, K.J. Davis, Y. Tseng, K. Konstantopoulos, D. Wirtz, Single-molecule analysis of cadherin-mediated cell-cell adhesion, J. Cell Sci. 119 (2006) 66-74

[12] B. Varga, C. Fazakas, J. Molnár, I. Wilhelm, R.A. Domokos, I.A. Krizbai, Z. Szegletes, G. Váró, A.G. Végh, Direct mapping of melanoma cell - endothelial cell interactions, J. Mol. Recognit. 30 (2016) e2603.

[13] R. Omidvar, M. Tafazzoli-Shadpour, M.A. Shokrgozar, M. Rostami, Atomic force microscope-based single cell force spectroscopy of breast cancer cell lines: an approach for evaluating cellular invasion, J. Biomech. 47 (2014) 3373-3379.

[14] V. Sundar Rajan, V.M. Laurent, C. Verdier, A. Duperray, Unraveling the receptorligand interactions between bladder cancer cells and the endothelium using AFM, Biophys. J. 112 (2017) 1246-1257.

[15] V. Hofschröer, K.A. Koch, F.T. Ludwig, P. Friedl, H. Oberleithner, C. Stock, A. Schwab, Extracellular protonation modulates cell-cell interaction mechanics and tissue invasion in human melanoma cells, Sci Rep 7 (2017) 42369.

[16] K.E. Malek-Zietek, M. Targosz-Korecka, M. Szymonski, The impact of hyperglycemia on adhesion between endothelial and cancer cells revealed by single-cell force spectroscopy, J. Mol. Recognit. 30 (2017) e2628.

[17] B.B. Weksler, E.A. Subileau, N. Perrière, P. Charneau, K. Holloway, M. Leveque, H. Tricoire-Leignel, A. Nicotra, S. Bourdoulous, P. Turowski, D.K. Male, F. Roux, J. Greenwood, I.A. Romero, P.O. Couraud, Blood-brain barrier-specific properties of a human adult brain endothelial cell line, FASEB J. 19 (2005) 1872-1874.

[18] J.L. Hutter, J. Bechhoefer, Calibration of atomic-force microscope tips, Rev. Sci. Instrum. 64 (1993) 1868-1873.

[19] J.E. Sader, J.A. Sanelli, B.D. Adamson, J.P. Monty, X. Wei, S.A. Crawford, J.R. Friend, I. Marusic, P. Mulvaney, E.J. Bieske, Spring constant calibration of atomic force microscope cantilevers of arbitrary shape, Rev. Sci. Instrum. 83 (2012) 103705.

20] M.J. Higgins, R. Proksch, J.E. Sader, M. Polcik, S. Mc Endoo, J.P. Cleveland, S.P. Jarvis, Noninvasive determination of optical lever sensitivity in atomic force microscopy, Rev. Sci. Instrum. 77 (2006) 013701.

[21] A.G. Végh, C. Fazakas, K. Nagy, I. Wilhelm, J. Molnár, I.A. Krizbai, Z. Szegletes, G. Váró, Adhesion and stress relaxation forces between melanoma and cerebral endothelial cells, Eur. Biophys. J. 41 (2012) 139-145.

[22] X. Zhang, A. Chen, D. De Leon, H. Li, E. Noiri, V.T. Moy, M.S. Goligorsky, Atomic force microscopy measurement of leukocyte-endothelial interaction, Am. J. Physiol. Heart Circ. Physiol. 286 (2003) H359-H367.

[23] B.J. Briscoe, K.S. Sebastian, The elastoplastic response of poly(methyl methacrylate) to indentation, Proc. R. Soc. Lond. Math. Phys. Eng. Sci. 452 (1996) 439-457.

[24] E.U. Azeloglu, K.D. Costa, Atomic force microscopy in mechanobiology: measuring microelastic heterogeneity of living cells, Methods Mol. Biol. Clifton NJ. 736 (2011) 303-329.

[25] D.F. Williamson, R.A. Parker, J.S. Kendrick, The box plot: a simple visual method to interpret data, Ann. Intern. Med. 110 (1989) 916-921.

[26] V. Cardile, G. Malaponte, C. Loreto, M. Libra, S. Caggia, F.M. Trovato, G. Musumeci, Raf kinase inhibitor protein (RKIP) and phospho-RKIP expression in melanomas, Acta Histochem. 115 (2013) 795-802.

[27] N. Jonjic, I. Martìn-Padura, T. Pollicino, S. Bernasconi, P. Jílek, A. Bigotti, R. Mortarini, A. Anichini, G. Parmiani, F. Colotta, E. Dejana, A. Mantovani, P.G. Natali, Regulated expression of vascular cell adhesion molecule-1 in human malignant melanoma, Am. J. Pathol. 141 (1992) 1323-1330.

[28] Y. Rolland, M. Demeule, L. Fenart, R. Béliveau, Inhibition of melanoma brain metastasis by targeting melanotransferrin at the cell surface, Pigment Cell Melanoma Res. 22 (2009) 86-98.

[29] C. Fazakas, I. Wilhelm, P. Nagyoszi, A.E. Farkas, J. Hasko, J. Molnar, H. Bauer, H.C. Bauer, F. Ayaydin, N.T. Dung, L. Siklos, I.A. Krizbai, Transmigration of melanoma cells through the blood-brain barrier: role of endothelial tight junctions and melanoma-released serine proteases, PLoS One 6 (2011) e20758.

[30] J. Molnár, C. Fazakas, J. Haskó, O. Sipos, K. Nagy, Á. Nyúl-Tóth, A.E. Farkas, A.G. Végh, G. Váró, P. Galajda, I.A. Krizbai, I. Wilhelm, Transmigration characteristics of breast cancer and melanoma cells through the brain endothelium: role of Rac and PI3K, Cell Adhes. Migr. 10 (2016) 269-281.

[31] K. Pogoda, J. Jaczewska, J. Wiltowska-Zuber, O. Klymenko, K. Zuber, M. Fornal, M. Lekka, Depth-sensing analysis of cytoskeleton organization based on AFM data, Eur. Biophys. J. 41 (2012) 79-87.

[32] M. Lekka, K. Pogoda, J. Gostek, O. Klymenko, S. Prauzner-Bechcicki, J. Wiltowska- 
Zuber, J. Jaczewska, J. Lekki, Z. Stachura, Cancer cell recognition - mechanical phenotype, Micron 43 (2012) 1259-1266.

[33] W. Xu, R. Mezencev, B. Kim, L. Wang, J. McDonald, T. Sulchek, Cell stiffness is biomarker of the metastatic potential of ovarian cancer cells, PLoS One 7 (2012) e46609.

[34] G. Smolyakov, B. Thiebot, C.C. Campillo, S. Labdi, C. Séverac, J. Pelta, E. Dague, Elasticity, adhesion and tether extrusion on breast cancer cells provide a signature of their invasive potential, ACS Appl. Mater. Interfaces 8 (2016) 27426-27431.

[35] J. Schmitz, M. Benoit, K.E. Gottschalk, The viscoelasticity of membrane tethers and its importance for cell adhesion, Biophys. J. 95 (2008) 1448-1459.
[36] P. Sundd, M.K. Pospieszalska, K. Ley, Neutrophil rolling at high shear: flattening, catch bond behavior, tethers and slings, Mol. Immunol. 55 (2013) 59-69.

[37] F. Rico, C. Chu, M.H. Abdulreda, Y. Oin, V.T. Moy, Temperature modulation of integrin-mediated cell adhesion, Biophys. J. 99 (2010) 1387-1396.

[38] M. Benoit, C. Selhuber-Unkel, Measuring cell adhesion forces: theory and principles, Methods Mol. Biol. Clifton NJ. 736 (2011) 355-377.

[39] O. du Roure, A. Buguin, H. Feracci, P. Silberzan, Homophilic interactions between cadherin fragments at the single molecule level: an AFM study, Langmuir 22 (2006) 4680-4684. 


\section{Annex 2 - Publications}

\section{Myotube elasticity of an amyotrophic lateral sclerosis mouse model (revised submitted manuscript)}

Varga B., Martin M., Hilaire C., Sanchez-Vicente A., Areias J., Salsac C., Cuisinier F.J.G., Cedric Raoul C., Scamps F., and Gergely C. 


\title{
Myotube elasticity of an amyotrophic lateral sclerosis mouse model
}

Béla Varga ${ }^{1,3}$, Marta Martin-Fernandez ${ }^{1}$, Cécile Hilaire ${ }^{2}$, Ana Sanchez-Vicente ${ }^{2}$, Julie Areias $^{2}$, Céline Salsac ${ }^{2}$, Frederic J.G. Cuisinier ${ }^{3}$, Cedric Raoul ${ }^{2}$, Frédérique Scamps ${ }^{2,+}$ and Csilla Gergely ${ }^{1,+, *}$

${ }^{1}$ L2C, Univ Montpellier, CNRS, Montpellier, France

2 INM, INSERM, Univ Montpellier, Montpellier, France

${ }^{3}$ LBN, Univ Montpellier, Montpellier, France

* Corresponding author: csilla.gergely@ umontpellier.fr

+ These authors contributed equally to this work

\begin{abstract}
Amyotrophic lateral sclerosis (ALS) is a fatal neurodegenerative disease that affects the motor system leading to generalized paralysis and death of patients. The understanding of early pathogenic mechanisms will help to define early diagnostics criteria that will eventually provide basis for efficient therapeutics.
\end{abstract}

Early symptoms of ALS usually include muscle weakness or stiffness. Therefore, mechanical response of differentiated myotubes from primary cultures of mice expressing the ALScausing $S O D 1^{G 93 A}$ mutation was examined by atomic force microscopy. Simultaneous acquisition of topography and cell elasticity of ALS myotubes was performed by force mapping method, compared with healthy myotubes and supplemented with immunofluorescence and qRT-PCR studies. Wild type myotubes reveal a significant difference in elasticity between a narrow and a wide population, consistent with maturation occurring with higher actin expression relative to myosin together with larger myotube width. However, this is not true for $S O D 1^{G 93 A}$ expressing myotubes, where a significant shift of thin population towards higher elastic modulus values was observed.

We provide evidence that SOD1 mutant induces structural changes that occurs very early in muscle development and well before symptomatic stage of the disease. These findings could significantly contribute to the understanding of the role of skeletal muscle in ALS pathogenesis. 


\section{Introduction}

Amyotrophic lateral sclerosis (ALS) is a neurodegenerative disease, which causes a gradual degradation of motor functions, with an incidence of 2.16 per 100000 person-years in Europe $^{1}$. The scientific interest to investigate the disease started to raise in the 90 's, following the discovery of ALS-causing mutations in the $\mathrm{Cu} / \mathrm{Zn}$ superoxide dismutase (SOD1) gene and new insights in the glutamate neurotransmitter system ${ }^{2}$. The origin of ALS in $5-10 \%$ of the cases is familial, while the rest of the patients diagnosed are considered as sporadic ${ }^{2}$. The survival time after first symptoms for $50 \%$ of the patients is below 30 months, while only $20 \%$ of patients survive after 5 years and a small percentage are alive after 10 years ${ }^{3}$. Mutations in SOD1 are responsible for approximately $20 \%$ of the familial and $5 \%$ of the seemingly sporadic ALS ${ }^{2,4,5}$. Transgenic mice overexpressing human mutated SOD1 gene provided a robust model mimicking the main pathological traits of human ALS ${ }^{5}$.

Nanobiomechanics, as an emerging powerful technology to explore mechanical aspects of biological matter at the nanoscale, has recently opened new horizons by generating a significant contribution in the comprehension of various human diseases. Besides helping in the understanding of mechanisms behind disease progression, biomechanical investigation of physiological and pathological processes of different diseases provided valuable knowledge for the development of therapies ${ }^{6}$.

The main tools of nanobiomechanics are atomic force microscopy (AFM) ${ }^{7,8}$, optical tweezer/stretcher ${ }^{9,10}$ and cell traction force microscopy ${ }^{11}$, but other techniques have also been used to study single cell mechanical properties such as magnetic twisting cytometry ${ }^{12}$, micropipette aspiration ${ }^{13}$, cell poker ${ }^{14}$ or scanning acoustic microscopy ${ }^{15}$. AFM, besides recording high-resolution three-dimensional images on biological samples in native physiological environments, holds the advantage to easily manipulate the sample, with forces at pico-newton scale. Thanks to this unique feature, AFM has the potential to spatially resolve the sample's elasticity by nanoindentation, and to map sample properties that are directly correlated to the topography.

Some early AFM studies on skeletal muscles have investigated the surface morphology and transverse elasticity of rabbit and drosophila myofibrils 16,17. The myofibrils sectioned from mature skeletal muscle have shown elasticity values from 11 to $94 \mathrm{kPa}$, depending on the loci. Mathur et al. performed the first measurements on intact cells. They compared general 
elasticity of skeletal and cardiac muscle cells in liquid, getting $24.7 \pm 3.5 \mathrm{kPa}$ and $100.3 \pm 10.7 \mathrm{kPa}$ elastic modulus values respectively ${ }^{18}$. A work from the same group investigated elastic modulus of skeletal muscle cells throughout differentiation ${ }^{19}$, and have reported a sharp increase in the average elasticity from $10 \mathrm{kPa}$ (day 1) to $35-45 \mathrm{kPa}$ after 8 days in vitro (DIV) differentiation. In both studies, C2C12 murine myoblast cell line was used. The first complete three-dimensional topography and mechanical characterization of intact, living skeletal muscle fibers were performed by Defranchi and his coworkers ${ }^{20}$, measuring an average elasticity value of $61 \pm 5 \mathrm{kPa}$ on the sarcolemma of the fibers, while Ogneva et al. have characterized mechanical properties of muscle fibers at sites corresponding to Z-disks, M-bands, and regions between them ${ }^{21}$.

Although several studies examined mechanical properties of healthy skeletal muscle cells from different origin and in various states of differentiation, few investigated the effect of diseases on skeletal muscle cell elasticity, the majority of which addresses mainly muscular dystrophies ${ }^{22-24}$. To the best of our knowledge there is no study addressing the mechanical properties of developing ALS diseased satellite cells. Here, our objective was to study the elasticity of ALS myoblasts and myotubes isolated from the muscles of asymptomatic $S O D 1^{G 93 A}$ mice to understand whether early structural disturbances could contribute to ALS pathogenesis, which may lead to advancements in early diagnosis and therapeutics of ALS.

\section{Results}

\section{Elasticity of myoblasts in stage of elongation}

To obtain comprehensive information about the elastic properties, AFM was used and whole cell force maps recorded on primary myoblasts after keeping them in differentiation medium from 6 to 8 DIV. The heterogeneity of cell culture allows examining not only different populations of myotubes, but single myoblasts as well. Figure 1 displays the elastic modulus distribution along the surface of myoblasts in two different stages of myotube formation. Figure 1A depicts a myoblast in spindle like morphology stage with reduced and homogenously distributed elasticity, while in Figure $1 \mathrm{~B}$ the projection of a more elongated, but still single, myoblast is represented. The average elastic modulus values measured over the central area of the cells were similar for wildtype and SOD1 mutant myoblasts, amounting $720.47 \pm 88.55 \mathrm{~Pa}, n=7$ and $667.25 \pm 103.72 \mathrm{~Pa}, \quad n=8$, respectively (Figure 1C-Body). Elastic modulus of projections of the more elongated myoblasts were significantly higher 
compared with body values, amounting $1176.64 \pm 183.94 \mathrm{~Pa}(n=8, * p<0.05)$ in wildtype myoblast and $1540 \pm 184.50 \mathrm{~Pa}(n=13$, *** $p<0.001)$ in $S O D 1^{G 93 A}$ myoblasts. As also observed for central area, no differences in projections were observed between the two genotypes (Figure 1C-Projection).
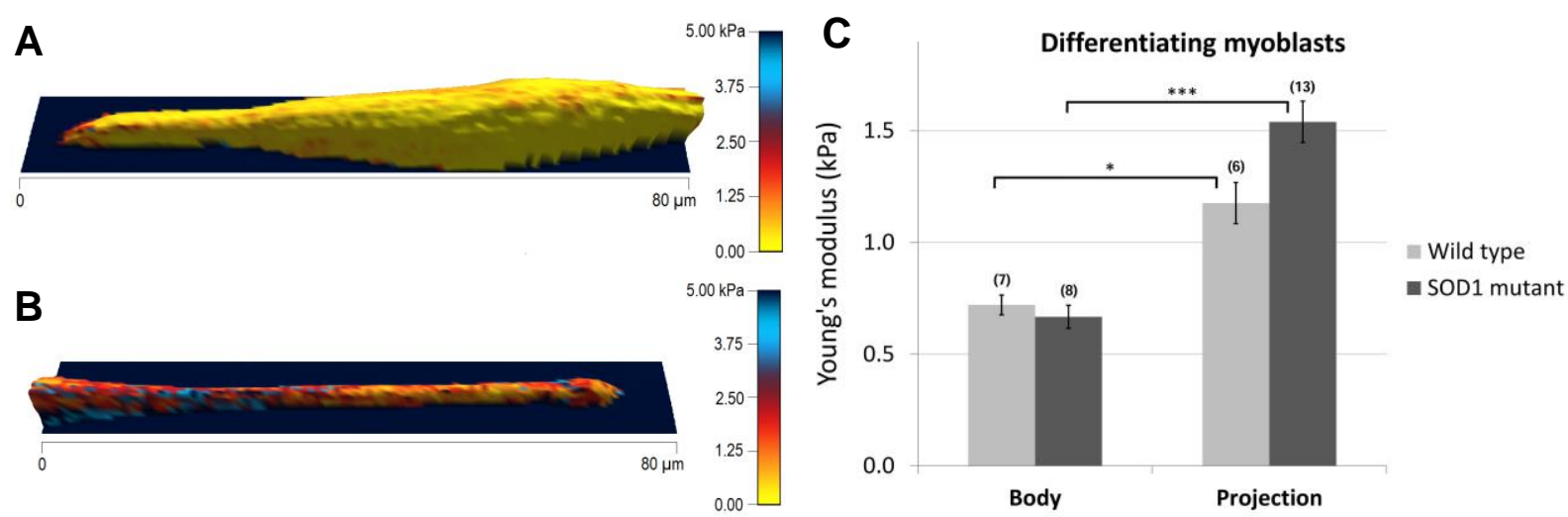

Figure 1. Elasticity of wildtype and SOD1 mutant myoblast initiating elongation. 3D-reconstructions of differentiating myoblasts with elasticity coloration are represented in different stages: a spindle-like morphology (A) and an elongated projection (B). Yellow color depicts softer portions, while red to blue colors show stiffer regions. Color bar goes from $0 \mathrm{kPa}$ (yellow) to $5 \mathrm{kPa}$ (dark blue). C: Comparison of cell body's and projection's average elasticity between wildtype and SOD1 mutant single myoblasts, prior cell fusion $\left(* p<0.05,{ }^{* * *} \mathrm{p}<0.001\right.$, Mann-Whitney test). The number of the analyzed force maps is indicated in brackets.

Previous experiments reported that elastic modulus changes during myotube maturation is mainly dependent on actin and myosin, but not on beta-tubulin levels ${ }^{19,25}$. To correlate the observed elasticity changes between soma and projection with cytoskeletal protein content, the ratio of actin-myosin expression was determined using immunocytochemistry. As observed in earlier studies, myoblasts in vitro have bipolar-shaped forms prior fusion (Figure 2) with actin cytoskeleton playing a major role in this differentiation process ${ }^{26}$. Double staining experiments clearly show that myosin expression was higher than actin in the soma, while the opposite was observed in projections (Figure 2 A, B arrows). Unlike myosin, actin staining was expressed up to the extremities of the bundles during the process of myoblast elongation which is consistent with its structural role for initiating and maintaining the structure of growing processes ${ }^{27,28}$ (Figure 2C).

Altogether, these results suggest that low Young's modulus values (around $500 \mathrm{~Pa}$ ) reflect myosin abundance while high values (from $1000 \mathrm{~Pa}$ ) would be a marker of higher actin expression over myosin. In addition, as no differences in elasticity were evidenced between wildtype and $S O D 1^{G 93 A}$ myoblasts, this suggests similar expression and compartmentation in these cytoskeletal proteins at this early stage. 


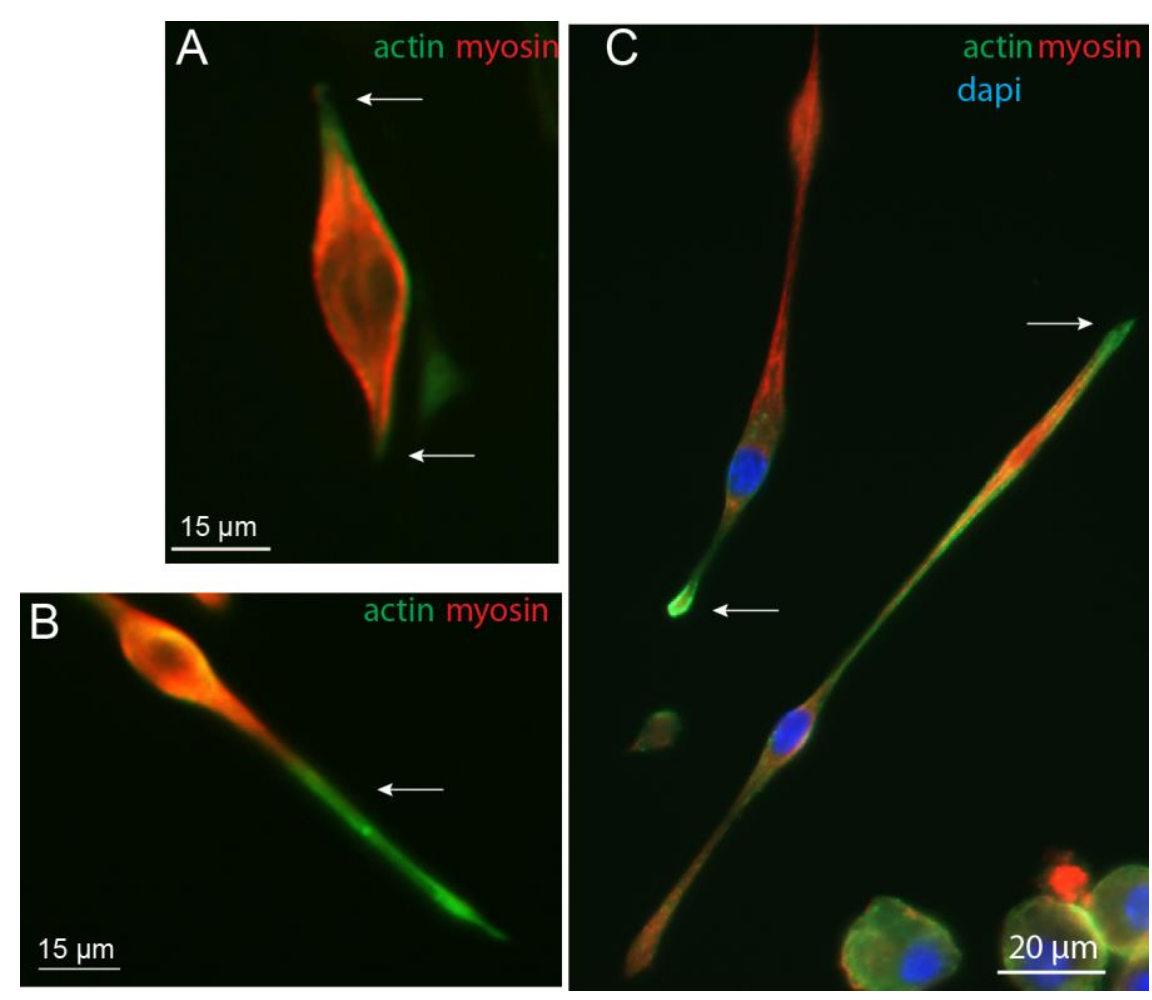

Figure 2. Immunofluorescence of actin and myosin. Immunofluorescence images with actin (green), myosin (red) and nucleus (blue) staining of myoblasts in the process of elongation, observed at 7 DIV.

\section{SOD1 mutant myotubes show increased elastic modulus}

As cell cultures present large heterogeneity regarding the diameter of myotubes during fusion process, we performed a Gaussian distribution analysis of myotube thickness as depicted in Figure 3. Tube diameter varies from $1.7 \mu \mathrm{m}$ to $15 \mu \mathrm{m}$, with a mean value of $5.19 \pm 0.14 \mu \mathrm{m}$ $(n=415)$ for wildtype and $5.17 \pm 0.11 \mu \mathrm{m}(n=599)$ for SOD1 mutant myotubes $(\mathrm{p}=0.89, \mathrm{t}-$ test). The absence of significant differences between wildtype and SOD1 mutant myotube diameter suggests that at this stage, the mutation does not induce atrophy. Therefore, we used the median value of $4.62 \mu \mathrm{m}$, as a cut-off value for a narrow/wide classification, due to an equal grouping of data into thin and thick populations.
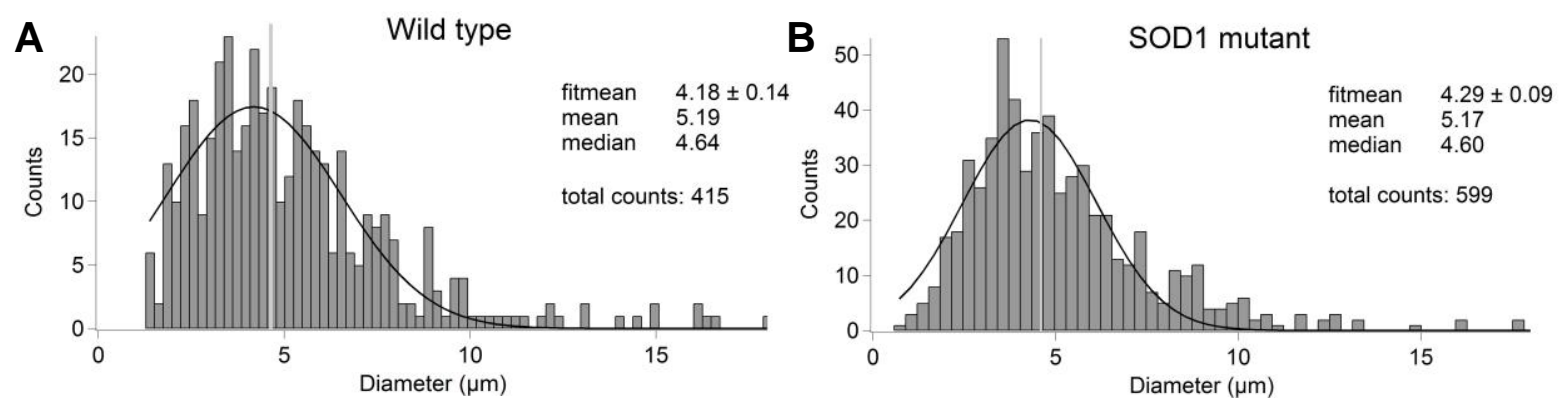

Figure 3. Transverse dimension distributions. A and B shows the thickness distributions, meas ured on optical images, of wildtype and SOD1 mutant myotubes, respectively. Black curves represent the Gaussian fitting, while vertical gray lines indicate the median of the data. 
In the following experiments, AFM was used to compare the elastic modulus of thin and thick wildtype $(n=28)$ and $S O D 1^{G 93 A}(n=42)$ myotubes (Figure 4 and Figure 5, respectively) from 3 wildtype and $3 S O D 1^{G 93 A}$ primary cultures. Figure $4 \mathrm{~A}$ and $\mathrm{B}$ shows two representative topographical images of thin and thick wildtype myotubes, reconstructed from force maps by using the contact point of the collected force curves as the height, and the elasticity parameter for coloration values. The range values of measured elastic modulus had large variations from some hundreds of $\mathrm{Pa}$ up to $10 \mathrm{kPa}$ observed not only between individuals, but also within single force maps. These variations were addressed by fitting elasticity distributions of each force map with a sum of two Gaussian functions, illustrated as light gray curves on Figure 4C, D. Consequently, all force maps were associated with a double average, corresponding to the peaks of the double Gaussian fit, which gives an index of elasticity variability.
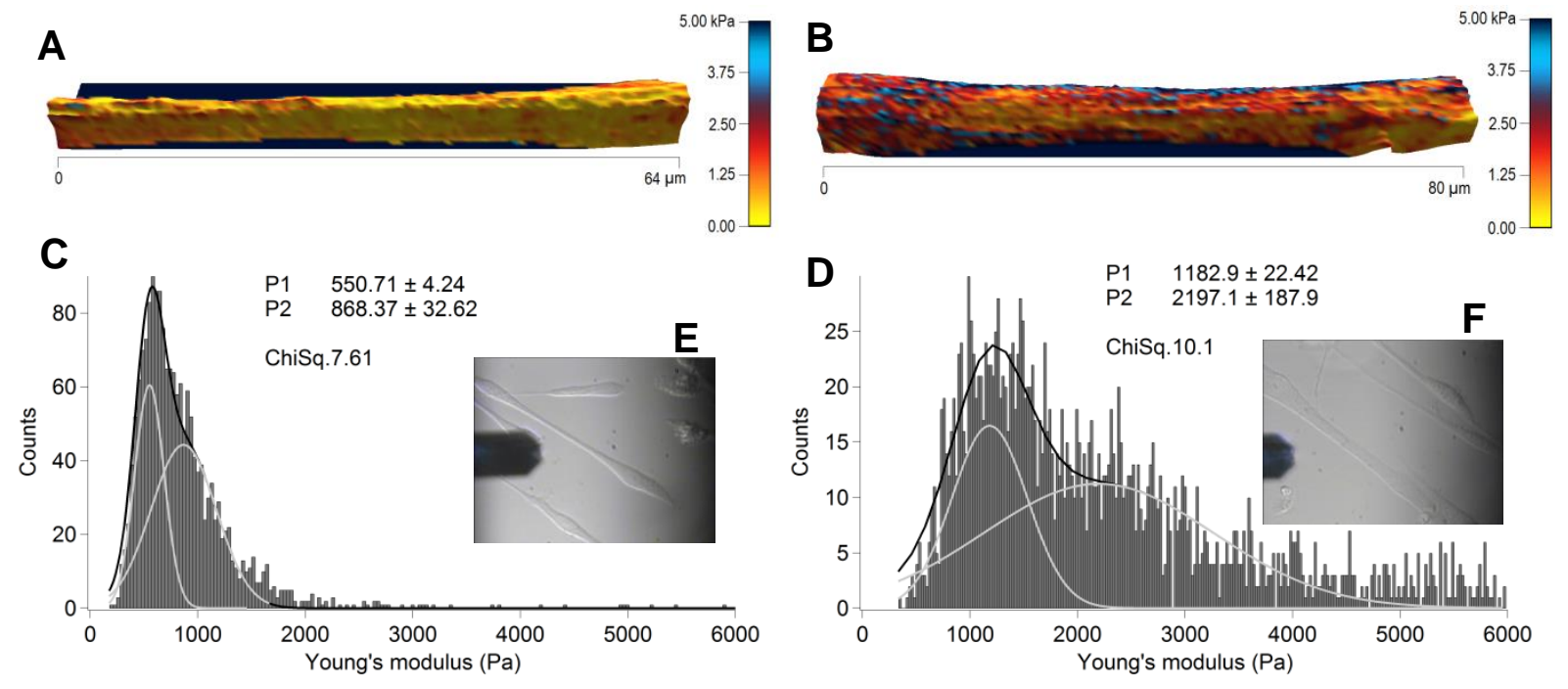

Figure 4. Elasticity of thin (left) and thick (right) wildtype myotubes. 3D-reconstruction of representative thin (A) and thick (B) myotubes, with elasticity coloration. Yellow color shows softer portions, while red to blue colors show stiffer regions. Color bar goes from $0 \mathrm{kPa}$ (yellow) to $5 \mathrm{kPa}$ (dark blue). C and $\mathbf{D}$ represent the elasticity distributions of force maps corresponding to $\mathrm{A}$ and $B$ respectively. Light gray curves are single Gaussian functions, while black curves represent

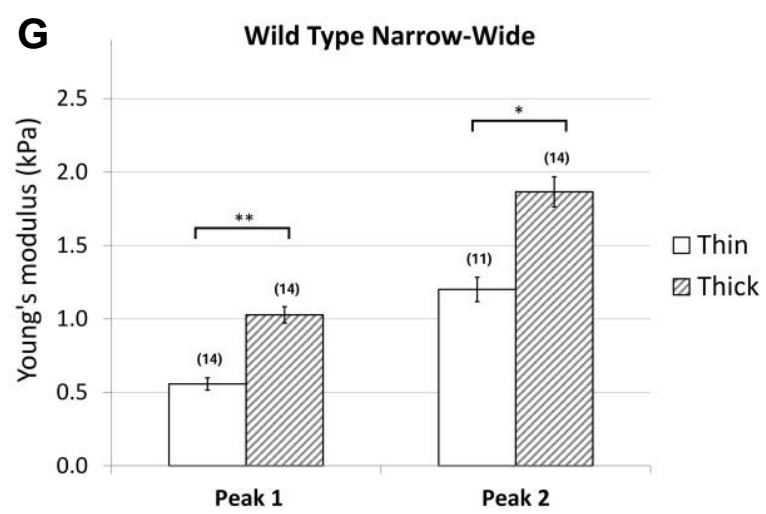
the sum of the two. Insets $\mathbf{E}$ and $\mathbf{F}$ show the optical images of the measured myotubes. G: The bars represent the obtained average of the double Gaussians (Peak 1 and Peak 2), fitted on the elasticity value distributions of individual force maps, measured on thin and thick myotubes. In brackets the number of the analyzed force maps is denoted. Error bars are standard error of the mean. As indicated, significant difference was found on both peaks of the Gaussian fit $\left({ }^{*} \mathrm{p}<0.05,{ }^{* *} \mathrm{p}<0.01\right.$, Mann-Whitney test).

Collecting optical images (Figure 4E, F), before, during and after the measurements, ensured the exclusion of those data where potential morphological changes throughout force volume acquisition were observed. The obtained average elasticity values of double fitting were 
$557.05 \pm 83.81 \mathrm{~Pa}$ and $1200.70 \pm 165.89 \mathrm{~Pa}, n=14$ for thin myotubes and $1027.88 \pm$ $110.38 \mathrm{~Pa}$ and $1865.47 \pm 204.14 \mathrm{~Pa}, n=14$ for thick myotubes, showing a significant difference $(* * p<0.01, * p<0.05)$ between the two population on both peaks (Figure 4G). Therefore, there was an overall significant increase in elasticity of thick myotubes.

Representative elasticity colored topographical maps (A and B) and the corresponding optical images $\left(\mathrm{E}\right.$ and $\mathrm{F}$ ) of thin and thick $S O D 1^{G 93 A}$ mutant myotubes are shown in Figure 5. Force map analysis show Young's moduli of $974.14 \pm 107.34 \mathrm{~Pa} / 1839.34 \pm 206.48 \mathrm{~Pa}$ for thin myotubes (Figure 5C) and $1280.81 \pm 115.97 \mathrm{~Pa} \mathrm{/} 2337.47 \pm 239.14 \mathrm{~Pa}$ for the thick population (Figure 5D). Interestingly, these values presented no statistical difference suggesting no differences in elasticity between thin and thick $S O D 1^{G 93 A}$ myotubes (Figure 5G).
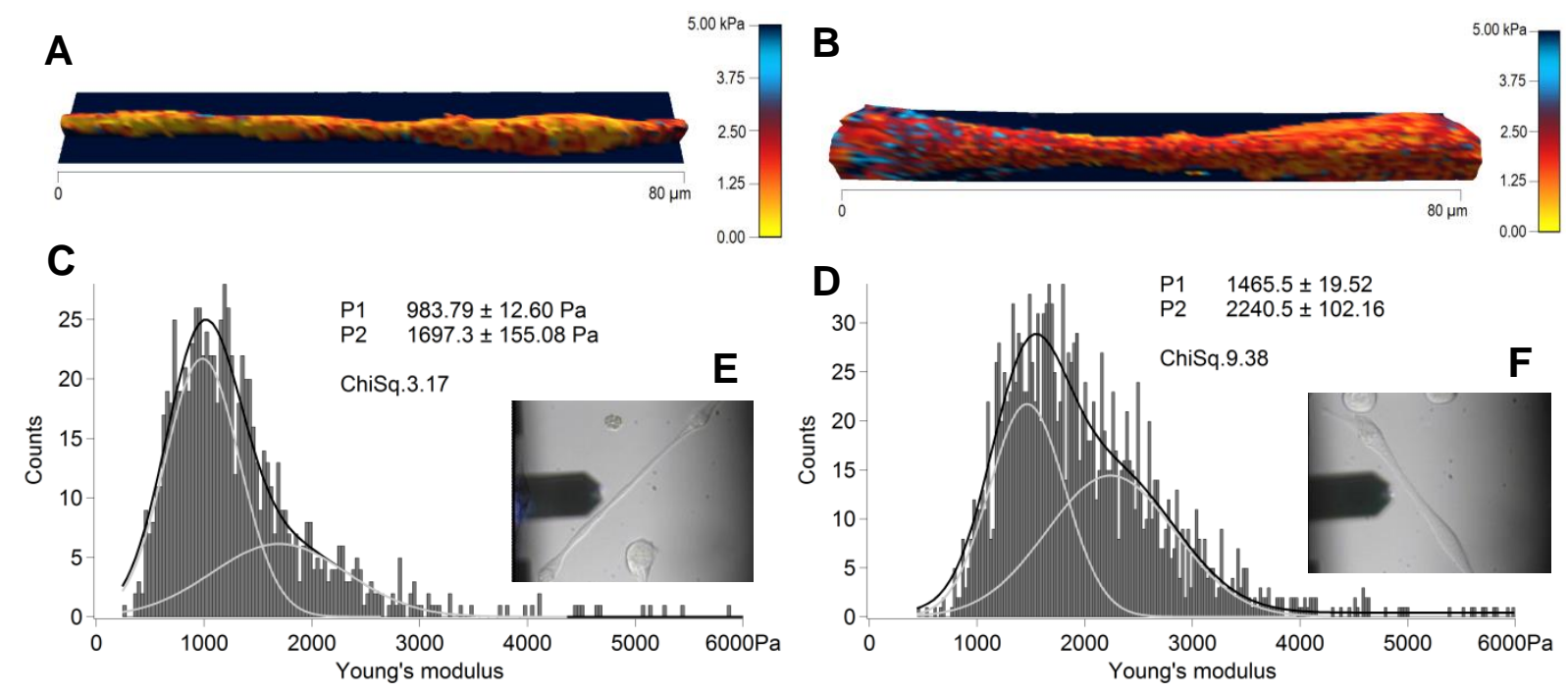

Figure 5. Elasticity of thin (left) and thick (right) SOD1 mutant myotubes. 3D-reconstructions with elasticity coloration of thin (A) and thick (B) SOD1 mutant myotubes are presented. Yellow color indicates softer portions, while red to blue colors show harder regions. Color bar goes from $0 \mathrm{kPa}$ (yellow) to $5 \mathrm{kPa}$ (dark blue). $\mathbf{C}$ and $\mathbf{D}$ represent elasticity distributions of force maps $\mathrm{A}$ and $\mathrm{B}$ respectively. Light gray curves are single Gaussians, while black curves are the sum of the two. The insets $\mathbf{E}$ and $\mathbf{F}$ show optical images of the measured

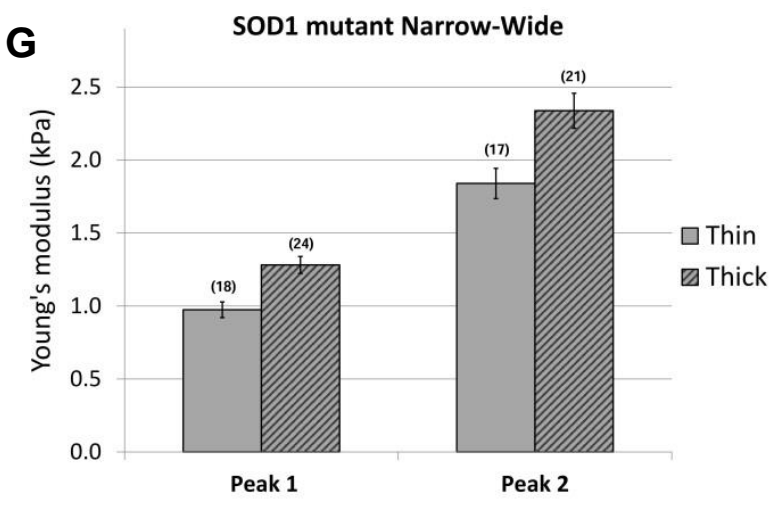
myotubes. G: The bars represent the obtained average of the double Gaussians (Peak 1 and Peak 2), fitted on the elasticity value distributions of individual force maps. In brackets the number of the analyzed force maps is indicated. Error bars are standard error of the mean. No significant difference was found between the two populations.

Analysis of elasticity between wildtype and SOD1 ${ }^{G 93 A}$ myotubes evidenced a shift of the thin myotubes expressing SOD1 mutant towards higher elasticity values compared to wildtype, 
while there was no significant difference in elasticity values between the two thick populations of wildtype and $S O D 1^{G 93 A}$ myotubes (Figure 6). Altogether, these results suggest that the population of wildtype myotubes at 6-8 DIV is highly heterogeneous in term of elasticity, while expression of $S O D 1^{G 93 A}$ leads to homogenization of the entire population towards hardest structures.



Figure 6. Average elasticity of the wildtype and SOD1 mutant myotubes. The bars represent the obtained average of the double Gaussians (Peak 1 and Peak 2), fitted on the elasticity value distributions of individual force maps. In brackets the number of the analyzed force maps is indicated in brackets. Error bars are standard error of the mean. As indicated, the elasticity of thin wildtype myotubes is significantly lower than thin SOD1 and thick wildtype as well $\left({ }^{*} \mathrm{p}<0.05,{ }^{* *} \mathrm{p}<0.01\right.$, Mann-Whitney test).

\section{SOD1 mutation decreases myosin heavy chain gene isoforms expression}

From our data on myoblasts, it appeared that a higher content of myosin relative to actin soften the tissue and that wildtype myotubes are softer than $S O D 1^{G 93 A}$ myotubes. Therefore, we tentatively correlated biophysical properties of myotubes with myosin and actin expression during myotube formation.

Immunostaining of actin and myosin were performed on wildtype myotubes at 7 DIV in differentiation medium. Using these cytoskeletal markers, two processes of myotube formation could be evidenced. The first correspond to the so-called primary fusion that consists of the construction of a poly-nucleated single fiber as shown in Figure 7A. In this representative example, myoblast 1 is in the process of fusion that allows seeing an elongated actin structure that seems to initiate the fusion process in the myotube 2. Perpendicular to the fiber, several myoblasts (3-5) make contact together and with the forming myotube using an actin edge before the fusion. This thin myotube illustrates the mixed contribution of actin and myosin with stronger staining for myosin to the fiber that could account for elasticity 
corresponding to peak 1. In addition, punctiform actin and myosin staining, reminiscent to striation, were observed in some regions of the myotubes (Figure 7D, E). These spots of actin could account for the harder structures evidenced with peak 2 analysis.
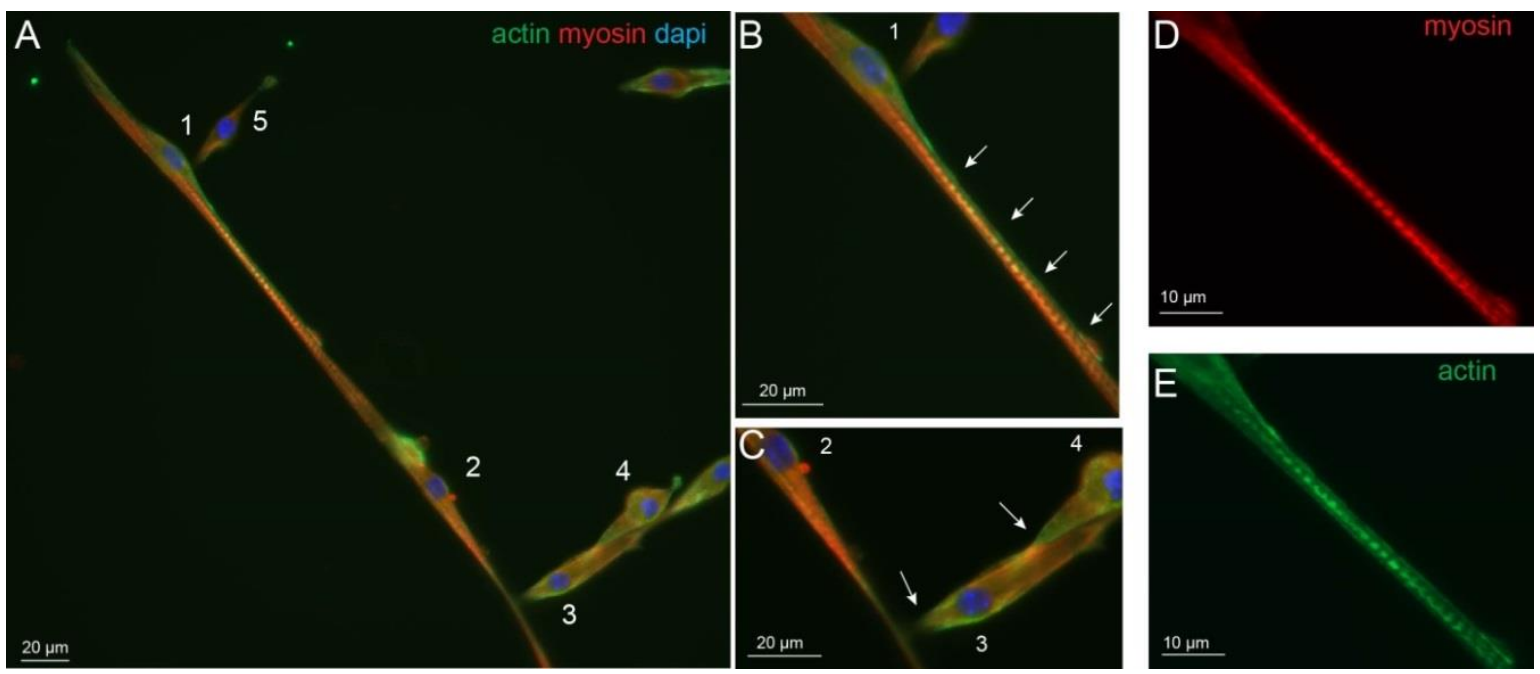

Figure 7. Primary fusion of wildtype myotubes. Immunofluorescence images are presented with actin (green), myosin (red) and nucleus (blue) staining of wildtype myotubes at 7 DIV. A: Primary fusion process can be observed while the actin rich projection of myoblast 1 (B, white arrows) is elongated along myotube 2 and seems to initiate fusion with it. Myoblasts 3-5 present fusion initiation with perpendicular orientation on the myotube by an actin rich contact region (C, white arrows). The enlargements D and E show the well separated striations of myotube 2 with myosin and actin staining, respectively.

An illustration of thick myotubes is shown in Figure S1 under a fusion process. While we could discern spots of actin, it was much harder to have such resolution with myosin. This seems to corroborate the trends towards harder elasticity in thick myotubes. However, same analysis of actin-myosin staining in $S O D 1^{G 93 A}$ myotubes did not allow revealing differences compared to wildtype (data not shown).

Due to the limit of detection and quantification, we used quantitative RT-PCR to address whether SOD1 mutation induces changes in actin and myosin gene expression in 7 DIV. As displayed in Figure 8A, the two actin skeletal isoforms, Actal v1 and Actal v2, tended to be increased in $S O D 1^{G 93 A}$ expressing myotubes. At this early developmental stage, embryonic and neonatal myosin heavy chain (MHC) genes Mhy3 and Myh8 were abundantly expressed and SOD1 mutation induced an apparent decreased expression of Myh3, although not significant. Although less expressed than immature isoforms, the adult MHC gene isoforms, Myhl coding for MHCIIx, fast fibers, Myh2 coding for MHCIIa, the fast fatigue resistant fibers, Myh4 coding for MHCIIb, the fast fatigable fibers and Myh7 coding for MHC- $\beta$, the slow fibers ${ }^{29}$, were also detected in 7 DIV myotube cultures (Figure 8B). Interestingly, among these 4 isoforms, there was a three-fold decrease in Myh2 expression level and a 2-fold 
decrease in Mhy4 expression level in $S O D 1^{G 93 A}$ myotubes. The overexpression of human $S O D 1^{G 93 A}$ in myotube was confirmed using primer against the human SOD1 (Ct was around $18, n=3 S O D 1^{G 93 A}$ mice, a value reflecting a high expression of the transgene) that was absent in wildtype myotubes ( $\mathrm{Ct}$ not detectable, $n=3$ wild type mice).

A

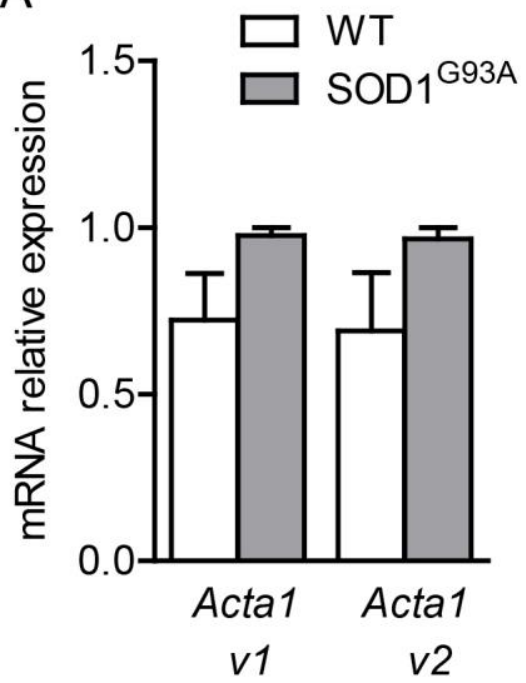

B

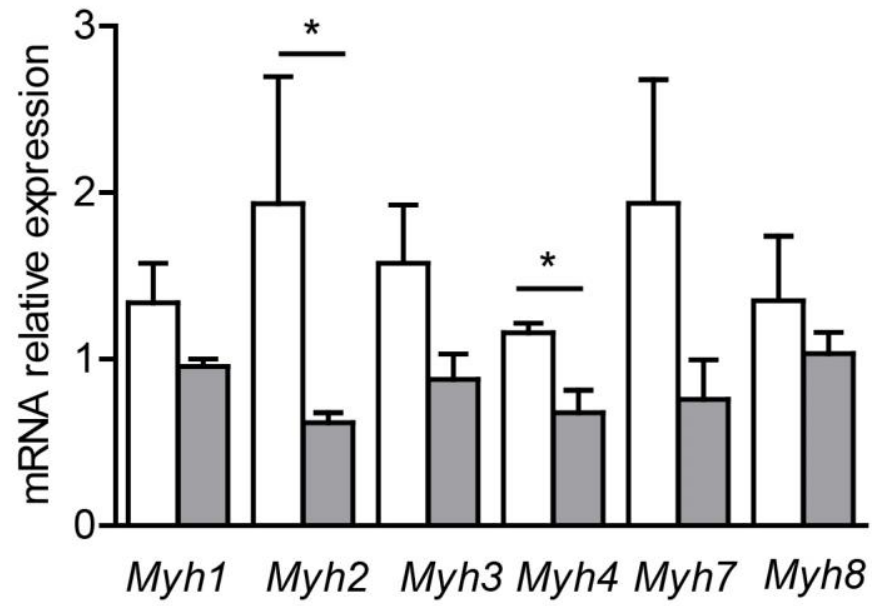

Figure 8. Actin and myosin heavy chain gene expression of wildtype and SOD1 mutant myotubes. Quantitative RT-PCR measurement of (A) two actin isoforms (Acta1 v1, Acta1 v2) as well as (B) embryonic (Myh3), neonatal (Myh8) and adult myosin isoforms Myh1, 2, 4 and 7 expressed in wildtype and SOD1 mutant myotubes (Mann-Whitney test, ${ }^{*} \mathrm{p}<0.05 ; n=3$ SOD1G93A and wild-type cultures).

\section{Discussion}

Elasticity depends both on protein expression and cytoskeletal organization, making nanobiomechanics an effective tool to monitor subtle modifications in diseased cells. As primary myoblasts allow deciphering molecular processes involved in muscle development, aging and repair, we applied atomic force spectroscopy on primary myoblasts isolated from an ALS mouse model to reveal elasticity features during early differentiation stage into myotubes. Although numerous studies were performed on differentiating myotubes and fully differentiated myofibers, most of them have used single force measurements at only specific parts of the cells 19,21. As cells are largely heterogeneous, mapping the nanomechanical properties of the entire cell is needed providing more comprehensive data to a better understanding of the underlying mechanisms. Accordingly, we performed force maps along large portions of the two types of myotubes, with a resolution of $100 \times 20$ pixels, where each pixel corresponds to a single force curve. This method allows interpreting results as a three dimensional topographic image with a true elasticity coloration, where the height values are 
derived from the contact point and the elasticity values from fitted indentation of the force curves.

The process of myotube formation is composed by a series of complex morphological events. It starts with the anchorage and proliferation of myoblasts, which then aligned in a spindle like morphology with growing elongated projections, are constantly searching for other cells and finally followed by cell fusion in case of a successful encounter. Following 6 to 8 days of differentiation cell culture presents a high heterogeneity, which is not limited to myotubes with different thicknesses, but contains a considerable amount of differentiating single myoblasts, still in search of other cells to fuse with. For myoblasts two different states can be also observed. One has usually a spindle like morphology showing generally a homogeneous distribution and rather low values of elasticity, while the second state is characterized by well elongated projections on one or both sides of the spindle like cell body, with an increased elasticity as shown in Figure 1. Interestingly, while the elasticity of less elongated myoblasts and the central portions of more elongated myoblasts have similar values for both cell types, increased elastic modulus values can be observed for the projections of elongated SOD1 mutant myoblasts. Unlike myoblasts, the elastic inhomogeneity of the myotubes observable in the colored figures can be recognized on the elasticity distributions as a widening effect. To better interpret this inhomogeneity, the histograms of the calculated Young's modulus values of each force maps were fitted by a sum of two Gaussians (Figure 4C, D and Figure 5C, D).

Elastic modulus was monitored relative to myotube thickness. Width analysis of myotubes shows a continuum from very thin ones, presumably right after their fusion, to rather thick myotubes apparently in a more mature state when even bundles could be observed. This interpretation was corroborated with morphological analysis of the actin and myosin content. The obtained most commonly occurring elastic modulus values were ranged from some hundreds of $\mathrm{Pa}$ up to $4 \mathrm{kPa}$, which is slightly smaller than it would be expected according to previously reported experiments ${ }^{18,19}$. One reason for this could be the use of a $\mathrm{C} 2 \mathrm{C} 12$ murine cell line, in the case of these earlier studies, while we used primary murine cells. Another explanation might be the hardness of the collagen coating we used to promote strong anchorage of the cells onto the plate. Indeed, the measured $100 \mathrm{kPa}$ elasticity of the collagen film is far from the physiological elasticity of the extracellular matrix ${ }^{30}$.

Not only the diameter, but also the number of fused cells, as the building blocks of myotubes was highly variable. Previous studies reported a large increase in elastic moduli value of myotubes throughout differentiation ${ }^{19}$. Consistent with these studies, we show that elasticity 
variations between the different morphologies of wildtype myotubes correlate a higher elastic modulus with maturation state. In SOD1 mutant, elasticity shift towards hardest values in the thin population could suggest that there is an increased maturation process. However, the dimension frequency measurements, using optical microscopy images, show no differences with the wildtype population that argues against an increased number of fusioning ALS myotubes. This result demonstrates that, at this developmental stage, the mutation does not induce atrophy.

No obvious differences were observed between wildtype and $S O D 1^{G 93 A}$-expressing myotubes using actin and myosin staining. However, the more sensitive quantitative analysis of gene expression evidenced a decrease in MHC genes coding for the fast fatigue resistant fibers (Mhy2) and the fast fatigable fibers (Mhy4) together with the tendency towards less embryonic myosin expression which could account for the shift of mutant myotubes towards harder elasticity. These results suggest that in addition to motoneuron death, loss of regenerative potential of the ALS-sensitive fiber types contributes to muscle wasting in ALS disease progression. In agreement with our data, several studies on satellite cells obtained at later stage of the same ALS mouse model or from symptomatic ALS patients skeletal muscles evidence decrease in myosin heavy chain protein ${ }^{31}$, altered capacity of satellite cells to activate the myogenic program necessary for muscle mass maintenance ${ }^{32,33}$. Altogether, these data support that the decrease in Mhy2 and Mhy4 expression level is a potential contributor to pathology. Moreover, the existence of some threshold level of expression of multiple proteins that contributes to change in membrane elasticity has been also suggested ${ }^{19}$. Therefore, our data obtained at early pre-symptomatic stage point that early defects in myosin heavy chain composition or distribution reflected by changes in elasticity could be a major factor leading to progressive muscular weakness, independently of denervation ${ }^{34}$.

In summary, our force spectroscopy data reveal differences between the nanomechanical behavior of SOD1 mutant myotube populations and wildtype myotubes, consistent with the trend towards a higher actin content and a lower myosin content observed with qPCR experiments in SOD1 mutant myotubes. These results suggest a faster hardening without accompanying faster maturation process of ALS diseased skeletal myoblasts during myotube differentiation. 


\section{Materials and Methods}

\section{Animals}

B6.Cg- $\mathrm{Tg}\left(\mathrm{SOD} 1{ }^{*} \mathrm{G} 93 \mathrm{~A}\right) 1 \mathrm{Gur} / \mathrm{J}\left(S O D 1^{G 93 A}\right)$ mice were maintained on a C57BL/6 background and purchased from Jackson Labs. All experiments were approved by the Direction Départementale des Services Vétérinaires de l'Hérault (Certificate of Animal Experimentation $\mathrm{n}^{\circ}$ B34-65, 19 August 2010), and were done in compliance with the European community and national directives for the care and use of laboratory animals.

\section{Myoblast isolation and differentiation}

For primary culture of satellite cells, we used the offspring of female C57BL/6 and male $S O D 1^{G 93 A}$ mice. Satellite cells were obtained from hind limb muscle of 3-4 weeks old mice (pre-symptomatic for $S O D 1^{G 93 A}$ ). Two females and one male were used for wild-type primary cultures and three females for $S O D 1^{G 93 A}$ mice. After mincing muscles, an enzymatic digestion was performed in Ham's F10 media (Gibco) supplemented with $2.5 \mathrm{mM} \mathrm{CaCl}, 0.5 \mathrm{mg} / \mathrm{ml}$ dispase II (Sigma) and $10 \mathrm{mg} / \mathrm{ml}$ collagenase B (Sigma). Following 15 minutes incubation twice at $37^{\circ} \mathrm{C}$, a mechanical dissociation was performed. Muscle digest was passed through a $70 \mu \mathrm{m}$ mesh filter, transferred to a $15 \mathrm{ml}$ tube and spinned $5 \mathrm{~min}$ at $1000 \mathrm{rpm}$. The pellet was diluted in culture media (Ham's F10, 20\% fetal bovine serum, 2\% penicillin/streptomycin, 2.5 $\mathrm{ng} / \mathrm{ml}$ recombinant human fibroblast growth factor-basic, bFGF; Gibco) and placed in a 60 $\mathrm{mm}$ uncoated plastic plate for $1 \mathrm{hr}$ to favor fibroblasts adherence. Afterwards, the content was removed and placed into a plate coated with net-like patterned structure of collagen (as described in details elsewhere ${ }^{28}$ ) at $37^{\circ} \mathrm{C}, 7 \% \mathrm{CO}_{2}$. Satellite cells were allowed to multiply until they reach 70-80\% confluence and then split with $0.25 \%$ trypsin to enhance the colony. Experiments were performed from fourth to fifth passage. For myoblasts differentiation and fusion, the serum was decreased to $2 \%$.

\section{Atomicforce microscopy}

The experimental system was an Asylum Research MFP-3D atomic force microscope mounted on an Olympus ix-71 inverted optical microscope, used both for optical imaging and force spectroscopy.

For all measurements gold-coated silicon-nitride Bio-levers (BL-RC150VB, Olympus, Japan) were used, having a nominal spring constant of $30 \mathrm{pN} / \mathrm{nm}$ and a resonant frequency of 37 $\mathrm{kHz}$ in air, which drops to $6 \mathrm{kHz}$ in liquid. The cantilevers were equipped with a $\mathrm{V}$-shaped 
tip, having a half-opening angle of $45^{\circ}$ and a radius around $30 \mathrm{~nm}$. After 6 to 8 days of differentiation in vitro, the myotubes were transferred under the AFM head in serum free Leibovitz medium (Sigma), which enables maintaining the physiological conditions for long time in $\mathrm{CO}_{2}$ free atmosphere. The measurements were taken at $32^{\circ} \mathrm{C}$ within $4 \mathrm{~h}$ after the cells were taken out from the incubator. According to our observations, the cells preserve their viability during this period. Prior each measurement the spring constant of cantilevers was determined using a combination of thermal noise and Sader methods, available within the driving software ${ }^{35-37}$.

\section{Force spectroscopy}

Force maps were recorded with a resolution of $25 \times 100$ points at each selected area of usually $10 \times 80 \mu \mathrm{m}$, total data collection time being less than 35 minutes. At every pixel of the map single force curves were recorded with a constant loading speed of $7 \mu \mathrm{m} / \mathrm{s}$, using a piezo-extension rate of $1.2 \mathrm{~Hz}$ to minimize hydrodynamic and viscoelastic artefacts ${ }^{8}$. Total force distance was kept at $3 \mu \mathrm{m}$ with a maximum load of $500 \mathrm{pN}$. The Young's modulus was calculated from the approaching part of force curves, using a modified Hertz model ${ }^{38}$ based on the work of Sneddon ${ }^{39}$ and further developed for different AFM tip shapes ${ }^{40-42}$. The Poisson's ratio of the cells was assumed to be 0.5 , as suggested for soft incompressible materials ${ }^{43}$. All the force curves were fitted manually one by one in order to avoid any poorly fitted data points, as a possible consequence of automatic software calculations that may lead to an inaccurate elasticity map.

\section{Immunocytochemistry}

Myotubes at 7 DIV in differentiation medium were fixed for 15 min in $4 \%$ paraformaldehyde in PBS, and incubated for $20 \mathrm{~min}$ in $15 \%$ donkey serum in PBS. They were then incubated $2 \mathrm{~h}$ at room temperature with the primary antibodies (anti-rabbit Actin 1:100, Sigma; and antimouse Myosin Heavy Chain 1:100, DSBH, A4.1025). After a wash in PBS, cultures were incubated for $1 \mathrm{~h}$ at room temperature with secondary antibodies, and were mounted in Mowiol. Images were collected using Zeiss 40X EC Plan Neofluar 1.3NA oil objective.

\section{Data analysis and statistics}

The forces were analyzed within the Asylum Research software. Image processing was performed with ImageJ software. All data are reported as mean \pm standard error of the mean (SEM). An F-test for equal variance and two samples t-test for means comparison (significantly different or not) were performed. Statistical significance was set at $p \leq 0.05$. 


\section{Data Availability}

The datasets generated during and/or analysed during the current study are available from the corresponding author on reasonable request.

\section{References}

1. Logroscino, G. et al. Incidence of amyotrophic lateral sclerosis in Europe. J. Neurol. Neurosurg. Psychiatry 81, 385-391 (2010).

2. Kiernan, M. C. et al. Amyotrophic lateral sclerosis. Lancet 377, 942-955 (2011).

3. Talbot, K. Motor neuron disease. Pract. Neurol. 9, 303-309 (2009).

4. Rosen, D. et al. Mutations in $\mathrm{Cu} / \mathrm{Zn}$ superoxide dismutase gene are associated with familial amyotrophic lateral sclerosis. Nature 362, 59-62 (1993).

5. Gurney, M. E. et al. Motor Neuron Degeneration in Mice That Express a Human Cu,Zn Superoxide Dismutase Mutation. Science (80-. ). 264, 1772-1775 (1994).

6. Lee, G. Y. H. \& Lim, C. T. Biomechanics approaches to studying human diseases. Trends Biotechnol. 25, 111-118 (2007).

7. Binnig, G., Quate, C. F. \& Gerber, C. Atomic Force Microscope. Physical Review Letters 56, 930-933 (1986).

8. Radmacher, M., Fritz, M., Kacher, C. M., Cleveland, J. P. \& Hansma, P. K. Measuring the viscoelastic properties of human platelets with the atomic force microscope.

Biophys. J. 70, 556-67 (1996).

9. Svoboda, K., Schmidt, C. F., Branton, D. \& Block, S. M. Conformation and elasticity of the isolated red blood cell membrane skeleton. Biophys. J. 63, 784-793 (1992).

10. Guck, J. et al. The Optical Stretcher: A Novel Laser Tool to Micromanipulate Cells. Biophys. J. 81, 767-784 (2001).

11. Munevar, S., Wang, Y. \& Dembo, M. Traction Force Microscopy of Migrating Normal and H-ras Transformed 3T3 Fibroblasts. Biophys. J. 80, 1744-1757 (2001).

12. Laurent, V. M. et al. Assessment of mechanical properties of adherent living cells by bead micromanipulation: comparison of magnetic twisting cytometry vs optical tweezers. J. Biomech. Eng. 124, 408-421 (2002).

13. Hochmuth, R. M. Micropipette aspiration of living cells. J. Biomech. 33, 15-22 (2000).

14. Zahalak, G. I., McConnaughey, W. B. \& Elson, E. L. Determination of cellular mechanical properties by cell poking, with an application to leukocytes. J. Biomech. Eng. 112, 283-294 (1990).

15. Bereiter-Hahn, J., Karl, I., Lüers, H. \& Vöth, M. Mechanical basis of cell shape: investigations with the scanning acoustic microscope. Biochem. Cell Biol. 73, 337-48 (1995). 
16. Yoshikawa, Y., Yasuike, T., Yagi, A. \& Yamada, T. Transverse elasticity of myofibrils of rabbit skeletal muscle studied by atomic force microscopy. Biochem. Biophys. Res. Commun. 256, 13-19 (1999).

17. Nyland, L. R. \& Maughan, D. W. Morphology and transverse stiffness of Drosophila myofibrils measured by atomic force microscopy. Biophys. J. 78, 1490-7 (2000).

18. Mathur, A. B., Collinsworth, A. M., Reichert, W. M., Kraus, W. E. \& Truskey, G. A. Endothelial, cardiac muscle and skeletal muscle exhibit different viscous and elastic properties as determined by atomic force microscopy. J. Biomech. 34, 1545-1553 (2001).

19. Collinsworth, A. M., Zhang, S., Kraus, W. E. \& Truskey, G. A. Apparent elastic modulus and hysteresis of skeletal muscle cells throughout differentiation. Am.J. Physiol. Cell Physiol. 283, C1219-C1227 (2002).

20. Defranchi, E. et al. Imaging and elasticity measurements of the sarcolemma of fully differentiated skeletal muscle fibres. Microsc. Res. Tech. 67, 27-35 (2005).

21. Ogneva, I. V, Lebedev, D. V \& Shenkman, B. S. Transversal stiffness and young's modulus of single fibers from rat soleus muscle probed by atomic force microscopy. Biophys. J. 98, 418-424 (2010).

22. Pasternak, C., Wong, S. \& Elson, E. L. Mechanical function of dystrophin in muscle cells. J. Cell Biol. 128, 355-361 (1995).

23. Puttini, S. et al. Gene-mediated Restoration of Normal Myofiber Elasticity in Dystrophic Muscles. Mol. Ther. 17, 19-25 (2009).

24. van Zwieten, R. W. et al. Assessing dystrophies and other muscle diseases at the nanometer scale by atomic force microscopy. Nanomedicine 9, 393-406 (2014).

25. Grady, M. E., Composto, R. J. \& Eckmann, D. M. Cell elasticity with altered cytoskeletal architectures across multiple cell types. J. Mech. Behav. Biomed. Mater. 61, 197-207 (2016).

26. Peckham, M. Engineering a multi-nucleated myotube, the role of the actin cytoskeleton. J. Microsc. 231, 486-493 (2008).

27. Dent, E. W. \& Gertler, F. B. Cytoskeletal Dynamics and Review Transport in Growth Cone Motility and Axon Guidance. Neuron 40, 209-227 (2003).

28. Martin, M. et al. Morphology and nanomechanics of sensory neurons growth cones following peripheral nerve injury. PLoS One 8, e56286 (2013).

29. Schiaffino, S. \& Reggiani, C. Fiber Types in Mammalian Skeletal Muscles. Physiol. Rev. 91, 1447-1531 (2011).

30. Engler, A. J. et al. Myotubes differentiate optimally on substrates with tissue-like stiffness: Pathological implications for soft or stiff microenvironments. J. Cell Biol. 166, 877-887 (2004).

31. Pradat, P.-F. et al. Abnormalities of satellite cells function in amyotrophic lateral sclerosis. Amyotroph. Lateral Scler. 12, 264-271 (2011).

32. Scaramozza, A. et al. Skeletal Muscle Satellite Cells in Amyotrophic Lateral Sclerosis. 
Ultrastruct. Pathol. 38, 295-302 (2014).

33. Manzano, R. et al. Altered in vitro proliferation of mouse SOD1-G93A skeletal muscle satellite cells. Neurodegener. Dis. 11, 153-164 (2013).

34. Loeffler, J.-P., Picchiarelli, G., Dupuis, L. \& Gonzalez De Aguilar, J.-L. The Role of Skeletal Muscle in Amyotrophic Lateral Sclerosis. Brain Pathol. 26, 227-236 (2016).

35. Higgins, M. J. et al. Noninvasive determination of optical lever sensitivity in atomic force microscopy. Rev. Sci. Instrum. 77, 1-5 (2006).

36. Sader, J. E., Hughes, B. D., Sanelli, J. A. \& Bieske, E. J. Effect of multiplicative noise on least-squares parameter estimation with applications to the atomic force microscope. Rev. Sci. Instrum. 83, (2012).

37. Hutter, J. L. \& Bechhoefer, J. Calibration of atomic-force microscope tips. Rev. Sci. Instrum. 64, 1868-1873 (1993).

38. Hertz, H. Üeber die Berührung fester elastischer Körper. J. fur die Reine und Angew. Math. 156-171 (1881). doi:10.1515/crll.1882.92.156

39. Sneddon, I. N. The relation between load and penetration in the axisymmetric boussinesq problem for a punch of arbitrary profile. Int. J. Eng. Sci. 3, 47-57 (1965).

40. Weisenhorn, A. L., Khorsandi, M., Kasas, S., Gotzos, V. \& Butt, H. J. Deformation and height anomaly of soft surfaces studied with an AFM. Nanotechnology 4, 106-113 (1993).

41. Vinckier, A. \& Semenza, G. Measuring elasticity of biological materials by atomic force microscopy. FEBS Lett. 430, 12-16 (1998).

42. Butt, H. J., Cappella, B. \& Kappl, M. Force measurements with the atomic force microscope: Technique, interpretation and applications. Surf. Sci. Rep. 59, 1-152 (2005).

43. Boudou, T., Ohayon, J., Picart, C. \& Tracqui, P. An extended relationship for the characterization of Young's modulus and Poisson's ratio of tunable polyacrylamide gels. Biorheology 43, 721-728 (2006).

\section{Acknowledgements}

We are grateful to the personnel of the Réseau d'Histologie Expérimentale de Montpellier, the imaging facility MRI, member of the national infrastructure France-BioImaging supported by the French National Research Agency (ANR-10-INBS-04, «Investments for the future»)and the INM animal facility for their services.

\section{Author contributions statement}

C.G. and F.S. conceived the experiments. C. G. conducted the experiments. F. S. performed the qPCR and immunocytochemistry experiments and prepared the corresponding figures. 
B. V. performed the AFM measurements, analyzed the results, prepared the corresponding figures and wrote the main manuscript text. M. M. provided advice and contributed to the AFM measurements. C. H., A. S.-V., J. A., and C. S. performed genotyping, cell culturing and differentiation of myotubes. F. C. and C. R. provided advice during data analysis and contributed to manuscript writing. All authors reviewed the manuscript.

\section{Funding sources}

A.M.S. was a recipient of NUMEV grant. This work was supported by grants from the Institut National de la Santé et de la Recherche Médicale (Inserm), the Association française pour la Recherche sur la SLA (ARSLA), ANR Mimetic, ANR-14-RARE-0006 E-RARE FaSMALS and the LabEx NUMEV (ANR-10-LABX-20).

\section{Conflicts of interest}

The authors declare that they have no conflicts of interest. The corresponding author is responsible for submitting a competing financial interests statement on behalf of all authors of the paper. 


\section{Myotube elasticity of an amyotrophic lateral sclerosis mouse model}

Béla Varga, Marta Martin-Fernandez, Cécile Hilaire, Ana Sanchez-Vicente, Julie Areias, Céline Salsac, Frederic J.G. Cuisinier, Cedric Raoul, Frédérique Scamps and Csilla Gergely

\section{Supplementary Information}

\section{Genotyping}

Genotyping was carried out on DNA isolated from tail clips. A multiplex PCR with the following primers: SOD13 Forward: 5'-TTCTGTTCCCTTCTCACTGT-3'; SOD13 Reverse: 5'TCCCCTTTGGCACTTGTATT-3'; SOD15 Forward: 5'-TGTTGGGAGGAGGTAGTGATTA-3'. SOD15 Reverse: 5'-AGCAGAGTTGTGTTAGTTTTAG-3'.

\section{Quantification of gene expression}

Myoblasts were seeded at the density of 10,000 cells per $\mathrm{cm}^{2}$ in $60 \mathrm{~mm}$ collagen coated plates (280,000 myoblasts per plate). Total mRNA was extracted with the RNeasy Mini Kit (Qiagen) as described by Pieraut et al. ${ }^{1}$. The eluted mRNA was quantified by spectrophotometry (Nanodrop). Following gDNA wipe out, RT was performed with Quantitect RT kit (Qiagen). The primer sequences, designed with Primer-BLAST at NCBI, are listed in Table 1.

Table 1. Primers. Name, sequence, amplicon length (Al) and melting point (Tm) of primers used for qRT-PCR are listed below.

\begin{tabular}{|c|c|c|c|}
\hline Target genes & Sequences & Al & $\mathrm{Tm}$ \\
\hline $\begin{array}{l}\text { Acta1 } \\
\text { (Actin skeletal muscle variant } 1 \text { ) }\end{array}$ & $\begin{array}{l}\text { F: AAGTCCTGCAAGTGAACAAGC } \\
\text { R: TTCGTCGCACATGGTGTCTA }\end{array}$ & 80 & 59 \\
\hline $\begin{array}{l}\text { Acta2 } \\
\text { (Actin skeletal muscle variant 2) }\end{array}$ & $\begin{array}{l}\text { F: ACGTGAAGCCTCACTTCCTA } \\
\text { R: TGTCTAGTTTCTGCTGCTCTG }\end{array}$ & 64 & 58 \\
\hline $\begin{array}{l}\text { Myh1 } \\
\text { (adult Myosin Heavy Chain IIx) }\end{array}$ & $\begin{array}{l}\text { F: TTCAAGTTTGGACCCACGGT } \\
\text { R: AGTGAGAGAGCCTGCCTTTA }\end{array}$ & 54 & 59 \\
\hline $\begin{array}{l}\text { Myh2 } \\
\text { (adult Myosin Heavy Chain Ila) }\end{array}$ & $\begin{array}{l}\text { F: TCCAAGTTCCGCAAGATCCA } \\
\text { R: GCGCATGACCAAAGGTTTCA }\end{array}$ & 193 & 59 \\
\hline $\begin{array}{l}\text { Myh3 } \\
\text { (embryonic Myosin Heavy Chain) }\end{array}$ & $\begin{array}{l}\text { F: TGTTGAGATTGCAGGATCTGG } \\
\text { R: TGCTGGGCTTCCTGAACTT }\end{array}$ & 121 & 59 \\
\hline $\begin{array}{l}\text { Myh4 } \\
\text { (adult Myosin Heavy Chain IIb) }\end{array}$ & $\begin{array}{l}\text { F: TTCCGTAAGATCCAGCACGA } \\
\text { R: TCCTGTCACCTCTCAACAGA }\end{array}$ & 151 & 58 \\
\hline $\begin{array}{l}\text { Myh7 } \\
\text { (adult Myosin Heavy Chain-beta) }\end{array}$ & $\begin{array}{l}\text { F: TGAGCATTCTCCTGCTGTTTC } \\
\text { R: TGAGCCTTGGATTCTCAAACG }\end{array}$ & 138 & 58 \\
\hline
\end{tabular}


Myh8

(neonatal Myosin Heavy Chain)

hSOD1

(human superoxide dismutase 1 )

Polr2j

(polymerase (RNA) II polypeptide J)
F: ACAATCCAATGCCAACCTGG

R: TCCTTCCTCTGCAAGATGTGT

F: ACAAAGATGGTGTGGCCGAT

R: AACGACTTCCAGCGTTTCCT

F: ACCACACTCTGGGGAACATC

R: CTCGCTGATGAGGTCTGTGA

Quantitative RT-PCR (qRT-PCR) was performed with $100 \mathrm{ng}$ of total cDNA using SYBR Green (Qiagen) and the LightCycler system (Roche Diagnostics), after initial activation for 15 min at $95^{\circ} \mathrm{C}, 45$ cycles of $94^{\circ} \mathrm{C}$ for $15 \mathrm{~s}, 60^{\circ} \mathrm{C}$ for $20 \mathrm{~s}$ and $72^{\circ} \mathrm{C}$ for $35 \mathrm{~s}$ were carried out. After PCR amplification, a melting curve analysis was carried out to ensure PCR specificity. Polymerase (RNA) II polypeptide J (Polr2J) levels were used to normalize the amounts of cDNA. $\triangle \mathrm{Ct}$ was calculated as the difference between the $\mathrm{Ct}$ values, determined with the equation $2-\Delta \mathrm{Ct}$.

\section{Additional figures}
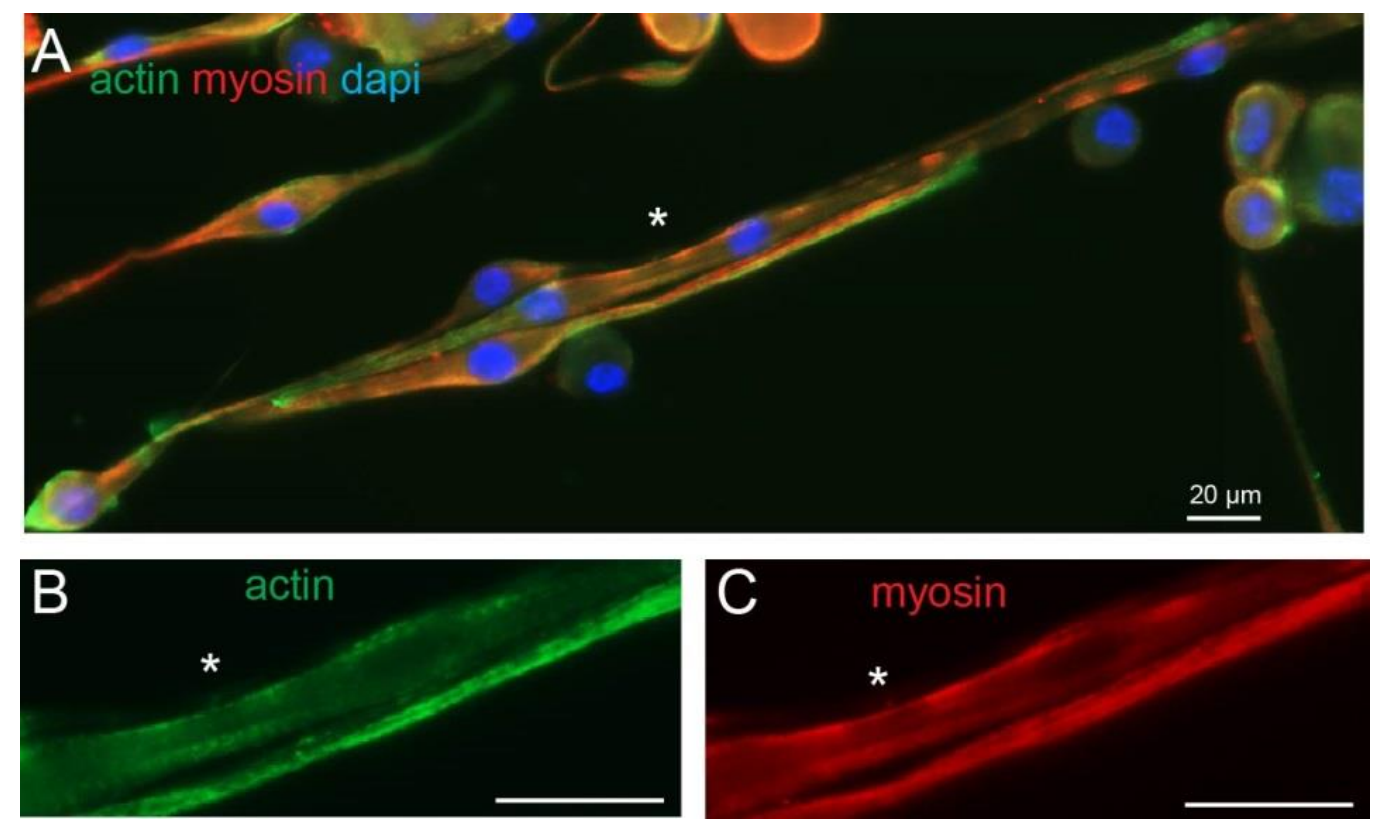

Figure S1. Maturation of wildtype myotubes. A: Immunofluorescence image of wildtype myotubes at 7 DIV with actin (green), myosin (red) and nucleus (blue) staining. B and C represent an enlargement of the marked area showing a more ordered actin (B), but a less ordered myosin distribution (C) along the myotube.

\section{References}

1. Pieraut, S. et al. An Autocrine Neuronal Interleukin-6 Loop Mediates Chloride Accumulation and NKCC1 Phosphorylation in Axotomized Sensory Neurons. $J$. Neurosci. 31, 13516-13526 (2011). 